\title{
Modell der Bildung und Stabilität von Adhäsionsclustern in biologischen Membranen
}

\section{Dissertation}

zur Erlangung des mathematisch-naturwissenschaftlichen

Doktorgrades

"Doctor rerum naturalium"

der Georg-August-Universität Göttingen

im Promotionsprogramm Chemie
der Georg-August University School of Science (GAUSS)

vorgelegt von

\section{Eva Maria Sunnick}

geboren in Worms

Göttingen, 2013 


\section{Betreuungsausschuss}

Prof. Dr. Andreas Janshoff

Institut für Physikalische Chemie, Georg-August-Universität Göttingen

Dr. Florian Rehfeldt

3. Physikalisches Institut, Georg-August-Universität Göttingen

\section{Mitglieder der Prüfungskommission}

Referent:

Prof. Dr. Andreas Janshoff

Institut für Physikalische Chemie, Georg-August-Universität Göttingen

Korreferent:

Dr. Florian Rehfeldt

3. Physikalisches Institut, Georg-August-Universität Göttingen

Weitere Mitglieder der Prüfungskommission

Prof. Dr. Burkhard Geil

Institut für Physikalische Chemie, Georg-August-Universität Göttingen

Prof. Dr. Sarah Köster

Institut für Röntgenphysik, Georg-August-Universität Göttingen

Prof. Dr. Marina Bennati

Max-Planck-Institut für Biophysikalische Chemie

Prof. Dr. Bert de Groot

Max-Planck-Institut für Biophysikalische Chemie

Tag der mündlichen Prüfung: 19.08.2013 
Die vorliegende Arbeit wurde am Institut für Physikalische Chemie der Georg-August-Universität Göttingen unter der Betreuung von

Prof. Dr. Andreas Janshoff

in der Zeit von Oktober 2009 bis Juli 2013 angefertigt. 

Auch aus Steinen,

die einem in den Weg gelegt werden, kann man Schönes bauen.

J. W. v. Goethe

für Gabi

-du fehlst 

1 Einleitung 1

1.1 Zelluläre Adhäsion . . . . . . . . . . . . . . . . . . . . . . . . 1

1.2 Biologische Grundlagen . . . . . . . . . . . . . . . . . . . . . . 2

1.2.1 Aufbau der Zelle . . . . . . . . . . . . . . . . . . 2

1.2.2 Zell-Substrat-Kontakte . . . . . . . . . . . . . . 4

2 Motivation $\quad 7$

3 Theorie 9

3.1 Grundlagen . . . . . . . . . . . . . . . . . . . . . . . . . . . . 9

3.2 Stochastisches Federmodell . . . . . . . . . . . . . . . . . . 11

3.3 Elastisches Kontinuumsmodell . . . . . . . . . . . . . . . . . . . . 15

3.4 Elastisch, stochastisches Modell . . . . . . . . . . . . . . . . . . . 19

3.5 Gitter-Federnmodell . . . . . . . . . . . . . . . . . . . . . . . 23

3.6 Membranfluktuationen . . . . . . . . . . . . . . . . . . 27

4 Modell $\quad 35$

4.1 Einfedermodell . . . . . . . . . . . . . . . . . . . . . 37

4.2 Harmonisches Mehrfedernmodell . . . . . . . . . . . . . . . . . . . . . . 40

4.2.1 Modellierung der Membranform . . . . . . . . . . . . . . . . . . . . 45

4.2.2 Emergenz metatstabiler Zustände . . . . . . . . . . . . . . . . . 47

4.2.3 Attraktive Kraft zwischen Adhäsionsbindungen . . . . . . . . . . 51

4.2.4 Stochastische Bindungsstabilität . . . . . . . . . . . . . . . 52

4.3 Zusammenfassung . . . . . . . . . . . . . . . . . . . . 53

5 Simulationen $\mathbf{5 5}$

5.1 Monte Carlo Simulation . . . . . . . . . . . . . . . . . . . . 55

5.1 .1 Monte Carlo Methode . . . . . . . . . . . . . . . . . . . . 55

5.1 .2 Algorithmus . . . . . . . . . . . . . . 56 
5.2 Mehrfedernmodell . . . . . . . . . . . . . . . 69

5.2.1 Formierung von Bindungsclustern $\ldots \ldots \ldots \ldots$

5.2 .2 Boltzmann-Dynamik . . . . . . . . . . . . . . . 78

5.2 .3 Clusterstabilität . . . . . . . . . . . . . . . . . . . . 83

6 Ergebnisse 103

6.1 Stabilitätsgrenzen . . . . . . . . . . . . . . . . . 103

6.1.1 Übergang zwischen Instabilität und Metastabilität geschlossener Bindungen . . . . . . . . . . . . . . . . . 104

6.1.2 Übergang zwischen Metastabilität und Stabilität geschlossener Bindungen bzw. Stabilität und Metastabilität offener Bindungen . 105

6.1.3 Übergang zwischen Metabilität und Instabilität offener Bindungen 106

6.2 Attraktive Wechselwirkungen . . . . . . . . . . . . . 107

6.2.1 Dynamische Bindungsöffnung . . . . . . . . . . . . . 110

6.2.2 Kraftverteilung in geclusterten Bindungen . . . . . . . . . 111

$\begin{array}{lll}7 & \text { Zusammenfassung } & 113\end{array}$

$\begin{array}{ll}\text { Anhang } & 115\end{array}$

1 Variationsrechnung . . . . . . . . . . . . . . . . . 115

2 Formfunktion .................... 116

3 Parameterverzeichnis . . . . . . . . . . . . . . . 117 


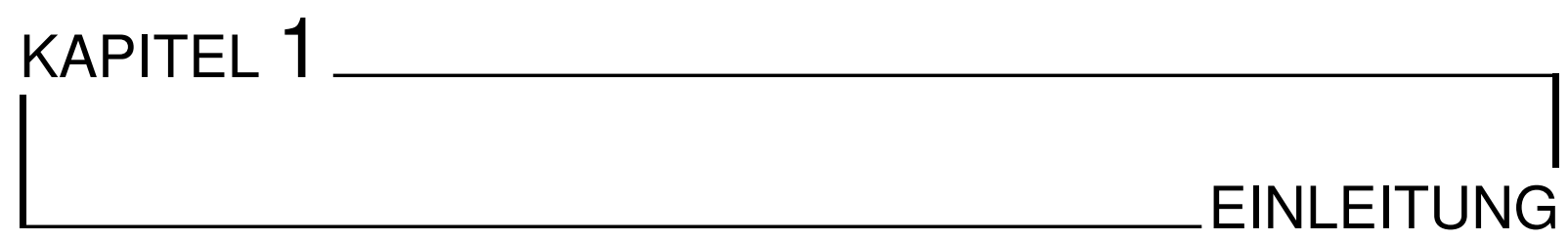

\subsection{Zelluläre Adhäsion}

Die Zelle ist die kleinste Einheit des Lebens. Im menschlichen Körper gibt es circa 200 verschiedene Zelltypen, die die unterschiedlichsten Aufgaben erfüllen. Diese Arbeit beschäftigt sich mit dem Prozess der zellulären Adhäsion.

Die Zelladhäsion ist ein Schlüsselschritt während der Zellentwicklung, Differenzierung und zur Gewährleistung der Zellmotilität. Die biologische Adhäsion ist ein hochregulierter Vorgang, der von vielen Faktoren außerhalb und innerhalb der Zelle abhängig ist.[1, 2, 3, 4, 5] Die biologische Adhäsion involviert Oberflächenrezeptoren, Signalkaskaden sowie das Cytoskelett und ist damit ein komplexer mehrstufiger Prozess, der aus biochemischer und physikalischer Sicht Gegenstand der aktuellen Forschung ist.[6, 7] Metastasierung von Tumoren, Wundheilung, die Immunantwort, Embryogenese und inflammatorische Prozesse sind nur einige Beispiele bei denen die Zelladhäsion eine Rolle spielt. Ein besseres Verständnis des Adhäsionsprozesses ist somit nicht nur für das wachsende Feld des tissue-engineerings sondern auch für die medizinische Forschung von entscheidender Bedeutung.

Zelluläre Adhäsion basiert auf nicht-kovalenten Wechselwirkungen hauptsächlich zwischen Transmembranproteinen (Integrinen) und der extrazellulären Matrix. Die meisten eukaryotischen Zellen sind in der Lage zweidimensionale Ansammlungen von Integrinen, so genannte Fokalkontakte, zu bilden, welche sie nutzen um an ein Substrat zu binden und Informationen über ihre Umwelt zu sammeln.[8, 9] Das Clustern dieser schwachen Wechselwirkungen ermöglicht es Zellen schnell auf veränderte Umwelteinflüsse zu reagieren und starke, langlebige Kontakte zu bilden. Diese überdauern die limitierte Lebenszeit der schwachen, nicht-kovalenten Einzelbindungen auf Grund der kollektiven Effekte zwischen den Bindungen in einem Adhäsionscluster.[10] Integrine sind intrazellulär an das Cytoskelett gebunden, so dass der Adhäsionsprozess ein Zusammenspiel mit Signaltransduktionskaskaden ermöglicht. [11, 12] Die biologischen Grundlagen der Zelladhäsion werden in Abschnitt 1.2 erläutert. 
Theoretische Modelle zur Beschreibung der Physik der zellulären Adhäsion werden in Kapitel 3 zusammengefasst. Neben dem Ansatz der theoretischen Modellentwicklung zur Beschreibung der Stabilität von Adhäsionsclustern gibt es zahlreiche experimentelle Techniken, die sich damit beschäftigen den Prozess der Zelladhäsion genauer aufzuklären. Die Techniken zur experimentellen Untersuchung der zellulären Adhäsion wie das Rasterkraftmikroskop (AFM) [13, 14] und der surface force-Apparat (SFA) $[15,16]$ wurden in den letzten Jahren optimiert. Selhuber et al. verwendeten ein EinzelzellKraftmikroskopaufbau um den Einfluss der Integrinanordnung (engl. patterning) auf den Adhäsionsprozess zu untersuchen. Sie fanden heraus, dass die Ablösekraft nichtlinear mit der Zeit und auch mit kleiner werdenden Integrinabständen zunimmt. Die Zeitabhängigkeit verschwindet für große Integrinabstände. Für Integrinabstände von 35 bis $55 \mathrm{~nm}$ steigt die Ablösekraft auf Werte bis zu $1 \mathrm{nN}$ und für Abstände größer als $60 \mathrm{~nm}$ erreicht sie einen maximalen Wert von $500 \mathrm{pN}$. Das Prinzip des nanopatternings des Substrats, das heißt der gezielten Anordnung von Integrinen, liefert Informationen über den Effekt des Interginclusterns im Adhäsionsprozess in der frühen Phase der Bildung des Zell-Substrat-Kontakts.[13, 14]

Der surface force-Apparat (SFA) ermöglicht die abstandsabhängige Messung intermolekularer Kräfte zwischen Oberflächen mit einer Auflösung von bis zu $10 n N$.[15, 16] Durch die Entwicklung des AFMs wurde die Auflösung von Einzelbindungsereignissen möglich. Einzelmolekül-Kraftspektroskopie gilt als wertvolle Methode um Energielandschaften einzelner nicht-kovalenter Bindungen zu bestimmen und hat einen großen Beitrag dazu geleistet, das Verhalten von Bindungen unter Kraft besser zu verstehen. Rissereignisse einzelner Bindungen sind normalerweise irreversibel mit vernachlässigbarer Rückbindungswahrscheinlichkeit. Bindungen innerhalb eines Clusters zeigen dagegen eine komplexere Physik, auf Grund endlicher Rückbindungswahrscheinlichkeiten, Kooperativität in Abhängigkeit der lateralen Organisation und Steifigkeit der Membran und der Bindungen.

\subsection{Biologische Grundlagen der zellulären Adhäsion}

Im Folgenden werden der Zellaufbau, sowie die für die zelluläre Adhäsion wichtigen Zellbestandteile beschrieben. Besonderer Fokus liegt auf den Zell-Substrat-Kontakten und hier auf den durch Integrine gebildeten fokalen Adhäsionskontakten.

\subsubsection{Aufbau der Zelle}

Das Zellinnere von Eukaryoten ist durch eine Phospholipiddoppelschicht, die Zellmembran, vom extrazellulären Raum abgegrenzt. In der Zellmembran befinden sich Membranproteine, die nur eine Phospholipidschicht durchdringen, sowie Transmembranproteine, die die komplette Zellmembran durchspannen. Dadurch können Informationen über die Eigenschaften des Zellsubstrats in das Zellinnere übermittelt werden. Die zelluläre Adhäsion wird somit zum einen aus dem Inneren der Zelle regu- 
liert, gleichzeitig hat sie aber auch Einfluss auf Signaltransduktionswege und andere Prozesse innerhalb einer Zelle. Mikrotubuli, Intermediärfilamente und Aktinfilamente bilden zusammen das Cytoskelett und verleihen der Zelle mechanische Stabilität, ermöglichen intrazellulären Transport und Bildung von Membrandeformationen, wie sie zum Beispiel bei der Zellteilung, der Endocytose oder Migration nötig sind.

Die Zelle kann die elastischen Eigenschaften des Cytoskeletts beispielsweise durch stärkere Verlinkungen, oder durch Erhöhung der durch molekulare Motoren wirkenden elastischen Spannung modulieren.[17] Das Cytoskelett verfügt durch seine Aktinfilamente über Ankerpunkte zu Integrinen und damit zur extrazellulären Matrix (ECM).[18]

\subsubsection{Extrazelluläre Matrix}

Die extrazelluläre Matrix besteht aus fünf verschiedenen Klassen von Makromolekülen. [19] Diese sind Kollagen, Elastin, Proteoglycan, Hyaluron und adhäsive Glykoproteine. [20] Unterschiedliche mechanische Eigenschaften der ECM können durch Variationen der zuvor genannten Proteinklassen erreicht werden. So sind verschiedene Zellen in der Lage extrazelluläre Matrixproteine in unterschiedlicher Konzentration oder geometrischer Anordnung je nach den zu erfüllenden Anforderungen zu bilden.

Im Prinzip sind Interaktionen zwischen ECM und Zelle unspezifischer Natur, wobei es spezifische Interaktionen gibt, die Matrix und Zelle organisieren. Diese spezifischen Interaktionen sind zum einen Protein-Protein-Wechselwirkungen und zum anderen Protein-Zucker-Wechselwirkungen. Adhäsive Glykoproteine dienen dazu den Halt zwischen Zelle und Substrat zu gewährleisten, aber auch zur Übermittlung von Signalen in das Cytosol. Die Bindung von adhäsiven Glykoproteinen zu Zellen geschieht hauptsächlich über heterodimere Transmembranrezeptoren, die Integrine. Integrinbindungsstellen von vielen adhäsiven Proteinen beinhalten das Tripeptid Arginin-GlycinAsparaginsäure (RGD). [21]

\subsubsection{Integrine}

Integrine sind Transmembranproteine, welche intrazellulär mit Hilfe verschiedener die Adhäsion regulierender Proteine an das Cytoskelett gebunden sind und extrazellulär über ihre RGD-Gruppen an die extrazelluläre Matrix und hier an das Fibronektin binden (siehe Abbildung 1.1). [22, 23, 24]

Die Heterodimere bestehen aus einer $\alpha$ - und einer $\beta$-Kette. Die Untereinheiten verfügen jeweils über eine große extrazelluläre Domäne, eine einzelne transmembrane Helix und eine kurze cytoplasmatische Domäne. [23, 8] Die Vielfalt an Integrinen in Wirbeltieren entsteht durch die Kombinationsmöglichkeiten der $18 \alpha$ - und acht $\beta$-Ketten, welche 24 verschiedene bekannte Dimere bilden. [25, 26] Die Konformation der Integrine wird von extra- und intrazellulären Liganden, und von den darauf wirkenden Kräften beeinflusst. Der offene Zustand hat die höchste Affinität zu extrazellulären Liganden und die Bindung zu diesen Liganden stabilisiert den offenen Zustand. [27] Die Bindung des cytosolischen Proteins Talin an die cytoplasmatische Domäne der $\beta$-Kette gilt als 


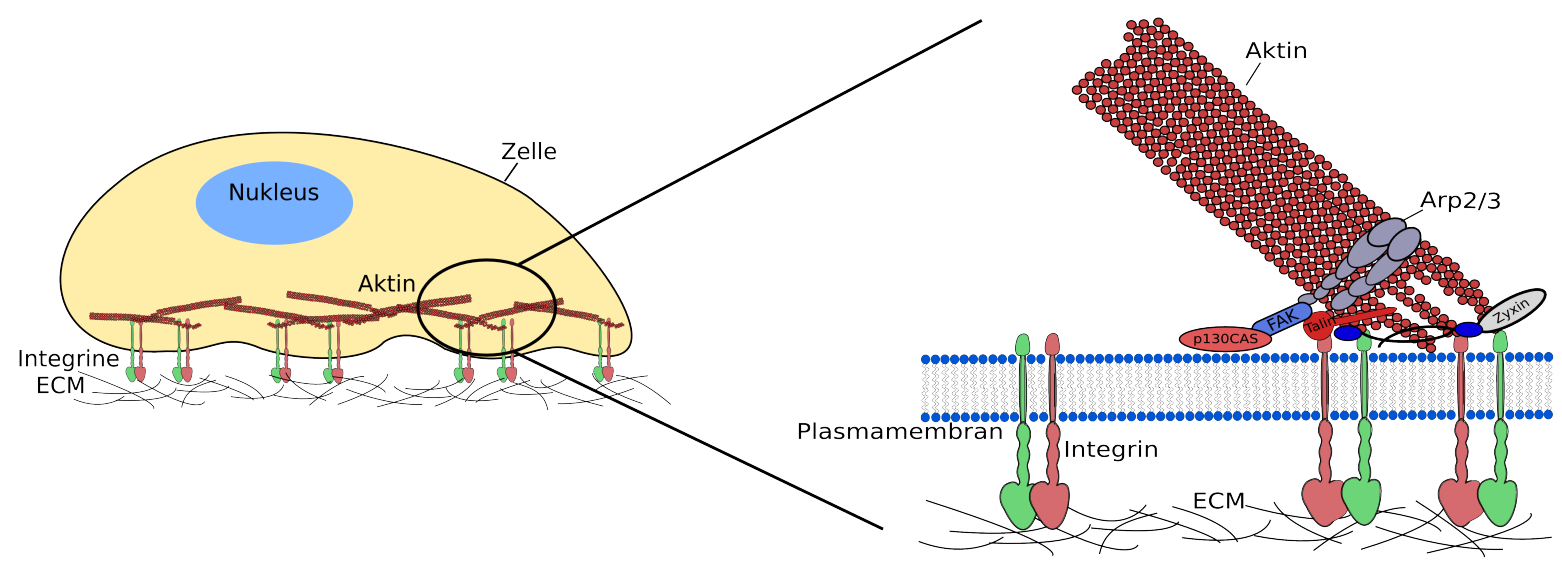

Abbildung 1.1: Schematische Darstellung eines fokalen Adhäsionskontaktes. Integrinheterodimere durchspannen die Plasmamembran der Zelle, sie sind extrazellulär an die ECM und intrazellulär an das Aktincytoskelett gebunden.

entscheidender Schritt zur Integrinaktivierung. [28, 29]

Die Separierung der transmembran-, sowie der cytoplasmatischen Domäne durch Konformationsänderungen sind Schlüsselschritte zur Aktivierung. Integrine fungieren als bidirektionale Verbindungen zwischen der extrazellulären Matrix und dem Cytoskelett.[30] Im Cytosol hat die Bindung zu extrazellulären Liganden Einfluss auf die Aktivität von Signaltransduktionsproteinen, welche mit cytoplasmischen Domänen assoziiert sind. Dieser Einfluss kann auch in die entgegengesetzte Richtung wirken und cytosolische Proteine sind in der Lage die Affinität von Integrinen zu adhäsiven Glykoproteinen zu beeinflussen. Integrin-Substrat-Bindungen sind Mechanosensoren und generieren Signale, welche Zellproliferation, -differenzierung und Zelltod kontrollieren und schaffen die physikalischen Verbindungsstellen, welche nötig sind um interne Kräfte an die Matrix zu übertragen und externen Kräften zu widerstehen. [31, 32]

\subsubsection{Zell-Substrat-Kontakte}

Von den verschiedenen Arten der Zell-Substrat-Kontakte wie Hemidesmosomen, Podosomen und fokale Adhäsionskontakte soll hier nur auf die letztgenannten eingegangen werden. Alle adhärenten Zelltypen bilden Zell-Matrix-Kontakte aus, diese können sich jedoch in ihrer Morphologie, Größe und zellulären Verteilung unterscheiden.

\subsubsection{Fokale Adhäsionskontakte}

Fokale Adhäsionskontakte sind flache, elongierte Strukturen mit einer Länge von $2-5 \mu \mathrm{m}$ und Lebenszeiten im Größenbereich von zehn Minuten. Sie sind häufig in der Zellperipherie lokalisierte, zweidimensionale Ansammlungen einer bestimmten Anzahl Integrin-RGD-Bindungen mit einer Stärke von je einigen $10 k_{\mathrm{B}} T$ zur Bildung einer starken Zell-Substrat-Bindung. [8, 11, 33] Fokale Adhäsionskontakte sind aktinverbunden- 
de Strukturen, die Zugkräfte von der Zelle zur ECM und auch entgegengesetzt übertragen. [28, 34] Die Entwicklung eines fokalen Adhäsionspunktes wird biologisch durch die kleine GTPase Rho-A stimuliert und durch Aktin-Myosin-Kontraktiliät gesteuert.[2] Rho-A wirkt auf die Aktin-Myosin-Kontraktilität über eine Kinasekaskade, die die regulatorische leichte Kette von Myosin II phosphoryliert. Die erhöhte Kontraktilität führt zu einer Bündelung von Aktinfasern zu Stressfasern und zum Clustern von Integrinen und assoziierten Proteinen und damit zur Entwicklung von Fokalkontakten.[35] Fokalkomplexe bilden eine weitere Art der Zell-Substrat-Kontakte, sie sind $1 \mu \mathrm{m}$ groß, punktförmig, mit einer Lebenszeit von wenigen Minuten und am Rand des Lamellipodiums lokalisiert. Diese Fokalkomplexe spielen eine wichtige Rolle bei der Zellmigration und als Vorläufer der fokalen Adhäsionskontakte, induziert werden sie durch das GuaninNukleotid-bindende Protein Rac. Fokale Adhäsionskontakte stellen zum einen starke Verbindungsstellen zwischen Zelle und ECM dar, zum anderen dienen sie als Zentrum für Signale die eine Vielzahl an intrazellulären Signaltransduktionswegen steuern, welche Zellwachstum, Überleben und Genexpression beeinflussen. [31, 18] Deren Ausbildung geschieht in einem zeitlichen Rahmen von ein bis zwei Stunden nach der Adhäsion. Fokalkomplexe reifen zu Fokalkontakten wenn Spannung darauf appliziert wird. Bei migrierenden Zellen bleiben die Fokalkontakte relativ zum Substrat fixiert und die Zelle wandert darüber. Sie bilden sich an der Vorderflanke der Zelle, zwischen der Vorderflanke und dem Kern wachsen stabile Fokalkontakte und zwischen Kern und dem hinteren Ende lösen sie sich wieder auf. 



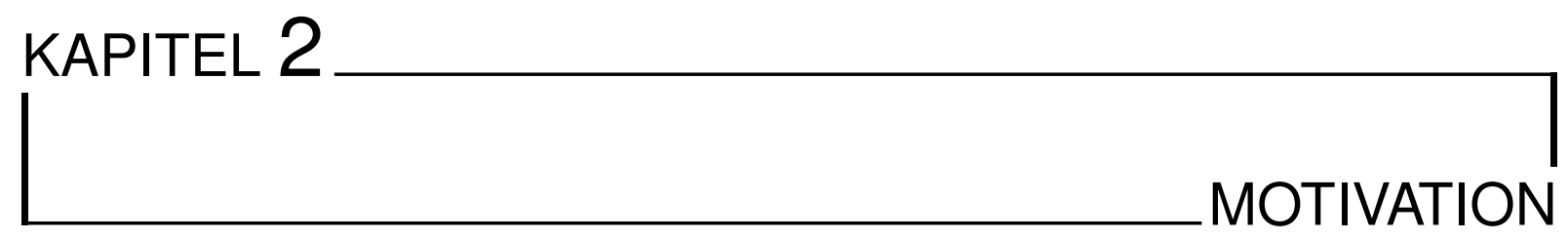

Der zelluläre Adhäsionsprozess hat entscheidende Bedeutung während der Embryonalentwicklung, der Zelldifferenzierung, Migration, Motilität und für verschiedene Immunreaktionen.[36, 37] Eine Vielzahl von Erkrankungen, wie zum Beispiel auch die Entwicklung und Metastasierung von Tumoren gehen mit einer Fehlfunktion im Adhäsionsverhalten einher. Ein umfassendes Verständnis der verschiedenen Schritte und Triebkräfte der zellulären Adhäsion erlaubt es die Entstehung von Krankheiten im Kontext gestörter Adhäsion und mögliche Behandlungswege zu erforschen.

Wie in Kapitel 1 beschrieben ist die Ansammlung von Integrinen in Fokalkontakten ein zentraler Schritt zur Bildung von einerseits dynamischen, andererseits stabilen, langlebigen Kontakten zwischen einer Zelle und dem jeweiligen Substrat. In der Zellbiologie existiert die Theorie, dass die Ausbildung von Stressfasern und die Aktivierung von Signalkaskaden zur Anordnung von Integrinen in zweidimensionale Ansammlungen führen. Die Frage ob das Clustern von Integrinen auch lediglich von physikalischen und chemischen Eigenschaften der Bindungen, Zelle und Substrat ausgelöst werden kann und damit unabhängig von intrazellulären biologischen Prozessen geschieht ist Gegenstand aktueller Forschung.[12, 38, 39]

Trotz der intensiven Forschung auf dem Gebiet der fokalen Adhäsion ist noch nicht verstanden ob es einen physikalischen Grund dafür gibt, dass die Zelle Cluster von Integrinen gegenüber homogenen Bindungsverteilungen bevorzugt. Entropische Beiträge würden eigentlich eine homogene Verteilung von Adhäsionsbindungen verursachen, beziehungsweise diese erhalten. Die Rolle und Existenz der physikalischen Ursprünge zur Bildung von Adhäsionsclustern konnten jedoch noch nicht aufgeklärt werden. Bisherige Modelle, die in Kapitel 3 vorgestellt werden, beschäftigen sich hauptsächlich mit der Stabilität und der Lebenszeit bestehender Bindungscluster. In dieser Arbeit wird ein theoretisches Modell entwickelt, dass sich darüber hinaus mit den energetischen Wurzeln der Ausbildung von Adhäsionsclustern aus homogen verteilten Bindungen und deren Stabilität beschäftigt. 



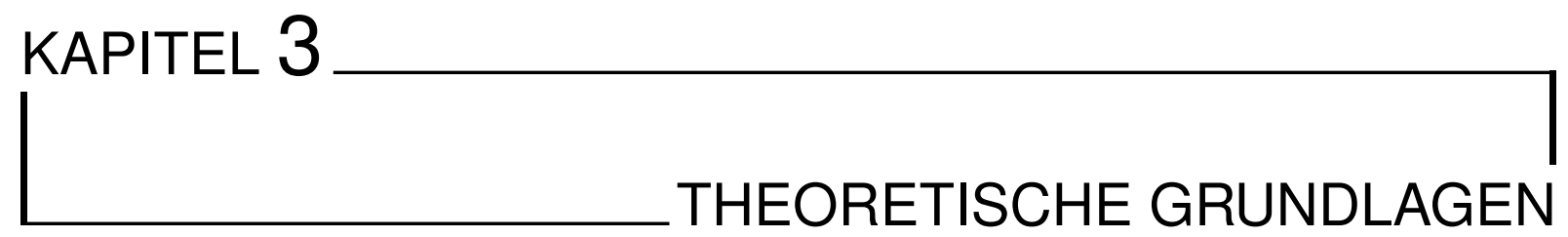

\subsection{Grundlegendes zur Zelladhäsion}

Ein erstes Modell zur theoretischen Beschreibung der Rolle spezifischer Bindungen in der Zelladhäsion wurde 1978 von Bell formuliert. [40] Frühere Modelle bezogen lediglich unspezifische elektrische Kräfte zwischen Zellen ein, die daraus resultieren, dass Zellen geladen und polarisierbar sind. In einer späteren Arbeit von 1984 beschäftigt Bell sich mit der Konkurrenz zwischen unspezifischer Repulsion und spezifischer Bindung. [41] Die unspezifische Repulsion entsteht durch die Wechselwirkung zwischen hydrophilen Polymeren auf der Zelloberfläche und wird ausgeglichen durch die Ausbildung von Bindungen zwischen mobilen Oberflächenrezeptoren. Adhäsionsbindungen haben endliche Lebenszeiten und zeigen schwache nicht-kovalente Wechselwirkungen. Es bilden sich zweidimensionale Ansammlungen (Cluster) von Bindungen um den Kontakt zwischen Zelle und Substrat zu stärken. Um Zell-Substrat-Bindungen ausbilden zu können muss der Abstand zwischen Zelle und Substrat in der Kontaktregion klein genug sein. Dann kann Adhäsion stattfinden und das repulsive Potential überwunden werden.

Wichtige Parameter zur theoretischen Beschreibung der Ausbildung und Stabilität von Zell-Substrat-Kontakten sind die Kraftkonstanten der Bindungen, deren Länge und Bindungsaffinität, sowie die maximale Kontaktfläche zwischen Zelle und Substrat und die mechanischen Eigenschaften des Substrats. Im Folgenden werden einige der in der Literatur bekannten Modelle zur theoretischen Beschreibung der Zelladhäsion erläutert und deren Ergebnisse und Limitationen dargestellt. Man kann zwischen Ansätzen unterscheiden, die sich mit der Kräfteverteilung über die Bindungen in einem Adhäsionscluster beschäftigen und solchen die die Formierung eines Clusters zu beschreiben versuchen. Nach Kramers wird eine Bindung als Brown'sches Teilchen in einer viskosen Umgebung beschrieben, das sich in einer eindimensionalen Energielandschaft entlang der Bindungsachse bewegt.[42, 43, 44, 45] Abbildung 3.1 (a) zeigt als Modell für die Zelladhäsion die Energielandschaft $U(x)$ als Funktion der Reaktionskoordinate 
$x$.[43] Im geschlossenen Zustand befindet sich die Bindung im Energieminimum bei kleinen Rezeptor-Ligand-Abständen $x=x_{\mathrm{bd}}$. Der geschlossene Zustand ist durch eine Übergangsbarriere vom offenen Zustand separiert.[40] Aus Kramers-Theorie ergibt sich eine Dissoziationsrate der Bindung von:

$$
k_{0}=v_{D} \cdot \exp \left(-\frac{E_{\mathrm{ts}}}{k_{\mathrm{B}} T}\right)
$$

mit $E_{\mathrm{ts}}=U\left(x_{\mathrm{ts}}\right)-U\left(x_{\mathrm{bd}}\right)$ der Höhe der Energiebarriere in Bezug auf den gebundenen Zustand. Der Vorfaktor $v_{D}$ hat die Dimension einer inversen Zeit und ist durch die Form des Potentials bestimmt.
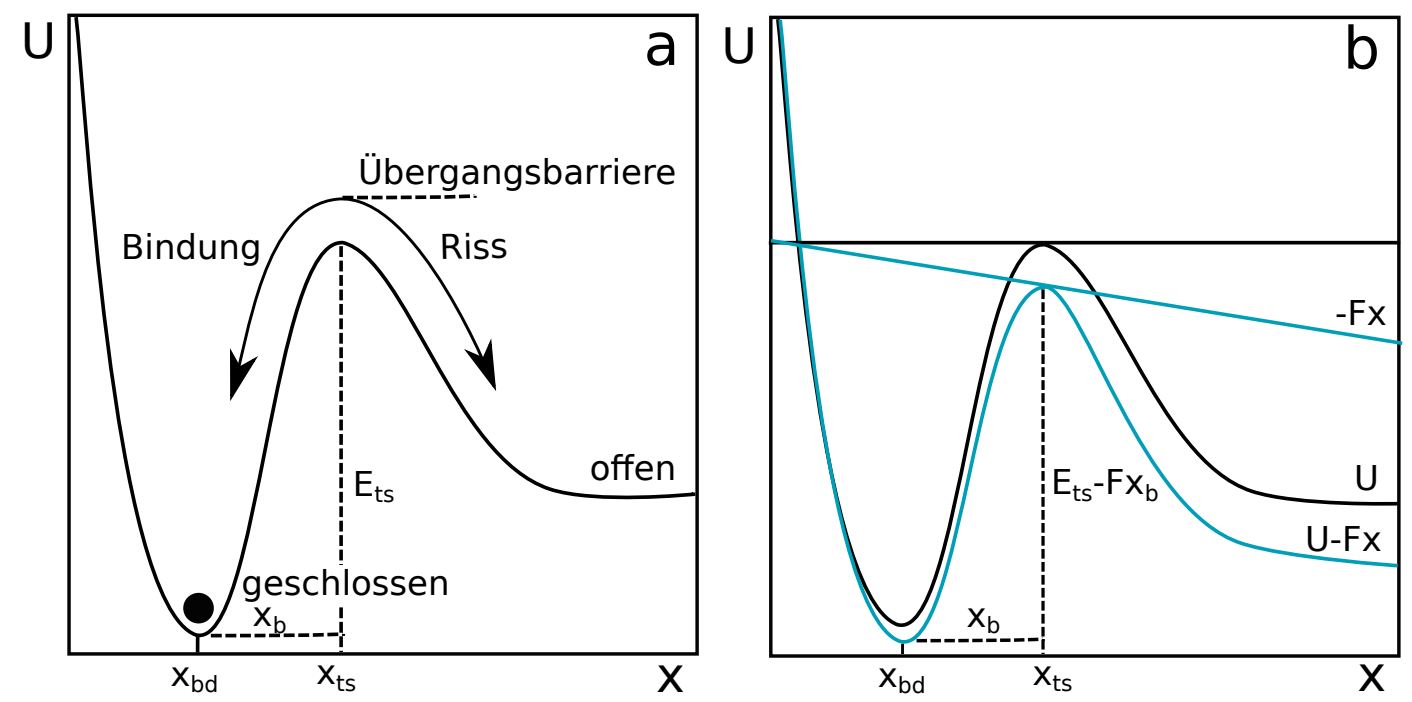

Abbildung 3.1: (a) Potentielle Energie $U(x)$ als Funktion des Abstandes zwischen Rezeptor und Ligand $x$ als Modell für eine Adhäsionsbindung. Der geschlossene Zustand $x_{\text {bd }}$ ist durch eine Energiebarriere (bei $x_{\mathrm{ts}}$ ) vom offenen Zustand getrennt. Bindungsriss und Bindungsschluss wird durch den Übergang des Brown'schen Teilchens über die Energiebarriere beschrieben. (b) Verkippung des Potentials durch eine applizierte Kraft F.[43]

Bell untersuchte die Bindungsdissoziation unter einer applizierten Kraft F.[40] Für diesen Fall ergibt sich, wie in Abbildung 3.1 (b) gezeigt, ein zusätzliches Potential $-F x$, welches zu einer Verkippung der Energielandschaft führt.[43]

Die zuvor durch Kramers-Theorie beschriebene Dissoziationsrate (Gleichung 3.1) wurde von Bell um den Einfluss dieser applizierten Kraft erweitert.

Die Applikation einer Kraft führt zur Addition von $-F x$ zur potentiellen Energie, $U(\mathrm{x} ; \mathrm{F})=U(\mathrm{x})-F x$. Bei einer scharfen Energiebarriere, reduziert sich ihre Höhe $E_{\mathrm{ts}}$ proportional zur applizierten Kraft $F$. Bei ausreichender Höhe der Energiebarriere kann die Theorie von Kramers weiterhin angewendet werden und die Rissrate unter Kraft aus Gleichung 3.1 abgeleitet werden. Die Höhe der Energiebarriere unter Kraft ist damit $E_{\mathrm{ts}}(\mathrm{F})=E_{\mathrm{ts}}-F x_{\mathrm{B}}$. 
Die Rissrate unter Kraft ergibt sich zu:

$$
k_{\text {off }}=v_{D} \exp \left(-\frac{\left(E_{\mathrm{ts}}-F x_{\mathrm{B}}\right)}{k_{\mathrm{B}} T}\right)=v_{D} \exp \left(-\frac{E_{\mathrm{ts}}}{k_{\mathrm{B}} T}\right) \exp \left(\frac{F x_{\mathrm{B}}}{k_{\mathrm{B}} T}\right)=k_{0} \cdot \exp \left(\frac{F}{F_{\mathrm{B}}}\right)
$$

Bindungsbruch wird als Entkommen aus einem lokalen Energieminimum über eine Übergangsbarriere beschrieben. Daraus resultiert ein exponentieller Zusammenhang zwischen Kraft und Bindungsbruchrate, welcher als Bell-Gleichung bezeichnet wird:

$$
k_{\text {off }}(F)=k_{0} \cdot \exp \left(\frac{F}{F_{\mathrm{B}}}\right)
$$

Die Bruchrate unter Kraft wird mit $k_{\text {off }}(F)$ bezeichnet, die Bruchrate in Abwesenheit einer applizierten Kraft $k_{0}, F_{\mathrm{B}}=\frac{k_{\mathrm{B}} T}{\chi_{\mathrm{B}}}$ ist abhängig von der Struktur der Bindung und fungiert als intrinsische Kraftskalierung für die Bindungsstärke. $F_{\mathrm{B}}$ ist die Kraft, die nötig ist, um die Energiebarriere zwischen offenem und geschlossenem Zustand um eine Einheit der thermischen Energie $k_{\mathrm{B}} T$ zu reduzieren.[43]

In den letzten Jahren wurden einige Modelle entwickelt, um die wesentlichen Elemente der Clusterbildung und Stabilität zu beschreiben. [36, 46] Einige dieser Modelle werden jetzt vorgestellt.

\subsection{Stochastisches Federmodell von Erdmann und Schwarz}

Erdmann und Schwarz erweiterten ein zunächst von Bell (1978) und Seifert (2000) formuliertes Modell, welches Skalierungsgesetze für verschiedene Federsteifigkeiten der Bindungen bereitstellt.[40, 47] Erdmann und Schwarz verwenden ein stochastisches Modell um einen tieferen Einblick in die Kräfteverteilung über die Adhäsionsbindungen in einem Fokalkontakt zu erhalten. In Abbildung 3.2 sieht man die Modellierung der Bindungen im Fokalkontakt als Federn, welche an eine, durch eine Feder gehaltene Membranplatte als Kraftüberträger binden. Der Kraftüberträger (engl. force transducer) an der Zellmembran und die Liganden am Substrat werden als harmonische Federn mit den Gleichgewichtslängen $l_{\mathrm{t}}$ und $l_{\mathrm{b}}$ und den Federkonstanten $k_{\mathrm{t}}$ und $k_{\mathrm{b}}$ modelliert. Der Gleichgewichtsabstand von Rezeptoren und Liganden wird mit $l$ bezeichnet. Die Auslenkungen der Bindungsfedern und des Kraftüberträgers werden mit $x_{\mathrm{b}}$ und $x_{\mathrm{t}}=l-x_{\mathrm{b}}$ bezeichnet.[48]

Erdmann und Schwarz untersuchten die kraft- bzw. abstandsabhängige Dynamik der Rezeptor-Ligand-Bindung.[49, 48] In ihrem Modell gehen Erdmann und Schwarz von einem Adhäsionscluster mit einer konstanten Anzahl paralleler Bindungen aus. Die Bindungen können geschlossen oder offen sein. Die auf den Cluster wirkende Kraft wird homogen über die $i$ geschlossenen Bindungen $\left(0 \leq i \leq N_{t}\right)$ aufgeteilt.[50] Diese Annahme kann getroffen werden, wenn der Kraftüberträger mit einer weichen Feder 


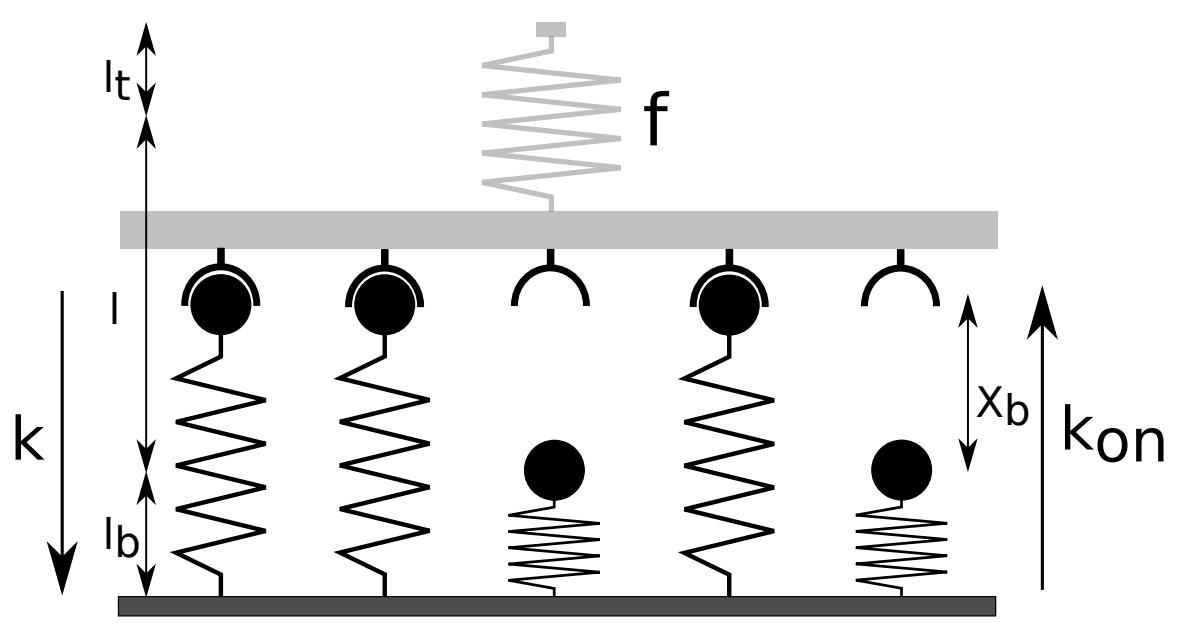

Abbildung 3.2: Mechanisches Modell einer Adhäsionsstelle mit einem Cluster bestehend aus $N_{\mathrm{t}}=5$ Bindungen. Hier sind 3 Bindungen geschlossen und 2 Bindungen geöffnet. Der Kraftüberträger an der Zellmembran und die Liganden am Substrat werden als harmonische Federn modelliert mit den Gleichgewichtslängen $l_{\mathrm{t}}$ und $l_{\mathrm{b}}$ und den Federkonstanten $k_{\mathrm{t}}$ und $k_{\mathrm{b}}$. Die Auslenkungen von Bindungsfedern und Kraftüberträger werden mit $x_{\mathrm{b}}$ und $x_{\mathrm{t}}=l-x_{\mathrm{b}}$ bezeichnet.[48] Geschlossene Bindungen reißen mit einer kraftabhängigen Rate $k=k_{0} \cdot \exp \left(\frac{f}{i}\right)$ und offene Bindungen werden mit einer kraftunabhängigen Rate $k_{\text {on }}$ geschlossen.[49]

verbunden ist.[51] Nach Bell nehmen Erdmann und Schwarz in ihrem Modell an, dass eine geschlossene Bindung unter Kraft mit einer Dissoziationsrate

$$
k=k_{0} \cdot \exp \left(\frac{F}{i F_{\mathrm{b}}}\right)
$$

reißt. Beim Öffnen einer Bindung findet eine Neuverteilung der Kraft über die geringere Anzahl der verbliebenen Bindungen statt und die Kraft pro Bindung steigt. Für die Assoziation einer einzelnen offenen Bindung wird angenommen, dass die Rate $k_{\text {on }}$ unabhängig von der applizierten Kraft ist.

Die Anzahl der geschlossenen Bindungen liegt zwischen $i=0$ für den vollständig dissoziierten Zustand und $i=N_{\mathrm{t}}$ für den vollständig gebundenen Zustand. Daraus ergibt sich, dass das Modell $N_{\mathrm{t}}+1$ diskrete Zustände annehmen kann. Da jede Bindung ihren Zustand durch stochastische Übergänge ändern kann, ändert sich die stochastische Variable $i$ in diskreten Schritten mit \pm 1 .

Die stochastische Dynamik eines Bindungsclusters kann durch eine Mastergleichung beschrieben werden und diese lautet für das vorliegende Modell:

$$
\frac{d p_{\mathrm{i}}}{d \tau}=r_{\mathrm{i}+1} p_{\mathrm{i}+1}+g_{\mathrm{i}-1} p_{\mathrm{i}-1}-\left\{r_{\mathrm{i}}+g_{\mathrm{i}}\right\} p_{\mathrm{i}} .
$$

Hier beschreibt $p_{\mathrm{i}}(\tau)$ die Wahrscheinlichkeit, dass $i$ Bindungen zum Zeitpunkt $\tau$ geschlossen sind.

Als Übergangsraten für Gleichung 3.5 formulieren Erdmann und Schwarz für die Dissoziation eine von der applizierten Kraft abhängige Rate, die sich aus den bereits von 
Bell hergeleiteten Zusammenhängen ableitet und

$$
r(\mathrm{i})=i \cdot k_{0} \cdot e^{\frac{F_{\mathrm{b}}(i)}{F_{0}}}
$$

beträgt. Hier ist $i$ die Anzahl der geschlossenen Bindungen, $k_{0}$ die Öffnungsrate bei einer wirkenden Kraft $F_{\mathrm{b}}=0$ und $F_{0}$ die interne Kraftskalierung. Die Vorwärtsrate des Bindungsschlusses offener Bindungen

$$
g(i)=k_{\mathrm{on}} \cdot\left(N_{\mathrm{t}}-i\right) \rho x_{\mathrm{b}}
$$

ist stark abhängig vom Rezeptor-Ligand-Abstand. Mit $k_{\text {on }}$ der Rate des Bindungsschlusses, $\left(N_{\mathrm{t}}-i\right)$ der Anzahl offener Bindungen und $\rho x_{\mathrm{b}}$ der Wahrscheinlichkeit der Liganden nah an der Oberfläche zu sein. Die Rate des Bindungsschlusses ist damit abstandsabhängig. Beim Schließen einer Bindung wird die Kraft über die neue, höhere Anzahl der Bindungen aufgeteilt. Die Auslenkung der Bindungsfedern und damit der Membran-Substrat-Abstand wird verringert und neue Bindungen werden leichter geschlossen.

Die Einführung dimensionsloser Größen erlaubt eine einfachere Beschreibung des Systems mit nur noch drei Parametern (Clustergröße $N_{\mathrm{t}}$, Bindungsrate $\gamma$ und Kraft f). Es wird eine dimensionslose Zeit $\tau=k_{0} t$, die dimensionslose Kraft $f=\frac{F}{F_{\mathrm{b}}}$ und die dimensionslose Bindungsrate $\phi=\frac{k_{o n}}{k_{0}}$ definiert. Die dimensionslose Einzelmolekülrissrate ist dann $\frac{k}{k_{0}}=\exp (f)$.[49]

Die Raten für Wachstum $g_{\mathrm{i}}$ und Zerfall $r_{\mathrm{i}}$ des Clusters lauten, formuliert in dimensionslosen Größen

$$
r_{\mathrm{i}}=r(i)=i \cdot \exp \left(\frac{f}{i}\right)
$$

und

$$
g_{\mathrm{i}}=g(i)=\phi\left(N_{\mathrm{t}}-i\right)
$$

Die kritische Kraft $f_{\mathrm{c}}$ für die Cluster gerade noch stabil sind lässt sich berechnen.

Bei $f<f_{\mathrm{c}}$ können Cluster stabil sein, bei $f=f_{\mathrm{c}}$ verschwinden diese stabilen Bereiche. Für Werte von $\phi<1$, also vernachlässigbarem Bindungsschluss ergibt sich:

$$
f_{\mathrm{c}} \approx \frac{\phi N_{\mathrm{t}}}{e} \text {. }
$$

Die kritische Kraft nimmt also mit $\phi$ ab, da der Cluster sich ohne Bindungsschlussereignisse von alleine abbaut. Für $\phi>1$ gilt :

$$
f_{\mathrm{c}} \approx 0.5 N_{\mathrm{t}} \ln \phi .
$$

Diese geringe Abhängigkeit der kritischen Kraft von der dimensionslosen Bindungsrate $\phi$ zeigt, dass die Kraftskalierung $F_{\mathrm{b}}$ der Einzelbindung ebenso bestimmt mit welcher 
Skalierung sich der Bindungscluster als ganzes auflöst. Die Analyse von Erdmann und Schwarz zeigt, dass die Stabilität von Adhäsionsclustern durch die Höhe der applizierten Kraft reguliert werden kann. Fokalkontakte in Zellen befinden sich wahrscheinlich nahe dieser kritischen Kraft, da so kleine Änderungen in der durch das Cytoskelett übertragenen Spannung zu stark veränderter Dynamik in Adhäsionsclustern führen können. In ihrer Molekularfeldbeschreibung finden sie unter Einbezug des LigandRezeptor-Abstandes eine Bistabilität, die zu einer Hysterese für Bindungsschluss- und Bindungsbruchereignissen führt. Bindungsschluss aus dem offenen Zustand findet bei kleineren Abständen statt als Bindungsbruch aus dem gebundenen Zustand.[48] Als Grund für die auftretende Bistabilität gelten zwei positive Rückkopplungsmechanismen, einer für Bindungsbruch und der andere für Bindungsriss. Diese sind darauf zurückzuführen, dass Bindungsschluss den Abstand zum Substrat verringert und deshalb neue Bindungen leichter geschlossen werden. Bindungsriss führt zu einer Erhöhung der Kraft auf die verbleibenden Bindungen und erhöht damit die Rate des Bindungsrisses. Das bedeutet die in der Mastergleichung verwendeten Übergangsraten sind stark abhängig von der Anzahl geschlossener Bindungen.

Limitationen des von Erdmann und Schwarz entwickelten Modells sind die Annahme der Bindungsrate $k_{\mathrm{on}}$ als kraftunabhängig. Diese Annahme stellt eine Näherung an die realen Begebenheiten dar, welche in einer Weiterentwicklung des Modells überdacht werden sollte. Bei ihren abstandsabhängigen Betrachtungen beziehen sie bereits den Abstand zwischen Rezeptor und Ligand in ihre Berechnungen ein und diskutieren einen kooperativen Effekt durch Bindungsschluss. Schließen einer Bindung erhöht die Wahrscheinlichkeit, dass weitere Rezeptor-Ligand-Paare nah an der Oberfläche sind und binden können. Ein weiterer Aspekt ist die Annahme, dass alle Bindungen im Adhäsionscluster äquivalent sind. Andere theoretische Modelle (siehe folgende Abschnitte) behandeln Bindungen am Rand eines Clusters so, dass sie eine stärkere Last tragen oder verwenden verschiedene Spezies von Bindungen, welche sich durch ihre Länge oder die Bindungsaffinität unterscheiden. In dem diskutierten Modell von Erdmann und Schwarz ist die maximale Bindungsanzahl im Cluster $N_{\mathrm{t}}$ festgelegt. Sie gehen in ihren Rechnungen und Simulationen von einer geclusterten Anfangskonfiguration aus und berechnen deren Lebenszeit bei unterschiedlichen Raten für Bindungsbruch und Bindungsschluss, sowie die mittlere Anzahl geschlossener Bindungen. Die Bindungen im Cluster haben hier feste Positionen und können lediglich geöffnet oder geschlossen werden. Die Randbedingung für $i=0 \mathrm{im}$ stochastischen Modell ist eine artifizielle absorbierende Barriere und die für $i=N_{\mathrm{t}}$ ist eine reflektierende Barriere. Das bedeutet die Lebenszeit eines Clusters ist erreicht, wenn die Bindungsanzahl erstmals die absorbierende Barriere berührt. Das von Erdmann und Schwarz entwickelte einfache Federmodell ist in Kombination mit stochastischer Behandlung von Bindungsassoziation und -dissoziation in der Lage die Stabilität von vorhandenen Adhäsionsclustern zu erklären. 


\subsection{Elastisches Kontinuumsmodell von Lin und Freund}

Lin et al. entwickelten ein stochastisches Modell zur Berechnung der auf die Bindungen in einem Adhäsionscluster wirkenden Last, basierend auf Bell's Modell für das Verhalten von Bindungen unter Kraft.[52] In diesem Zwei-Zustand-Modell wird der Zellkörper als elastisches Kontinuum modelliert, durch das die Kraft auf die Adhäsionszone übertragen wird. Die Bindung wird als sehr viel härter angenommen als der elastische Zellkörper und deren Deformation damit vernachlässigt.
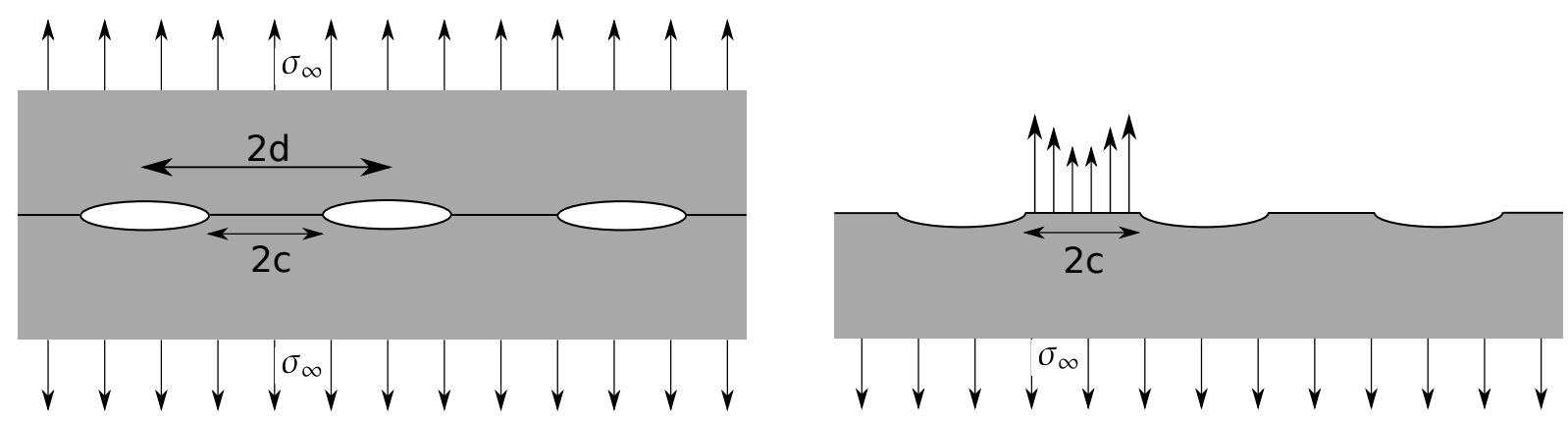

Abbildung 3.3: Skizze zweier elastischer Körper in adhäsivem Kontakt. An der Grenzfläche befinden sich periodisch angeordnete Adhäsionszonen, der Länge $2 c$ und mit dem Abstand $2 d$. Es wird eine Zugspannung $\sigma_{\infty}$ appliziert, wodurch die Körper deformiert werden. Rechts sieht man einen isolierten Köper und die Verteilung der Last innerhalb einer Adhäsionszone.[52]

Abbildung 3.3 zeigt zwei elastische Körper mit dem selben elastischen Modulus $E$ und Poissonzahl $v$ in adhäsivem Kontakt. Die Adhäsionszonen sind periodisch über die Grenzfläche verteilt. Eine Adhäsionszone hat die Größe $2 c$ und der Abstand zwischen den Adhäsionszonen beträgt $2 d$. Durch die an die elastischen Körper senkrecht zur Bindungsachse angelegten Zugspannung $\sigma_{\infty}$ werden diese elastischen Körper deformiert. Die Verteilung der Last innerhalb einer Adhäsionszone ist im rechten Teil der Abbildung gezeigt. Die Kraft auf einen Adhäsionsbereich der Länge $2 d$ beträgt $2 d \sigma_{\infty}$. Die Kraftverteilung innerhalb einer Adhäsionszone wie in Abbildung 3.3 berechnet sich für das Intervall $-c<x<c$ unter der Annahme, dass $2 d \gg 2 c$ nach folgender Gleichung:

$$
\sigma_{\infty}(x, 0) \approx \frac{2 d \sigma_{\infty}}{\pi c} \frac{1}{\sqrt{1-\frac{x^{2}}{c^{2}}}}
$$

Diese Verteilung der übertragenen Last zeigt die Annahme, dass Bindungen am Rand des Clusters eine relativ hohe Belastung im Gegensatz zu den Bindungen im Inneren des Clusters tragen. Dieses Ergebnis ergibt sich aus der klassischen Bruchmechanik. Das elastische Modul $E$ und die Poissonzahl $v$ von Membran und Substrat werden als identisch angenommen. Diese Näherung ist bei der Untersuchung einer Zell-ZellAdhäsion zulässig, im Falle der Zell-Substrat-Adhäsion gibt sie die Wirklichkeit nicht wieder. Die zeitabhängige Anzahl geschlossener Bindungen lässt sich auf einen ran- 
dom walker abbilden der sich mit vorgebenen stochastischen Raten zwischen einer reflektierenden und einer absorbierenden Barriere bewegt. Hier ist die Rate zur Bildung einer Bindung $k_{0}=1$ und damit unabhängig von allen vorhandenen Modellparametern. In Abbildung 3.4 ist eine Adhäsionszone mit einzelnen Rezeptor-Ligand-Paaren dargestellt. Diese haben alle die gleiche Breite $a$ und den regelmäßigen Abstand $b$ zueinander.

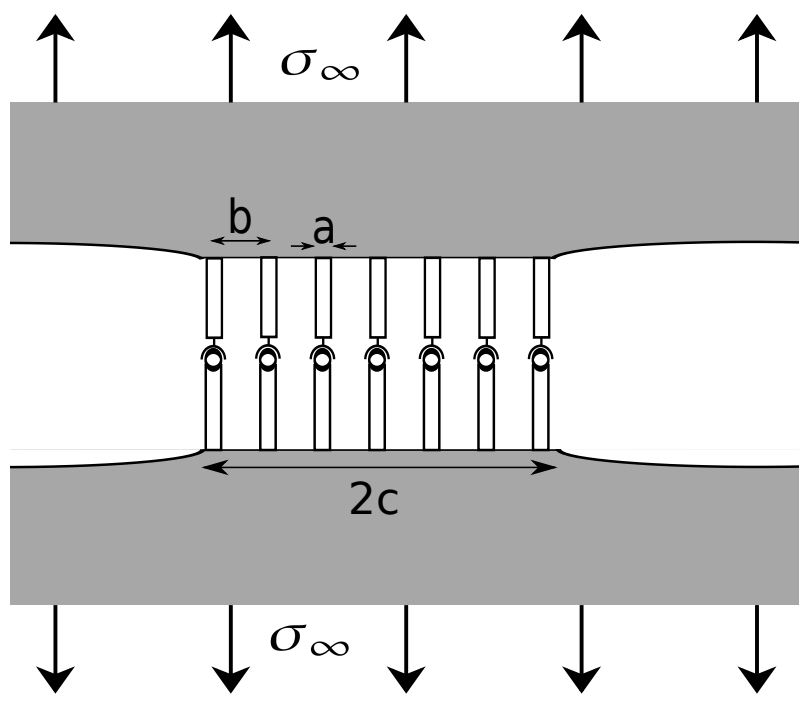

Abbildung 3.4: Schematische Abbildung einer einzelnen Adhäsionszone bestehend aus sieben Einzelbindungen nach dem Modell von Lin und Freund. Die Breite jeder Rezeptor-Ligand-Bindung wird mit $a$ bezeichnet und der Abstand der Bindungen mit $b$.[52]

Im Gegensatz zu dem Modell von Erdmann und Schwarz ist der Übergang zwischen dem geschlossenen und dem offenen Zustand nur für Rezeptoren am Rand des Adhäsionsclusters erlaubt, da diese überproportional große Kräfte erfahren. Bindungsformierung und Bindungsbruch sind rein stochastischer Natur.

Die Dissoziationsrate

$$
k_{\text {off }}=k_{0} \cdot e^{\frac{f}{f_{0}}}
$$

ist abhängig von der auf die Bindung wirkenden Kraft, mit $k_{0}$ und $f_{0}$ als Konstanten und $f$ als der Betrag der Kraft, welche auf die Bindungen wirkt. Durch diese exponentielle Abhängigkeit der Dissoziationsrate von der Kraft, ergibt sich die Modellannahme, dass nur äußere Bindungen reißen da diese der größten Kraft ausgesetzt sind und damit die höchste Dissoziationswahrscheinlichkeit besitzen. In Monte Carlo Simulationen wurde das Brechen aller Bindungen im Cluster zugelassen, dies führte zu ähnlichen Ergebnissen wie die Annahme, dass nur Bindungen am Rand der Adhäsionszone brechen können.[52]

Die Assoziationsrate wird mit dem konstanten Wert

$$
k_{\text {on }}=1
$$

pro Zeiteinheit angenommen. Mit $n$ für die Anzahl der geschlossenen Bindungen und $N$ für die maximale Bindungszahl gilt $n=N$ als reflektierende Barriere und $n=0$ als 
absorbierende Barriere. Sind alle Bindungen geöffnet, können keine Bindungen wieder geschlossen werden.

Abbildung 3.5 zeigt ein System im Zustand $n$, welches mit der Rate für Bindungsbruch $r(n)$ in den Zustand $n-1$ übergehen kann in dem eine der äußeren Bindungen reißt. Durch Bindungsschluss einer der äußeren Bindungen kann das System mit der Rate $g(n-1)$ in den Zustand $n$ zurückkehren.

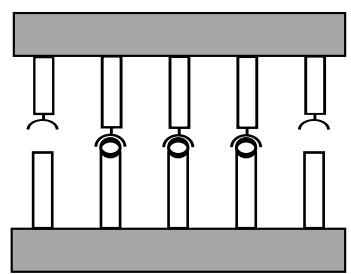

(n)

\section{$g(n-1)$}

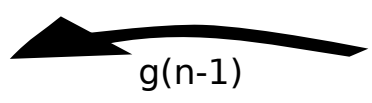

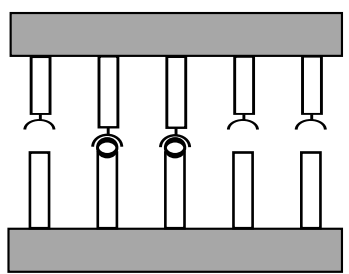

$(n-1)$

$r(n)$

Abbildung 3.5: Adhäsionszone bestehend aus fünf möglichen Bindungen. Links sind drei Bindungen geschlossen, rechts zwei. Mögliche Übergänge und dazugehörige Raten zwischen den Zuständen. Übergänge können nur an den randständigen Positionen stattfinden und sind rein stochastischer Natur.[52]

Die verschiedenen Übergangsraten für Bindungsbruch und Bindungsschluss lassen sich für $1<n \leq N$ folgendermaßen berechnen:

$$
\begin{gathered}
r(1)=k_{0} \cdot \exp \left(\frac{F}{f_{0}}\right) \\
r(n)=2 k_{0} \cdot \exp \left(\frac{F_{\mathrm{c}}(n)}{f_{0}}\right) .
\end{gathered}
$$

$F=2 d \sigma_{\infty}$ ist die gesamte übertragene $\operatorname{Kraft}$ und $F_{c}(n)$ die auf eine der randständigen Bindungen wirkende Kraft. Die Raten $g(n)$ für den Bindungsschluss können für $1<n<N-1$ bestimmt werden zu:

$$
\begin{gathered}
g(0)=g(N)=0 \\
g(N-1)=1 \\
g(n)=2
\end{gathered}
$$

Lin und Freund fanden in ihrem zweidimensionalen Modell eine optimale Größe für einen molekularen Bindungscluster von $600-1000 \mathrm{~nm}$ und eine optimale Bindungsanzahl von 15-25 Bindungen für die die Adhäsionsstärke maximal ist. Diese optimale Clustergröße geht daraus hervor, dass die inhomogene Kraftverteilung über die Bindungen kleinere Cluster begünstigt und die Möglichkeit des stochastischen Bindungsschlusses größere Cluster. Da nur ein zweidimensionales Modell untersucht wird, kann 
man nicht davon ausgehen, dass die gefundene optimale Anzahl Bindungen der Anzahl an Integrinen in einem Fokalkontakt entspricht. Die durchschnittliche Lebenszeit eines Bindungsclusters ist stark abhängig von dessen Größe. Durch die absorbierende Barriere bei $n=0$ ist das Ende der Lebenszeit eines Clusters definiert. Es existiert ein Fenster in der Clustergröße, in dem die Lebenszeit maximal ist. Unterhalb der idealen Anzahl $n$ geschlossener Bindungen erreicht der Cluster relativ schnell die absorbierende Barriere bei $n=0$, da der Bereich in dem sich der Cluster als random walker zwischen absorbierender und reflektierender Barriere bewegen kann klein ist. Dieses Fenster in der Clustergröße geben Lin und Freund als Erklärung für die experimentell beobachtete homogene Größenverteilung in Adhäsionsclustern von circa $1 \mu \mathrm{m}$ an.

Eine in dem Modell von Lin und Freund getroffene Vereinfachung betrifft kooperatives Verhalten zwischen Adhäsionszonen. Die Last pro Adhäsionszone gilt als unabhängig von der Existenz benachbarter Adhäsionszonen. Jegliche Kooperativität wird hiermit ausgeschlossen. In der Realität würde das heißen, dass die Last, die ein Fokalkontakt trägt durch das Entstehen zusätzlicher Fokalkontakte nicht minimiert würde. In späteren Modellen und auch in dem in dieser Arbeit entwickelten Modell wird dieser kooperative Effekt diskutiert. Wie auch in dem stochastischen Federnmodell von Erdmann und Schwarz wird in dem Modell von Lin und Freund die Stabilität eines künstlich erzeugten regelmäßigen Bindungsclusters unter Kraft untersucht. Die erhaltene optimale Clustergröße gilt für eine gegebene maximale Anzahl an Bindungen. Eine weitere Limitation des Modells ist die Tatsache, dass sowohl der Abstand der Bindungen $b$, als auch der Bindungsradius $a$ konstant sind. Der Einfluss der Bindungsdichte auf die Adhäsionsstärke wird somit nicht untersucht. Des weiteren sind die Bindungen an ihren Positionen fixiert und Diffusion der Bindungspartner in der Zellmembran wird somit vernachlässigt. Auch die Frage ob ein Cluster sich auflöst oder homogen verteilte Bindungen ihren Abstand verringern kann nicht adressiert werden. Lin und Freund verwenden identische E-Module und Poissonzahlen für Zelle und Substrat. Der Einfluss der Substratsteifigkeit ist ein interessanter Aspekt bei der Frage der physikalischen Modellierung der zellulären Adhäsion und konnte bereits theoretisch und experimentell gezeigt werden.[38, 53] Auf steifen Substraten ist sowohl die Fläche der Fokalkontakte größer als auf weichen Substraten, als auch deren Anzahl und Stabilität erhöht.[32, 54] 


\subsection{Kombiniertes elastisch, stochastisches Modell nach Gao}

Gao et al. beschäftigten sich mit der Lebenszeit und der Stabilität von adhäsiven Bindungsclustern zwischen elastischen Medien.[10] Hierbei fokussierten sie sich zum einen auf den Winkel unter dem die Kraft auf den Cluster appliziert wird und zum anderen auf unterschiedliche elastische Eigenschaften der Matrix.[10, 55, 39] Bindungsöffnung ist als thermisch assisitiertes Austreten aus einem Energieminimum über eine Barriere der potentiellen Energie zu betrachten. Die Applikation einer externen Kraft verkippt das Potential und beeinflusst damit den Prozess des Bindungsbruchs (siehe hierzu Abbildung 3.1). Experimentell, sowie theoretisch konnte gezeigt werden, dass die Lebenszeit einer einzelnen molekularen Bindung exponentiell mit zunehmender Last abnimmt. In einem Bindungscluster ist dieser Prozess weniger trivial, auf Grund der kollektiven Effekte zwischen den Adhäsionsbindungen. Das Modell von Gao et al. ist eine Verbindung der elastischen Beschreibung des Adhäsionskontaktes und der statistischen Beschreibung des Einzelbindungsverhaltens. Die Analyse nach diesem Modell ergibt, dass das kombinierte elastische Modul aus Zelle und Substrat eine wichtige Rolle zur Kontrolle der Kraftverteilung an der Grenzfläche und der Clusterstabilität spielt. Auf sehr weichen Substraten können keine Fokalkontakte ausgebildet werden, da hier das bruchähnliche Verhalten nicht durch eine Versteifung des Cytoskeletts ausgeglichen werden kann.[39] Auf steifen Substraten ist es Zellen möglich ihre Cytoskelettsteifigkeit zu regulieren und langlebige Fokalkontakte zu bilden. Es wurde weiterhin gezeigt, dass Zellen in der Lage sind Fokalkontakte als Antwort auf eine angelegte Kraft reversibel auszudehnen oder zu verkleinern um die Kraft pro Flächeneinheit (Spannung) im Bereich eines konstanten Wertes von 5,5 kPa zu halten.

Abbildung 3.6 zeigt eine Skizze des theoretischen Modells. Ein Cluster aus LigandRezeptor-Bindungen bildet eine Adhäsionszone der Länge $2 c$ zwischen zwei elastischen Medien. Die applizierte Kraft $F$ wirkt senkrecht zur Grenzfläche. Die Adhäsionsbindungen befinden sich in einem festen Abstand $b$ zueinander. Einer der elastischen Körper stellt den Zellkörper da, der andere die extrazelluläre Matrix, beziehungsweise das Substrat.

Die elastischen Eigenschaften der beiden Materialien unterscheiden sich und man bedient sich eines kombinierten Young-Moduls $E^{*}$, welches nach

$$
\frac{1}{E^{*}}=\frac{1-v_{\mathrm{C}}^{2}}{E_{\mathrm{C}}}+\frac{1-v_{\mathrm{S}}^{2}}{E_{\mathrm{S}}}
$$

erhalten wird. Die Bindungen werden als harmonische Federn mit einer Federkonstanten $k_{\mathrm{LR}}$ modelliert. Um die Verteilung der Last auf jede Bindung zu berechnen werden Gleichungen aus der Elastizitätstheorie angewendet. Für eine Bindungsposition $x_{\mathrm{i}}$ innerhalb der Adhäsionszone wird die Auslenkung, welche durch eine andere Bindung an der Position $x_{\mathrm{j}}$ mit $i \neq j$ verursacht wird über folgende elastische Funktion angegeben als 


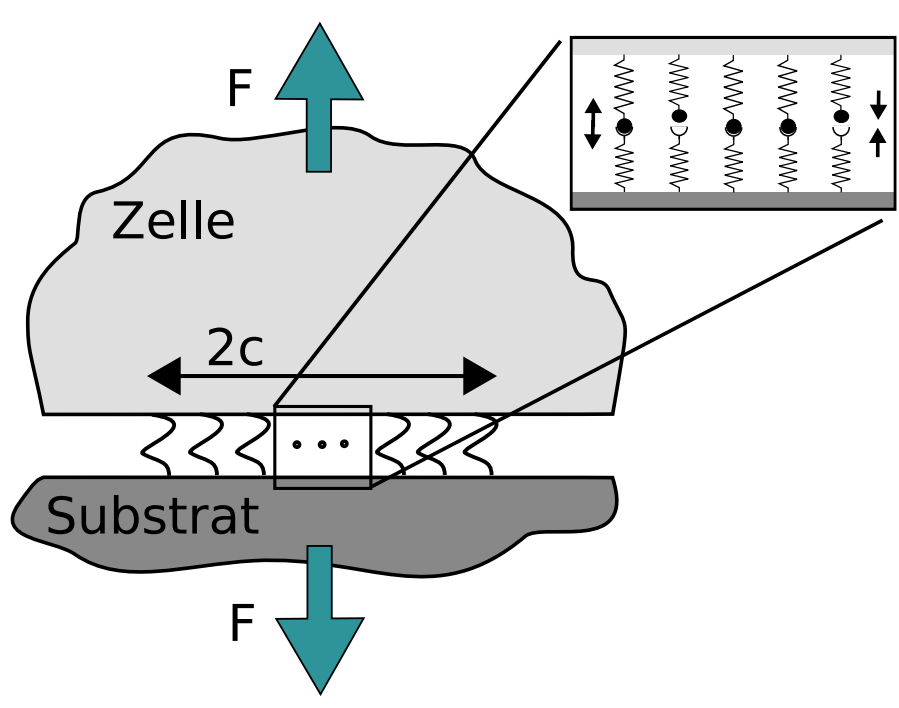

Abbildung 3.6: Schematische Abbildung des theoretischen Modells zur Adhäsion zweier elastischer Körper durch einen Cluster von RezeptorLigand-Bindungen unter einer Kraft F. Die Größe des Bindungsclusters beträgt $2 c$, die Zelle besitzt ein Young-Modul $E_{C}$ und eine Poissonzahl $v_{C}$, die von den elastischen Eigenschaften des Substrats $E_{\mathrm{S}}$ und $v_{\mathrm{S}}$ abweichen.[10]

$$
w_{\mathrm{ij}}=\frac{1}{\pi E^{*} b} 2 F_{\mathrm{j}}\left(\ln \left|x_{\infty}-x_{\mathrm{j}}\right|-\ln \left|x_{\mathrm{i}}-x_{\mathrm{j}}\right|\right) \text {. }
$$

$F_{\mathrm{j}}$ bezeichnet die Kraft auf die Bindung an der Position $x_{\mathrm{j}}$ und $x_{\infty}$ einen Referenzpunkt der keinen Einfluss auf die Berechnung der Kraft hat.

Die Auslenkung am Punkt $x_{\mathrm{i}}$ veruracht durch die Kraft $F_{\mathrm{i}}$ ist gegeben durch:

$$
w_{\mathrm{ii}}=-\frac{1}{\pi E^{*}} \frac{F_{\mathrm{i}}}{2 a_{0} b}\left(2 a_{0} \ln 4+C_{\mathrm{i}}\right) .
$$

Der Radius der Einzelbindungen wird hier mit $a_{0}$ bezeichnet, $C_{\mathrm{i}}$ ist eine Längenkonstante, die so gewählt ist, dass $F_{\mathrm{i}}$ an der Position $x_{\infty}$ keine Auslenkung verursacht.

Die Anwendung der geometrischen Beziehung $u(x)+w(x)=h$ an der Position einer geschlossenen Bindung $x_{\mathrm{i}}$ und Substitution des linearen Federngesetz $F_{\mathrm{i}}=k_{\mathrm{LR}} u_{i}$ führt zu Gleichung:

$$
\sum_{j=1, j \neq i}^{n} \frac{1}{\pi E^{*} b} 2 F_{\mathrm{j}}\left(\ln \left|x_{\infty}-x_{\mathrm{j}}\right|-\ln \left|x_{\mathrm{i}}-x_{\mathrm{j}}\right|\right)-\frac{1}{\pi E^{*}} \frac{F_{\mathrm{i}}}{2 a_{0} b}\left(2 a_{0} \ln 4+C_{\mathrm{i}}\right)+\frac{F_{\mathrm{i}}}{k_{\mathrm{LR}}}-h=0 .
$$

Mit $n$ der Anzahl geschlossener Bindungen innerhalb der Adhäsionszone. Die $n+1$ unbekannten Kräfte lassen sich aus den obigen $n$ Gleichungen lösen unter der Annahme, dass die Gesamtkraft sich, wie in Gleichung

$$
\sum_{i=1}^{n} F_{\mathrm{i}}=F
$$

gezeigt aus den Einzelkräften je Bindung zusammensetzt. Der Abstand $\delta_{\mathrm{i}} z$ wischen zwei elastischen Körpern an der Position $x_{i}$ einer offenen Bindung kann mit Hilfe folgender Gleichung berechnet werden: 


$$
\delta_{\mathrm{i}}=h+l_{\mathrm{b}}-\left(\sum_{j=1, j \neq i}^{n} \frac{1}{\pi E^{*} b} 2 F_{\mathrm{j}}\left(\ln \left|x_{\infty}-x_{\mathrm{j}}\right|-\ln \left|x_{\mathrm{i}}-x_{\mathrm{j}}\right|\right)-\frac{1}{\pi E^{*}} \frac{F_{\mathrm{i}}}{2 a_{0} b}\left(2 a_{0} \ln 4+C_{\mathrm{i}}\right)\right) \text {. }
$$

Die Ruhelänge der nicht ausgelenkten Ligand-Rezeptor-Bindung beträgt $l_{\mathrm{b}}$.

Die Dissoziation und die Assoziation von Bindungen erfolgt nach stochastischen Formulierungen, die auf der Theorie von Bell beruhen.[40] Die Rate für die Dissoziation einer Bindung wird mit Gleichung 3.3 direkt aus dem Bell-Modell übernommen. Die Assoziationsrate $k_{\text {on }}$ ist, wie bei Erdmann und Schwarz diskutiert, abhängig vom LigandRezeptor-Abstand, siehe Gleichung 3.7.[48] Gao et al. fanden ein optimales Größenfenster der Adhäsionskontakte für das die Lebenszeit maximal ist. Die untere Grenze dieses Fensters entsteht beim Übergang des einzelmolekülähnlichen Verhaltens mit endlicher Lebenszeit zu statistisch stabilen Adhäsionszonen. Die obere Grenze ist geprägt durch bruchähnliches Verhalten bei großen Clustern. Die Kraftverteilung über die Bindungen in der Adhäsionszone ist abhängig von den elastischen Eigenschaften von Zelle und Substrat. Je größer das reduzierte Young-Modul, desto stabiler sind größere Cluster. Der Effekt der Krafterhöhung auf randständige Bindungen kommt bei größerem reduzierten Young-Modul weniger stark zum Tragen. Im Grenzbereich eines sehr hohen reduzierten Young-Moduls gilt das Modell von Erdmann und Schwarz und die Stärke des Clusters wird unabhängig von der Anzahl der Bindungen. Das hier vorgestellte Modell stellt also eine Erweiterung des stochastischen Federmodells von Erdmann und Schwarz dar, durch den Einbezug der elastischen Eigenschaften von Zelle und Substrat. Die Stabilität eines Clusters wird definiert über die Clusterstärke, sie ist der Punkt, an dem die Lebenszeit unter einer bestimmten Last unendlich wird.

Die Winkelabhängigkeit der applizierten Kraft auf die Adhäsionszone wurde als ein weiterer Effekt der die Stabilität von Bindungsclustern beeinflusst untersucht.[55] Abbildung 3.7 skizziert diesen Fall einer angelegten Zugspannung unter einem Winkel $\theta$ an zwei elastische Körper in adhäsivem Kontakt.

Die stochastischen Raten für Bindungsdissoziation und Assoziation ergeben sich, wie bei dem Ursprungsmodell aus Bells Annahmen für Bindungen unter Kraft. Die elastischen Gleichungen ergeben sich wiederum aus den oben verwendeten elastischen Funktionen unter Einbezug des Winkels $\theta$ unter dem die Zugspannung wirkt.

Kleinere Zugwinkel führen zu stabileren Clustern, die Lebenszeit des Adhäsionskontaktes geht gegen unendlich, wenn der Winkel unter einen kritischen Wert gesenkt wird. Dieser Zusammenhang ist interessant, da Zellen während des Adhäsionsprozesses abflachen und damit der Winkel der Aktinfilamente zum Substrat minimiert wird. Zellen sind in der Lage zwischen kurz- und langlebiger Adhäsion umzuschalten, in dem sie die Zugrichtung des Aktins am Fokalkontakt im Bereich dieses kritischen Winkels halten. Limitationen in diesem Modell sind die Annahme von immobilen Ligand-Rezeptor-Bindungen an der Zell-Substrat-Grenzfläche und die rein elastische Modellierung der Zelle, welche in der Natur über komplexere Regulationsmechanismen verfügt und sich viskoelastisch verhält. In dem erweiterten Modell einer schräg 

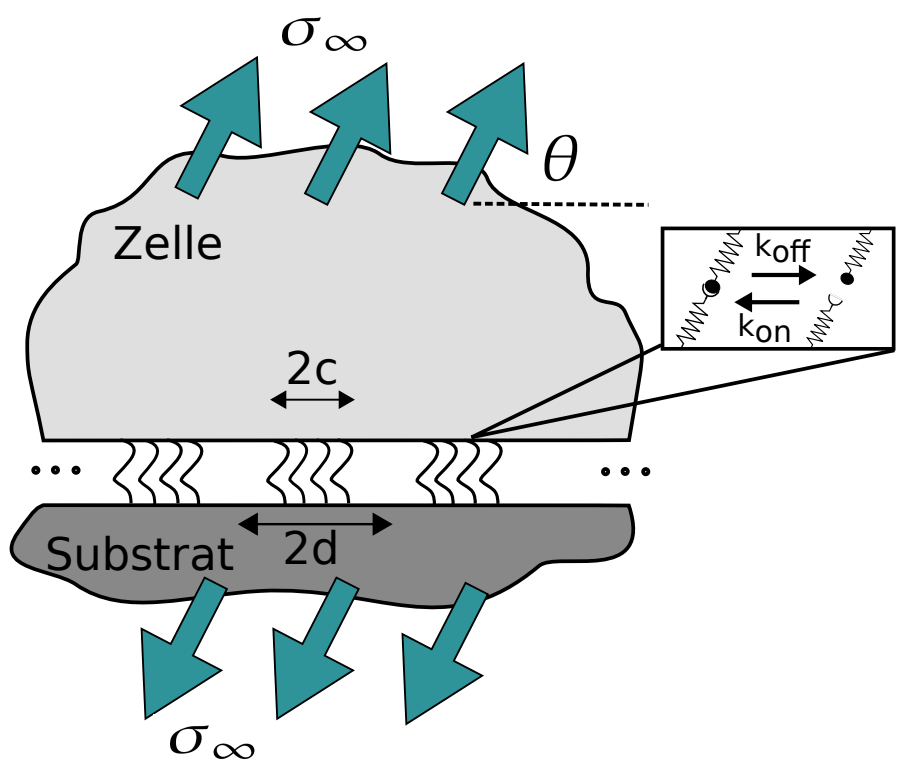

Abbildung 3.7: Skizze periodisch angeordneter Adhäsionscluster zwischen zwei elastischen Körpern mit unterschiedlichen elastischen Eigenschaften unter einer schräg angelegten Zugspannung.[55]

angelegten Zugspannung wird explizit darauf hingewiesen, dass die Stabilität mehrerer periodisch angeordneter Cluster untersucht wird. Die Berechnungen beziehen sich auf Grund der Periodizität aber auf nur einen Cluster, mögliche kooperative Effekte zwischen benachbarten Clustern werden damit nicht untersucht. Die Bindungen im untersuchten Cluster haben regelmäßige Abstände und feste Positionen, der Effekt der Diffusion von Bindungen in der Membran wird also ebenfalls vernachlässigt. 


\subsection{Gitter-Federnmodell von Hammer und Paszek}

Paszek und Hammer publizierten 2009 ein Modell, das sich auf den Aspekt des Integrinclusterns und damit die Bildung von Adhäsionskontakten fokussiert, wohingegen sich frühere Modelle häufig nur mit der Stabilität bestehender Cluster beschäftigen. [12] Paszek und Hammer formulieren als zentrale Fragestellung ihrer Arbeit ob die Glykokalyx das Clustern von Integrinen unabhängig von intrazellulären Proteinen beeinflussen kann und inwieweit dieses durch physikalische und chemische Parameter der extrazellulären Matrix moduliert werden kann. Um diese Fragen zu adressieren, untersuchten Hammer und Paszek den Einfluss von Systemeigenschaften wie Glykokalyxsteifigkeit und Integrin-Ligand-Affinität auf das Clustern der Integrine. Das Modell von Paszek bedient sich einer mechanischen Beschreibung der Zell-ECM-Grenzfläche, die Integrin-Ligand-Bindungen werden als Hook'sche Federn modelliert. Durch diese Beschreibung ist es möglich die zuvor erläuterten, abstandsabhängigen kinetischen Raten zur Bindungsdissoziation nach Bell zu implementieren. Ein Gitter-Federn-Modell (engl. lattice spring model, LSM) wie in Abbildung 3.8 skizziert, wird verwendet um das elastische Verhalten der Zellmembran und der ECM beziehungsweise des Substrats zu beschreiben. Die unspezifische Zell-Matrix-Repulsion verursacht durch Repellermoleküle der Glykokalyx entsteht im Modell durch ein repulsives Potential zwischen der Membranplatte und dem Substrat. Die Länge dieser Federn und damit die Dicke der Glykokalyx bestimmt den initialen Abstand zwischen Membran und Substrat. Integrinbindungen werden dem Algorithmus als Federn zugefügt, das Öffnen einer Bindung führt zur Entfernung dieser Feder. Die Bildung einer Bindung bringt Membran und ECM in näheren Kontakt. Integrine können aktiv oder inaktiv sein und aktive Integrine können an die ECM binden.

Die durch die Glykokalyx ausgelösten repulsiven Kräfte zwischen Zellmembran und Substrat entstehen durch ein Zusammenspiel verschiedener Effekte, wie elektrostatische Repulsion, osmotischer Druck und sterische Kompression der Glykokalyxketten. Diese Effekte wurden in einem Term für den mechanischen Widerstand zusammengefasst und werden durch folgendes harmonisches Potential pro Einheitsfläche beschrieben.

$$
\frac{1}{2} k_{\mathrm{g}} H(x, y)^{2}
$$

$H$ beschreibt die lokale Kompression der Glykokalyx und $k_{\mathrm{g}}$ die effektive Steifigkeit pro Einheitsfläche.

LSMs werden in der Bruchmechanik verwendet um die elastischen Eigenschaften von Festkörpern zu beschreiben. Bei einer geeigneten Wahl der Gitterparameter und der Federanordnung erhält man Ergebnisse entsprechend der Elastizitätstheorie. Durch die Modellierung der Integrinbindungen und der Glykokalyx als Hook'sche Federn bietet sich die Verwendung eines LSM-Modells an, da sich hier die zusätzlichen Federn leicht implementieren lassen. Das aus dem LSM erhaltene System verhält sich wie ein isotroper elastischer Festkörper mit einer konstanten Poissonzahl $v=\frac{1}{4}$ und einem 


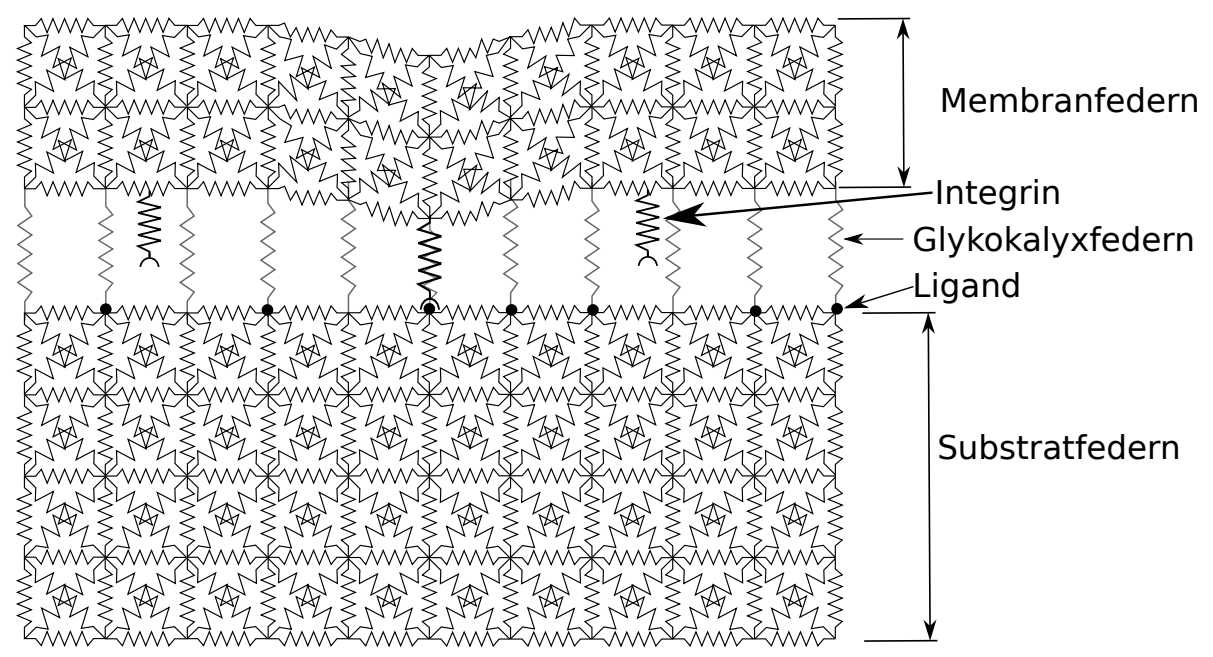

Abbildung 3.8: Gitter-Federn-Modell zur Untersuchung der Integrindynamik. Das Modell dient zur numerischen Beschreibung der mechanischen Eigenschaften von Zelle und ECM bzw. Substrat. Integrin-Ligand-Bindungen werden als zusätzliche Federn zwischen den unteren Knoten des Membran- und den oberen Knoten des Substratgitters modelliert. Ebenso wird die Glykokalyx als einfaches harmonisches Potential durch Federn ergänzt. [12]

einstellbarem Young-Modul.

$$
Y=\frac{5 \sigma}{2 \Delta x}
$$

$\Delta x$ ist der Gitterknotenabstand und $\sigma$ die Hook'sche Federkonstante in dem in Abbildung 3.8 gezeigten Modell. Wenn $\Delta x$ klein ist, im Verhältnis zu den betrachteten Längenskalen verhält sich das Federnsystem näherungsweise wie ein elastisches Kontinuum.

Um die, durch die Glykokalyx verursachte Repulsion zu modellieren werden zusätzliche Federn zwischen Membranfedernnetzwerk und Substratfedernnetzwerk eingefügt. Die Federkonstanten der Glykokalyx $\sigma_{\mathrm{g}}$ steht in Relation mit der effektiven Kompressibilität der Glykokalyxschicht:

$$
k_{\mathrm{g}}=\frac{\sigma_{\mathrm{g}}}{\Delta x^{2}} \text {. }
$$

Relaxation des kompletten Federnnetzwerkes ins mechanische Gleichgewicht ermöglicht die Berechnung der durch die Bildung von Integrinbindungen verursachte Deformation des LSMs.

Die im LSM gespeicherte potentielle Energie ist

$$
E=\frac{1}{2} \sum_{i} \sum_{j} \sigma_{i j}\left(\left|r_{i j}\right|-l_{i j}\right)^{2}
$$

mit der Summe $i$ über alle Knoten im System und der Summe $j$ über alle Knoten, die mit Knoten $i$ verbunden sind. $\left|r_{\mathrm{ij}}\right|$ ist der Abstand zwischen den Knoten $i$ und $j, \sigma_{\mathrm{ij}}$ und 
$l_{\mathrm{ij}}$ bezeichnen Federkonstante und Gleichgewichtslänge der Feder, die Knoten $i$ und $j$ verbindet.

Die Minimierung der Systemenergie ist erreicht, wenn die Vektorsumme der Kräfte aller Knoten 0 beträgt.

$$
F_{\mathrm{i}}=-\sum_{\mathrm{j}} \sigma_{\mathrm{ij}}\left(\frac{\left|r_{\mathrm{ij}}\right|-l_{\mathrm{ij}}}{\left|r_{\mathrm{ij}}\right|}\right) r_{\mathrm{ij}}=0
$$

Zur Minimierung von Randeffekten verursacht durch die endliche Systemgröße werden periodische Randbedingungen verwendet.

Integrinrezeptoren werden zufällig über die Zell-Substrat-Grenzfläche verteilt bis die gewünschte Dichte erreicht ist. Die Positionen der ECM-Liganden sind beschränkt auf die Knotenpositionen, wohingegen die Position von Integrinen in der Membran frei ist. Wie bereits beschrieben können Integrine drei verschiedene Zustände einnehmen, inaktiv, aktiv und gebunden. Zur Vereinfachung wird in diesem Modell davon ausgegangen, dass nur aktive Integrine binden können. Ein Integrin kann damit folgende Reaktionen eingehen, die im vorliegenden Modell untersucht werden. Aktive Integrine können deaktiviert werden, ebenso können inaktive Integrine aktiviert werden. Aktive Integrine können Bindungen ausbilden und vorhandene Bindungen können reißen. Zusätzlich wird in dem von Paszek formulierten Modell erstmals die Diffusion von ungebundenen Integrinen berücksichtigt und stellt auch eine mögliche Reaktion dar. Die Raten zur Aktivierung und zur Inaktivierung $k_{\mathrm{a}}$ und $k_{\mathrm{i}}$ sind phänomenologische Größen.

Die abstandsabhängigen Raten für Bindungsriss $k_{\mathrm{r}}$ und Bindungsschluss $k_{\mathrm{f}}$ werden nach dem Bell-Modell formuliert.

$$
k_{\mathrm{r}}(F)=k_{\mathrm{r}}^{0} \cdot \exp \left(\frac{F \gamma}{k_{\mathrm{B}} T}\right)
$$

Die Kraft auf die Bindung ist $F, k_{\mathrm{r}}^{0}$ ist die intrinsische Dissoziationsrate ohne Krafteinwirkung und $\gamma$ beschreibt die Kraftkonstante der Bindung.

Die Assoziationsrate wird für aktive Integrine berechnet, die sich innerhalb eines cutoff-Abstandes eines Bindungspartners befinden. Für alle Integrine die weiter von einem Bindungspartner entfernt sind wird die Assoziationsrate 0 gesetzt.

Die Assoziationsrate ergibt sich aus der Boltzmann-Verteilung zu

$$
k_{\mathrm{f}}(F)=k_{\mathrm{f}}^{0} \cdot \exp \left(\frac{F \gamma-\Delta E}{k_{\mathrm{B}} T}\right) .
$$

Mit $k_{\mathrm{f}}^{0}$ der intrinsischen Assoziationsrate in Abwesenheit applizierter Kräfte und $\Delta E$ der minimalen Änderung der mechanischen potentiellen Energie durch die Bildung der Bindung.

Diffusionsbewegungen werden als Sprünge definierter Länge $\Delta l$ in die vier Raumrichtungen entlang der $x$ - und $y$-Achse beschrieben. Die Rate $k_{\mathrm{d}}$ für einen solchen Sprung ist gegeben durch: 


$$
k_{\mathrm{d}}=\frac{4 D}{\Delta l^{2}} .
$$

$D$ ist der Diffusionskoeffizient der Integrine in einer Membran $\left(10^{-10} \frac{\mathrm{cm}^{2}}{\mathrm{~s}}\right)$. Die Sprunglänge $\Delta l$ in den Simulationen ist im Größenbereich des Integrindurchmessers.

Wie in der Literatur beschrieben, zeigen sich in dem Modell von Paszek und Hammer komplexe Integrin-Adhäsionsmuster. Deformationen in der Zellmembran oder der ECM, die durch Bindungsschluss verursacht werden, führen zu einer Modifikation der abstandsabhängigen kinetischen Raten für andere potentielle Integrin-LigandInteraktionen. Integrinbindungen ziehen Zellmembran und Substrat in größere räumliche Nähe und neue Bindungen werden leichter geschlossen, da die energetischen Kosten zur elastischen Deformation der Membran durch die erste Bindung für jede weitere Bindung erniedrigt werden. Je steifer die Membran beziehungsweise das Substrat, desto weniger groß die laterale Ausdehnung der durch eine Bindung verursachten Deformationen und damit die Kooperativität zwischen Bindungen. Dieser Effekt hat zur Folge, dass eine erhöhte Steifigkeit der Glykokalyx zur Bildung von dichter gepackten Bindungsclustern auf Grund dieser gehemmten Integrinbindungskooperativität führt. Die Bildung von Integrinclustern ist abhängig von dem Wechselspiel zwischen Integrin-induzierter Adhäsion und Glykokalyx-induzierter Zell-ECM-Repulsion. Bezüglich der anfänglich formulierten Fragestellung kann mit dem von Paszek formulierten Modell gezeigt werden, dass das Clustern von Integrinen abhängig von der Dicke und Steifigkeit der Glykokalyx sowie von physkalischen und chemischen Eigenschaften von Zelle und extrazellulärer Matrix ist. Das bedeutet, dass bereits vor der Aktivierung von intrazellulären Signalkaskaden, Integrine in der Lage sind ihre Umgebung zu sondieren und damit den Adhäsionsprozess zu aktivieren. 


\subsection{Membranfluktuationen als Ursprung der Adhäsion}

Eine interessante Eigenschaft von Membranen sind ihre Formfluktuationen, welche die Membranadhäsion beeinflussen können.[56, 57] Artifizielle Vesikel dienen als Modellsystem für Zellmembranen. Diese fluiden Vesikel im thermischen Gleichgewicht erfahren lediglich thermische Fluktuationen, die über die Helfrich effektive freie Energie charakterisiert sind.[58] Diese Energie beinhaltet die Biegeenergie, die Gauss'sche Biegesteifigkeit und die Membranspannung. Biegeenergie und Gauss'sche Biegesteifigkeit sind Materialeigenschaften, welche von der Membranzusammensetzung abhängen. Die Spannung steht im Zusammenhang mit der zusätzlichen Fläche, die in den Fluktuationen der Membranform gespeichert sind.

Modelle basierend auf Mischungen von Adhäsionsbindungen unterschiedlicher Länge [59] und Modelle die Adhäsionsbindungen mit Repellermolekülen mischen [12] beschreiben erfolgreich die Stabilität von Bindungsclustern. Andere Arbeiten sehen die thermische Rauigkeit der Membran als Grund des kooperativen Effektes zwischen Adhäsionsbindungen.[60, 61, 62, 63, 64] Auf diesen Ansatz zur Erklärung der Bildung und Stabilität von Adhäsionsclustern wird hier detaillierter eingegangen.

Weikl et al., sowie Smith et al. und andere Gruppen untersuchten den Einfluss thermischer Membranfluktuationen im Nanometerbereich auf den Adhäsionsprozess.[59, $61,65,66,67]$ Thermische Ondulationen verursachen, dass eine Membran in größerer Entfernung zum Substrat temporär eine lokale größere räumliche Nähe zum Substrat erreichen kann. Dadurch begünstigen Ondulationen die Bildung einzelner Bindungen, da das System durch Ondulationen Konfigurationen niedrigerer Energien einnehmen kann. Weikl beschäftigte sich zunächst mit der Adhäsion von Membranen an ein Substrat über spezifische und allgemeine Wechselwirkungen.[68] Hierzu betrachtet er vereinfachte Membranen bestehend aus zwei Komponenten, welche zum einen klassische Lipide enthalten und zum anderen hoch spezifisch bindende Rezeptoren für die Zelladhäsion. Dadurch ist es möglich, das Zusammenspiel zwischen spezifischen und unspezifischen Wechselwirkungen und die Phasenseparation während des Adhäsionsprozesses zu untersuchen. Die spezifischen Wechselwirkungen resultieren aus Rezeptormolekülen die in der Membran eingebettet sind. Die unspezifischen Wechselwirkungen sind repulsiver Natur und entstehen beispielsweise durch elektrostatische Kräfte zwischen geladenen Membranen. Durch die unterschiedlichen Wechselwirkungen entsteht eine Potentialbarriere und es kommt zu einer Phasenseparation in der Membran. Fluktuationen innerhalb der Membran erniedrigen die Potentialbarriere und verringern die Tendenz zur Phasenseparation. In einem erweiterten Modell verwendet Weikl Rezeptoren unterschiedlicher Länge um den Effekt der Domänenbildung zu untersuchen.[65, 59, 64] Dieser Längenunterschied führt zu einer membraninduzierten Repulsion zwischen den verschiedenen Rezeptor-Ligand-Komplexen. Die Membran muss unter Aufwendung von Biegeenergie gekrümmt werden um die unterschiedlichen Längen auszugleichen. Das Gleichgewichtsverhalten zweier Membranen, die über lange und kurze Rezeptor-Ligand-Komplexe gebunden sind ist abhängig von ihrem Energiepotential, welches zwei Minima besitzt, und der Biegesteifigkeit 
der Membranen. Das Potentialminimum bei kleinen Abständen beschreibt die Wechselwirkungen der kurzen Rezeptor-Ligand-Bindungen und das Minimum bei größeren Abständen die Wechselwirkungen über die langen Rezeptoren. Die Tiefen dieser Potentialminima sind abhängig von den Konzentrationen der Rezeptoren und den jeweiligen Bindungsenergien. Bei flachen Potentialen können Membransegmente induziert durch thermische Fluktuationen die Energiebarriere überwinden. Bei tieferen Minima der Potentiale ist diese Energiebarriere zu hoch und es wird eine Linienspannung verursacht, die zur Bildung großer Membrandomänen führt, die entweder in Minimum 1 oder 2 gebunden sind.

Smith et al. arbeiteten zunächst an adhärierenden Riesenvesikeln, die über entsprechende Rezeptoren an eine mit Liganden präparierte Oberfläche binden.[62] Sie zeigten eine zweiphasige Wechselwirkung zwischen Membran und Substrat. In der ersten Phase, bei großen Abständen, durch ein unspezifisches harmonisches Potential und bei kleinen Membran-Substrat-Abständen über die spezifischen Ligand-RezeptorWechselwirkungen.[63] Eine Adhäsionszone entsteht durch die Sedimentation eines Vesikels Richtung Substrat in das schwache Membran-Substrat-Potential circa $100 \mathrm{~nm}$ über der Oberfläche. Hier bildet sich eine stark fluktuierende Kontaktzone aus. In diesem Abstand der Membran zum Substrat ist die Bildung einer spezifischen LigandRezeptor-Bindung bei einer nicht fluktuierenden Membran quasi unmöglich. Das fluktuationsinduzierte Annähern der Membran an das Substrat erlaubt eine Wechselwirkung zwischen Ligand und Rezeptor und ist damit verantwortlich für die Bildung der ersten spezifischen Bindung. Diese erste Bindung deformiert die Membran, hält sie in der Nähe des Substrats und erhöht damit die Wahrscheinlichkeit zur Ausbildung weiterer Bindungen in der Umgebung der ersten Bindung, dies wird als Nachbareffekt bezeichnet. Dichtes Packen der Bindungen unterdrückt Fluktuationen zwischen den Bindungen. Fluktuationen üben einen Zug auf bereits vorhandene Bindungen aus und würden zu deren Öffnung führen. In Simulationen konnte Smith zeigen, dass keine stabile Adhäsion möglich ist, wenn Fluktuationen im freien Zustand über der Oberfläche unterdrückt werden und die Membran nicht deformierbar ist. Sie berechnen die Gesamtenergie einer Domäne von $N$ Bindungen und untersuchen deren Abhängigkeit vom Abstand $b$ zwischen den Bindungen, siehe Abbildung 3.9.

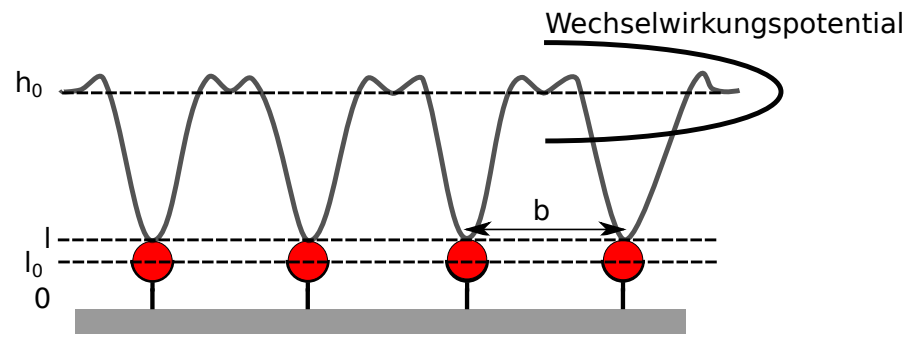

\begin{abstract}
Abbildung 3.9: Ausschnitt einer gebundenen Membran die in einem harmonischen Potential deformiert wird und fluktuiert. Die Bindungen haben einen regulären Abstand $b$ zueinander.[61]
\end{abstract}

Die Gesamtenergie ist gegeben durch den Helfrich Hamiltonian.[61, 69, 68, 70] 


$$
\mathcal{H}_{0}=\int_{A} d r\left[\frac{\kappa}{2}\left(\nabla^{2} h(\mathbf{r})\right)^{2}+\frac{\sigma}{2}(\nabla h(\mathbf{r}))^{2}+\frac{\gamma}{2}\left(h(\mathbf{r})-h_{0}\right)^{2}\right]
$$

Hier wird über die betrachtete Gesamtfläche $A$ integriert. Der erste Term auf der rechten Seite ist die Biegeenergie der Membran mit $\kappa$, der Biegesteifigkeit der Membran. $h(\mathbf{r})$ mit $\mathbf{r}=(x, y)$ ist die Höhe der Membran über dem Substrat an der Position $\mathbf{r}$. Der zweite Term steht für die Membranspannung $\sigma$. Der letzte Term gibt das MembranSubstrat-Wechselwirkungspotential mit einem harmonischen Potential der Stärke $\gamma$ und einem Minimum bei der Höhe $h_{0}$ wieder. Die Rezeptoren werden als harmonische Federn mit einer Gleichgewichtslänge $l_{0}$ und einer Federkonstanten $\lambda$ modelliert. Liganden und Rezeptoren wechselwirken über ein Potential mit einer Potentialtiefe $\epsilon_{\mathrm{b}}$ von $1-35 k_{\mathrm{B}} T$. Der Gesamthamiltonian $\mathcal{H}$ einer Domäne bestehend aus $N$ Bindungen an den Positionen $r_{b}^{j}$ ist damit:

$$
\mathcal{H}=\mathcal{H}_{0}+\frac{\lambda}{2} \sum_{j=1}^{N}\left(l\left(\mathbf{r}_{\mathrm{b}}^{\mathrm{j}}\right)-l_{0}\right)^{2}+N \epsilon_{\mathrm{b}} \equiv N \mathcal{H}_{\mathrm{d}}+N \epsilon_{\mathrm{b}} .
$$

Die Auslenkung der $j$-ten Bindungsfeder ist gegeben durch $l\left(\mathbf{r}_{\mathrm{b}}^{\mathrm{j}}\right) . \mathcal{H}_{\mathrm{d}}$ bezeichnet die Deformationsenergie pro Bindung gespeichert in der Membran und den Rezeptoren. Der letzte Term der Gleichung beschreibt die Bindungsenthalpie. Eine Domäne aus $N$ Bindungen ist stabil, wenn ihre freie Energie $\mathcal{F}_{\mathrm{b}}^{\mathrm{N}}$ kleiner ist als die des ungebundenen frei fluktuierenden Zustandes $\mathcal{F}_{\mathrm{ub}}^{\mathrm{N}}$. Das heißt, wenn gilt:

$$
\Delta \mathcal{F}^{\mathrm{N}}=\mathcal{F}_{\mathrm{b}}^{\mathrm{N}}-\mathcal{F}_{\mathrm{ub}}^{\mathrm{N}}<0
$$

Lipowsky und Sackmann geben die Fluktuationsamplitude einer Membran unter Spannung an.[71] Die Fluktuationsamplitude einer durchschnittlich flachen Membran positioniert im Minimum eines unspezifischen Potentials $\langle h(\mathbf{r})\rangle=h_{0}$ entspricht dieser Amplitude und ist gegeben durch:

$$
\Sigma_{0}^{2}=\frac{1}{A} \sum_{q} \frac{1}{\kappa q^{4}+\sigma q^{2}+\gamma}=\frac{\arctan \left(\sqrt{4 \kappa \gamma-\sigma^{2}} / \sigma\right)}{2 \pi \sqrt{4 \kappa \gamma-\sigma^{2}}} .
$$

Mit der Summe über alle Wellenvekoren q. Zum Vergleich verschieden dicht gepackter Domänen mit der gleichen Bindungsanzahl $N$, die dann eine unterschiedliche Fläche $A$ einnehmen, wird die freie Energiedichte $\Delta f \equiv \frac{\Delta \mathcal{F}^{\mathrm{N}}}{\mathrm{A}}$ betrachtet. Wenn $\Delta f$ negativ ist sind die untersuchten Domänen stabil.

In dem vorgestellten Modell wird die Stabilität verschieden dichter Domänen verglichen. Hierfür wird der Abstand zwischen den Bindungen variiert und die Fläche der Domäne angepasst. Die Auslenkung jeder Bindung innerhalb der Domäne ist gleich, da ein regelmäßiger Abstand zwischen den Bindungen angenommen wird. Auch die randständigen Bindungen erfahren im Gegensatz zu anderen Modellen [52, 12] die 
gleiche Kraft wie Bindungen im Inneren der Domäne. Bei zwei verschiedenen Abständen der Bindungen in der Domäne werden stabile Bereiche gefunden. Daraus wird die Koexistenz von dicht und weniger dicht gepackten Domänen erklärt, wobei eine Koexistenz dieser Domänen mit dem vorgestellten Modell nicht gezeigt werden konnte. Durch die Immobilität der Bindungen in dem Modell und die Anpassung der Fläche auf den jeweiligen Abstand der Bindungen ist es nicht möglich eine wirkliche Koexistenz verschiedener Domänen zu beobachten. Als Hauptgrund für die Existenz der zwei stabilen Domänen unterschiedlicher Dichte wird ein sogenannter overshoot der Membranhöhenfunktion genannt. Bei einem großen Abstand $d$ zwischen den Bindungen verhalten diese sich wie isolierte Bindungen. Die Bindungen verursachen eine lokale Deformation der Membran, in der diese bevor sie im Minimum des unspezifischen Potentials von $h_{0}$ wieder flach wird, $h_{0}$ übersteigt (overshoot). Durch Annäherung der Bindungen werden diese overshoots über die benachbarten Bindungen geteilt und die Gesamtkosten der Biegeenergie minimiert. Sobald die overshoots komplett überlappen erscheint ein Minimum in $\Delta f$. Weiteres Annähern der Bindungen erhöht die Biegeenergie wieder und eine Potentialbarriere entsteht. Wenn die overshoots verschwinden beginnt die Membran zwischen den Bindungen flach zu werden und die Energie läuft gegen ein Minimum für minimale Abstände $d$. Mit steigender Membranspannung werden die overshoots der Membran weniger ausgeprägt, wobei die Deformationsenergie steigt. Wenn der Abstand $d$ gegen Null läuft wird die Membran auf Grund der hohen Bindungsdichte flach und die Deformationsenergie und die Flukuationen werden unabhängig von der Spannung. Der Einfluss der Membranfluktuationen ist auf separierte Bindungen besonders groß und hat einen hohen Einfluss auf die Ausbildung der ersten Bindung und in diesem Modell auf die Dichte der Bindungsdomäne. In dem hier vorgestellten Modell werden jedoch große Bindungsdomänen untersucht, in denen dieser Einfluss nicht so groß sein dürfte. Im zellulären System steht die basolaterale Membran unter einer durch das Cytoskelett induzierten Spannung. Diese Spannung unterdrückt Membranfluktuationen im Gegensatz zum Adhäsionsprozess bei Vesikeln. Die Existenz von Transmembranproteinen in der Zellmembran reduziert ebenfalls Membranondulationen im Vergleich zu einer reinen Lipidmembran.

Mit der frühen Phase der Fokalkontaktbildung beschäftigen sich Smith et al. in späteren Arbeiten [67]. Hier untersuchen sie, ab welcher kritischen Bindungsanzahl eine Adhäsionsstelle stabil wird und weiterwächst. Eine Skizze des Modells ist in Abbildung 3.10 dargestellt.

Dargestellt sind berechnete Membranprofile abgebildet für null (schwarz), eine (dunkelblau) und zwei (hellblau) Bindungen in der Domäne. $h_{0}$ ist der Membran-SubstratAbstand, $h^{\mathrm{b}}$ die Höhe der ausgelenkten Bindung, $l_{0}$ die Gleichgewichtshöhe der Bindung und $d$ die Höhenänderung der Membran beim Bindungsschluss. Weiterhin sind die effektiven Assoziations- und Dissoziationsraten $K_{n}^{\text {on }}$ und $K_{n}^{\text {off }}$ der wachsenden Domäne gezeigt. Da die Form der Membran für eine bzw. zwei Bindungen nahezu identisch ist, wird die Näherung getroffen, das hier auch identische höhenabhängige Assoziationsraten für den Rand einer Adhäsionsdomäne angenommen werden können.

Die kritische Bindungsanzahl im Nukleationskern $N_{C}$ wird erreicht, wenn der Anstieg 


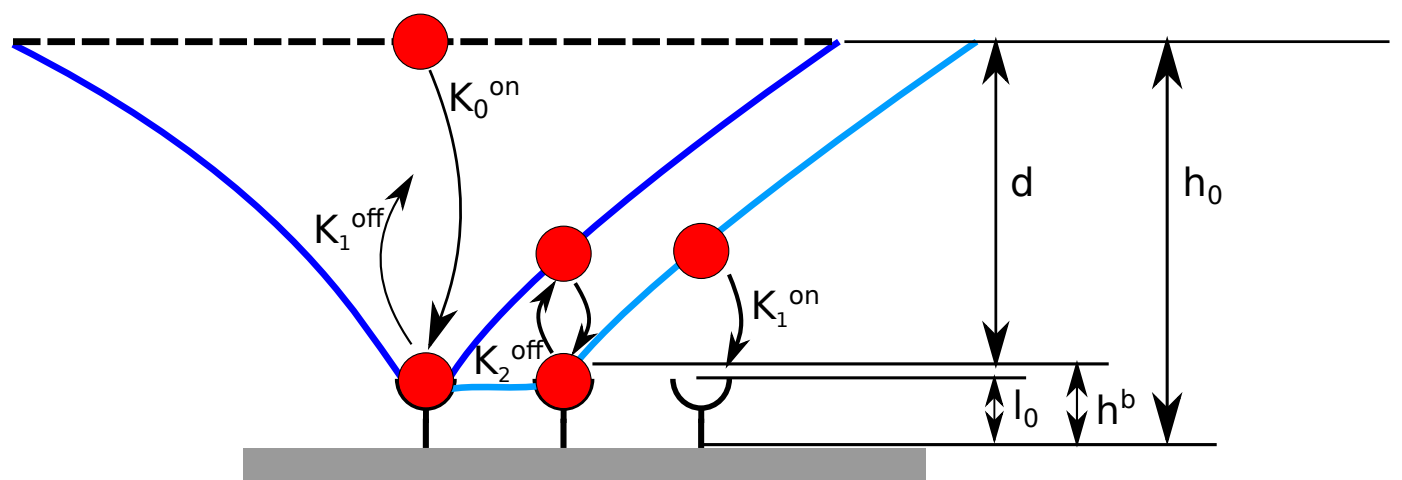

Abbildung 3.10: Membranprofile für null (schwarz), eine (dunkelblau) und zwei (hellblau) Bindungen in der Domäne. Die Form der Membran in den letzten beiden Fällen ist nahezu identisch. Die effektiven Assoziations- und Dissoziationsraten $K_{n}^{o n}$ und $K_{n}^{\text {off }}$ der wachsenden Domäne sind ebenfalls dargestellt.[67]

der freien Energie auf Grund der Membrandeformation gleich dem Energiegewinn durch die Bindungsenthalpie ist.

$$
N_{\mathrm{C}}=1+\frac{4 d^{4} \rho_{\mathrm{r}} \gamma \sqrt{\gamma \kappa}}{\pi\left(\gamma d^{2}-2 \bar{\epsilon}_{\mathrm{b}} \rho_{\mathrm{r}}\right)^{2}}
$$

Mit $d$ der Höhenänderung der Membran, $\rho_{\mathrm{r}}$ der Rezeptordichte, und $\bar{\epsilon}_{b}$ der effektiven Affinität des Ligand-Rezeptor-Paares. Für diese gilt:

$$
\bar{\epsilon}_{\mathrm{b}}=\epsilon_{\mathrm{b}}+k_{\mathrm{B}} T \ln \frac{\left[\frac{\lambda \alpha^{2}}{2 \pi}\right]}{2}
$$

Mit $\epsilon_{\mathrm{b}}$ der Bindungsaffinität des Ligand-Rezeptor-Paares und $\alpha$ der Reichweite des Wechselwirkungspotentials.

Unterhalb der kritischen Nukleationskerngröße $N_{C}$ ist die Adhäsion unstabil, oberhalb dieser Größe können stabile Adhäsionsdomänen gebildet werden. Abhängig von der Bindungsaffinität des Ligand-Rezeptor-Paares fanden Smith et al. stabile Nukleationskerne bestehend aus 2-4 Bindungen.

Die Dynamik des Nukleationsprozesses ist abhängig von den Raten der Assoziation $k^{\text {on }}(h)$ und der Dissoziation $k^{\text {off }}(h)$. Dadurch dass Rezeptoren und Liganden an gegenüberliegenden Oberflächen gebunden sind, sind die Raten abhängig von deren Abstand $h$. Die Raten erfüllen die Bedingung des detaillierten Gleichgewichts:

$$
\frac{k^{\text {off }}(h)}{k^{\text {on }}(h)}=\exp \left[\left(\frac{\lambda}{2}\left(h-l_{0}\right)^{2}-\bar{\epsilon}_{\mathrm{b}}\right)\right]
$$

Bezugnehmend auf frühere Arbeiten $[72,73]$ ist die Assoziationsrate $k^{\text {on }}$ abhänig von der Wahrscheinlichkeit einen Liganden und einen Rezeptor innerhalb der Reichweite $\alpha$ des Wechselwirkungspotentials zu finden: 


$$
k^{\mathrm{on}}(h)=k_{0} \sqrt{\frac{\lambda \alpha^{2}}{2 \pi}} \exp \left[-\frac{\lambda}{2}\left\{\left(h-l_{0}\right)-\alpha\right\}^{2}\right]
$$

$k_{0}$ ist die intrinsische Reaktionsrate. Die Dissoziationsrate $k^{\text {off }}$ ergibt sich aus der Bedingung des detaillierten Gleichgewichts in Gleichung 3.40 und ist abhängig von der effektiven Bindungsaffinität $\bar{\epsilon}_{\mathrm{b}}$. Membranfluktuationen treten auf Zeitskalen auf, die viel kürzer sind als $k_{0}^{-1}$. Deshalb durchläuft die Membran die gesamte Höhenwahrscheinlichkeitsverteilung $p_{\mathrm{n}}$, bevor eine Bindung dissoziiert oder assoziiert. Mit der Fluktuation der Membran ändern sich gleichzeitig die abstandsabhängigen Raten $k^{\text {on }}(h)$ und $k^{\text {off }}(h)$. Durch diese verschiedenen Zeitskalen lassen sich effektive Raten, $K_{\mathrm{n}}^{\text {off }}$ und $K_{\mathrm{n}}^{\text {on }}$ um die $n$-te Bindung zu brechen oder die $(n+1)$-te Bindung zu bilden, definieren. Die effektiven Raten werden definiert, in dem über die lokalen Raten $k^{\text {on }}(h)$ und $k^{\text {off }}(h)$ in Bezug auf die charakteristische Verteilung $p_{n}$ gemittelt wird. Man erhält:

$$
K_{\mathrm{n}}^{\text {off }} \equiv \int d h^{\mathrm{b}} p_{\mathrm{n}}\left(h^{\mathrm{b}}\right) k^{\mathrm{off}}\left(h^{\mathrm{b}}\right)
$$

und

$$
K_{\mathrm{n}}^{\mathrm{on}} \equiv \rho_{1} \int d h^{\mathrm{r}} p_{\mathrm{n}}\left(h^{\mathrm{r}}\right) k^{\mathrm{on}}\left(h^{\mathrm{r}}\right) .
$$

Die Höhe der Membran an der Position einer Bindung am Rand der Bindungsdomäne und über dem benachbarten freien Rezeptor wird mit $h^{\mathrm{b}}$ und $h^{\mathrm{r}}$ angegeben. Die effektiven Raten sind abhängig vom Median $\overline{h_{\mathrm{n}}^{\mathrm{b}, \mathrm{r}}}$ und der Varianz $\sigma_{\mathrm{n}}^{\mathrm{b}, \mathrm{r}}$ der relevanten Höhenverteilung. Durch die zuvor getroffene Näherung, dass die Membran am Rand der Domäne eine konstante Form hat unabhängig von der Anzahl der Bindungen innerhalb der Domäne, werden lediglich vier verschiedene Raten $\left(K_{0}^{\text {on }}, K_{1}^{\text {on }}, K_{1}^{\text {off }}, K_{2}^{\text {off }}\right)$ benötigt. Zunächst wird die effektive Rate zur Bildung der ersten Bindung $K_{0}^{\text {on }}$ betrachtet. Im Durchschnitt liegen Ligand und Rezeptor nicht in Bindungsreichweite. Fluktuationen der Membran bringen die Bindungspartner in die Wechselwirkungsreichweite $\alpha$, in der sie mit der Rate $k^{\text {on }}(h)$ assoziieren. Durch Bildung des Mittelwertes über diese Ereignisse erhält man $K_{0}^{o n}$. Die Ausbildung der ersten Bindung deformiert die Membran zur Höhe

$$
h_{1}^{\mathrm{b}}=h_{0}-\frac{8 h_{0} \sqrt{\gamma \kappa}+\lambda l_{0}}{8 \sqrt{\gamma \kappa}+\lambda}
$$

und bildet die charakteristische Form der Randregion der Adhäsionsdomäne. Die erste Bindung reißt mit der Rate $K_{1}^{\text {off }}$ oder die Domänenbildung geht weiter und eine zweite Bindung bildet sich mit der Rate $K_{1}^{\text {on }}$. Da sich die Membran durch die erste Bindung schon näher am Substrat befindet ist $K_{1}^{\text {on }}$ größer als $K_{0}^{\text {on }}$. Die Bildung der zweiten Bindung stabilisiert die erste Bindung, weswegen die zweite Dissoziationsrate $K_{2}^{\text {off }}$ kleiner ist als $K_{1}^{\text {off }}$. Es konnten abhängig von der effektiven Bindungsaffinität Werte für die kritische Größe des Nukleationskerns $N_{C}$ bestimmt werden. Die Fluktuationen der 
Membran sind verantwortlich für die Ausbildung der ersten Bindung, da dadurch die Bindungspartner in die Reichweite des Wechselwirkunspotentials gebracht werden. In diesem Modell werden die Rezeptoren auf dem Substrat auf einem Gitter positioniert und können nicht diffundieren. Es werden also immer Domänen mit einer regelmäßigen Anordnung betrachtet. Die Raten für die Bindungsassoziation und -dissoziation sind abhängig von der Höhe der Membran über dem Substrat. Eine vorgenommene Vereinfachung ist jedoch die Reduktion auf vier effektive Raten, da die Form der Membran am Rand des Nukleationskerns unabhängig von dessen Größe als konstant angenommen wird. Dieser Ansatz ist für einen Nukleationskern aus wenigen Bindungen anwendbar, sobald man jedoch die weitere Dynamik der Fokalkontaktstabilität untersucht ist die Konfiguration der Membran komplexer. 



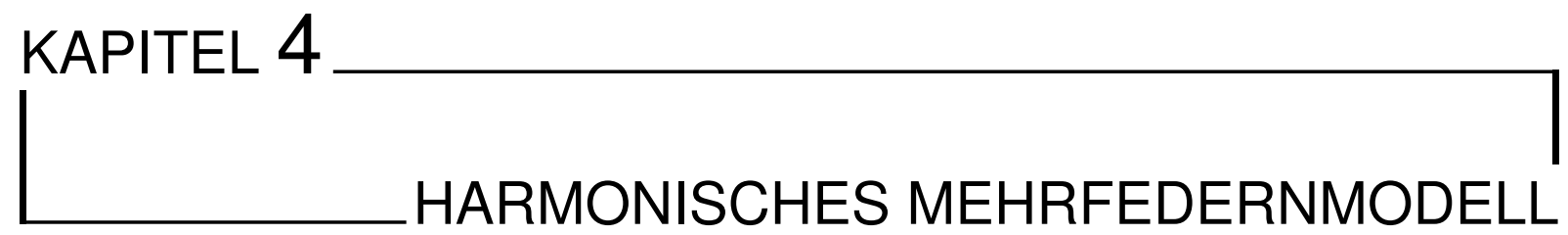

Im folgenden Kapitel wird das im Rahmen dieser Dissertation entwickelte Modell zur physikalischen Beschreibung der Bildung und Stabilität von fokalen Adhäsionskontakten erläutert. Das Modell basiert auf der Modellierung von Adhäsionsbindungen durch harmonische Federn. Eine Membran ist über eine variable Anzahl Adhäsionsbindungen an ein flaches Substrat gebunden. Die räumliche Anordnung der Adhäsionspunkte in einem Spannungsfeld ergibt eine Modulation lokaler Membran-Substrat-Abstände. Den Simulationen liegt ein übergeordnetes Modell der Kräfteverteilung in Adhäsionsclustern zu Grunde. Dieses geht davon aus, dass sich die auf eine Membran wirkende Kraft $F$ homogen verteilt, sodass also auf jeden infinitesimal kleinen Anteil der Membranfläche $A$ der gleiche Kraftanteil, die Zugspannung $\vec{\sigma}$, wirkt. Also

$$
\vec{\sigma}=\frac{d F}{d A} \text {. }
$$

Bei einer völlig homogen verteilten Bindungsanordnung ist die Kraft auf jede einzelne Bindung gleich groß, nämlich $\frac{F_{\text {ges }}}{N}$. Bindungscluster zeigen ein anderes Verhalten, denn die Bindungen am Rand des Clusters tragen eine höhere Kraft als Bindungen im Inneren.

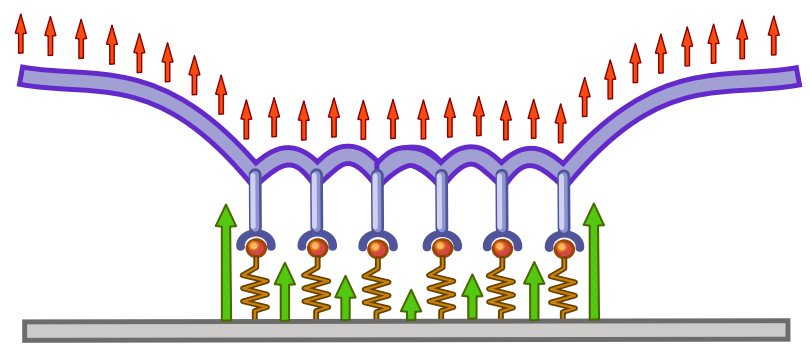

Abbildung 4.1: Skizze der Adhäsionsbindungen als harmonische Federn. An der Membran liegt eine gleichmäßige Spannung an (rote Pfeile) die Membran und Substrat separiert. Auf Bindungen am Rand eines Clusters wirkt eine größere Kraft als auf Bindungen im Clusterinneren, dargestellt durch grüne Pfeile.

Zur Berechnung der auf jeden einzelne Bindung wirkenden Kraft in einer beliebigen Konfiguration wird die Membran zerlegt in Bereiche die Einfluss auf diese Einzelbindungen ausüben (regions of influence, ROl's). 
Der Gradient der Membranenergiedichte, - $\operatorname{grad} \varrho_{e}\left(\vec{r}, S_{N}\right)$, ist der Ursprung eines Spannungsfeldes, bei dem alle Spannungsvektoren in Richtung der Position der geschlossenen Bindung zeigen. $S_{N}=\left\{r_{1}, r_{2}, \ldots ., r_{N}\right\}$ bezeichnet die Bindungskonfiguration, die durch die Positionsvektoren $r_{i}$ aller geschlossenen Bindungen definiert ist.

$$
\vec{\sigma}(\vec{r})=-\operatorname{grad} \varrho_{e}\left(\vec{r}, S_{N}\right)
$$

Man kann sich die Membranoberfläche als Mosaikmuster aus irregulären Mosaiksteinen vorstellen, von denen jeder exakt eine geschlossene Bindung in seinem Zentrum hat. Diese Zellen sind die Regionen der Membran in denen die zentrale Bindung Einfluss ausübt (ROl's), innerhalb einer Zelle zeigen alle Spannungsvektoren in Richtung der eingeschlossenen Bindung.

Eine Näherung zur Bestimmung des Bereichs der Membran deren Membranspannung jede Bindung tragen muss, stellt die Unterteilung der Membranfläche in Voronoi-Zellen dar. Voronoi-Zellen lassen sich konstruieren, indem die Mittelsenkrechten zwischen der betreffenden Bindung und allen Bindungen die sie umgeben miteinander verbunden werden (4.2). Man erhält die Membranfläche, deren Abstand zur betreffenden Bindung geringer ist, als der zu den restlichen Bindungen.

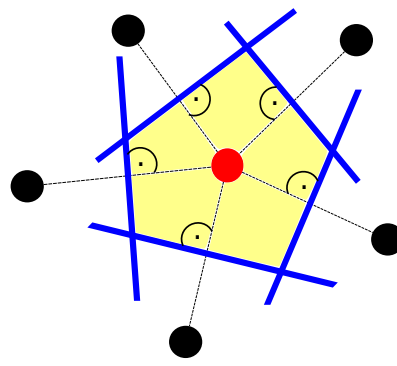

Abbildung 4.2: Konstruktion der Voronoi-Zelle der rot gefärbten Bindung, die von fünf schwarzen Bindungen umgeben ist. Die gestrichelten Linien verbinden die rot gefärbte Bindung mit allen Nachbarbindungen, die blauen Linien stellen die entsprechenden Mittelsenkrechten dar. Die gelb gefärbte Fläche beschreibt die VoronoiZelle der roten Bindung.

In Abschnitt 4.1 werden die Grenzen von Einfedermodellen aufgezeigt und es wird dargelegt warum Einfedermodelle zur Berechnung der Kraftverteilung über Adhäsionsbindungen nicht ausreichend sein können, um die Stabilität und Bildung von Adhäsionsclustern zu erklären.

Das harmonische Mehrfedernmodell erweitert die Einfedermodelle um eine zusätzliche Feder zur Modellierung der Membranelastizität. Das erlaubt eine Verteilung der Energie zwischen den beiden Energiereservoirs der Membran- und der Bindungsenergie und damit ein komplexeres Szenario von Bindungsstabilitäten.

In einem weiteren Schritt werden Boltzmann Faktoren für statistischen Bindungsschluss und Bindungsbruch eingeführt und damit die endliche Lebenszeit der Bindungen nachgestellt. Das entwickelten Modell zur physikalischen Beschreibung der Zelladhäsion wird als Monte Carlo Simulation in ein $C / C^{++}$-Programm implementiert und analysiert. 


\subsection{Grenzen von Einfedermodellen}

Mit einer Variationsrechnung lässt sich zeigen, dass in Einfedermodellen die Energie völlig homogen verteilter Bindungen immer niedriger ist als die einer inhomogenen Verteilung von Bindungen, siehe Anhang 1.

In Abbildung 4.3 ist die Einteilung verschiedener Bindungskonfigurationen in VoronoiZellen zu sehen. In der Simulation werden die Voronoi-Zellen der Bindungen bestimmt und mit deren Hilfe die Kraft und die Energie auf jede Bindung berechnet. Hier beginnt eine Simulation mit einer geclusterten Konfiguration, mit deutlich größeren VoronoiZellen für Bindungen am Rand des Clusters. Im Verlauf der Simulation geht diese Konfiguration unter Minimierung der potentiellen Energie in eine homogene Verteilung der Bindungen über.
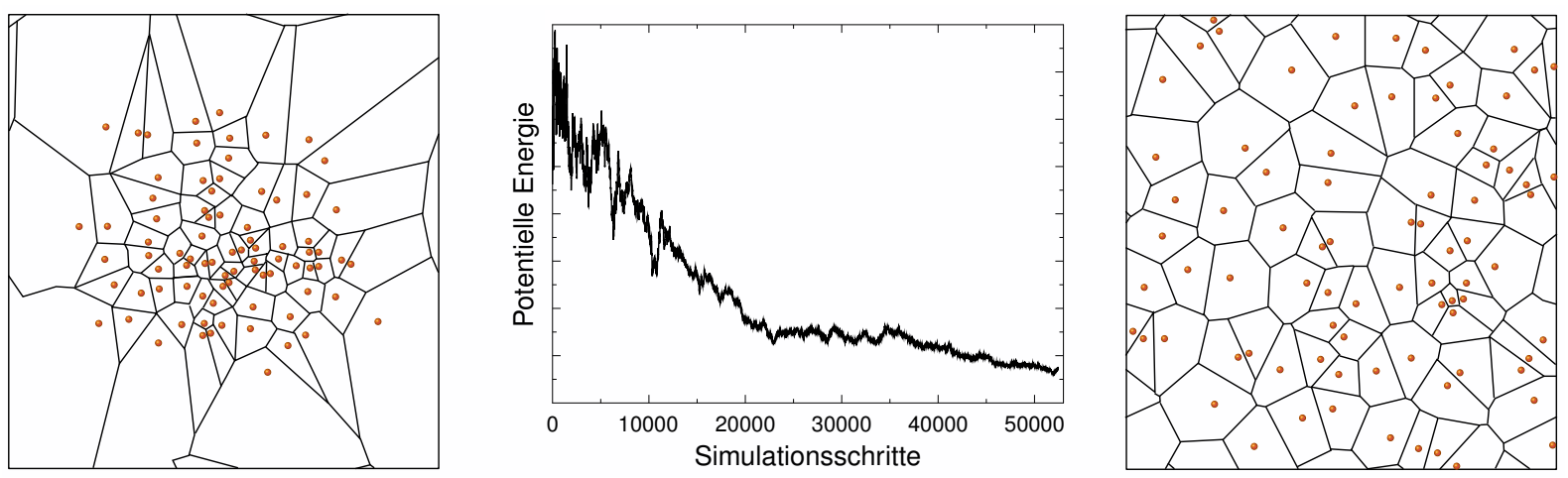

Abbildung 4.3: Die Einteilung der Membranfläche in Voronoi-Zellen dient zur Bestimmung der Kraft auf eine Bindung. Im Verlauf einer Simulation gehen die Bindungen von einer geclusterten Konfiguration unter Minimierung der Gesamtenergie zu einer homogenen Verteilung über.

Bindungen im Inneren des Clusters besitzen relativ kleine Voronoi-Zellen, tragen also eine geringe Kraft. Die randständigen Bindungen tragen eine sehr viel höhere Kraft. Im Simulationsverlauf zerfließt der Cluster und es resultiert eine homogene Bindungsverteilung, in der die Kraft pro Bindung gleich groß ist.

Es wird gezeigt, dass sich ein initial erzeugter dichter Bindungscluster, in dem hier verwendeten Einfedermodell, immer unter Minimierung der potentiellen Energie ausdehnt. In der homogenen Verteilung sind die ROl's der Bindungen gleich groß, das heißt die Bindungen tragen die gleiche Energie. Die Stabilität eines Bindungsclusters gegenüber einer homogenen Verteilung, wie sie in der biologischen Adhäsion beobachtet wird, kann mit einfachen Einfedermodellen nicht erklärt werden, da ein gegenteiliges Verhalten beobachtet wird.

Die Ergebnisse des Einfedermodells, basierend auf der Kraftverteilung über die Bindungen, werden in folgendem Abschnitt gezeigt. Es wird gezeigt, dass die Kraftverteilung über Bindungen zwischen einer Membran und einem Substrat nicht ausreichend ist um die Entstehung von Adhäsionsclustern zu erklären. 
Instabilität gegenüber Ausdehnung und Verformung Der energetische Vergleich verschiedener Anfangskonfigurationen wird durchgeführt um weiteren Einblick in die Stabilität von Bindungsclustern zu erhalten. Hierfür werden zunächst Cluster bestehend aus 81 Bindungen mit einem Radius zwischen 10 und 200 Längeneinheiten erzeugt. Die Ausdehnung dieser Cluster ist in Abbildung 4.4 gezeigt.
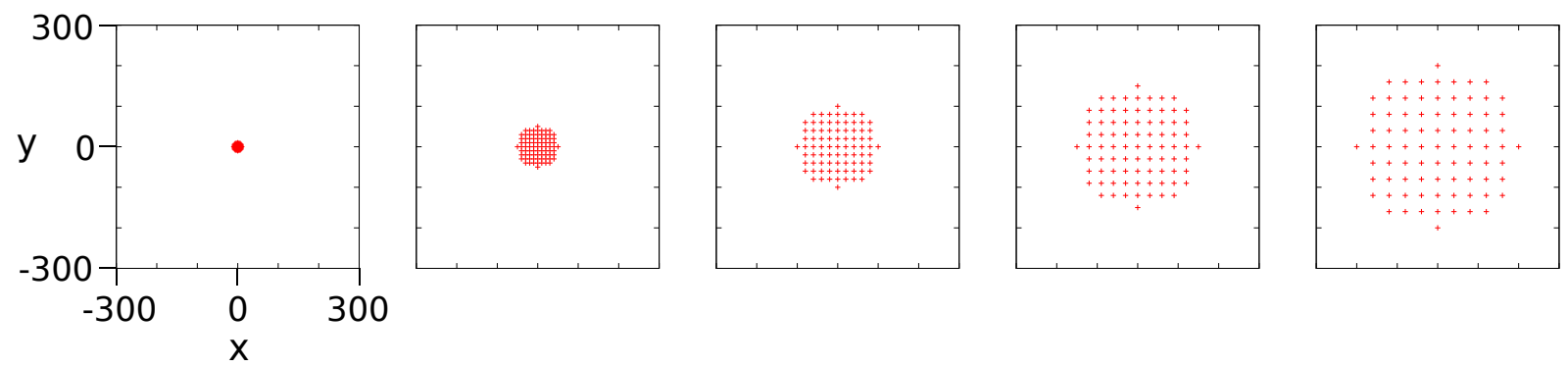

Abbildung 4.4: Ausdehnung des Clusterradius von 10 bis 200 Längeneinheiten.

Die potentielle Energie des Bindungsclusters bei Variation des Clusterradius zeigt einen deutlichen Trend, welcher in Abbildung 4.5 dargestellt ist. Je stärker die Kompression des Clusters, desto höher ist dessen potentielle Energie. Dichter gepackte Bindungen sind also energetisch weniger günstig, als separierte Bindungen.

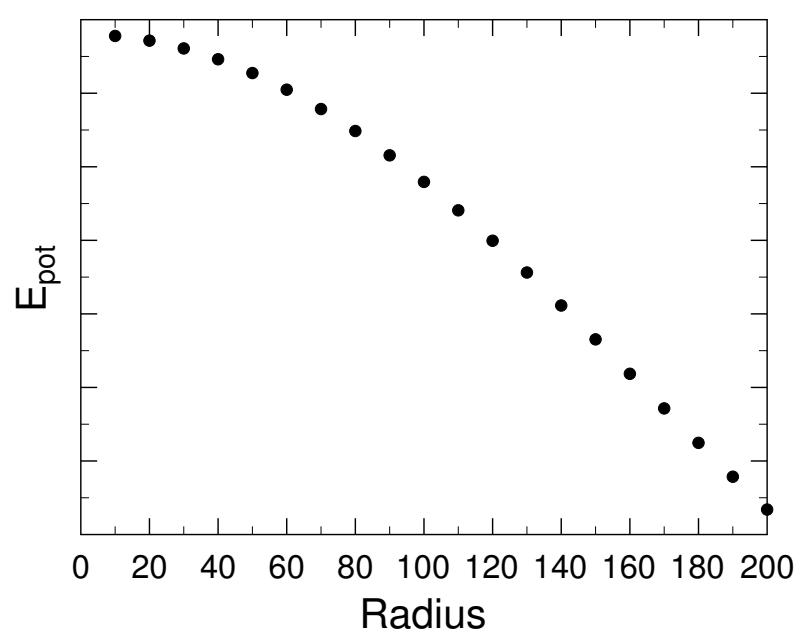

Abbildung 4.5: Auftragung der potentiellen Energie gegen den Clusterradius. Bei gleicher Bindungsanzahl nimmt die potentielle Energie mit zunehmendem Clusterradius ab.

Im Folgenden wird der zu Beginn runde Cluster elliptisch verformt. Hierfür wird die $x$-Achse des Clusters zunehmend gestreckt um einen elliptischen Bindungscluster zu erhalten. Bezeichnet man diese Achse mit $A$ und die kürzere Achse mit $B$, liefert der Ausdruck $\frac{A}{B}$ das Hauptachsenverhältnis der Ellipse. Das Hauptachsenverhältnis wird, wie in Abbildung 4.6 gezeigt von 1,0 bis 2,0 varriert und die potentielle Energie der erhaltenen Konfigurationen verglichen.

Die potentielle Energie nimmt mit zunehmendem Hauptachsenverhältnis ab. Dies ist in 

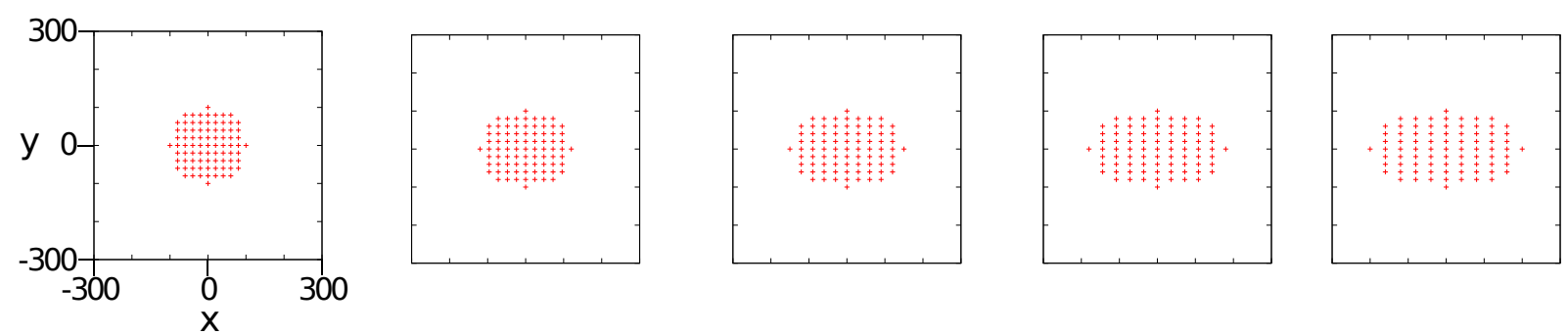

Abbildung 4.6: Verformung des Clusters hin zu einer Ellipse mit einem Hauptachsenverhältnis $\frac{A}{B}$ von 1,$0 ; 1,2 ; 1,8$ und 2,0 .

Abbildung 4.7 gezeigt. Deformation des Clusters führt zu dessen energetischer Stabilisierung.

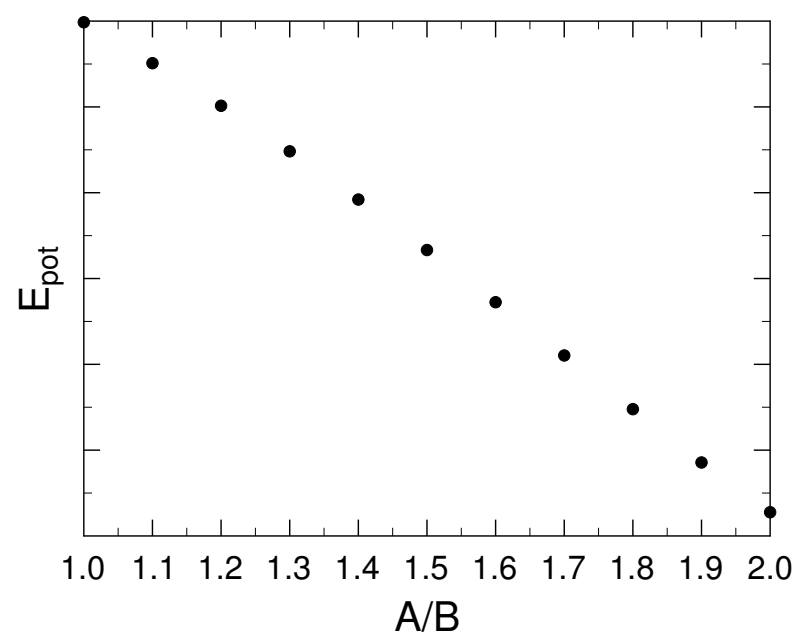
Abbildung 4.7: $\quad$ Auftragung der potentiellen Energie gegen das Hauptachsenverhältnis des Clusters. Mit zunehmender Elliptizität nimmt die potentielle Energie des Clusters ab.

Die in diesem Abschnitt durchgeführten Untersuchungen haben gezeigt, dass eine homogene Verteilung von Bindungen in jedem Fall energetisch günstiger ist als ein Bindungscluster. Je dichter die Bindungen innerhalb des Clusters, desto höher die resultierende potentielle Energie der Konfiguration. Auch die Verformung eines runden Clusters zu einer Ellipse führt zu einer Erniedrigung der potentiellen Energie. Die Existenz von Bindungsclustern in der Natur kann demnach nicht rein energetisch argumentiert werden. Sowohl Entropie als auch potentielle Energie wirken in Einfedermodellen in die Richtung einer homogenen Anordnung von Bindungen. Erdmann und Schwarz sowie Lin und Freund finden in ihren Modellen trotz allem durch die Einführung stochastischer Prozesse ideale Clustergrößen, für die die Lebenszeit maximal ist. In den Modellen gehen Erdmann und Schwarz und Lin und Freund jedoch immer von Bindungsclustern vorgegebener maximaler Größe aus. Da in dieser Arbeit ein Modell entwickelt wird, das die Ausbildung von Adhäsionsclustern aus einer homogenen Verteilung von Bindungen erklären soll wird der Ansatz des Einfedermodells modifiziert. 


\subsection{Harmonisches Mehrfedernmodell}

Ein Modell zur Erklärung der Stabilität und Ausbildung von Adhäsionsclustern bedarf Modifikationen im Vergleich zu den bisher behandelten Einfedermodellen. Diese werden im harmonischen Mehrfedernmodell (siehe 4.2) vorgenommen ${ }^{1}$, indem die Auslenkung der Membran als harmonisch mit einer Federkonstanten $k_{\mathrm{m}}$ angenommen wird und beim Schließen einer Bindung ein Energiebeitrag $\Delta E_{\mathrm{b}}$ frei wird.

Die Membran ist über Integrin-Ligand-Bindungen an das Substrat gebunden und ist einem homogenen Spannungsfeld senkrecht zur Substratebene ausgesetzt. Die Bindung von in die Membran eingebetteten Integrinen zu ECM-Liganden führt zu einer elastischen Auslenkung der Membran aus ihrer Gleichgewichtslage $h_{0}$. Diese Modellierung von Membran und Bindung als elastische Körper mit einer bestimmten Federkonstante führt zu einer Aufteilung der Systemenergie zwischen Membran- und Bindungsenergiereservoir.

Ein Startpunkt der theoretischen Beschreibung von Membran-Substrat-Adhäsionsmodellen ist die Zerlegung des Hamiltonians des Systems in zwei Teile, $\mathcal{H}=\mathcal{H}_{\text {bs }}+$ $\mathcal{H}_{\text {mem. }}$. Der erste Term beschreibt die im Bindungssystem gespeicherte potentielle Energie,

$$
\mathcal{H}_{\mathrm{bs}}=\sum_{i=1}^{N} E_{i}^{(b)}\left(S_{N}\right)=\sum_{i=1}^{N} b_{i} \Delta E_{b}+\frac{k_{b}}{2} \sum_{i=1}^{N} b_{i}\left(l_{i}-l_{0}\right)^{2} .
$$

Der Parameter $S_{N}$ gibt an, dass die Energie jeder einzelnen Bindung, $E_{i}^{(b)}\left(S_{N}\right)$, von der Konfiguration aller anderen Bindungen abhängig ist. Die Anzahl der möglichen Bindungen wird mit $N$ bezeichnet und $b_{i}=1$, wenn die $i$-te Bindung geschlossen ist und $b_{i}=0$ für offene Bindungen, $\Delta E_{\mathrm{b}}$ ist der Energiegewinn bei Bindungsschluss, $k_{b}$ die Kraftkonstante und $l_{i}$ die Auslenkung der $i$-ten Bindung aus ihrer Gleichgewichtslänge $l_{0}$. Der zweite Term, $\mathcal{H}_{\text {mem }}$, beschreibt die Energie, die in der Membrandeformation gespeichert ist. Der Helfrich Hamiltonian [58] wird erweitert um ein harmonisches Wechselwirkungspotential, das die unspezifische Wechselwirkung zwischen Membran und Substrat in einem bestimmten Abstand $L$ beschreibt.

$$
\begin{aligned}
\mathcal{H}_{\text {mem }}= & \int_{A} \mathrm{~d} \vec{r} \varrho_{e}\left(\vec{r}, S_{N}\right) \\
= & \int_{A} \mathrm{~d} \vec{r}\left\{\frac{\mathcal{K}_{c}}{2}\left[\nabla^{2} h\left(\vec{r}, S_{N}\right)\right]+\frac{\sigma}{2}\left[\nabla h\left(\vec{r}, S_{N}\right)\right]\right. \\
& \left.+\frac{\lambda}{2}\left[h\left(\vec{r}, S_{N}\right)-L\right]^{2}\right\} .
\end{aligned}
$$

$\varrho_{e}\left(\vec{r}, S_{N}\right)$ ist die Oberflächenenergiedichte der Membran, $\kappa_{c}$ das Biegemodul, $\sigma$ die Membranspannung und $\lambda$ die Federkonstante pro Flächeneinheit des unspezifischen Rückstellpotentials. $h\left(\vec{r}, S_{N}\right)$ beschreibt den Membran-Substrat-Abstand, der wiederum von

\footnotetext{
${ }^{1}$ Teile dieses Modells sind in einem Artikel in Physical Review E publiziert.[74]
} 
der spezifischen Konfiguration der Bindungen $S_{N}$ abhängig ist. Die Tatsache, dass beide Teile des Hamiltonians, $\mathcal{H}_{\text {bs }}$ und $\mathcal{H}_{\text {mem }}$ explizit von der Position aller geschlossenen Bindungen abhängen führt zu einem komplexen und kooperativen Mechanismus für die Bildung von Adhäsionsclustern.

Die Idee des harmonischen Mehrfedernmodells ist die Zerlegung des Membranhamiltonians, $\mathcal{H}_{\text {mem }}$, in Beiträge der einzelnen Bindungen. Dazu wird die Membranfläche in Zellen (ROl's) aufgeteilt die jeweils eine zentrale Bindung enthalten und innerhalb derer alle Spannungsvektoren in Richtung dieser Bindung zeigen.

Integration von $\varrho_{e}\left(\vec{r}, S_{N}\right)$ innerhalb einer $R O I$ ergibt den Membranbeitrag zur Gesamtenergie der eingeschlossenen Bindung, $E_{i}^{(m)}\left(S_{N}\right)$. Die Summe über alle Bindungen muss wieder den kompletten Membranhamiltonian aus Gleichung 4.4 ergeben.

$$
\begin{aligned}
\mathcal{H}_{\text {mem }} & =\int_{A} \mathrm{~d} \vec{r} \varrho_{e}\left(\vec{r}, S_{N}\right) \\
& =\sum_{i=1}^{N} \int_{R O I(i)} \mathrm{d} \vec{r} \varrho_{e}\left(\vec{r}, S_{N}\right)=\sum_{i=1}^{N} E_{i}^{(m)}\left(S_{N}\right) .
\end{aligned}
$$

Die Funktion $E_{i}^{(m)}\left(S_{N}\right)$ lässt sich bezüglich der Membranauslenkung $h\left(\vec{r}_{i}\right)$, also der Differenz der Membranhöhen zwischen dem offenen und dem geschlossenen Zustand einer Bindung an der Position der $i$-ten Bindung entwickeln. In dem harmonischen Mehrfedernmodell wird diese Entwicklung nach dem zweiten Term abgebrochen wodurch Biegung, Dehnung und alle anderen Beiträge zur Membranenergie der ROI durch ein einfaches harmonisches Potential ersetzt werden. Es wird angenommen, dass thermisch angeregte Membranondulationen vernachlässigbar sind, und dass das System mit einem Membranreservoir verbunden ist. Damit sind Formveränderungen der Membran in den Adhäsionszonen nicht beschränkt durch Membranflächenerhaltung. Diese Annahmen machen es möglich, alle Voronoi-Zellen im Membranmosaik mit einer einzigen Kraftkonstanten $k_{\mathrm{m}}$ zu beschreiben.

Das harmonische Mehrfedernmodell ist in Abbildung 4.8 skizziert.

Abbildung 4.9 zeigt die potentielle Energie von Membran $E_{\mathrm{m}}$ und Integrin-LigandBindung $E_{\mathrm{b}}$ als Funktion des Membran-Substrat-Abstandes $h_{0}$. Bei Bindungsschluss wird die Energie $\Delta E_{\mathrm{b}}$ frei.

Das Gleichgewicht der Kräfte resultierend aus Bindungs- und Membranauslenkungen führt zu einer Membranformfunktion, welche den Abstand zwischen Membran und Substrat beschreibt. Die Form einer elastischen Membran, auf die Kräfte wirken, lässt sich erhalten, durch eine Minimierung der Membranenergie. Diese Formfunktion wurde analytisch, unter der Annahme von Biegungs- und Dehnungsenergie als Hauptanteile zur Membranenergie, für verschiedene einfache Belastungssituationen erhalten.[75] In dem hier entwickelten Modell wird eine empirische Formfunktion verwendet, welche innerhalb der Monte Carlo Simulation weniger Rechenleistung erfordert. Abbildung 4.11 zeigt einen Vergleich der empirischen Formfunktion in grün beziehungsweise blau, und der analytisch erhaltenen Formfunktion in rot. Hier wird deutlich, dass die empirische 


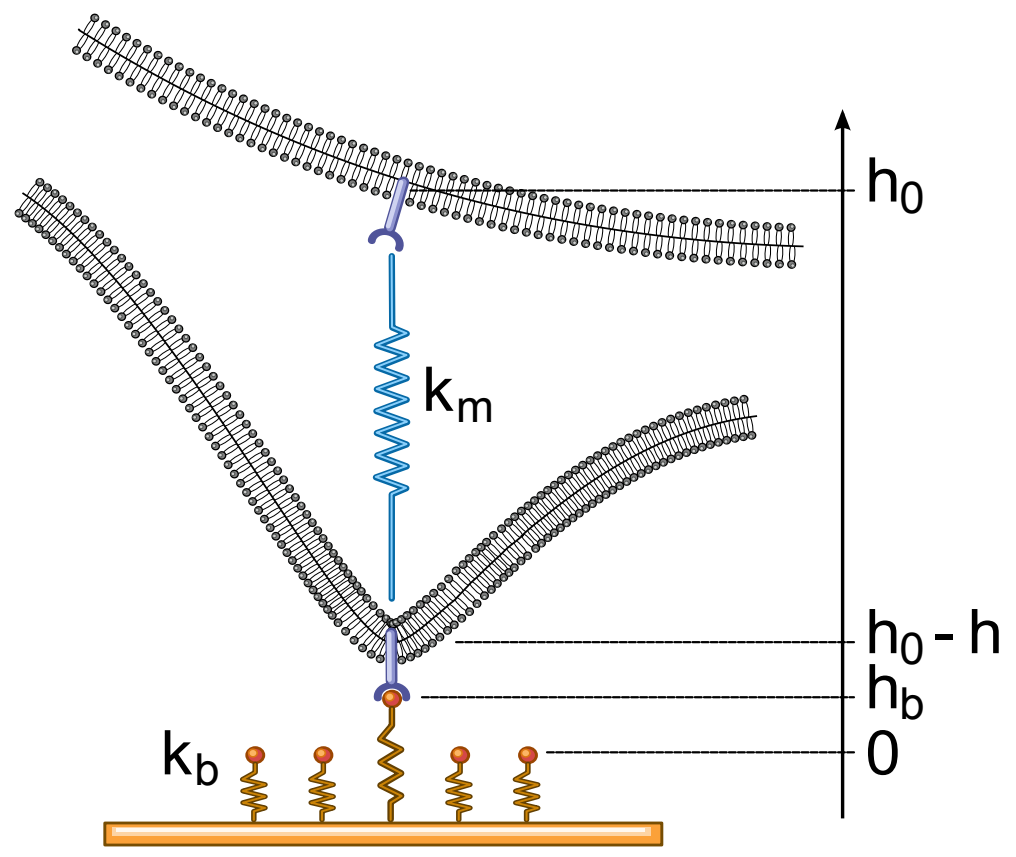

Abbildung 4.8: Skizze des har-
monischen Mehrfedernmodells.
In die Membran eingebettete
Integrinrezeptoren können an
Liganden in der extrazellulären
Matrix binden. Dies führt zu
einer lokalen Deformation
der Membran. Sowohl die
Membranauslenkung aus ihrer
Gleichgewichtslage $h_{0}$, als auch
die Integrin-Ligand-Bindungen
werden durch harmonische
Potentiale modelliert.

Funktion die Form der Membran recht gut wiedergibt und als Näherung verwendet werden kann. Die empirische Formfunktion basiert auf folgenden Annahmen. Nimmt man an, dass eine Membran über eine einzelne Bindung an ein Substrat gebunden ist, mit $h_{1}(\vec{r}), \vec{r}=(x, y)$ der Höhe der Membran über der Substratebene. Per Definition gilt $h_{1}(0,0)=0$ und diese Formfunktion einer einzelnen Bindung steigt monoton mit steigendem Abstand $|\vec{r}|$ vom Ursprung der Bindung.

Die Einführung einer Verteilung mehrerer geschlossener Adhäsionsbindungen resultiert in einer komplizierten Formfunktion, welche aus nicht linearen Überlagerungen von Formfunktionen einzelner Bindungen hervorgeht.

Bezeichnet man diese Formfunktionen als $h\left(\vec{r}, S_{N}\right)$, mit $S_{N}=\left\{r_{1}, r_{2}, \cdots, r_{N}\right\}$ den Positionsvektoren aller $N$ geschlossenen Adhäsionsbindungen, kann man folgende Annahmen machen

$$
\begin{array}{rll}
h\left(\vec{r}, S_{1}\right)=h_{1}\left(\vec{r}-\overrightarrow{r_{1}}\right) & & \\
h\left(\vec{r}, S_{\mathrm{N}}\right)=0 & \forall & \vec{r} \in S_{\mathrm{N}} \\
h\left(\vec{r}, S_{\mathrm{N}}\right)>0 & \forall & \vec{r} \notin S_{\mathrm{N}} \\
h\left(\vec{r}, S_{\mathrm{N}+1}\right) \leq h\left(\vec{r}, S_{\mathrm{N}}\right) & \forall & \vec{r}
\end{array}
$$

Gleichung 4.6 stellt den Zusammenhang zwischen dieser generellen Formfunktion mit der verschobenen Formfunktion einer einzelnen Bindung her. Gleichung 4.7 stellt sicher, dass die Formfunktion an den Positionen aller geschlossenen Bindungen der Konfiguration $S_{\mathrm{N}}$ verschwindet. Diese Annahme gilt für die Näherung, dass $k_{\mathrm{m}} \ll k_{\mathrm{b}}$ und damit dafür, dass die Dehnung der Integrin-Ligand-Bindung vernachlässigbar ist, im Vergleich zur Auslenkung der Membran an den Positionen der Bindungen. Gleichung 4.8 gibt an, dass die Membran überall von der Substratfläche separiert ist, außer 


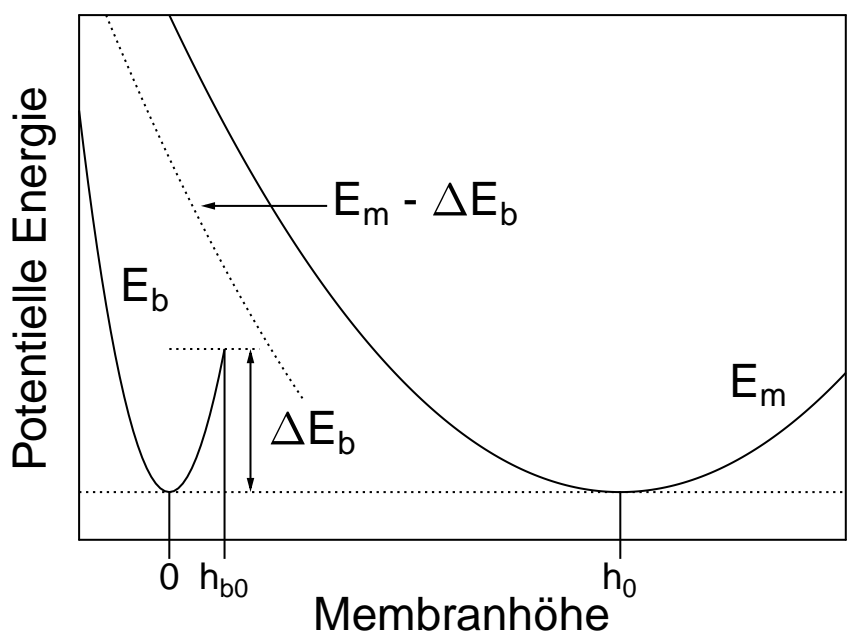

\begin{abstract}
Abbildung 4.9: $\quad$ Abbildung der potentiellen Energie als Funktion des MembranSubstrat-Abstands für IntegrinLigand-Bindung und Membran. Das Potential der Membran $E_{\mathrm{m}}$ ist breiter als das Potential der Bindung $E_{\mathrm{b}}$, da $k_{\mathrm{m}}<k_{\mathrm{b}}$. Bei Bindungsschluss wird die Energie $\Delta E_{\mathrm{b}}$ frei.
\end{abstract}

an den Positionen der geschlossenen Bindungen. Gleichung 4.9 ist eine der wichtigsten in diesem Modell. Sie beschreibt die Annahme, dass durch Einführung einer neuen geschlossenen Bindung in eine bestehende Bindungskonfiguration die Höhe der Membran über dem Substrat überall reduziert wird, mit Ausnahme der $N$ Positionen der geschlossenen Bindungen und in unendlichem Abstand zu allen geschlossenen Bindungen der Konfiguration.

$S_{\mathrm{N} \backslash k}$ bezeichnet eine Bindungskonfiguration resultierend aus einer Konfiguration $S_{\mathrm{N}}$ durch Öffnung der $k$-ten Bindung, während alle anderen Bindungen geschlossen und auf ihrer Position bleiben, und

$$
\Delta h_{k}\left(\vec{r}, S_{\mathrm{N}}\right)=h\left(\vec{r}, S_{\mathrm{N} \backslash k}\right)-h\left(\vec{r}, S_{\mathrm{N}}\right)
$$

beschreibt die Höhenänderung der Membran zwischen beiden Konfigurationen. Aus Gleichung 4.9 folgt, dass $h\left(\vec{r}, S_{\mathrm{N}}\right) \leq h\left(\vec{r}, S_{\mathrm{N} \backslash k}\right)$ und $\Delta h_{k}\left(\overrightarrow{r_{k}}, S_{\mathrm{N}}\right)=h\left(\overrightarrow{r_{k}}, S_{\mathrm{N} \backslash k}\right)$ die Auslenkung der Membran aus ihrer Gleichgewichtslage an der Position der $k$-ten Bindung, in Abwesenheit der $k$-ten Bindung. $F_{k}^{(m)}=-k_{m} \Delta h_{k}\left(\vec{r}_{k}, S_{\mathrm{N}}\right)$ bezeichnet die Rückstellkraft der Membran, die auf die $k$-te Bindung wirkt und $E_{k}^{(m)}=\frac{1}{2} k_{m}\left[\Delta h_{k}\left(\overrightarrow{r_{k}}, S_{\mathrm{N}}\right)\right]^{2}$ ist die Membrandeformationsenergie auf Grund der geschlossenen $k$-ten Bindung.

Die in Gleichung 4.7 angewendete Näherung impliziert, dass $\Delta h_{k}^{(b)}$, die Dehnung der Rezeptor-Ligand-Bindung, näherungsweise Null beträgt. Daher muss ein indirekter Weg gewählt werden um die in der gestreckten Rezeptor-Ligand-Bindung enthaltene elastische Energie zu erhalten. Im Gleichgewicht gilt $F_{k}^{(b)}=-F_{k}^{(m)}$ und $F_{k}^{(b)}=-k_{b} \Delta h_{k}^{(b)}$, daraus erhält man $\Delta h_{k}^{(b)}=\frac{k_{m}}{k_{b}} h\left(\overrightarrow{r_{k}}, S_{\mathrm{N} \backslash k}\right)$ und schließlich $E_{k}^{(b)}=\frac{k_{m}^{2}}{2 k_{b}} h^{2}\left(\overrightarrow{r_{k}}, S_{\mathrm{N} \backslash k}\right)$.

Der obere Index (b) und (m) markiert Bindungs- und Membrananteile zu Kräften, Höhen und Energien. Der Einfluss der $k$-ten geschlossenen Bindung auf die Deformation der Membran muss mit wachsendem Abstand zur Position der $k$-ten Bindung verschwinden. Demzufolge gilt $\Delta h_{k}\left(\vec{r}, S_{\mathrm{N}}\right) \leq \Delta h_{k}\left(\overrightarrow{r_{k}}, S_{\mathrm{N}}\right)$ für alle $\vec{r}$ in der $x, y$-Ebene. $\Delta h_{k}\left(\vec{r}, S_{\mathrm{N}}\right)$ muss kleiner sein, als die entsprechend normierte (invertierte) Formfunktion 
einer einzelnen Bindung in $\overrightarrow{r_{k}}$

$$
\Delta h_{k}\left(\vec{r}, S_{\mathrm{N}}\right) \leq \Delta h_{k}\left(\overrightarrow{r_{k}}, S_{\mathrm{N}}\right)\left[1-\frac{h\left(\vec{r}, S_{1}^{*}\right)}{h\left(\vec{r}_{k}, S_{1}^{*}\right)}\right] .
$$

wobei $S_{1}^{*}$ die Konfiguration mit einer einzelnen Bindung an Position $\overrightarrow{r_{k}}$ angibt (siehe Abbildung 4.10).

(a)

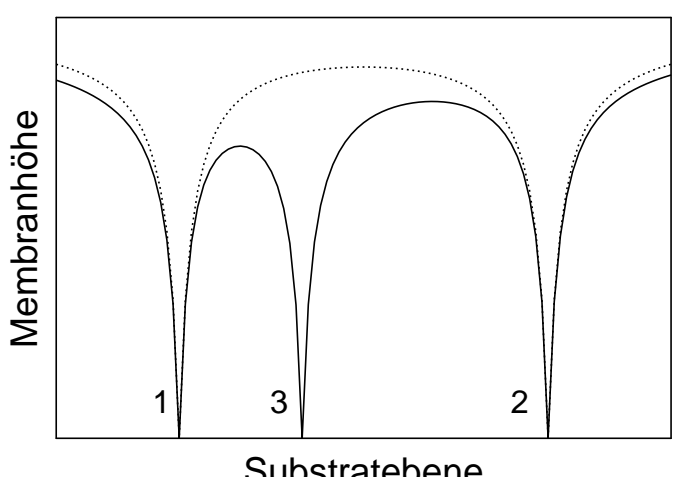

(b)

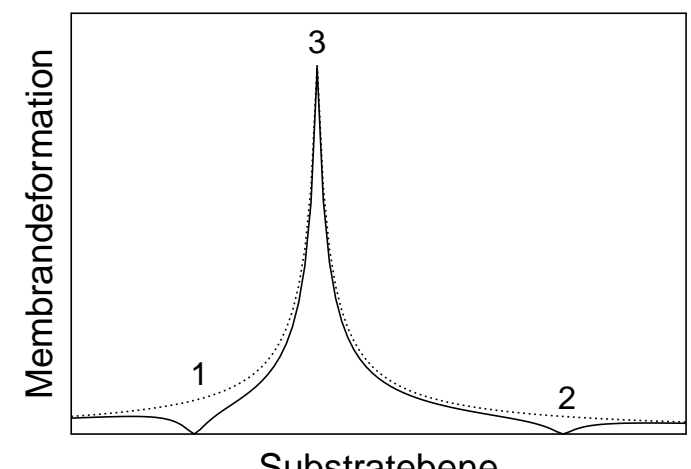

Abbildung 4.10: Skizze der Membranhöhe (a) und der Membrandeformation (b) für zwei Bindungskonfigurationen. Bei (a) ist die Membran zunächst durch zwei Bindungen an dem Substrat befestigt (gestrichelte Linie). Durch Bildung einer zusätzlichen dritten Bindung in dieser Konfiguration wird die Membranhöhe überall verändert, außer an den Positionen der ursprünglichen Bindungen (durchgezogene Line). In (b) sieht man die durch diesen Bindungsschluss verursachte Membrandeformation als durchgezogene Linie. Die gestrichelte Linie zeigt eine invertierte Formfunktion einer einzelnen Bindung an Position Nummer 3 und macht deutlich, dass die Membrandeformation kleiner ist als die Formfunktion.

Mit den Gleichungen 4.6 bis 4.11 ist es einfach zu zeigen, dass das Schließen einer zusätzlichen Bindung in einer Ursprungskonfiguration $S_{N}$ (Erzeugen einer finalen Konfiguration $S_{N+1}$ ) die Beträge der Kräfte aller bisher in der Konfiguration $S_{N}$ existierenden Bindungen reduziert.

$$
F_{k}^{(f)}-F_{k}^{(i)}=-k_{m} \Delta h_{\mathrm{N}+1}\left(\vec{r}_{k}, S_{\mathrm{N}+1 \backslash k}\right)<0 \quad \forall k \in\{1, \ldots, N\} .
$$

Die oberen Indizes ( $f$ ) und (i) bezeichnen den finalen und den ursprünglichen (initialen) Zustand. Ähnlich lässt sich die Annahme treffen, dass das Schließen einer zusätzlichen Bindung die Energie aller ursprünglich existierender Bindungen erniedrigt.

$$
\begin{aligned}
E_{k}^{(f)}-E_{k}^{(i)} & =\left[\frac{1}{2} k_{m}+\frac{k_{m}^{2}}{2 k_{b}}\right] \cdot\left[h^{2}\left(\vec{r}_{k}, S_{\mathrm{N}+1 \backslash k}\right)-h^{2}\left(\vec{r}_{k}, S_{\mathrm{N} \backslash k}\right)\right] \\
& \leq 0 \quad \forall k \in\{1, \ldots, N\} .
\end{aligned}
$$


Die Bildung einer neuen Bindung wird energetisch bevorzugt, wenn die Kosten um die Bindung zu Schließen, $E_{\mathrm{N}+1}^{(\mathrm{f})}$, kleiner ist als der gesamte Energiegewinn, der durch alle bereits existierenden Bindungen erhalten wird. Das heißt

$$
E_{N+1}^{(f)}<\left|\sum_{k=1}^{N}\left(E_{k}^{(f)}-E_{k}^{(i)}\right)\right| .
$$

Als ein direktes Ergebnis erhält man, dass neue Bindungen bevorzugt in der engen Nachbarschaft existierender Bindungen geschlossenen werden. Das ist die Triebkraft zur Enstehung von Bindungsclustern im harmonischen Mehrfedernmodell und erzeugt eine globale attraktive Kraft zwischen benachbarten Bindungen.

\subsubsection{Modellierung der Membranform}

Zur Modellierung der Membranform bedarf es einer Funktion, die die Form der Membran realistisch wiedergibt und die in den Monte Carlo Simulationen wenig Rechenzeit kostet. In dieser Arbeit wird ein empirischer Ansatz einer Formfunktion verwendet. Dieser lautet:

$$
h\left(\vec{r}, S_{\mathrm{N}}\right)=\left[\left(\frac{1}{L}\right)^{\beta}+\sum_{k=1}^{N}\left(\frac{1}{\mid \vec{r}-\overrightarrow{r_{k}}}\right)^{\beta}\right]^{-1} .
$$

Sie erfüllt die physikalischen Bedingungen 4.6-4.11 und ist in der Lage die analytische Einzelbindungsfunktion von Powers et al. [75] zu einem guten Grad wiederzugeben (siehe Abbildung 4.11). Ein Vorteil ist, dass sie weniger Rechenleistung erfordert als die analytische Einzelbindungsfunktion gegeben durch Gleichung 9 in Anhang 2.

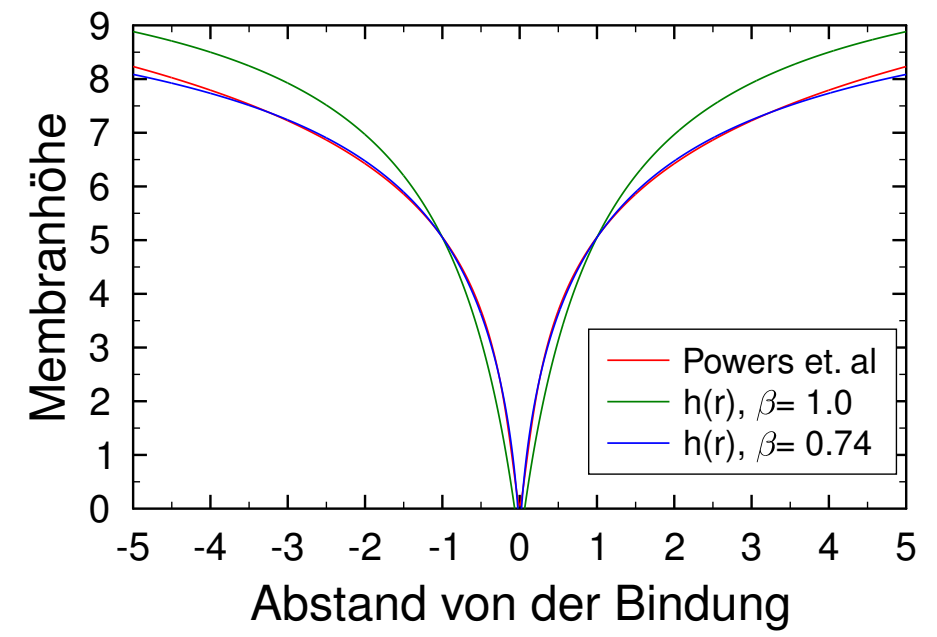

Abbildung 4.11: Vergleich der empirischen Formfunktion der Membran (grün, blau) und der analytischen Einzelbindungsformfunktion nach Powers et al. (rot) [75].

Powers et al. beschäftigen sich mit der Form eines Lipidbilayers zwischen zwei parallelen Ringen endlichen Abstandes. Sie zeigten, dass die Membran bei kleinen Abständen die Form von Katenoiden annimmt und bei großen Abständen der Ringe zylindri- 
sche Membranröhren (tether) bildet.

Die nach Gleichung 4.15 berechnete Membranform für eine Bindungskonfiguration bestehend aus 100 Bindungen ist in Abbildung 4.12 für die Parameter $L=100$ und $\beta=1$ dargestellt.

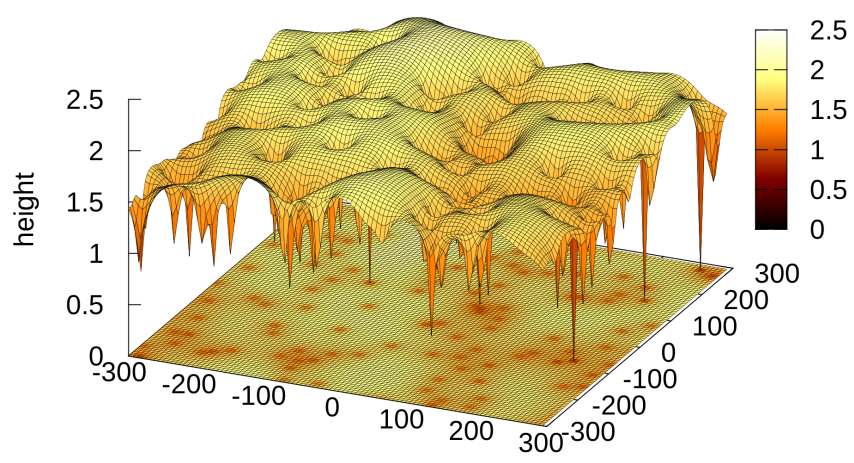

Abbildung 4.12: Dreidimensionale Abbildung der nach Gleichung 4.15 berechneten Membranform.

Abbildung 4.13 zeigt die zweidimensionale Projektion des Höhenprofils einer Konfiguration mit neun Bindungen (blau) und die entsprechende Konfiguration nach Schließen einer zusätzlichen zehnten Bindung (rot).

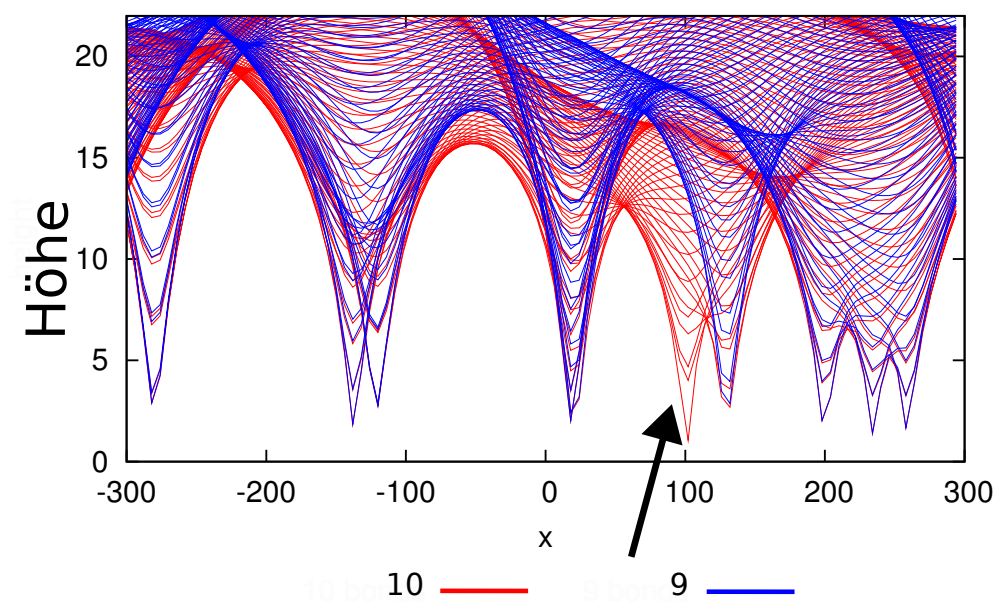

Abbildung 4.13: Vergleich der Höhenprofile der Membran für neun Bindungen (blau) und zehn Bindungen (rot) in einer 2D-Auftragung der Höhe gegen die $x$-Koordinate.

Das Schließen der zusätzlichen zehnten Bindung deformiert die Membran. An der Position der Bindung hat die Membranhöhe einen Wert von Null und an Positionen ohne Bindungen erniedrigt die zusätzliche Bindung den Membran-Substrat-Abstand im Vergleich zur Konfiguration mit neun Bindungen.

Mit Gleichung 4.15 steht also eine Formfunktion zur Verfügung, die die gestellten Anforderungen 4.6-4.9 erfüllt. 


\subsubsection{Emergenz metatstabiler Zustände}

In dem harmonischen Mehrfedernmodell ergeben sich vier vorstellbare Szenarien für die Stabilitäten einer Bindung. Bindungen können offen oder geschlossen vorliegen, und jeder dieser Zustände kann stabil, metastabil oder instabil sein. Eine Skizze der potentiellen Energien von stabilen, metastabilen und instabilen Zuständen einer einzelnen Bindung im Mehrfedernmodell ist in Abbildung 4.14 gezeigt.

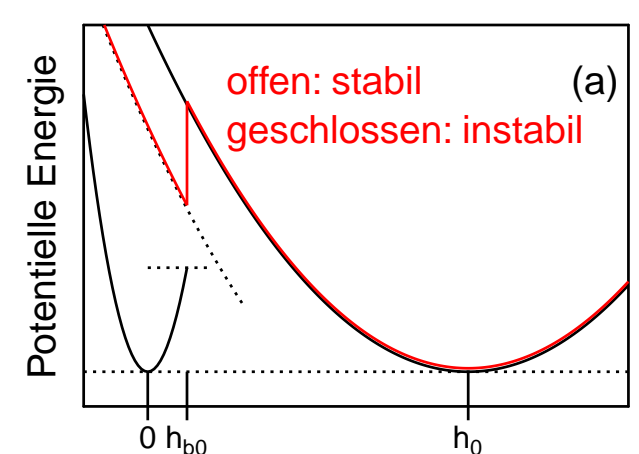

Membranhöhe

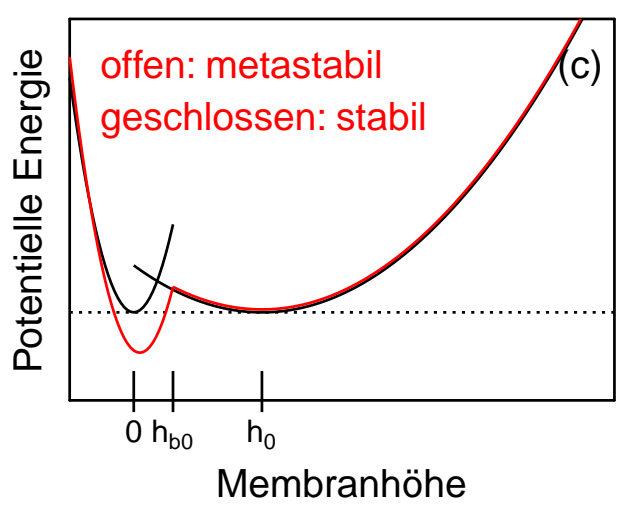

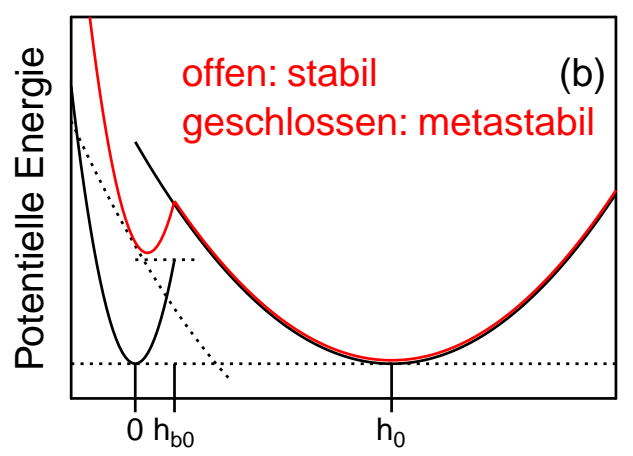

Membranhöhe

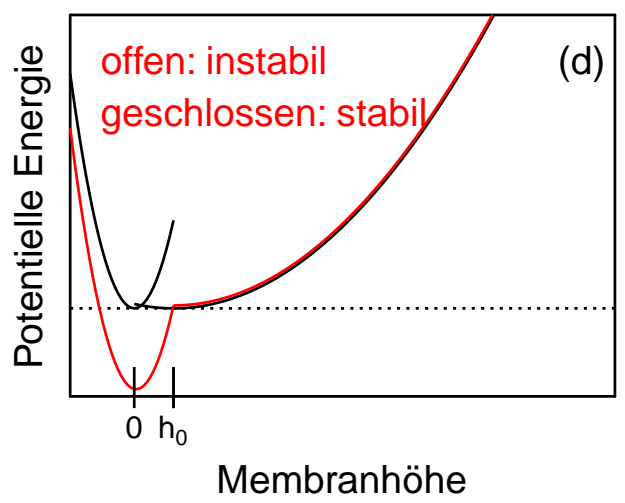

Abbildung 4.14: Skizze der potentiellen Energien von stabilen, metastabilen und instabilen Zuständen einer einzelnen Bindung im Mehrfedernmodell. Die Auslenkung der Membran aus ihrer ungebundenen Gleichgewichtsposition $h_{0}$ wird als breites parabolisches Potential modeliert. Wohingegen das harmonische Potential der Rezeptor-Ligand-Bindung durch eine schmale Parabel beschrieben wird, die den Ursprung der Höhenachse definiert (beide Potentiale sind als schwarze dünne Linien eingezeichnet). Die Ligand-Rezeptor-Bindung reißt, wenn die Kraft einen bestimmten Schwellwert überschreitet. Die Auslenkung der Bindung am Risspunkt, $h_{\mathrm{b}, 0}$ ist der Punkt, an dem die potentielle Energie der Bindung gleich der Bindungsbildungsenergie ist. Wenn die Bindung geschlossenen ist, führt das frei werden der Energie $\Delta E_{\mathrm{b}} \mathrm{zu}$ einem Sprung in der potentiellen Energie (rote Linie). Stabile oder metastabile geschlossene Bindungen können nur gebildet werden, wenn die Differenz zwischen Membran- und Bindungsbildungsenergie (gestrichelte Linie) die Parabel des Potentials der Bindung schneidet. Von (a) nach (d) wird die Membran an das Substrat angenähert und dadurch der geschlossene Zustand stabilisiert. 
Von (a) nach (d) wird die Membran zunehmend an das Substrat angenähert und dadurch der geschlossene Zustand stabilisiert.

Die Deformationsenergie der Membran, die durch die Bindung aus ihrer ungebundenen Gleichgewichtsposition $h_{0}$ ausgelenkt wird, wird als breites parabolisches Potential modeliert. Das harmonische Potential der Rezeptor-Ligand-Bindung wird durch eine schmale Parabel beschrieben. Diese definiert den Ursprung der Höhenachse (beide Potentiale sind als schwarze dünne Linien eingezeichnet). Die Ligand-RezeptorBindung reißt, wenn die Kraft auf die Bindung einen Schwellwert überschreitet. Die Auslenkung der Bindung am Risspunkt, $h_{\mathrm{b}, 0}$ ist der Punkt, an dem die potentielle Energie der Bindung gleich der Bindungsbildungsenergie ist. Durch Schließen der Rezeptor-Ligand-Bindung wird die Energie $\Delta E_{\mathrm{b}}$ frei und dies führt zu einem Sprung in der potentiellen Energie (rote Linie). Stabile oder metastabile geschlossene Bindungen können nur gebildet werden, wenn die Differenz zwischen Membran- und Bindungsbildungsenergie (gestrichelte Linie) die Parabel des Potentials der Bindung schneidet. Von (a) nach (d) wird die Membran an das Substrat angenähert und dadurch der geschlossene Zustand stabilisiert.

Das harmonische Mehrfedernmodell kann in dimensionslose Größen überführt werden, in dem der Rezeptor-Ligand-Risspunkt $\left(E_{\text {rup }}=\Delta E_{\mathrm{b}}, F_{\text {rup }}^{(b)}=-\sqrt{2 k_{\mathrm{b}} E_{\text {rup }}}, \Delta h_{\text {rup }}^{(b)}=-\right.$ $-F_{\text {rup }}^{(b)} / k_{\mathrm{b}}$ ) als Normalisierung für Kräfte und Membran-Substrat-Abstände verwendet wird. In diesen natürlichen Einheiten ist $k_{\mathrm{b}}=\left|F_{\text {rup }}^{(b)}\right| / \Delta h_{\mathrm{rup}}^{(b)}=1$, das Verhältnis $\kappa=k_{\mathrm{m}} / k_{\mathrm{b}}$ ist identisch mit $k_{\mathrm{m}}$, und die Bindungsbildungsenergie wird $\Delta E_{\mathrm{b}}=\frac{1}{2}$. Zur Vereinfachung wird $\gamma=\sqrt{\frac{1+\kappa}{\kappa}}$ eingeführt. In allen folgenden Abbildungen entsprechen die Höhen, Energien und Kräften diesen dimensionslosen Größen.

Die $i$-te geschlossene Bindung erreicht ihre Stabilitätsgrenze, das heißt den Punkt an dem, $F_{i}^{(b)}=-F_{i}^{(m)}=F_{\text {rup }}^{(b)}=1$ wenn die Membranauslenkung

$$
h_{0}=\Delta h_{i}^{(m)}\left(\vec{r}_{i}\right)=\frac{1+\kappa}{\kappa}
$$

übersteigt und geschlossene Bindungen können nur in Regionen existieren, in denen die Gleichgewichtshöhe der Membran kleiner als dieser Wert ist. Da die Gleichgewichtsauslenkung der Bindung

$$
\Delta h_{i}^{(b)}=\frac{\kappa}{1+\kappa} h_{0},
$$

ist, werden geschlossene Bindungen instabil wenn $\Delta h_{i}^{(b)}>1$.

Auf der anderen Seite werden geschlossene Bindungen stabil, wenn die Gesamtenergie, $E_{\text {tot }}\left(\Delta h_{i}^{(m)}\right)=E_{\mathrm{b}}\left(\Delta h_{i}^{(m)}\right)+E_{\mathrm{m}}\left(\Delta h_{i}^{(m)}\right)-\Delta E_{\mathrm{b}}$, negativ ist. Dies ist der Fall, wenn

$$
\Delta h_{i}^{(m)}\left(\vec{r}_{i}\right) \leq \sqrt{\frac{1+\kappa}{\kappa}} \text { und } \Delta h_{i}^{(b)}\left(\vec{r}_{i}\right) \leq \sqrt{\frac{\kappa}{1+\kappa}} .
$$

Offensichtlich gibt es eine Lücke zwischen Regionen von stabilen geschlossenen Bindungen und instabilen geschlossenen Bindungen. In dieser Region sind geschlossene 
Bindungen metastabil in Bezug auf offene Bindungen (Abb. 4.14, Teil (b)).

Ein ähnliches Verhalten findet sich auch für offene Bindungen. Sie sind instabil, wenn

$$
\Delta h_{i}^{(m)}\left(\vec{r}_{i}\right) \leq h_{\text {rup }}=1
$$

(siehe Abb. 4.14, Teil (d)), und sie werden stabil, sobald die geschlossenen Bindungen metastabil werden.

$$
\Delta h_{i}^{(m)}\left(\vec{r}_{i}\right) \geq \sqrt{\frac{1+\kappa}{\kappa}} \text { und } \Delta h_{i}^{(b)}\left(\vec{r}_{i}\right) \geq \sqrt{\frac{\kappa}{1+\kappa}} .
$$

Wiederum werden die Regionen der Stabilität und der Instabilität durch ein Gebiet separiert, in dem offene Bindungen metastabil in Bezug auf geschlossene Bindungen sind. Diese Regionen sind in Abbildung 4.15 zusammengefasst. Um den Zustand einer Bindung vollständig zu charakterisieren reicht es nicht aus, die Stabilität (stabil, metastabil, instabil) der geschlossenen Bindung zu kennen, sondern es muss auch spezifiziert werden welche Stabilität die Bindung hätte, wenn sie offen wäre.

Das selbe gilt für offene Bindungen, hier muss beachtet werden welche mögliche Stabilität die Bindung hätte wenn sie geschlossen wäre. Insgesamt führt das zu zehn unterscheidbaren Bindungszuständen welche in Abbildung 4.15 skizziert sind.

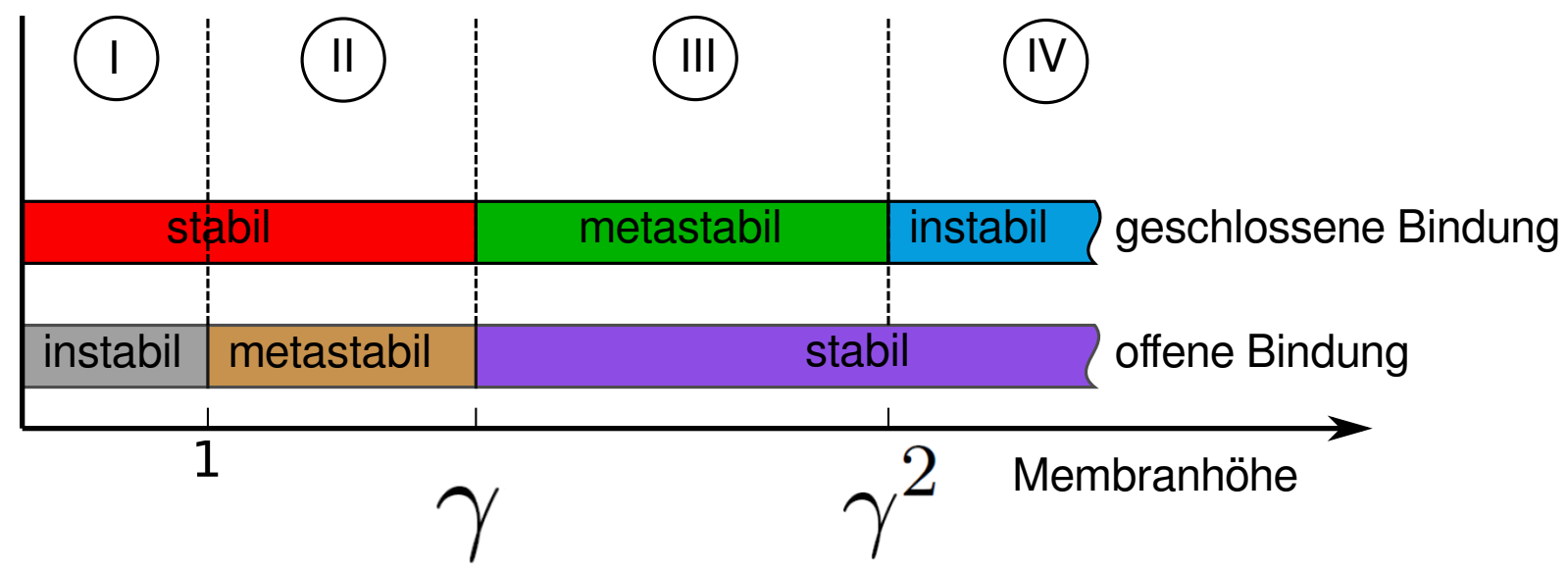

Abbildung 4.15: Stabilitätsregionen für geschlossene und offene Bindungen in Abhängigkeit der Membranhöhe, hier ausgedrückt durch $\gamma$.

Die Abfolge der potentiellen Energieprofile in Abbildung 4.14 führt zu einem komplexen Verhalten mit Hystereseeffekten bei der Modellierung von Bindungsöffnungs- und Bindungschlussereignissen während der Annäherung oder dem Rückzug der Membran an das bzw. von dem Substrat (Abb. 4.16).

Weit weg von dem Substrat können nur offen stabile Bindungen vorkommen (Marker '1' in Abb. 4.16). Durch Annäherung der Membran an das Substrat erreicht das System einen Punkt (Marker '2' in Abb. 4.16) an dem geschlossene Bindungen möglich werden als ein zweiter, aber metastabiler Zustand. Ohne thermische Fluktuationen bleiben hier alle Bindungen in der Membran in dem energetisch günstigeren offenen Zustand. Nach 


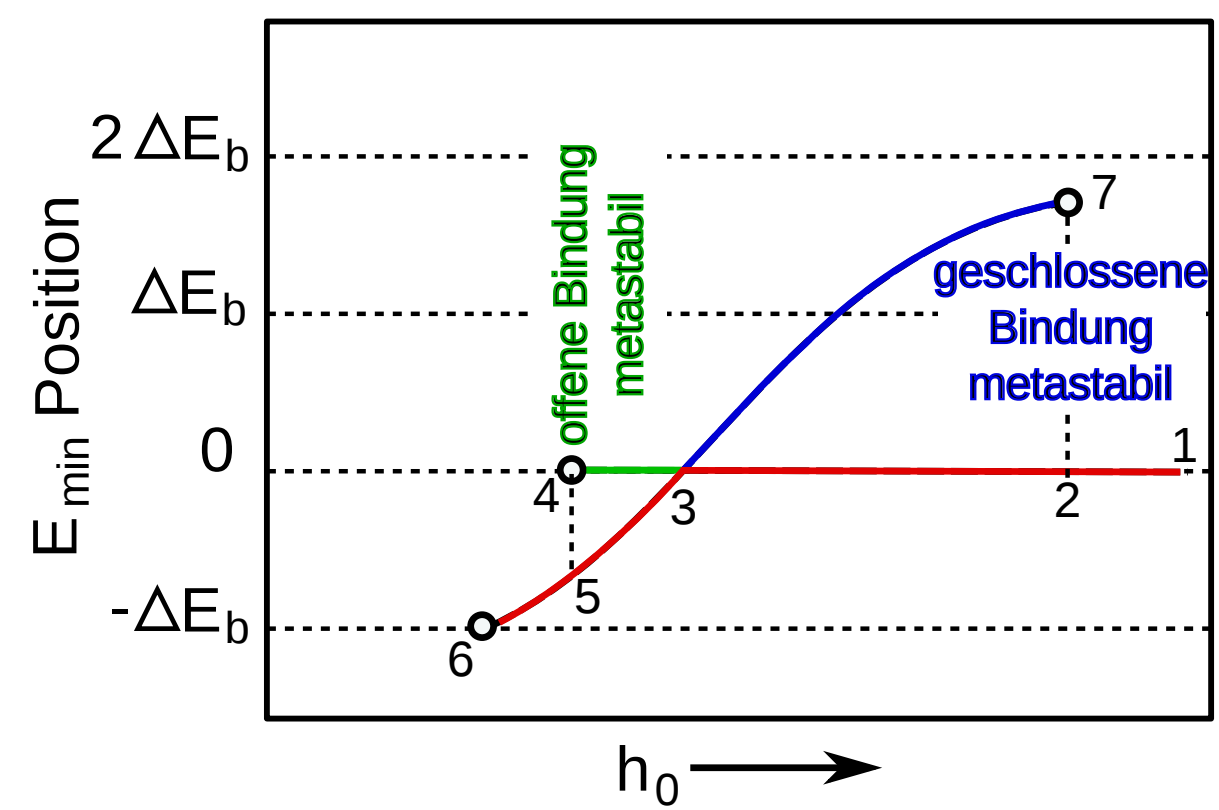

Abbildung 4.16: Hystereseeffekt im Bindungsschluss- und Bindungsöffnungsprozess. Gezeigt ist das Minimum der potentiellen Energie einer einzelnen Bindung als Funktion des MembranSubstrat-Abstandes $h_{0}$. Weit weg von der Oberfläche ' 1 ' ist der offene Zustand der einzig stabile Zustand der Bindung. Bei Annäherung an das Substrat taucht im Abstand '2' ein metastabil geschlossener Zustand auf. Dieser Zustand verliert durch weiteres Annähern Energie und unter Punkt '3' wird er zum bevorzugten Zustand des Systems. In einem deterministischen System verbleibt die Bindung trotzdem im offenen Zustand, bis dieser instabil wird (Punkt '4'). Hier springt die Bindung in den geschlossenen Zustand (Punkt '5'), welcher bis zu Punkt '6' Energie gewinnen kann. Hier befinden sich die Membran und das Substrat in Kontakt. Der Rückzug der Membran vom Substrat bewegt die geschlossene Bindung von Punkt '6' bis zu Punkt '7', an dem sie instabil wird und reißt.

Überschreiten von Punkt ' 3 ' wird der geschlossene Zustand der energetisch niedrigste Zustand und koexistiert mit dem jetzt metastabilen offenen Zustand. Wegen der Energiebarriere zwischen beiden Zuständen (siehe Abb. 4.14) verbleibt das System zunächst im offenen Zustand. Erst an Punkt '4', an dem der offene Zustand instabil wird springt das System über in einen geschlossen stabilen Zustand (Sprung zu Marker ' 5 ' in 4.16). Letztendlich, unter Punkt ' 6 ', befindet sich die Bindung in dem repulsiven Bereich ihres harmonischen Potentials. Beim Zurückziehen der Membran vom Substrat zeigt die selbe Argumentation, dass das System der Linie zwischen Punkt '6' hinauf zu Punkt ' 7 ' in Abbildung 4.16 ohne irgendwelche Änderungen des Zustands folgt. An Punkt ' 7 ' reißt die Bindung und das System springt zurück in den offenen Zustand an Punkt '2'.

Bei Vernachlässigung stochastischer on-off-Fluktuationen, ist der Zustand jeder Bindung vollständig bestimmt durch die Auslenkung der Membran, die notwendig ist um die Bindung zu schließen. In anderen Worten ist sie vollständig bestimmt durch den Wert der Formfunktion $h\left(\overrightarrow{r_{k}}, S_{\mathrm{N} \backslash k}\right)$ an der Position der Bindung $\overrightarrow{r_{k}}$. Die Formfunktion ist 
trotz allem eine hoch kooperative Funktion, die abhängig ist von den Positionen und Zuständen aller anderer Bindungen im System. Die Änderung des Zustands oder der Position einer einzelnen Bindung führt instantan zu einer Veränderung der Zustände aller anderen Bindungen.

\subsubsection{Attraktive Kraft zwischen Adhäsionsbindungen}

Eine inhärente Eigenschaft des harmonischen Mehrfedernmodells, die ohne detailiertes Wissen über die Membranformfunktion ersichtlich ist, ist das Auftauchen apparenter attraktiver Kräfte zwischen Adhäsionsbindungen. Die Bildung einer Adhäsionsbindung reduziert die Membranhöhe im gesamten System. Die Membranhöhe wird um so größer, je größer der Abstand zu existierenden Bindungen und Null an der Position der Bindung (siehe Abbildung 4.10). Die in einer Adhäsionsbindung gespeicherte Energie steigt mit der Membranhöhe die bei Bindungsöffnung an der Position der Bindung frei werden würde. Das Vorhandensein einer zweiten Bindung in der Nachbarschaft einer Bindung reduziert diese Gleichgewichtshöhe der Membran und erzeugt damit einen abstandsabhängigen Gradienten in der potentiellen Energie der ersten Bindung (siehe Abbildung 4.17).
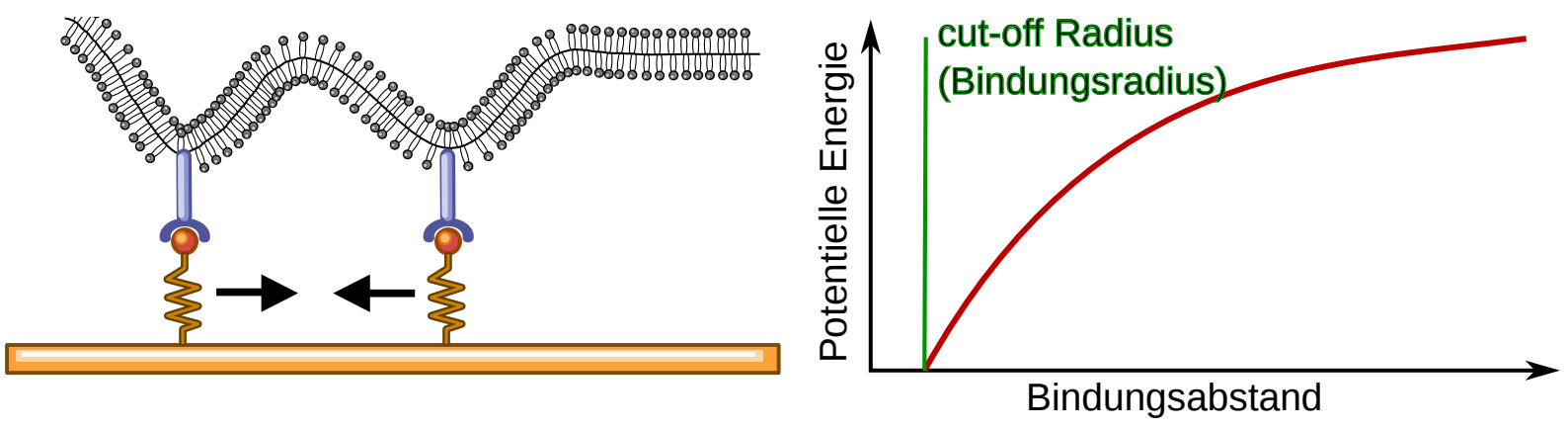

Abbildung 4.17: Verlauf der potentiellen Energie beim Annähern zweier Adhäsionsbindungen. Die potentielle Energie nimmt mit dem Abstand der Bindungen zueinander ab, bis zum repulsiven Bereich, welcher definiert ist durch den endlichen Radius der Bindungen.

Diese attraktiven Kräfte zwischen Adhäsionsbindungen gehen aus der Komplexität des Modells hervor, welches in den Gleichungen 4.6 bis 4.8 begründet ist. Dies ist eine Triebkraft für die Bildung von Adhäsionsclustern. Die Anziehung der Bindungen ist eine inhärente Systemeigenschaft und muss nicht in das Modell implementiert werden, wohingegen die Einführung einer repulsiven kurzreichweitigen Bindungswechselwirkung von Nöten ist, um den Kollaps aller mobiler Bindungen in einem einzelnen Punkt zu verhindern. Diese Repulsion entsteht durch nicht vernachlässigbare endliche Bindungsradien. Die attraktiven Kräfte zwischen Bindungen sind ein nicht-lineares Phänomen in dem Sinn, dass in einem System mit mehreren Bindungen die attraktiven Kräfte nicht in Überlagerungen von Interaktionen zwischen je zwei Bindungen zerlegt werden können. 


\subsubsection{Stochastische Bindungsstabilität}

In dem entwickelten Modell können stochastische Bindungsschluss- und Bindungsrisswahrscheinlichkeiten implementiert werden. Diese sind abhängig von der Kraft, die auf die einzelnen Bindungen wirkt und damit von der Gleichgewichtshöhe der Membran an der Position der Bindung. Durch diese Wahrscheinlichkeiten wird der endlichen Lebenszeit von Adhäsionsbindungen Rechnung getragen. In den Bereichen, in denen metastabile Bindungszustände auftreten, wird mit Hilfe von BoltzmannWahrscheinlichkeiten entschieden, ob diese Bindungen in ihrem Zustand verbleiben oder dieser geändert wird. Dies modelliert ein thermisch assisitiertes Entkommen aus einem lokalen Minimum der potentiellen Energie.

Die Wahrscheinlichkeit, dass eine offene Bindung geschlossen wird $p_{\text {on }}$ ist in Gleichung 4.25 formuliert. Die Bindungsschlusswahrscheinlichkeit ist abhängig von der Federkonstanten der Bindung und dem Abstand zwischen Ligand und Rezeptor. Die in diesem Modell verwendeten Zusammenhänge lassen sich aus dem von Gao formulierten Modell [10] herleiten. Die Wahrscheinlichkeit, dass sich ein Rezeptor innerhalb des Reaktionsradius $l_{\text {bind }}$ der Bindungsstelle befindet geben sie mit

$$
p=\frac{l_{\text {bind }}}{Z} \exp \left(-\frac{k_{\mathrm{b}}\left(\delta-l_{0}\right)^{2}}{2 k_{\mathrm{B}} T}\right)
$$

an. Mit $k_{\mathrm{b}}$ der Federkonstanten der Ligand-Rezeptor-Bindung, $l_{0}$ deren Gleichgewichtslänge und $\delta$ dem Zell-Substrat-Abstand. Die Zustandssumme $Z$ wird für das harmonische Mehrfedernmodell als unabhängig vom Zell-Substrat-Abstand $\delta$ angenommen. Demzufolge ergibt sich nach Gao et al. eine Gesamtrate der Assoziation von:

$$
k_{\mathrm{on}}=k_{\mathrm{on}}^{0 *} \frac{l_{\mathrm{bind}}}{Z} \exp \left(-\frac{k_{\mathrm{b}}\left(\delta-l_{0}\right)^{2}}{2 k_{\mathrm{B}} T}\right)
$$

mit $k_{\mathrm{on}}^{0 *}$ der Reaktionsrate zwischen den Bindungspartnern.[10] $k_{\text {on }}^{0 *} \frac{l_{\text {bind }}}{Z}$ wird als Konstante zu einem neuen Parameter $k_{\text {on }}^{0}$ zusammengefasst. Da es sich bei dem Term $\left(\delta-l_{0}\right)$ um einen Abstand handelt wird dieser Term im weiteren als Höhe $h$ bezeichnet.

Die Wahrscheinlichkeit zum Bindungsschluss lässt sich zu

$$
p_{\text {on }}=k_{\text {on }}^{0} \exp \left(-\frac{k_{\mathrm{b}} h^{2}}{2 k_{\mathrm{B}} T}\right)
$$

formulieren. Durch die Erweiterung des Bruchs mit $k_{\mathrm{b}}$ und Anwendung des Hook'schenGesetzes erhält man

$$
p_{\text {on }}=k_{\text {on }}^{0} \exp \left(-\frac{F^{2}}{k_{\mathrm{b}} 2 k_{\mathrm{B}} T}\right) .
$$

Aus Gleichung 4.24 lässt sich, die im harmonischen Mehrfedernmodell verwendete Gleichung unter Zuhilfenahme des Hook'schen Gesetz und dem Ausdruck für die potentielle Energie $E_{\text {pot }}=\frac{1}{2} k h^{2}$ herleiten. 


$$
\begin{aligned}
p_{\text {on }} & =k_{\mathrm{on}}^{0} \cdot \exp \left(-\frac{E_{\mathrm{pot}}}{k_{\mathrm{B}} T}\right) \\
& =k_{\mathrm{on}}^{0} \cdot \exp \left(-\frac{-\frac{1}{2} k_{\mathrm{b}} h^{2}}{k_{\mathrm{B}} T}\right) \\
& =k_{\mathrm{on}}^{0} \cdot \exp \left(-\frac{k_{\mathrm{b}} h^{2}}{E_{\mathrm{a}}^{\text {on }}}\right)
\end{aligned}
$$

Die Bindungsrate ohne applizierte Kraft ist $k_{\mathrm{on}}^{0}, E_{\mathrm{pot}}$ bezeichnet die potentielle Energie der Bindung. Der Parameter $E_{\mathrm{a}}^{\text {on }}$ ist ein zusammengesetzter Parameter, der nach den vorgenommenen Umformungen $2 k_{\mathrm{B}} T$ entspricht.

Die Wahrscheinlichkeit $p_{\text {off }}$, dass eine Bindung reisst, ergibt sich nach dem Bell-Modell [40]

$$
\begin{aligned}
p_{\text {off }} & =k_{\text {off }}^{0} \cdot \exp \left(\frac{F}{F_{\mathrm{B}}}\right) \\
& =k_{\text {off }}^{0} \cdot \exp \left(\frac{k_{\mathrm{b}} h}{F_{\mathrm{a}}^{\text {off }}}\right) .
\end{aligned}
$$

Der erste Teil der Gleichung entspricht dem von Bell formulierten Verhalten einer Bindung unter Kraft, siehe Gleichung 3.3, mit $k_{\text {off }}^{0}$ der Rissrate in Abwesenheit einer applizierten Kraft, $F$ der auf die Bindung wirkenden Kraft und $F_{\mathrm{B}}$ als intrinsische Kraftskalierung für die Bindungsstärke. Angewendet auf das harmonische Mehrfedernmodell resultiert der zweite Teil von Gleichung 4.26 mit $k_{\mathrm{b}}$ der Federkonstante der Bindung und $h$ deren Auslenkung. Der Parameter $F_{\mathrm{a}}^{\text {off }}$ entspricht wiederum einer Kraftskalierung.

\subsection{Zusammenfassung}

Aus dem harmonischen Mehrfedernmodell ergibt sich ein Szenario, in dem sich Bindungen entweder in einem geschlossenen, oder in einem offenen Zustand befinden können und jeder dieser Zustände stabil, metastabil oder instabil ist. Im Prinzip kann sich jede Bindung im geschlossenen Zustand befinden, solange ihre Bildungsenergie die gespeicherte elastische Energie in der Membrandeformation und der Bindungsauslenkung überschreitet. Eine Bindung reisst, sobald ihre Auslenkung zu Energien höher als $\left|\Delta E_{\mathrm{b}}\right|$ führt. Ein weiterer interessanter Aspekt der sich aus dieser Modellformulierung und den verschiedenen Bindungsstabilitäten ergibt, ist eine Hysterese beim Annähern und wieder Zurückziehen der Membran an das, beziehungsweise von dem Substrat. Die Höhe der nicht ausgelenkten Bindung wird Null gesetzt und die Länge der ausgelenkten Bindung mit $h_{\mathrm{b}}$ bezeichnet. Die Bindung reißt wenn $h_{\mathrm{b}}=h_{\text {rup }}=1$. Das Schließen einer Bindung führt zu einem Energiegewinn des Systems von $\Delta E_{\mathrm{b}}$. 
Die Höhe der Membran über dem Substrat an jedem Punkt wird durch eine empirische Formfunktion beschrieben und hat Einfluss auf die Stabilität der Bindung. Schließen einer Bindung aus großer Höhe ist energetisch ungünstiger als ein Bindungsschluss in einem Bereich, in dem die Membran bereits durch vorhandende Bindungen vordeformiert ist. Aus diesem Zusammenhang ergibt sich ein kooperativer Effekt bei der Bildung von Adhäsionsbindungen.

Die zentralen Aussagen der obigen Abschnitte - der Ursprung der attraktiven Kräfte zwischen Bindungen, die Existenz metastabiler Bindungszustände, der Hystereseeffekt und die Triebkraft der Clusterbildung - werden aus dem harmonischen Mehrfedernmodell mit einigen generellen Annahmen über das Verhalten der MembranSubstrat-Abstandsfunktion erhalten. Das Modell basiert auf zwei Modellparametern ( $\kappa$ und $N$ ). Die Einführung statistischer Bindungsriss- und -bildungswahrscheinlichkeiten macht das Modell weiterhin abhängig von den vier Parametern $k_{\mathrm{on}}^{0}, E_{\mathrm{a}}^{\text {on }}, k_{\mathrm{off}}^{0}$ und $F_{\mathrm{a}}^{\text {off }}$. Diese bestimmen die Dynamik des untersuchten Systems. 


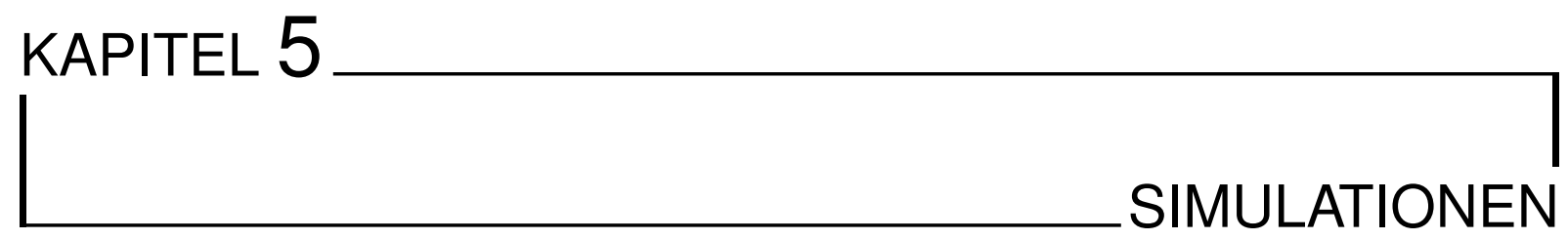

Im Folgenden werden Simulationen des harmonischen Mehrfedernmodells gezeigt und diskutiert. Anhand von Monte-Carlo-Simulationen wird geprüft, ob die aus den Modellannahmen (Kapitel 4) resultierenden Folgerungen bezüglich der Stabilität von Bindungsclustern und den energetischen Urspüngen der Bildung von Adhäsionsclustern zutreffen.

\subsection{Monte Carlo Simulation}

Um das Mehrfedermodell zu testen werden Computersimulationen mit Hilfe der stochastischen Monte Carlo Methode durchgeführt. Im Folgenden wird der allgemeine Verlauf einer Simulation wiedergegeben und es werden relevante Stellen des Programmalgorithmus dargestellt.

\subsubsection{Monte Carlo Methode}

Es werden Simulationen mit Hilfe der Monte Carlo Methode durchgeführt, hierbei wird der sogenannte Metropolis-Algorithmus angewendet und periodische Randbedingungen angenommen. Bei der in dieser Arbeit verwendeten Monte Carlo (MC) Methode wird die zufällig gewählte Konfiguration einer bestimmten Anzahl an Bindungen durch die zufällige Veränderung der Koordinaten einer Bindung modifiziert. Bei einer Minimierung der Energie des Systems wird jede neue Konfiguration akzeptiert, bei einem Energieanstieg wird die Konfiguration mit einer Wahrscheinlichkeit von $e^{-\frac{\Delta E}{k_{B} T}}$ akzeptiert und ansonsten abgelehnt. Dieses Verfahren generiert eine Sequenz von Punkten im Phasenraum.[77] Dieses Verfahren wurde von Nicholas Metropolis in den 1950er Jahren etabliert und ist unter dem Namen Metropolis-Algorithmus bekannt. [78, 76] Der 
Metropolis-Algorithmus erlaubt es innerhalb einer Monte Carlo Simulation in der Energielandschaft bergauf zu gehen und damit lokalen Minima zu entkommen. Dies ist möglich, da geringe Verschlechterungen in der Gesamtenergie mit einer BoltzmannWahrscheinlichkeit akzeptiert werden. Die geometrischen Perturbationen, das bedeutet die Veränderung der Koordinaten eines Teilchens, in jedem Schritt können unphysikalisch sein, dies ist ein Vorteil wenn zwei aufeinander folgende Konfigurationen durch eine Energiebarriere separiert sind. Ein Übergang zwischen energetisch separierten Regionen im Phasenraum ist so möglich. Jede Konfiguration die im Verlauf einer Monte Carlo Simulation angenommen wird ist lediglich abhängig von dem vorangegangen Punkt und einigen Zufallszahlen.

Der Kern eines Computerprogramms mit Monte Carlo Algorithmus ist ein Pseudozufallszahlengenerator und die Möglichkeit die Energie des Systems für bestimmte Koordinaten zu berechnen. In der vorliegenden Arbeit wird ein deterministischer Zufallszahlengenerator verwendet, diese haben den Vorteil, dass bei gleichen Ausgangsbedingungen immer die gleiche Folge von Zufallszahlen erzeugt wird, die Reproduktion von Simulationsergebnissen wird somit möglich.

\subsubsection{Periodische Randbedingungen}

Periodische Randbedingungen werden zur Minimierung von Randeffekten angewendet. [79] Es werden alle Bindungen in der Simulationsbox platziert und diese in alle Richtungen dupliziert. Die zentrale Box ist dann von unendlich vielen identischen virtuellen Boxen umgeben, welche wiederum von Simulationsboxen umgeben sind. Wenn eine Bindung die Simulationsbox durch die rechte Wand verlässt, wird ihr Abbild durch die linke Wand aus der Nachbarbox in die zentrale Simulationsbox gelangen. Das System ist somit formal unendlich und es existiert keine Grenzfläche mehr. Eine Schwierigkeit entsteht dadurch, dass jede der ursprünglichen $N$ Bindungen eine unendliche Anzahl an Abbildern von sich selbst und allen anderen Bindungen sieht. Zur eindeutigen Bestimmung des Abstandes zwischen zwei Bindungen wird ein cut off-Abstand in Größe der Boxlänge definiert und das minimum image konstruiert. [80]

\subsubsection{Algorithmus}

Im ersten Schritt der Simulation werden in einer Simulationsbox der Länge BoxLen eine bestimmte Anzahl an $N$ Bindungen erzeugt. Diese Bindungen werden je nach gewünschter Startkonfiguration homogen in der Simulationsbox verteilt, oder als ein oder mehrere Cluster mit bestimmten Radien.

Für diese Startkonfiguration werden die Höhen und die Energien der Membran, sowie die Auslenkung und Energie der Bindungen an jeder Stelle berechnet. Dadurch kann der Zustand jeder Bindung bestimmt werden, eine Bindung kann geschlossen oder offen sein und in jedem dieser Zustände stabil, metastabil oder instabil.

Zusammenfassend kann der Programmverlauf folgendermaßen dargestellt werden: 
1. Erzeugen einer Anfangskonfiguration: Berechnung der Energien und Membranhöhe, sowie der Bindungszustände für die aktuelle Konfiguration.

2. Entfernen von initial instabilen Bindungen: Instabile Bindungen werden zufällig bewegt, bis sie metastabil oder stabil sind (Annealing der Startkonfiguration).

3. Metropolisminimierung der Energie: Erzeugen neuer Bindungskonfigurationen durch Bewegen der Bindungen in einem diffusionsartigen Schritt.

\subsubsection{Erzeugen der Startkonfiguration}

Als Ausgangspunkt der Simulationen dienen verschiedene Startkonfigurationen einer bestimmten Anzahl an N Bindungen (NumBonds). Diese Anfangsbedingungen werden mit Hilfe verschiedener Funktionen erzeugt, die im Folgenden erläutert werden.

Die Funktion zur Erzeugung einer homogen verteilten Startkonfiguration CreateNewRandomPosition() wird im Folgenden gezeigt und erläutert. Zunächst werden neue Zufallskoordinaten für die Bindung BondNum erzeugt. BondNum ist eine Zahl zwischen [0,NumBonds-1]. Die Funktion prüft, dass die neue Bindung nicht mit existierenden Bindungen überlappt.

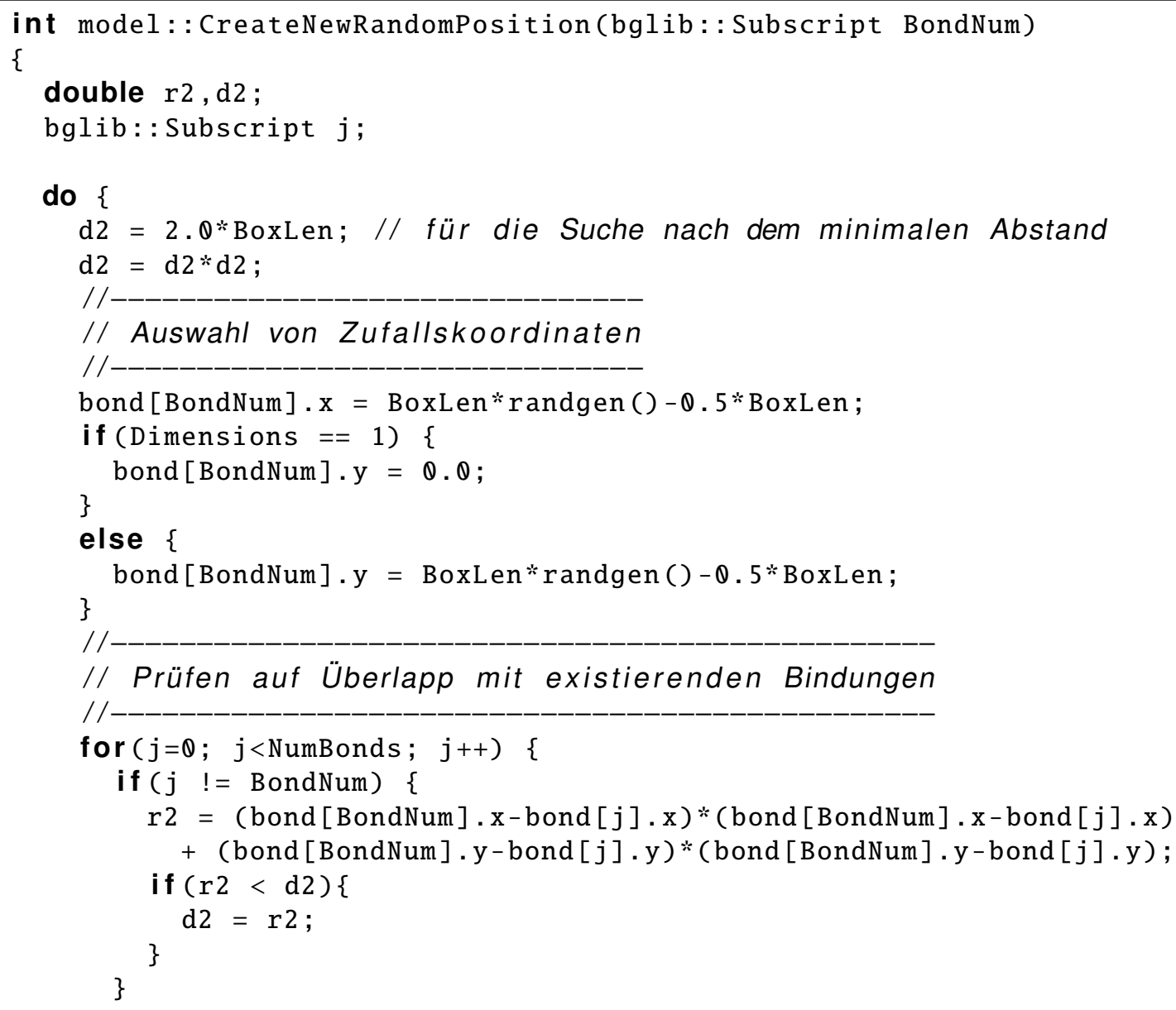




\section{\}}

\} while $(\mathrm{d} 2<4.0 *$ BondRadius*BondRadius);

return $(\theta)$;

\}

Die hier angegebenen Codezeilen erzeugen je eine Bindung mit zufälligen Koordinaten, welche innerhalb der Simulationsbox der Länge BoxLen liegen müssen und nicht mit bereits existierenden Bindungen überlappen dürfen. Der Ursprung der Simulationsbox liegt im Zentrum, die möglichen Koordinaten der Bindungen liegen also im Bereich von $-\frac{\text { BoxLen }}{2}$ bis $+\frac{\text { BoxLen }}{2}$. In den Zeilen 12-18 werden $x$ - und $y$-Koordinaten in diesem Bereich erzeugt. Der Ausdruck bond[BondNum].x ist die Variable, welche die $x$-Koordinate enthält. In Zeile 12 wird dieser Variablen ein Wert zugewiesen. Dieser Wert wird durch den Ausdruck BoxLen*randgen()- $0.5^{\star}$ BoxLen bestimmt. randgen() erzeugt eine Zufallszahl zwischen 0 und 1, welche mit der Länge der Simulationsbox multipliziert wird und dadurch eine Zahl zwischen 0 und BoxLen ergibt. Die abschlie-

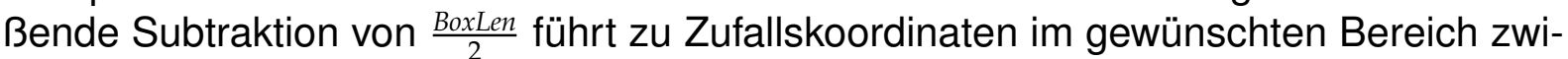
schen $-\frac{\text { BoxLen }}{2}$ und $+\frac{\text { BoxLen }}{2}$. Die Zeilen 13+14 gelten für ein eindimensionales Modell, bei dem der Wert der $y$-Koordinate 0 ist. Im zweidimensionalen Modell wird in Zeile 17, ein entsprechender Zufallswert für die y-Koordinate erzeugt. Mit den Zeilen 22-31 wird geprüft ob die Koordinaten der neuen Bindung mit den bereits existierenden Bindungen überlappen. Die Variable BondRadius beschreibt den Radius um eine Bindung, in dem keine zweite Bindung platziert werden kann.

Mit folgender Funktion CreateNewRandomPosition2() wird eine Startkonfiguration erzeugt, bei der die Bindungen sich bereits in einem Cluster eines vorgegebenen Radius InitialClusterRadius befinden.

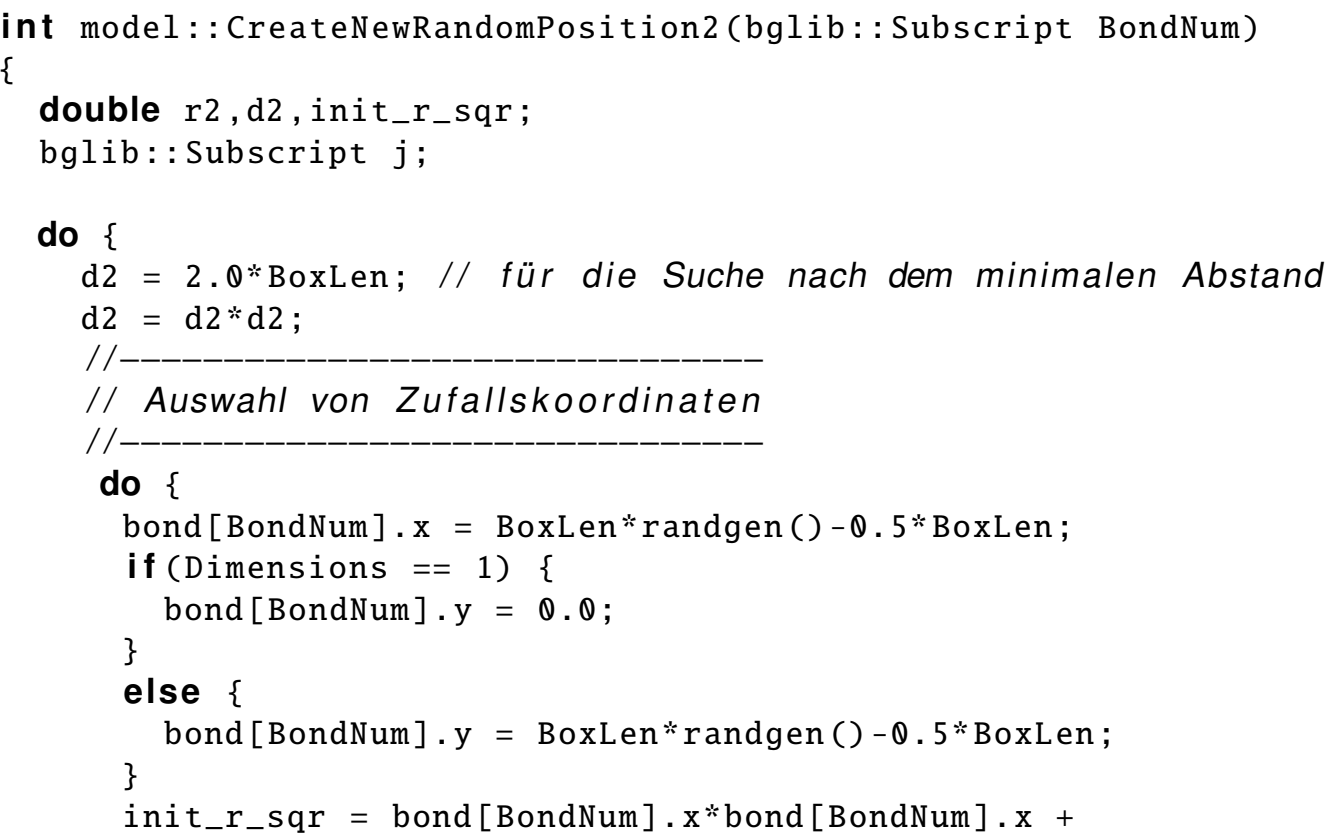




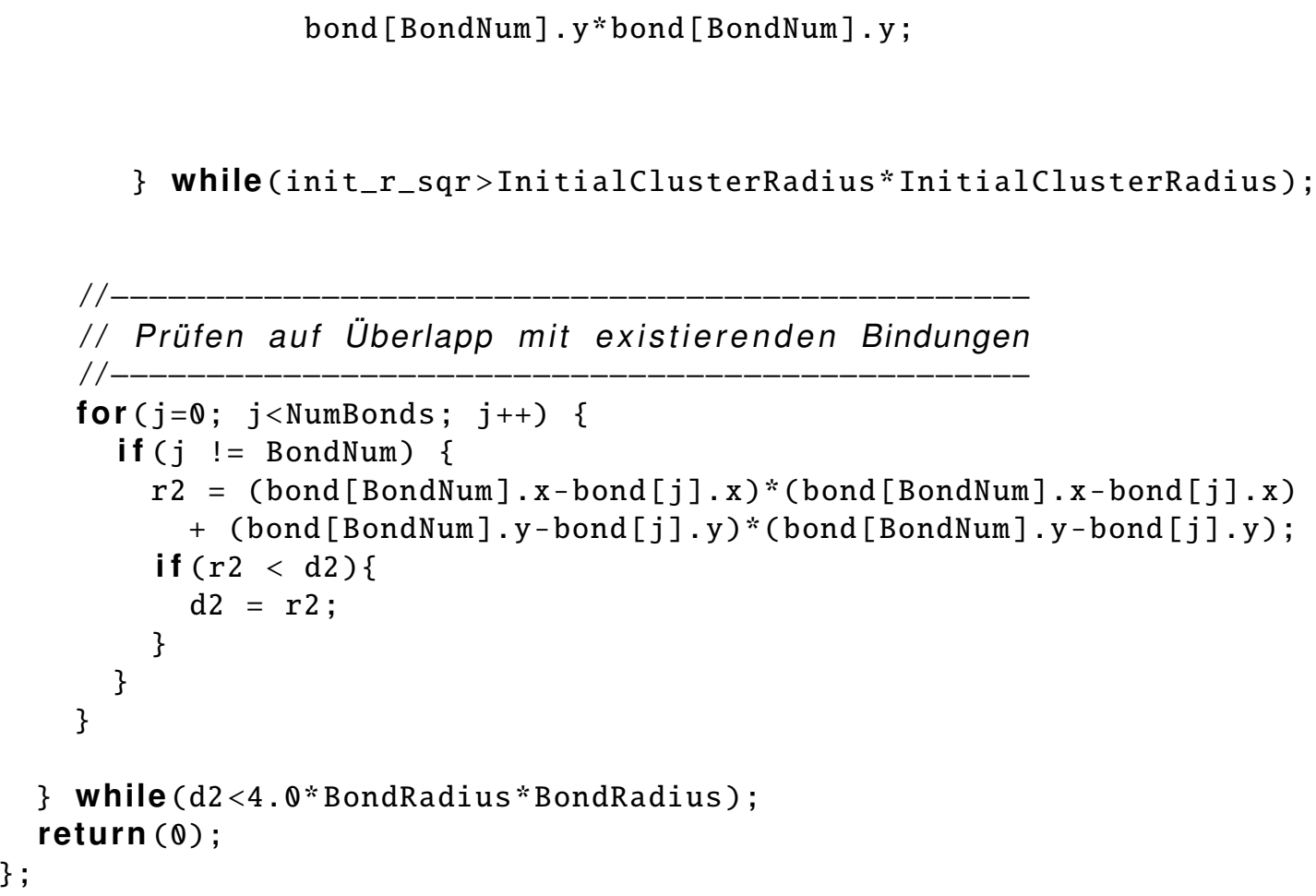

Im Gegensatz zu der homogen verteilten Starkonfiguration wird hier in einer weiteren do-Schleife in Zeile 12 bis 25 geprüft ob sich die erzeugten Koordinaten innerhalb eines inititalen Clusterradius InitialClusterRadius befinden. Die Codezeilen 31-41 dienen, wie in der oben beschriebenen Funktion dazu, zu prüfen ob die neu erzeugte Bindung mit bereits existierenden Bindungen überlappt.

Eine weitere mögliche Anfangskonfiguration wird mit der Funktion CreateNewRandomPosition3() erzeugt. Als Abwandlung zu der eben beschriebenen Funktion werden hier vier Bindungscluster mit je $\frac{\text { NumBonds }}{4}$ Bindungen in einem Abstand von $\frac{B o x L e n}{2}$ zu einander erzeugt.

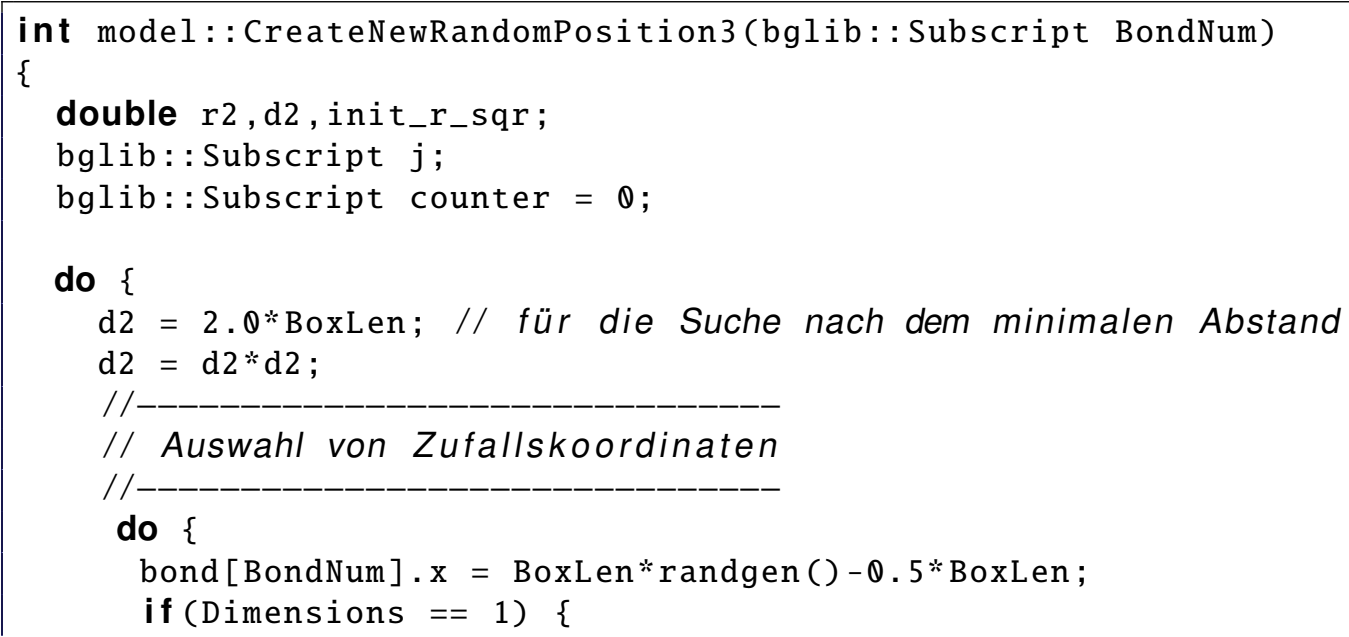




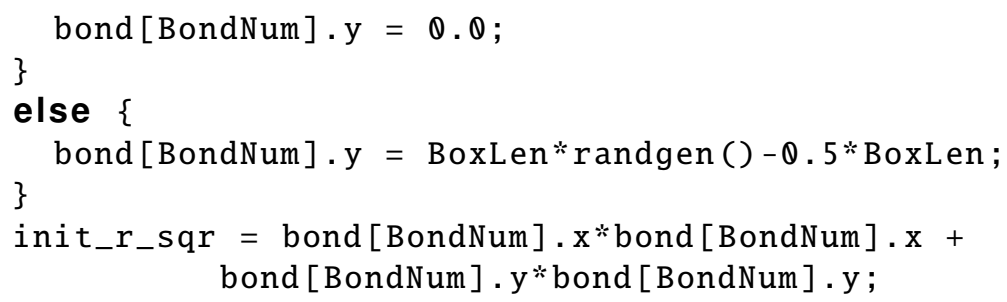

Von der zuvor beschriebenen Funktion CreateNewRandomPosition2() unterscheidet sich die hier gezeigte Funktion durch die Codezeilen 26-43. Hier werden je $\frac{1}{4}$ der Bindungen in einen der vier erzeugten Cluster verschoben. Nach Durchlaufen dieser Funktion zur Erzeugung einer Startkonfiguration befindet sich im Zentrum jedes Quadranten der Simulationsbox ein Cluster mit der Bindungszahl $\frac{\text { NumBonds }}{4}$ und einem Clusterradius InitialClusterRadius. 


\subsubsection{Bindungsstabilitäten}

Zunächst wird der Algorithmus der Funktion $h \_$without() gezeigt, diese dient dazu die Höhe der Membran der aktuellen Konfiguration zu berechnen für den Fall, dass die betrachtete Bindung offen wäre. Man erhält also die Gleichgewichtshöhe der Membran über dem Substrat, die beim Öffnen der Bindung frei werden würde. Die hierfür verwendete Gleichung 5.1 lautet folgendermaßen und wurde bereits bei der Modellbeschreibung eingeführt:

$$
h\left(\vec{r}, S_{\mathrm{N}}\right)=\left[\left(\frac{1}{L}\right)^{\beta}+\sum_{k=1}^{N}\left(\frac{1}{\mid \vec{r}-\overrightarrow{r_{k}}}\right)^{\beta}\right]^{-1} .
$$

Für die Simulationen wurde $\beta=1,0$ gesetzt.

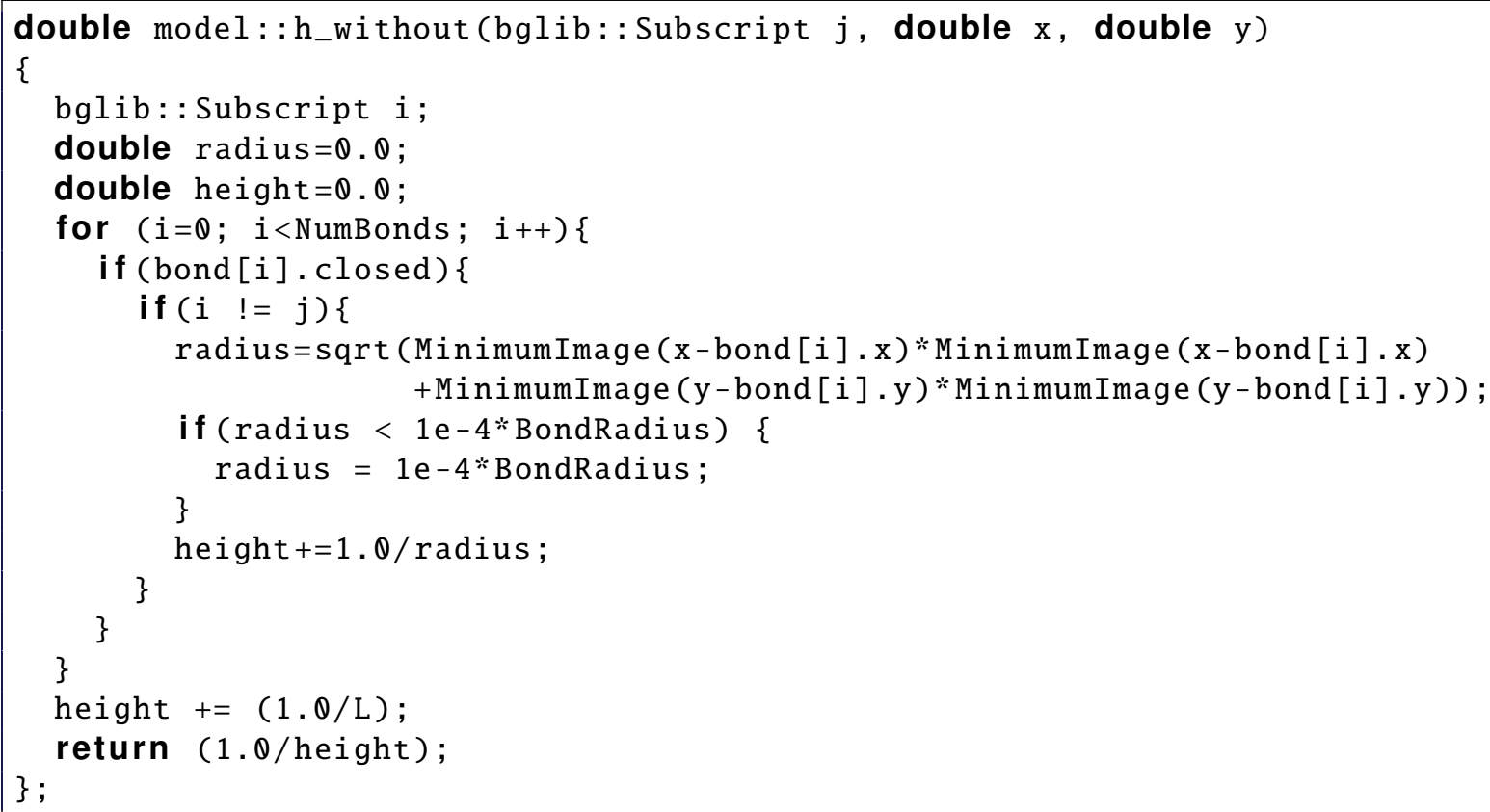

Diese Funktion liefert die Gleichgewichtshöhe der Membran über dem Substrat $h_{0}$ zurück, die beim Öffnen einer Bindung an dieser Position frei wird.

Mit Hilfe der Funktion GetBondState() werden die Auslenkungen und Energien der Membran und der Bindungen berechnet. Mit Hilfe der hier erhaltenen Werte kann der Zustand jeder Bindung bestimmt werden. Der hier angegebene Quellcode der Funktion GetBondState() wird in mehrere Teile zerlegt gezeigt und erläutert.

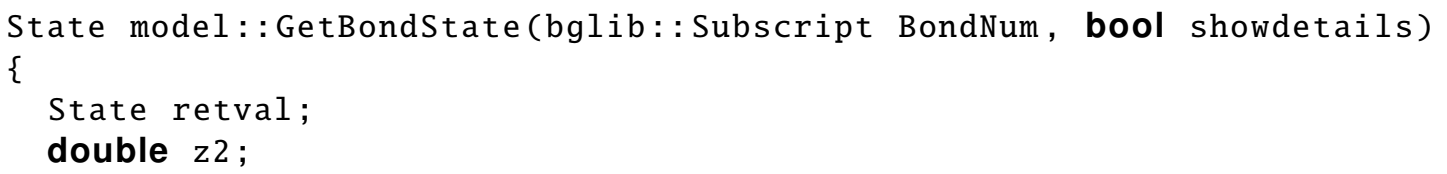




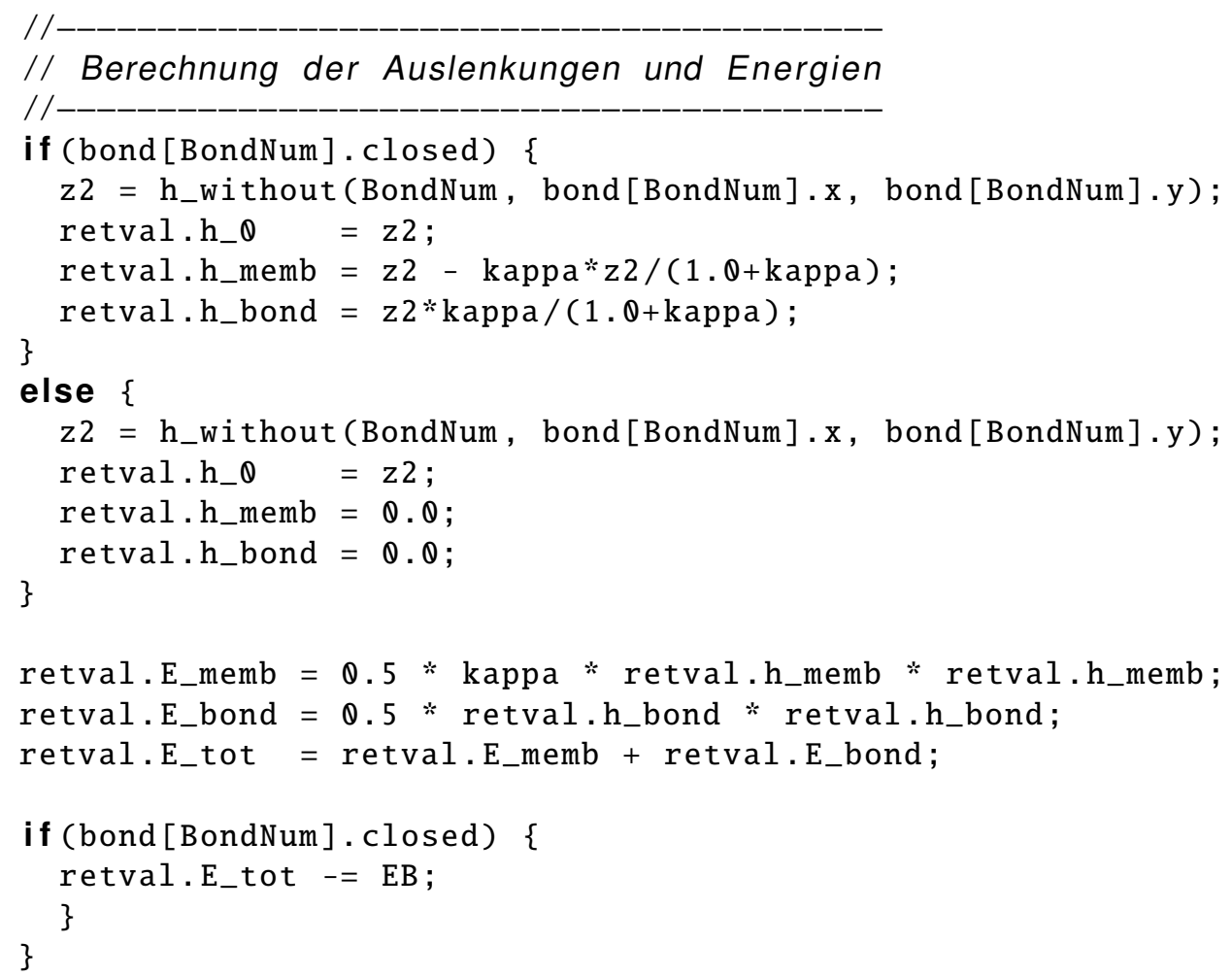

In den oben gezeigten Zeilen 9-14 werden die Gleichgewichtshöhe der Membran über dem Substrat $h_{0}$, die Auslenkung der Membran $h_{\text {memb }}$, sowie die Auslenkung der Bindung $h_{\text {bond }}$ für geschlossene Bindungen bestimmt. Der Wert von $h_{0}$ resultiert aus der Funktion $h$ without() für eine bestimmte Bindung BondNum mit ihren entsprechenden $x$ - und $y$-Koordinaten. Die Auslenkung der Membran wird in Zeile 12 nach Gleichung 5.2 berechnet.

$$
h_{\mathrm{memb}}=h_{0}-h_{0} \cdot \frac{\kappa}{1.0+\kappa}
$$

Und die Auslenkung der Bindungsfeder ergibt sich in Zeile 13 aus Gleichung 5.3 zu

$$
h_{\text {bond }}=h_{0} \cdot \frac{\kappa}{1.0+\kappa} .
$$

Die Zeilen 15-20 behandeln den Fall offener Bindungen. Die Gleichgewichtshöhe der Membran ergibt sich analog aus der Funktion $h$ without(), die Auslenkungen von Membran- und Bindungsfeder sind bei einer offenen Bindung gleich 0. Als nächstes erfolgt die Berechnung der Energie der Membran $E_{\text {memb }}$ und der Bindung $E_{\text {bond }}$, sowie der Gesamtenergie des Membran-Bindungssystems $E_{\text {tot }}$ in den Zeilen 22-29.

Die Energie der Membran $E_{\text {memb }}$ ist nach Zeile 22:

$$
E_{\mathrm{memb}}=\frac{1}{2} \kappa h_{\mathrm{memb}}^{2}
$$


Da die Federkonstante der Bindung 1,0 gesetzt wurde ergibt sich die Energie der Bindung $E_{\text {bond }}$ nach Codezeile 23 zu:

$$
E_{\mathrm{bond}}=\frac{1}{2} h_{\mathrm{bond}}^{2}
$$

Die Gesamtenergie $E_{\text {tot }}$ ergibt sich aus der Addition von Membranenergie und der Energie der Bindung, siehe Zeile 24 bzw. 27.

$$
E_{\text {tot }}=E_{\text {memb }}+E_{\text {bond }}
$$

Für geschlossene Bindungen wird hiervon die freiwerdende Energie beim Bindungsschluss $\Delta E_{\mathrm{b}}$ (im Quellcode $E B$ ) abgezogen und es gilt:

$$
E_{\mathrm{tot}}=E_{\mathrm{memb}}+E_{\mathrm{bond}}-\Delta E_{\mathrm{b}} \text {. }
$$

Im Folgenden ist der Quellcode dargestellt, der bestimmt in welchem Zustand eine Bindung ist, das heißt ob die Bindung offen oder geschlossen ist und ob der jeweilige Zustand stabil, metastabil oder instabil ist. Im Folgenden werden vier Fälle unterschieden.

Fall 1:

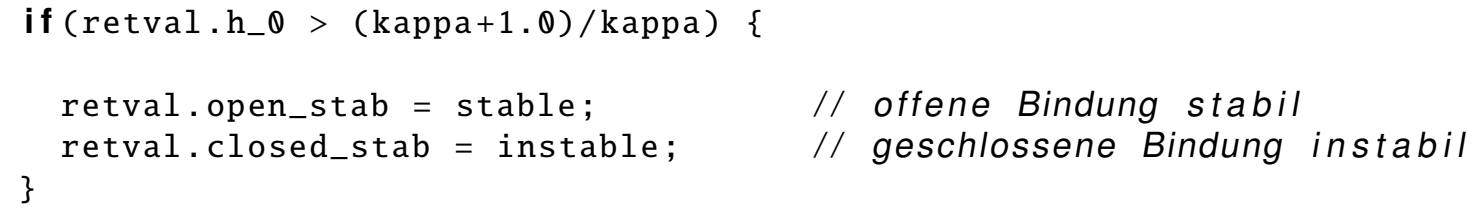

Fall 1 beschreibt Gleichgewichtshöhen der Membran für die

$$
h_{0}>\frac{\kappa+1,0}{\kappa}=\gamma^{2}
$$

gilt. Bindungen, bei denen die Gleichgewichtshöhe der Membran durch Fall 1 beschrieben wird sind im offenen Zustand stabil und im geschlossenen Zustand instabil.

Fall 2:

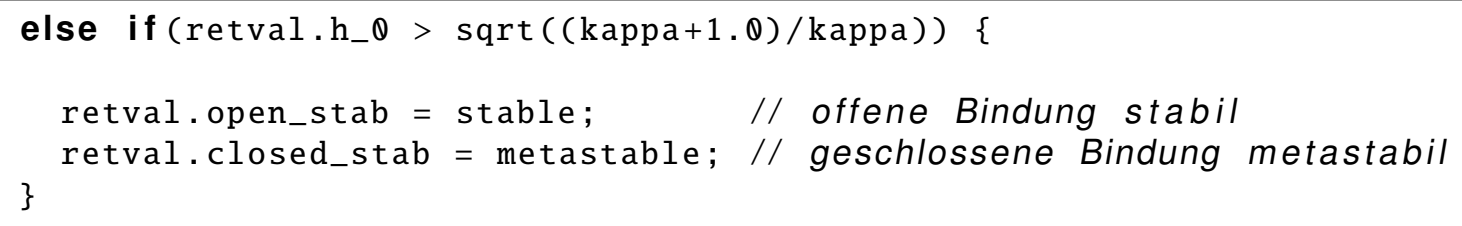

Fall 2 beschreibt Gleichgewichtshöhen die kleiner sind als in Fall 1 und gilt für:

$$
\gamma^{2}>h_{0}>\sqrt{\frac{\kappa+1,0}{\kappa}}=\gamma
$$


Bindungen in diesem Bereich der Gleichgewichtshöhe der Membran sind weiterhin offen stabil, aber geschlossene Bindungen sind metastabil.

Fall 3:

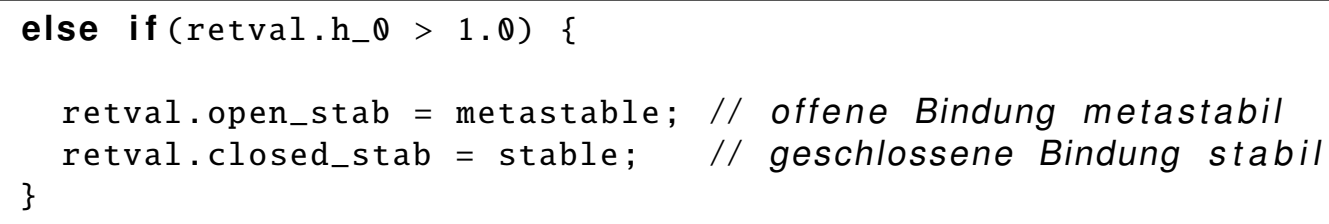

Fall 3 gilt für Gleichgewichtshöhen im Bereich

$$
\gamma>h_{0}>1,0 .
$$

Bindungen die in einem Bereich der Membran liegen, in dem die Gleichgewichtshöhe die Bedingung von Fall 3 erfüllt sind offen metastabil und geschlossen stabil.

Fall 4:

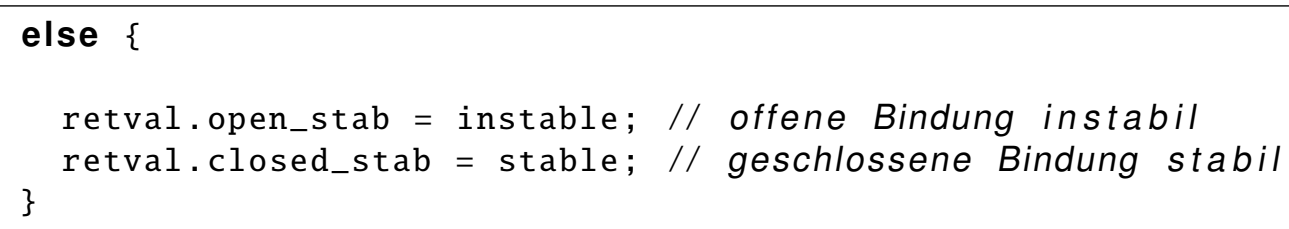

Fall 4 deckt Gleichgewichtshöhen der Membran ab, die kleiner sind als 1,0.

$$
1,0>h_{0}>0
$$

Hier sind offene Bindungen instabil und geschlossene Bindungen stabil.

\subsubsection{Energieminimierung}

Im Folgenden wird der Kern des Programms erläutert. Folgender Algorithmus läuft als do-Schleife über die Simulationsiterationen und führt zur Minimierung der Energie. Auch hier wird der Quellcode in Einzelteile zerlegt gezeigt und erläutert.

Der zuerst dargestellte Teil des Algorithmus wählt zufällig eine der Bindungen aus (Zeile 4). Als nächstes wird eine neue Position für diese Bindungen in einem bestimmten Radius um die alte Position ( $r=25$ für geschlossene Bindungen und $r=250$ für offene Bindungen) gesucht. Dies geschieht in den Codezeilen 5-12 wiederum über den Zufallszahlengenerator randgen(). Nachdem die neue Position der Bindung bestimmt wurde wird geprüft, dass die Bindung an ihrer neuen Position nicht mit anderen Bindungen überlappt. 


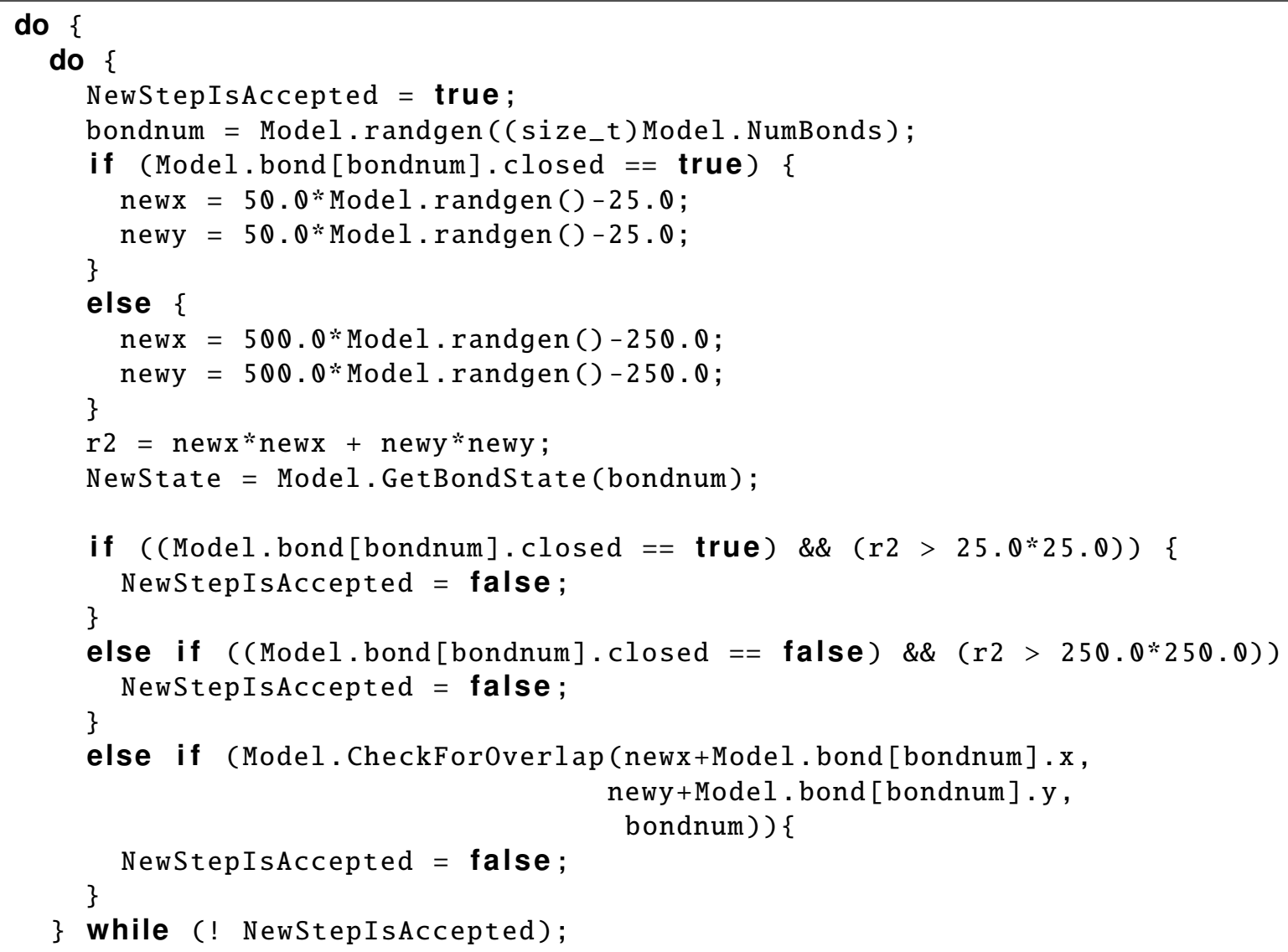

Zunächst dient der Quellcode in den Zeilen 16-21 zur Überprüfung, dass sich die neue Position der Bindung in dem festgelegten Radius um die alte Position befindet. Zeile 24-26 ruft die Funktion CheckForOverlap() auf um auszuschließen, dass die bewegte Bindung an ihrer neuen Position mit anderen Bindungen überlappt.

Nachdem die neue Position für die zufällig ausgewählte Bindung gefunden wurde, wird geprüft, ob die neue Konfiguration die Gesamtenergie minimiert. Hier wird der Metropolis-Algorithmus angewendet, das heißt Konfigurationen die zu einer geringen Erhöhung der Energie führen werden ebenfalls akzeptiert.

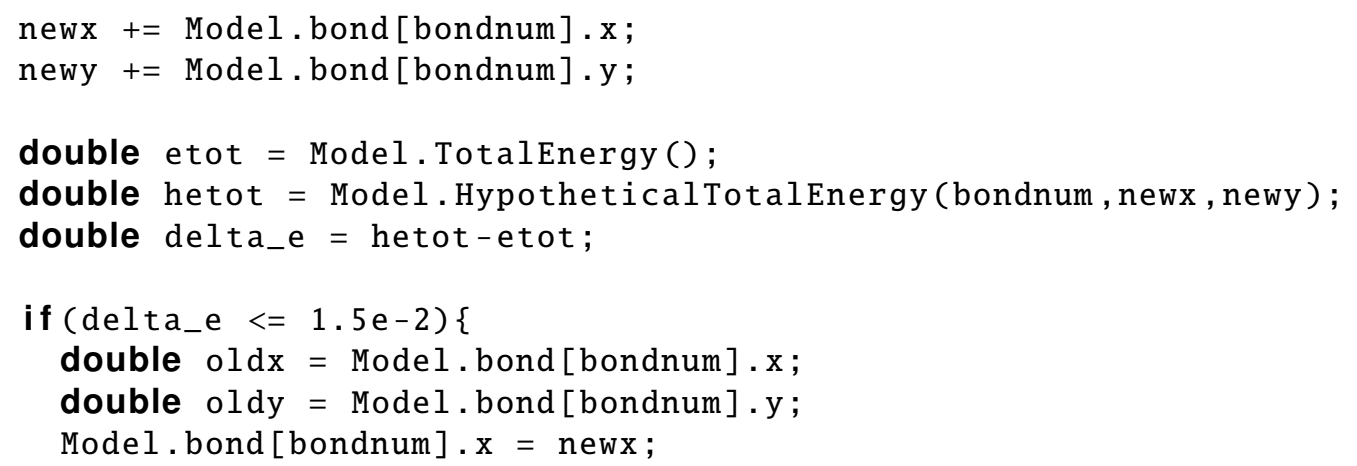


Die hier verwendeten Funktionen TotalEnergy() und HypotheticalTotalEnergy() summieren die zuvor berechneten Gesamtenergien pro Bindung über alle Bindungen auf, wobei letztere die hypothetische neue Position der bewegten Bindung verwendet. Zeilen 6 und 8 bilden die Differenz der beiden Energien und prüfen ob diese $\leq 1.5 \cdot 10^{-2}$ ist. ${ }^{1}$ Bei Erfüllen dieser Bedingung wird die Bindung auf die neue Position gesetzt (Zeile 9-12). Wenn die neue Konfiguration aus energetischer Sicht akzeptiert ist, werden die Bindungen in Bezug auf ihre Stabilitäten überprüft. Alle geschlossenen Bindungen die instabil geworden sind werden geöffnet, alle offen instabilen Bindungen werden geschlossen. Der Zustand metastabiler Bindungen wird mit einer BoltzmannWahrscheinlichkeit verändert. Die for-Schleife läuft über alle Bindungen und passt deren Zustand an (Zeile 1). Im ersten Abschnitt ist die gewählte Bindung geschlossen und der geschlossene Zustand ist instabil:

for (int bnum=0; bnum $<$ Model. NumBonds; bnum ++ ) \{

if ((Model.GetBondState(bnum). closed_stab == instable) \&\&

(Model. bond [bnum]. closed == true) \{

Model. bond [bnum $]$. closed = false;

\}

Die obigen Codezeilen 3 und 4 verwenden die zuvor erläuterte Funktion GetBondState() um den Zustand der Bindung abzufragen. Model.GetBondState(bnum).closed_stab $==$ instable bedeutet die Stabilität des geschlossenen Zustands ist instabil und Model.bond[bnum].closed $==$ true gibt an, dass die fragliche Bindung geschlossen ist, da closed true ist. Wenn diese beiden Bedingungen erfüllt sind wird die Bindung durch den in Zeile 5 angegebenen Code geöffnet (closed wird auf false gesetzt).

In dem Fall, dass die Bindung geschlossen ist, der geschlossene Zustand aber metastabil ist werden wieder Boltzmann-Wahrscheinlichkeiten verwendet um zu entscheiden ob sie geöffnet wird oder geschlossen bleibt.

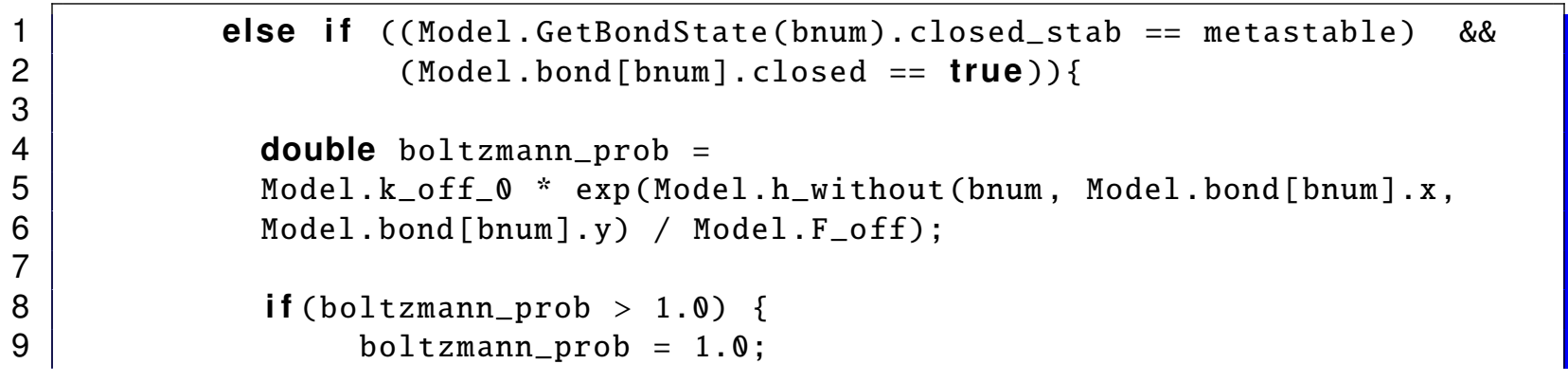

${ }^{1}$ Das ist eine leichte Modifikation des Metropolis-Algorithmus, in dem hier der Boltzmann-Faktor durch eine Konstante ersetzt wird. Dies bringt einen leichten Vorteil für die Rechenzeit des Programms. 


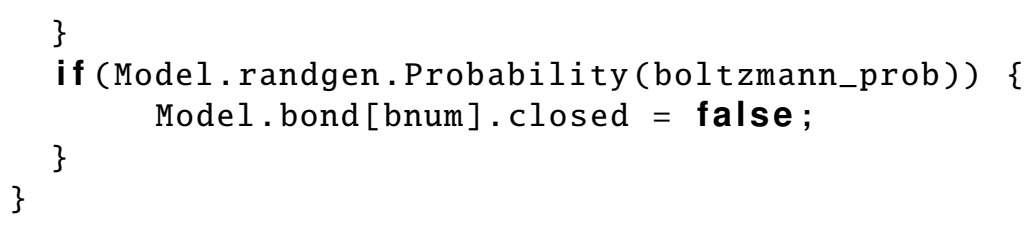

Die Boltzmann-Wahrscheinlichkeit (boltzmann_prob) wird in den Zeilen 4-6 berechnet. Die hier verwendete Gleichung wurde in Abschnitt 4.2.4 mit Gleichung 4.26 angegeben.

Die nächste Möglichkeit für Bindungszustände ist, dass die Bindung geschlossen und geschlossen stabil ist. Auch hier wird auf Grund der endlichen Lebenszeit von Bindungen, gewichtet mit einer Boltzmann-Wahrscheinlichkeit entschieden, ob die Bindung geöffnet wird. Da diese abhängig von der frei werdenden Membranhöhe ist, ist die Wahrscheinlichkeit kleiner als für metastabile Bindungen.

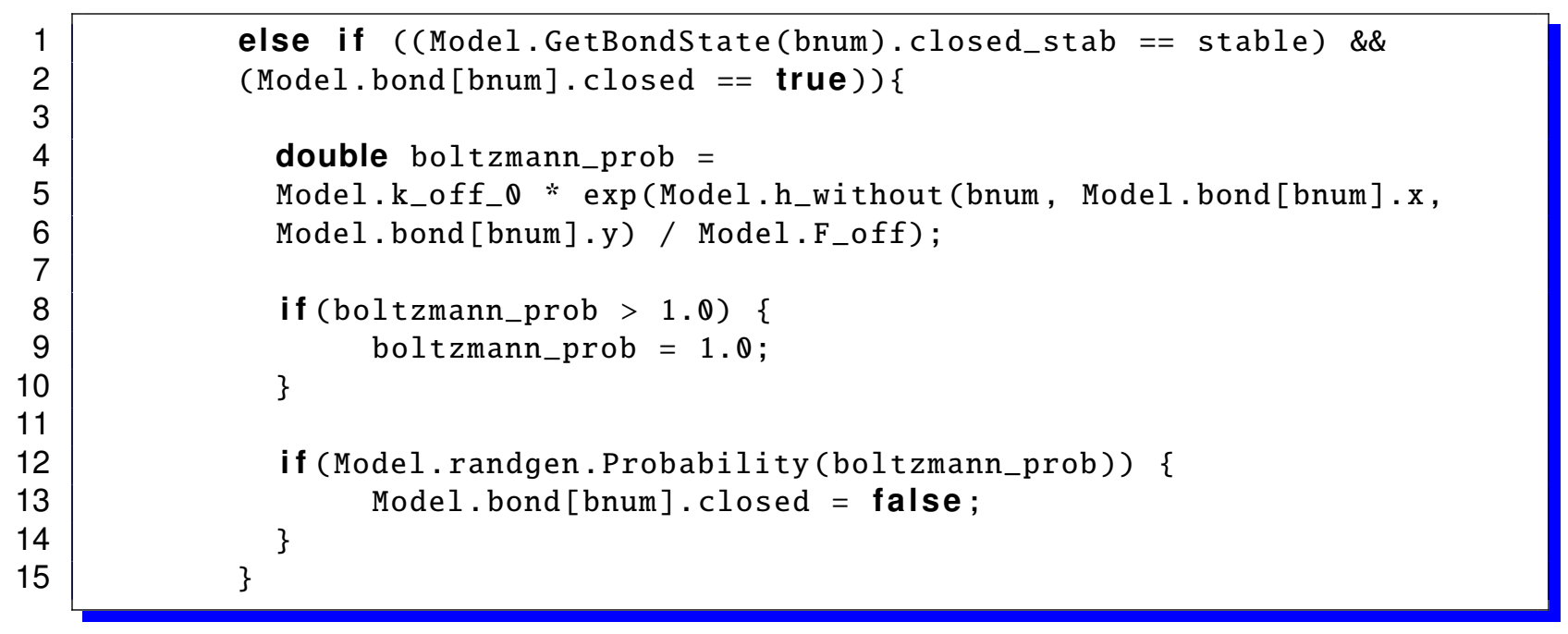

Offen instabile Bindungen werden immer geschlossen.

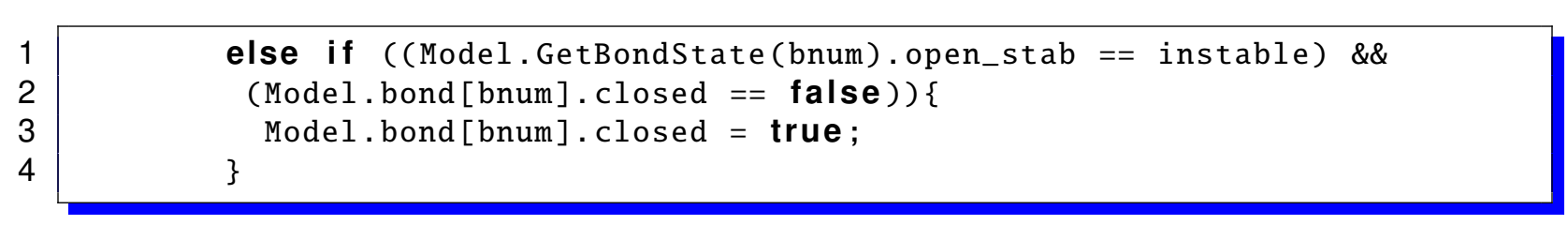

Ist die untersuchte Bindung offen und der offene Zustand metastabil, wird sie mit einer Boltzmann-Wahrscheinlichkeit geschlossen.

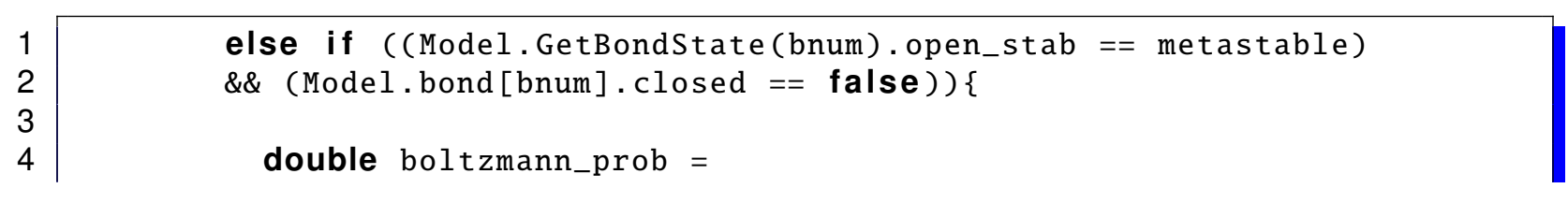




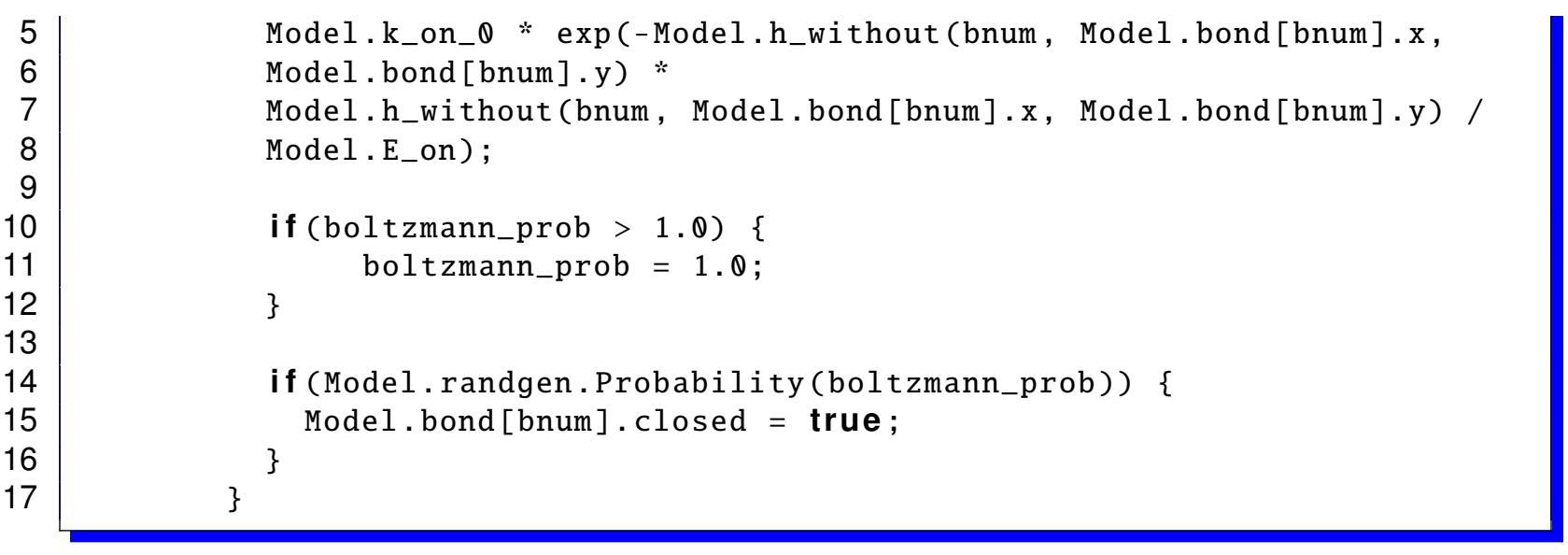

Hier wird die in Abschnitt 4.2.4 eingeführte Wahrscheinlichkeit zum Bindungsschluss $p_{\text {on }}$ (Gleichung 4.25) verwendet.

Wenn eine Bindung offen ist und der offene Zustand stabil ist, wird sie mit einer Boltzmann-Wahrscheinlichkeit geschlossen, wenn der geschlossene Zustand metastabil ist.

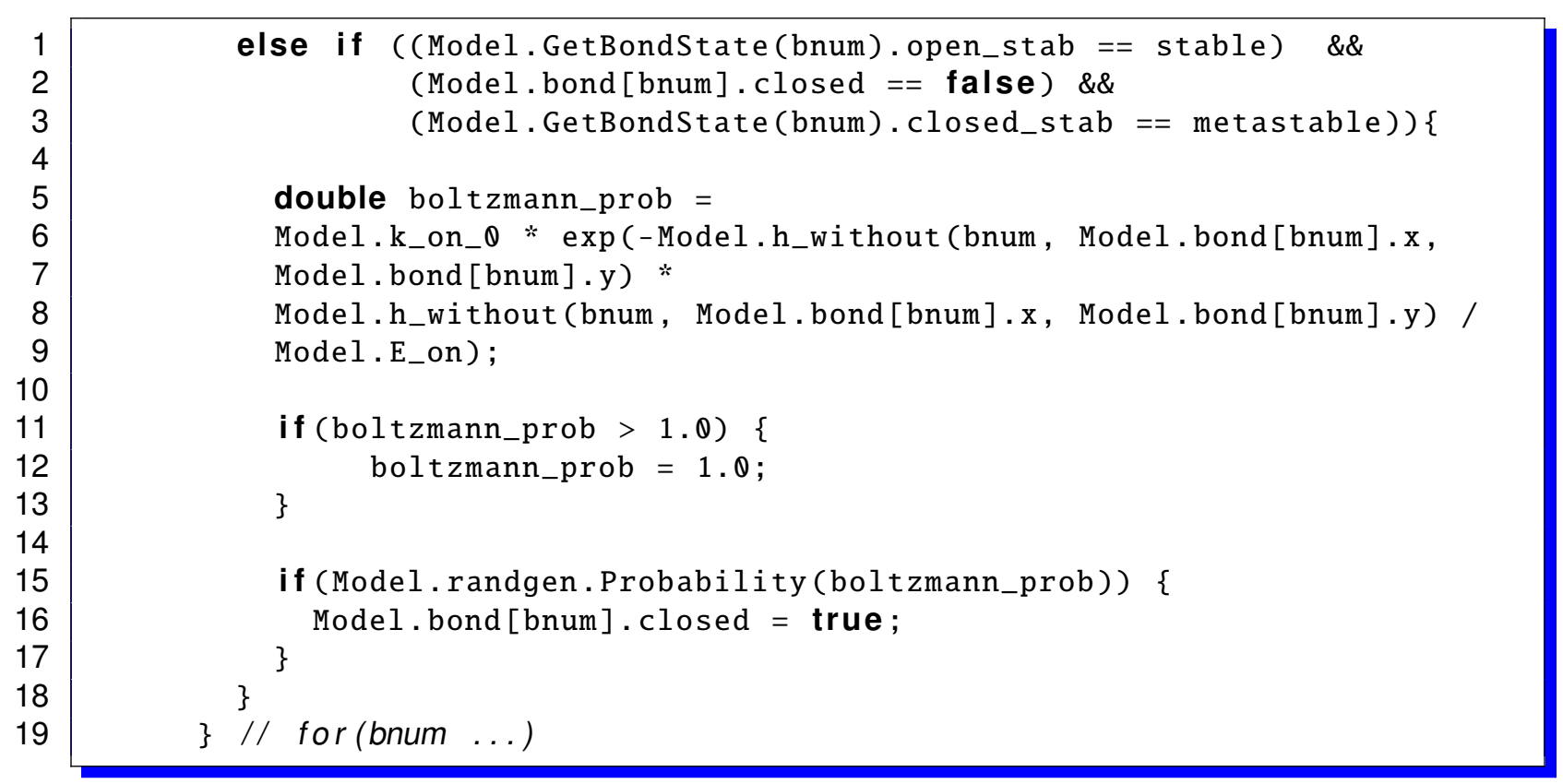

Die Klammer in Zeile 19 ist das Ende der for-Schleife über alle Bindungen, das heißt an diesem Punkt sind die Zustände aller Bindungen angepasst und eine neue zufällige Bindung wird ausgesucht, ihre Position verändert und erneut das eben erläuterte Programm durchlaufen.

Mit dem hier angegebenen Algorithmus ist es möglich Simulationen des harmonischen Mehrfedernmodells durchzuführen, um die Bildung und Stabilität von Adhäsionsclustern zu untersuchen und die Vorhersagen des Modells zu veranschaulichen. 


\subsection{Harmonisches Mehrfedernmodell}

Die Ergebnisse verschiedener Simulationen werden im Folgenden diskutiert.

\subsubsection{Formierung von Bindungsclustern}

Aus den im Modell enthaltenen attraktiven Wechselwirkungen zwischen Bindungen sollte die Formierung von Bindungsclustern aus einer homogenen Anfangskonfiguration zu beobachten sein. Der folgende Abschnitt beschäftigt sich mit der Formierung und der energetischen Stabilität von Bindungsclustern im harmonischen Mehrfedernmodell. Der hierzu verwendete Algorithmus besteht aus der Erzeugung einer zufällig homogen verteilten Bindungskonfiguration. Anschließend werden Bindungen zufällig ausgewählt und ihre Position verändert, wenn dies unter Energieminimierung geschieht (Metropolis) und die neue Position nicht mit den Radien der anderen Bindungen überlappt.

Annealing Phase Zu Beginn der Simulation durchläuft die Simulation eine sogenannte annealing-Phase, die dazu dient, initial geschlossen instabile Bindungen in metastabile oder stabile Bindungen zu überführen. Dieser Mechanismus wird angwendet um einen Simulationslauf mit Clusterbildung auch mit Simulationsparametern durchführen zu können, die das System bei Simulationsbeginn noch nicht stabilisieren. Man kann dies auch so verstehen, dass die Membran anfänglich mit dem Substrat in ausreichenden Kontakt gebracht wird, um erste Bindungen auszubilden. Es ist jedoch zu beachten, dass bei einer zu langen annealing-Phase keine homogene Verteilung der Bindungen mehr vorliegt und bereits ein mehr oder weniger loser Adhäsionscluster gebildet wird. Das muss bei der Interpretation der Ergebnisse gegebenenfalls berücksichtigt werden.

\subsubsection{Simulationsverlauf}

Im Folgenden ist der Verlauf einer solchen Simulation, zunächst von einer homogenen Verteilung ausgehend, gezeigt (Abbildung 5.1). In rot sind geschlossen stabile Bindungen, in grün geschlossen metastabile Bindungen und in blau geschlossen instabile Bindungen dargestellt. Es ist zu beobachten, dass im Simulationsverlauf zunehmend metastabile Bindungen zu stabilen Bindungen werden, während die Bindungen eine geclusterte Konfiguration einnehmen. Betrachtet man nun den Verlauf der potentiellen Energie in Abbildung 5.2, sieht man ein Absinken der Energie im Zusammenhang mit der Clusterbildung in negative Wertebereiche. Nach etwas $10^{5}$ Simulationsschritten ist die potentielle Energie negativ und die gesamte Konfiguration ist stabil. Die Auftragung der Anzahl stabiler, metastabiler und instabiler Bindungen im Simulationsverlauf, zeigt, dass mit der Clusterung der Bindungen metastabile Bindungen in stabile Bindungen überführt werden. 


\subsubsection{Konstante Bindungszahl}

Zunächst wird zu Testzwcken die Anzahl der Bindungen während der Simulation konstant gehalten. Das bedeutet, dass geschlossen instabile Bindungen nicht geöffnet werden. Unter diesen Bedingungen lässt sich abhängig von den gewählten Simulationsparametern die Ausbildung stabiler Cluster oder ein Auseinandereißen von Membran und Substrat beobachten. Das Abreißen der Membran erkennt man daran, dass ausschließlich instabile Bindungen vorhanden sind. In Grenzbereichen dieses Bistabilitätsgebiets wird je nach verwendeter Zufallszahlenfolge eines dieser beiden unterschiedlichen Ergebnisse erhalten.
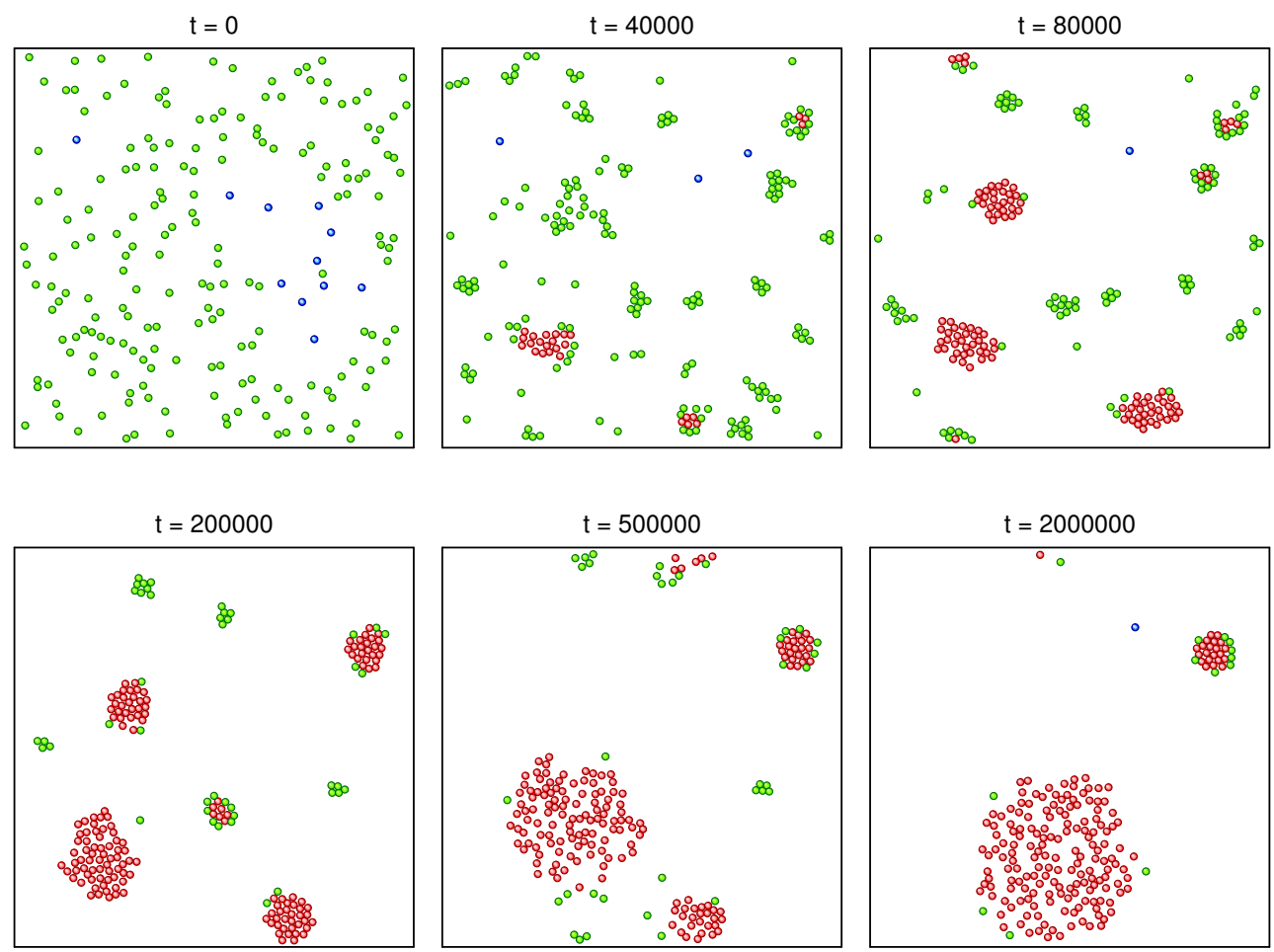

Abbildung 5.1: Entwicklung der Bindungskonfiguration bei Simulation des harmonischen Mehrfedernmodells mit konstanter Bindungsanzahl $N=200 . t$ gibt die Iteration an, bei der die gezeigte Konfiguration vorliegt. In grün sind metastabile Bindungen gezeigt, in blau instabile und in rot stabile Bindungen. Im Verlauf der Simulation entwickelt sich die zunächst überwiegend metastabile homogene Konfiguration hin zu einem Bindungscluster aus stabilen Bindungen.

Abbildung 5.2 zeigt den zu Abbildung 5.1 gehörigen Verlauf der potentiellen Energie, sowie die Anzahl an Bindungen in den einzelnen Stabilitätszuständen.

Die Energie sinkt mit der Clusterbildung, das harmonische Mehrfedernmodell ist also in der Lage die Entwicklung von Adhäsionsclustern unter Energieminimierung zu zeigen. Im unteren Teil von Abbildung 5.2 ist die Anzahl metastabiler, stabiler und instabi- 


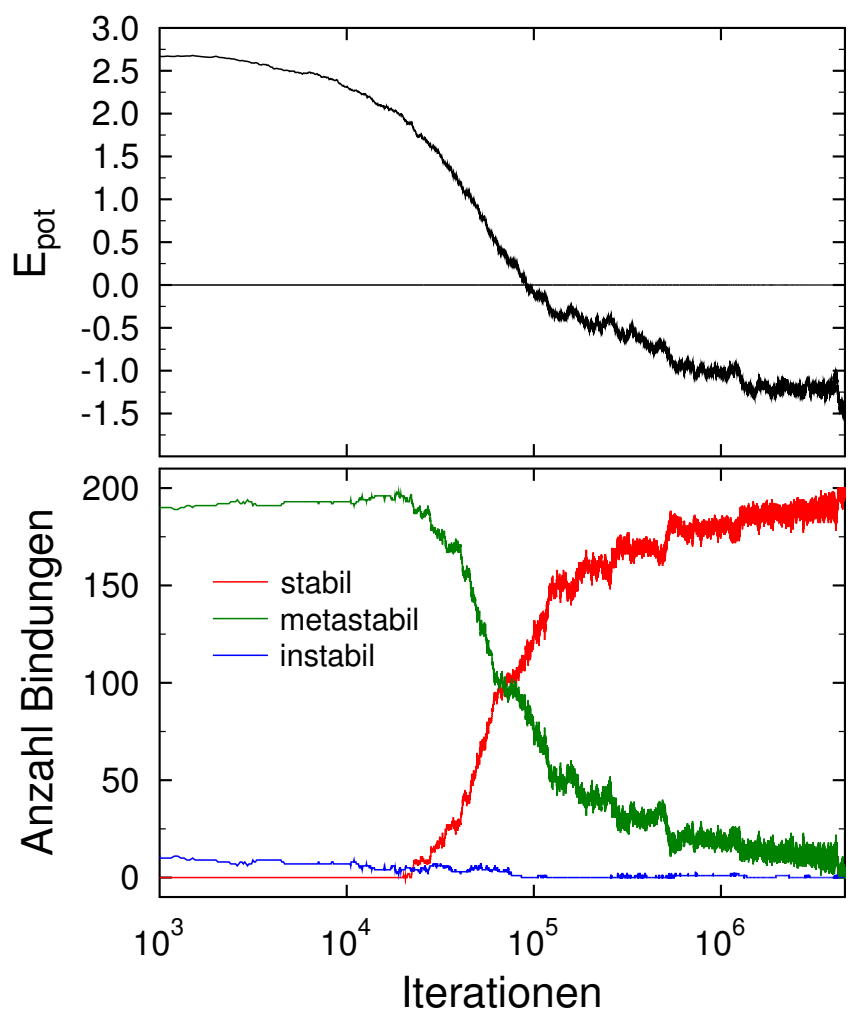

Abbildung 5.2: $\quad$ Potentieller Energieverlauf während der Simulation. Nach einer bestimmten Anzahl an Iterationen wird die Energie negativ und das System damit stabil. Unten ist ausgehend von einer Bindungsanzahl von 200 gezeigt, wie sich diese während der Simulation auf die drei möglichen Zustände (stabil, metastabil, instabil) aufteilen. Zu Beginn sind die meisten Bindungen metastabil, aber mit zunehmender Clusterbildung entstehen auch stabile Bindungen, welche am Ende der Simulation die Mehrheit darstellen.

ler Bindungen im Simulationsverlauf aufgetragen. Instabile Bindungen (blauer Graph) sind während der gesamten Simulation gleichmäßig maximal zehn vorhanden. Was andeutet, dass der kondensierte Cluster mit einer "Gasphaseän offenen Bindungen im Gleichgewicht stehen könnte, und Hoffnungen weckt, eine endliche Clustergröße auch im Überschuss an Integrinbindungen zu finden. Es ist deutlich zu erkennen, dass die Mehrzahl der metastabilen Bindungen in stabile Bindungen umgewandelt werden. Die Ausbildung von stabilen Adhäsionsclustern unter diesen Bedingungen legt den nächsten Schritt nahe, Variabilität der Anzahl geschlossener Bindungen.

\subsubsection{Variable Bindungszahl}

Im Folgenden werden Bindungen, die geschlossen instabil sind im Simulationsverlauf geöffnet. Weiterhin durchlaufen initial instabile Bindungen die annealing-Phase um in metastabile oder stabile Bindungen zu überführt werden. Die maximale Anzahl Bindungen in der Simulation ist die Zahl der zu Beginn gebildeten Bindungen. Wenn alle Bindungen geöffnet sind, können keine neuen Bindungen mehr geschlossen werden. Offene Bindungen haben einen Bewegungsradius der zehn mal so groß ist wie der geschlossener Bindungen. Geschlossen instabile Bindungen werden wieder geschlossen, wenn der geschlossene Zustand der Bindung wieder metastabil oder stabil wird. Zu Beginn der Simulation bei $t=0$ besteht die Konfiguration ausschließlich aus sta- 
bilen oder zumindest metastabilen Bindungen, die über die gesamte Simulationsbox verteilt sind, siehe Abbildung 5.3. Diese entwickelt sich zunächst zu einer Konfiguration aus mehreren kleinen Bindungsclustern, welche sobald sie eine gewisse Größe überschreiten stabil werden. Die Bindungscluster aus einer geringen Anzahl an Bindungen ziehen sich auf Grund der attraktiven Wechselwirkungen weiter an, bis am Ende ein Cluster aus $N=N_{\max }=150$ Bindungen vorliegt. Beziehungsweise werden Bindungen die vereinzelt, also in der "Gasphase"vorliegen von den bestehenden Clustern angezogen und diese Cluster wachsen dann auf Kosten von Einzelbindungen. Dieser ist unter den hier verwendeten Bedingungen $\kappa=0,1, L=100$, einer Simulationsbox der Kantenlänge 3000 und einem Repulsionsradius der Bindungen von 25,0 aus stabilen Bindungen aufgebaut.
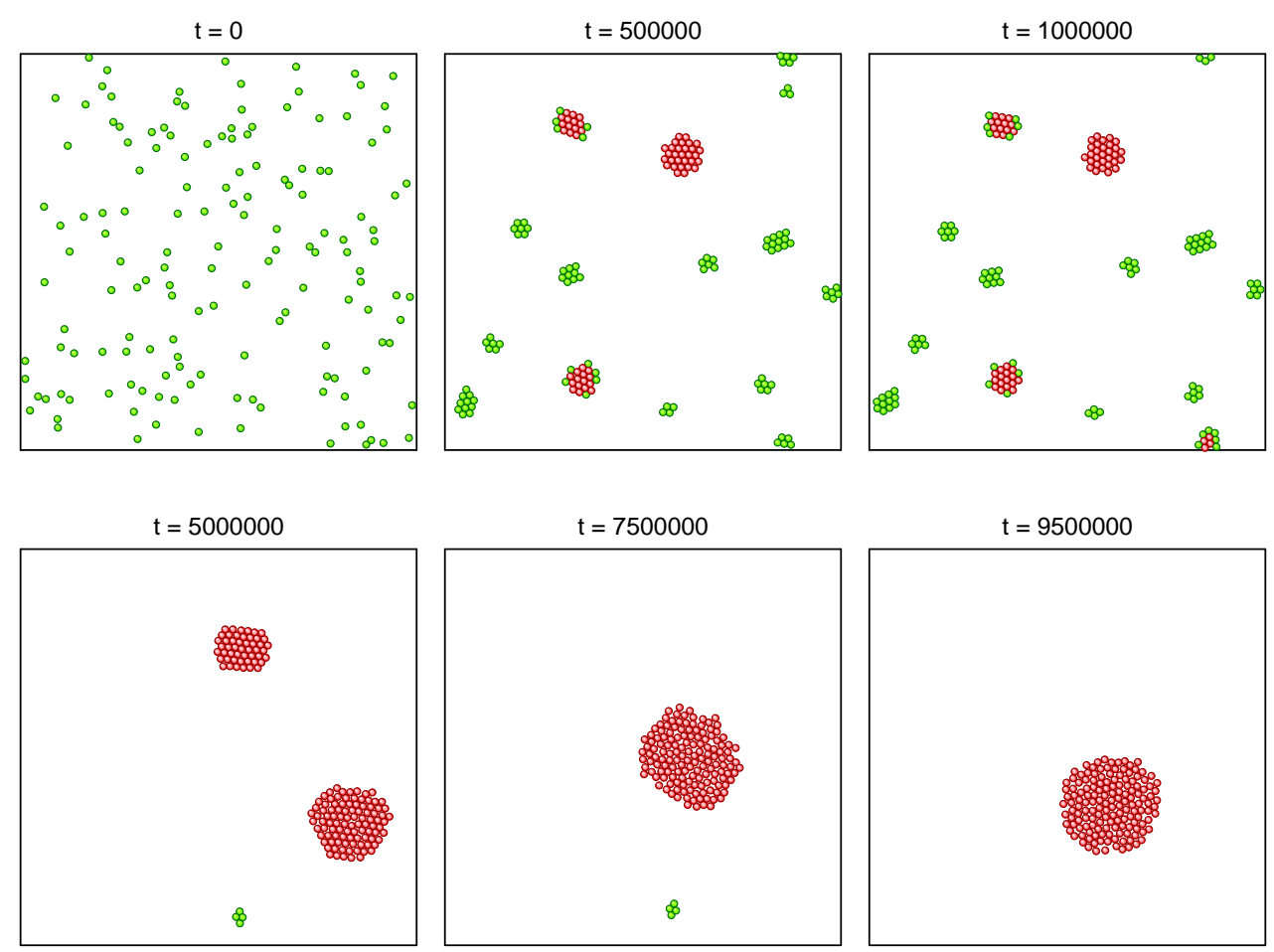

Abbildung 5.3: Entwicklung der Bindungskonfiguration mit maximal $N=150$ Bindungen. $t$ gibt die Iteration an, bei der die gezeigte Konfiguration vorliegt. In grün sind metastabile Bindungen gezeigt, in blau instabile und in rot stabile Bindungen. Im Verlauf der Simulation entwickelt sich die zunächst überwiegend metastabile homogene Konfiguration hin zu einem Bindungscluster aus stabilen Bindungen.

Abbildung 5.4 zeigt den Verlauf der potentiellen Energie für die zuvor gezeigte Simulation, so wie die Anzahl metastabiler, stabiler und instabiler Bindungen.

Die potentielle Energie sinkt während der gesamten Simulation und erreicht nach etwas mehr als $10^{6}$ Iterationen negative Werte, während die Bindungen zunehmend clustern. Negative Energiewerte werden hier erhalten an dem Punkt, an dem mehr stabile 


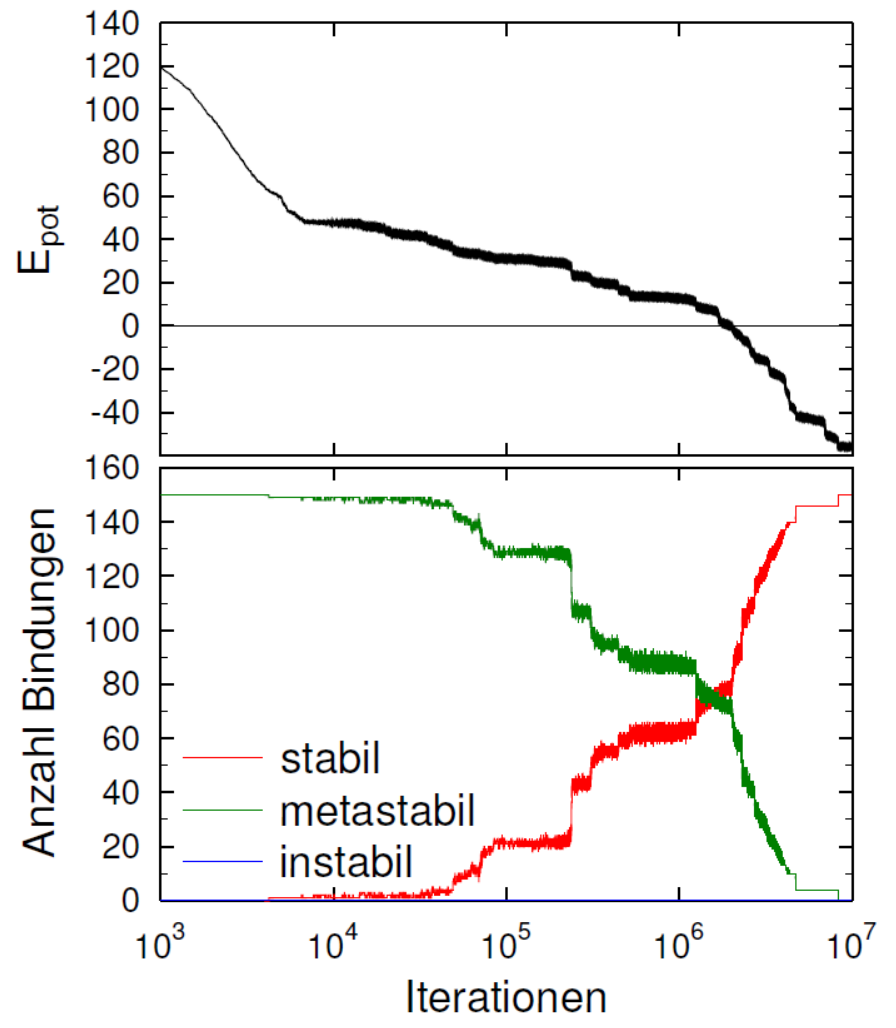

\begin{abstract}
Abbildung 5.4: Potentieller Energieverlauf während der Simulation. Nach einer bestimmten Anzahl an Iterationen wird die Energie negativ und das System damit stabil. Unten ist ausgehend von einer Bindungsanzahl von 150 gezeigt, wie sich diese während der Simulation auf die drei möglichen Zustände (stabil, metastabil, instabil) aufteilen. Zu Beginn sind die meisten Bindungen metastabil, aber mit zunehmender Clusterbildung entstehen auch stabile Bindungen, welche am Ende der Simulation die Mehrheit darstellen.
\end{abstract}

Bindungen als metastabile Bindungen vorliegen. Die Anzahl instabiler Bindungen ist der Vollständigkeit halber aufgetragen, beträgt mit den verwendeten Parametern jedoch 0, was auf einen runaway-growth der Cluster hindeutet. Solche Cluster saugen alle zur Vefügung stehenden Bindungen auf und wachsen grenzenlos an, bis sie alle möglichen Bindungen enthalten. Das ist ein Verhalten, das nicht den Beobachtungen in biologischen Systemen entspricht und zeigt, dass das Modell in dieser Form noch nicht vollständig sein kann.

Auch unter Bedingungen in denen die Bindungsanzahl nicht mehr künstlich konstant gehalten wird und instabile Bindungen geöffnet werden lassen sich aus einer homogenen Bindungskonfiguration Bindungscluster unter Energieminimierung erhalten.

Diese Art der Simulation mit variabler Anzahl geschlossener Bindungen durch Öffnung von Bindungen die im Simulationsverlauf instabil werden sollen im Folgenden näher untersucht werden. Hierfür wird der Verlauf der potentiellen Energie während der Simulation analysiert.

Abbildung 5.5 zeigt die zugehörige dreidimensionale Abbildung der Membranform für drei verschiedene Zeitpunkte der Simulation, deren Konfigurationen auch in Abbildung 5.3 gezeigt sind. 


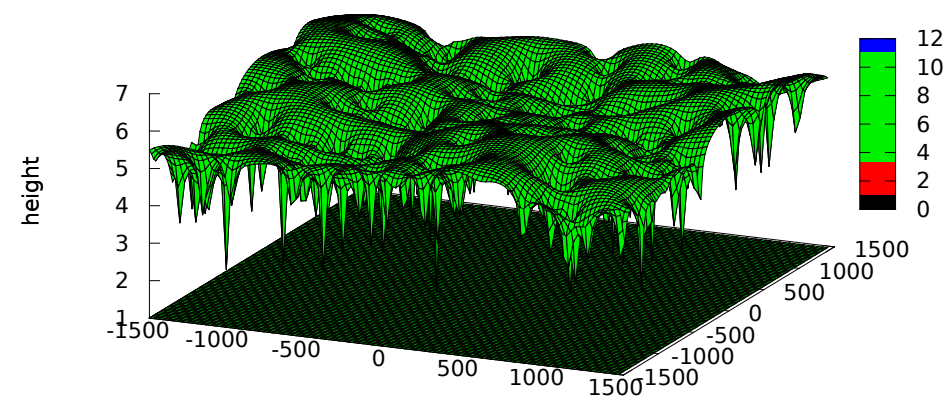

(a) Ausgangskonfiguration

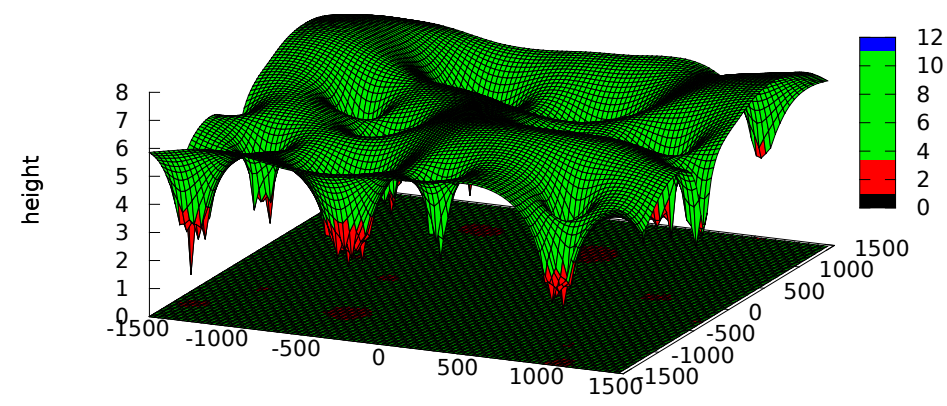

(b) nach $1 \cdot 10^{6}$ Iterationen

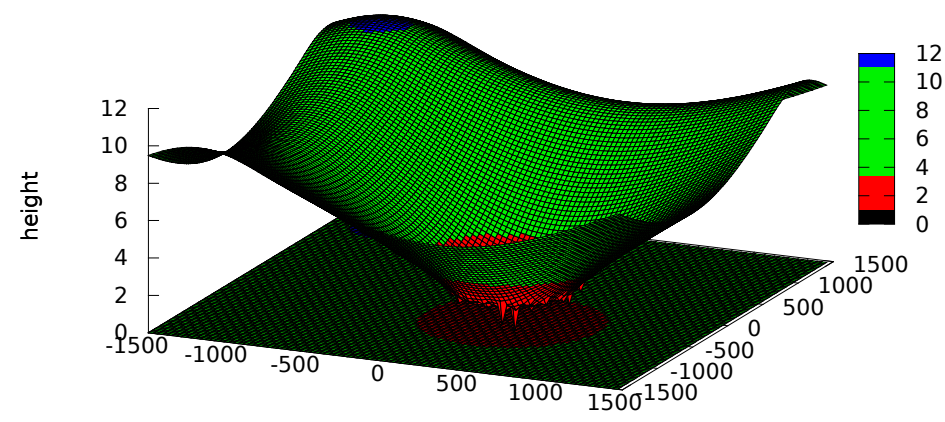

(c) nach $9,5 \cdot 10^{6}$ Iterationen

Abbildung 5.5: Dreidimensionale Abbildung der Membranform zu verschiedenen Zeitpunkten der Simulation $\left(t=0, t=1 \cdot 10^{6}\right.$ und $\left.t=9,5 \cdot 10^{6}\right)$. Die Farben in der Abbildung korrespondieren mit metastabilen (grün), stabilen (rot) und instabilen (blau) Regionen. 
In 5.5 (a) ist die Membranform der Ausgangskonfiguration gezeigt. Die gesamte Fläche ermöglicht lediglich metastabile (grüne) Bindungen. Die maximale Höhe der Membran in dieser Konfiguration beträgt 7,0. Instabile Bereiche bilden sich bei $\kappa=0,1$ bei einer Membranhöhe $h \geq 11,0$ und stabile Bereiche bei $h \leq 3,3$. Teil (b) der Abbildung zeigt die dreidimensionale Membranform nach $t=1 \cdot 10^{6}$ Iterationen, hier liegen bereits kleinere Ansammlungen von Bindungen vor und es bilden sich stabile Membranbereiche (rot). Weit entfernt von Bindungen erreicht die Membran eine maximale Höhe von 8. Bei Vorliegen nur noch eines stabilen Bindungsclusters, wie in (c) gezeigt, treten weit weg von diesem Cluster instabile Bereiche in der Membran auf (blau). Diese instabilen Bereiche zeichnen sich durch Membranhöhen $h \geq 11,0$ aus.

Potentielle Energie Genauere Betrachtung der potentiellen Energie der gezeigten Simulation zeigt zum einen, dass diese zum Teil stufenartig abfällt. Außerdem entstehen immer wieder kurze Anstiege der potentiellen Energie, die dann wieder auf das vorherige Niveau absinken. Diese beiden Effekten werden im Folgenden genauer beleuchtet.

Stufen im Verlauf der potentiellen Energie Im Energieverlauf in Abbildung 5.4 sieht man, dass die Energie an einigen Stellen in Stufen absinkt. Abbildung 5.6 ist ein Ausschnitt aus der obigen Kurve an der Stelle einer Stufe. Das Absinken der Energie geht mit der Bildung stabiler Bindungen einher.

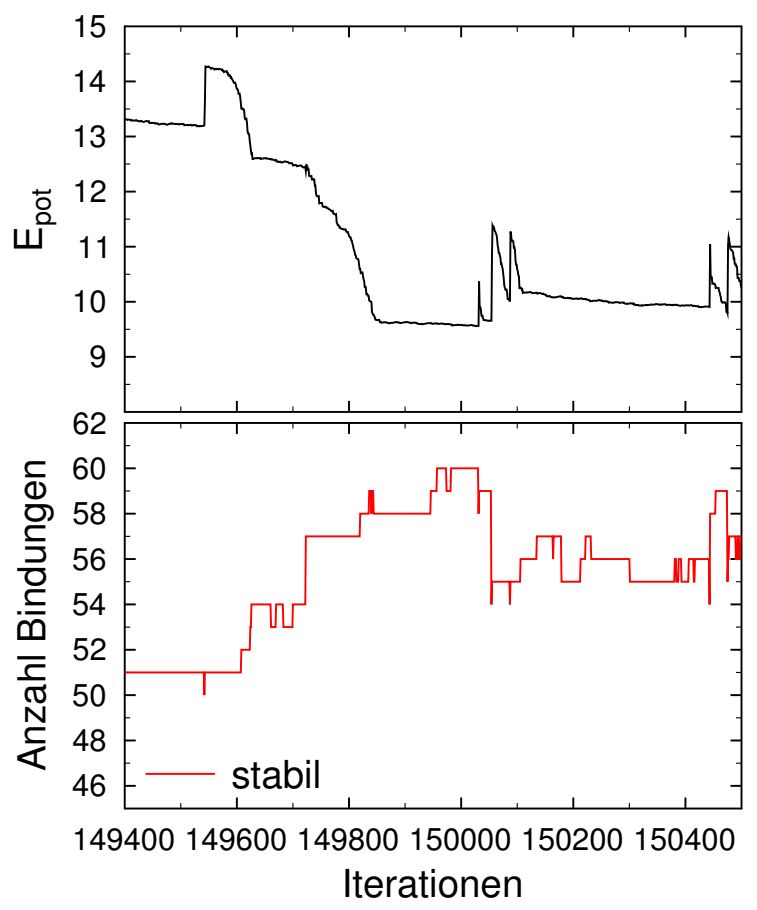

Abbildung 5.6: Ausschnitt aus dem Verlauf der potentiellen Energie. Der stufenartige Abfall der potentiellen Energie geschieht zeitgleich zur Bildung stabiler Bindungen. 
Schaut man sich die Konfiguration und die Stabilität der Bindungen im Bereich einer Stufe in der potentiellen Energie an, sieht man, dass hier metastabile Bindungen zu stabilen Bindungen umgewandelt werden. Im letzten Bild von Abbildung 5.7 sind die Stellen markiert an denen zusätzliche stabile Bindungen im Vergleich zur Konfiguration vor dem stufenartigen Energieabfall entstanden sind. Innerhalb von 500 Iterationen haben sich fünf metastabile Bindungen zu stabilen Bindungen entwickelt. Es existieren offensichtlich kaskadenartige Ereignisse von zeitlich dicht aufeinanderfolgenden Bindungskonversionen. Diese zeichnen sich durch eine Abfolge von Konversionen von geschlossen stabilen zu metastabilen Bindungen aus. In Abbildung 5.7 werden diese Bindungen hervorgehoben. Die Konversionen führen zu einer Stabilisierung der Bindungskonfiguration durch ein Absenken der potentiellen Energie.
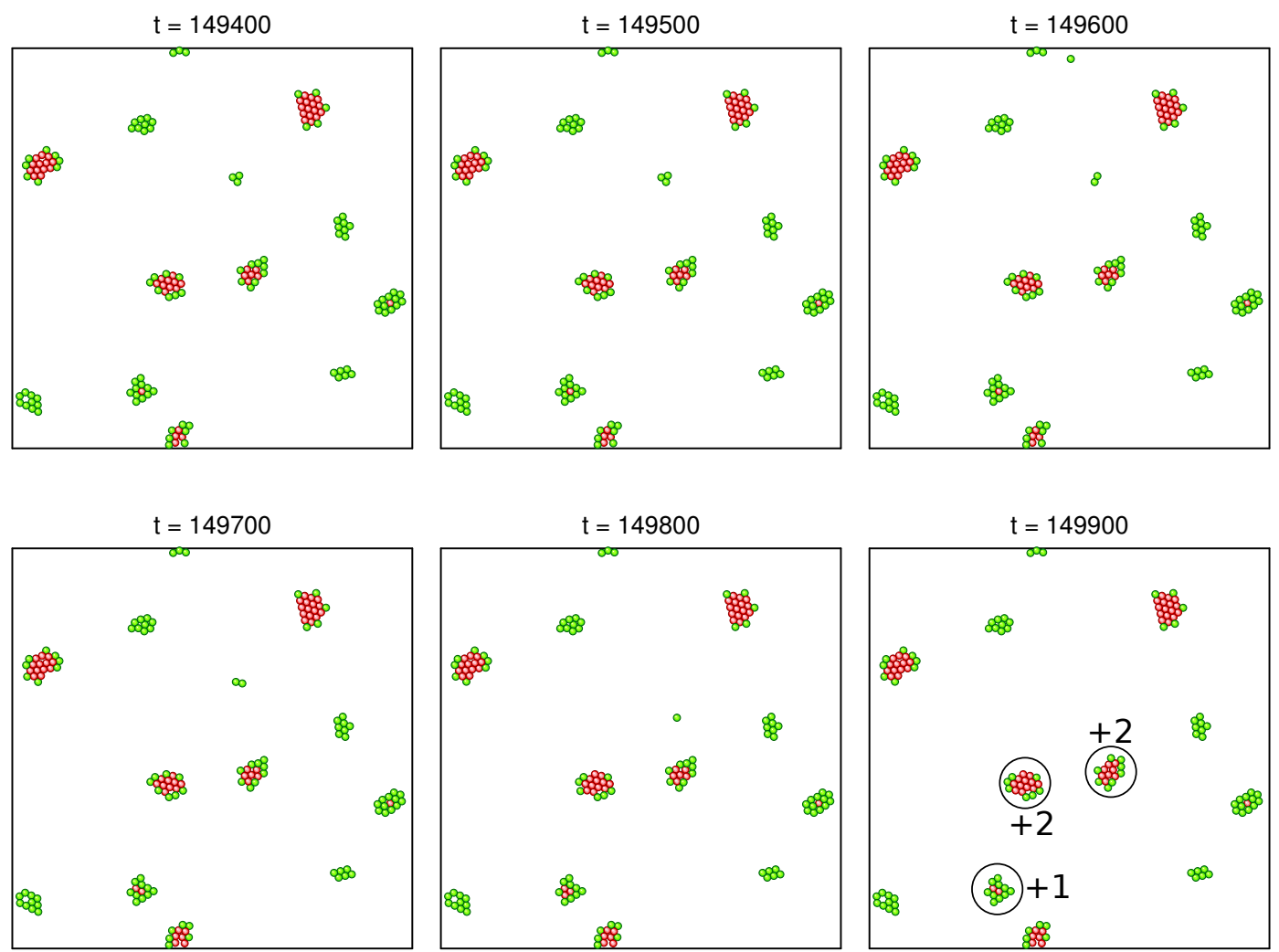

Abbildung 5.7: Entwicklung der Bindungskonfiguration in dem oben gezeigten Intervall während einer Stufe in der Energie. In grün sind geschlosssen metastabile Bindungen und in rot stabile Bindungen gezeigt.

Einzelrissereignisse Ein genauerer Blick in den Verlauf der potentiellen Energie offenbart Anstiege in der Energie, welche zeitlich mit der Öffnung von Bindungen korrelieren. Es ist möglich einzelne Rissereignisse, sogenannte single rupture events, in der Energie des Systems zu erkennen.

Abbildung 5.8 zeigt solche Einzelrissereignisse. Anhand der aufgenommenen Daten lässt sich dem Peak bei 150031 Iterationen eindeutig das Öffnen einer Bindung sowie 
der Übergang einer stabilen in eine metastabile Bindung zuordnen. An dem Verlauf der Anzahl stabiler Bindungen sieht man, dass eine der Bindungen im nächsten Simulationsschritt wieder stabil wird. Der höhere Anstieg nach 150054 Iterationen ist auf die Öffnung einer Bindung und den Übergang von vier stabilen zu metastabilen Bindungen zurück zu führen. Allein an den Werten der potentiellen Energie kann man diese Informationen nicht gewinnen, da die Energie jeder Bindung von der gesamten Konfiguration abhängt und damit keinen festen Wert besitzt.

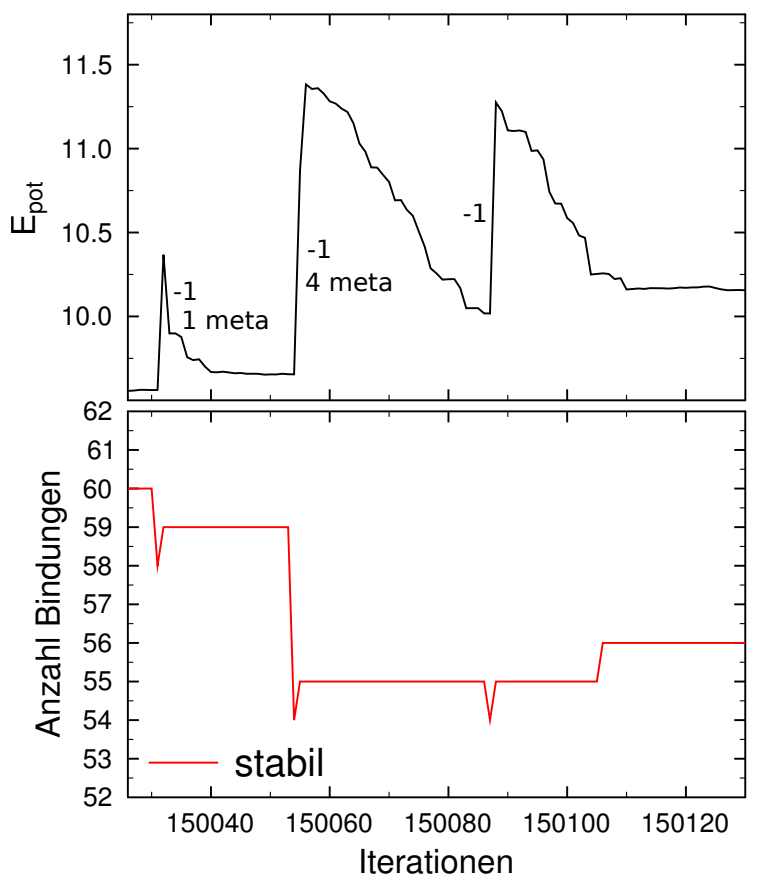

Abbildung 5.8: Ausschnitt aus dem Verlauf der potentiellen Energie. Man sieht kurze Anstiege in der Energie, denen einzelne Bindungsrissereignisse zugeordnet werden können. Die Anzahl stabiler Bindungen im unteren Teil der Abbildung zeigt, dass die Energieanstiege mit der Abnahme der Anzahl stabiler Bindungen einhergehen.

Bei den Einzelrissereignissen sind wieder kaskadenartige Vorgänge zu beobachten, aber im Unterschied zur vorne beschriebenen Bindungsstabilisierung hat hier ein Riss quasi-instantan viele weitere Bindungsrisse, beziehungsweise die Konversion geschlossen stabiler zu metastabilen Bindungen, zur Folge.

Zusammenfassung Es kann gezeigt werden, dass die Bildung stabiler Adhäsionscluster aus einer homogenen Verteilung mit dem harmonischen Mehrfedernmodell erklärbar ist. Zunächst wird die Anzahl geschlossener Bindungen künstlich konstant gehalten, in dem instabile Bindungen nicht geöffnet werden. Aber auch eine Erweiterung des Modells, in der man das Öffnen instabiler Bindungen zulässt, führt zu stabilen Adhäsionsclustern. Je nach gewählten Modellparametern werden Simulationen durchgeführt, bei denen sich ein stabiler Cluster bestehend aus allen geschlossenen Bindungen bildet, oder alle Bindungen im Simulationsverlauf instabil werden und aufreißen, woraufhin die Simulation beendet wird. Nun spiegelt die ausschließliche Öffnung instabiler Bindungen nicht in ausreichendem Maße die Realität wieder, in der die 
schwachen nicht-kovalenten Integrin-RGD-Bindungen eine endliche Lebenszeit besitzen und deshalb auch eine statistische Wahrscheinlichkeit besitzen zu reißen. Dieser Eigenschaft der Adhäsionsbindungen wird im Folgenden Rechnung getragen.

\subsubsection{Boltzmann-Dynamik}

In Abschnitt 4.2.4 wurden Wahrscheinlichkeiten zur stochastischen Bindungsdissoziation 4.26 und -assoziation 4.25 eingeführt. Angewendet werden diese Wahrscheinlichkeiten für Bindungen, die sich in einem metastabilen Zustand befinden sowie auf Bindungen die geschlossen stabil sind, da diese durch ihre endliche Lebenszeit auch eine gewisse Wahrscheinlichkeit zum Bindungsriss besitzen. Wie bereits in 4.2.4 erläutert, sind die Wahrscheinlichkeiten zur Bindungsdissoziation bzw. -assoziation abhängig von den vier Parametern $k_{\mathrm{on}}^{0}, k_{\mathrm{off}}^{0}$, $E_{\mathrm{a}}^{\mathrm{on}}$ und $F_{\mathrm{a}}^{\text {off }}$. Die Wahrscheinlichkeit hängt ebenso von der Höhe der Membran $h$ an der Position der Bindung ab. Bei der Assoziation von der Gleichgewichtshöhe der Membran an der Position der Bindung, bei der Dissoziation von der Höhe die durch Bindungsöffnung frei wird. Dies entspricht einer Wichtung der Assoziation bzw. Dissoziation mit der Stabilität der Bindung, da auch diese von $h$ abhängt. Eine Herausforderung ist es nun passende Werte für die vier variablen Parameter zu finden, die zur Ausbildung stabiler Cluster führen können. Werden die Wahrscheinlichkeiten zu klein eingestellt, geht die Dynamik verloren und die Simulationen entsprechen den zuvor besprochenen ohne Implementierung von Dynamik. Werden zu viele Bindungen über die Boltzmann-Dynamik geöffnet, führt das zu einer Destabilisierung der Bindungskonfiguration und damit zum Aufreissen aller Bindungen. Jede Öffnung einer Bindung erhöht die Kraft auf die verbleibenden Bindungen und damit die Wahrscheinlichkeit zu deren Riss.

Zunächst wird für ein bestimmtes Parameterset $\left(F_{\mathrm{a}}^{\text {off }}=10,0, k_{\text {off }}^{0}=5 \cdot 10^{-4}, k_{\text {on }}^{0}=0,1\right.$, $E_{\mathrm{a}}^{\text {on }}=10,0, \kappa=0,1$ und $\left.L=100\right)$ gezeigt wie eine Simulation von $N=150$ Bindungen mit Boltzmann-Dynamik verläuft.

Abbildung 5.9 zeigt die Entwicklung der Bindungskonfiguration aus einer homogenen Verteilung, bestehend aus geschlossen metastabilen und offen stabilen Bindungen, hin zu einem geschlossen stabilen Cluster.

Die potentielle Energie sinkt während der Bildung des Bindungsclusters auf Werte im negativen Bereich (siehe Abbildung 5.10).

Im Verlauf der Clusterformierung bilden sich geschlossen stabile Bindungen aus geschlossen metastabilen Bindungen. Da geschlossen instabile Bindungen nach ihrer Entstehung geöffnet werden, liegt ihre Anzahl während der gesamten Simulation bei Null.

Die Energieverteilung über die Bindungsfedern $E_{\mathrm{b}}$ ist in Abbildung 5.11 für die oben gezeigten Konfigurationen dargestellt. Bei einer zufällig homogenen Verteilung sind die Energien entsprechend gleichmäßig verteilt. Diese Energieverteilung wird zunächst durch ein Wachsen der Flanke zu kleinen Energien, breiter solange kleinere Bindungscluster entstehen. Wenn kleine Cluster zu einem großen Cluster kondensieren zieht 

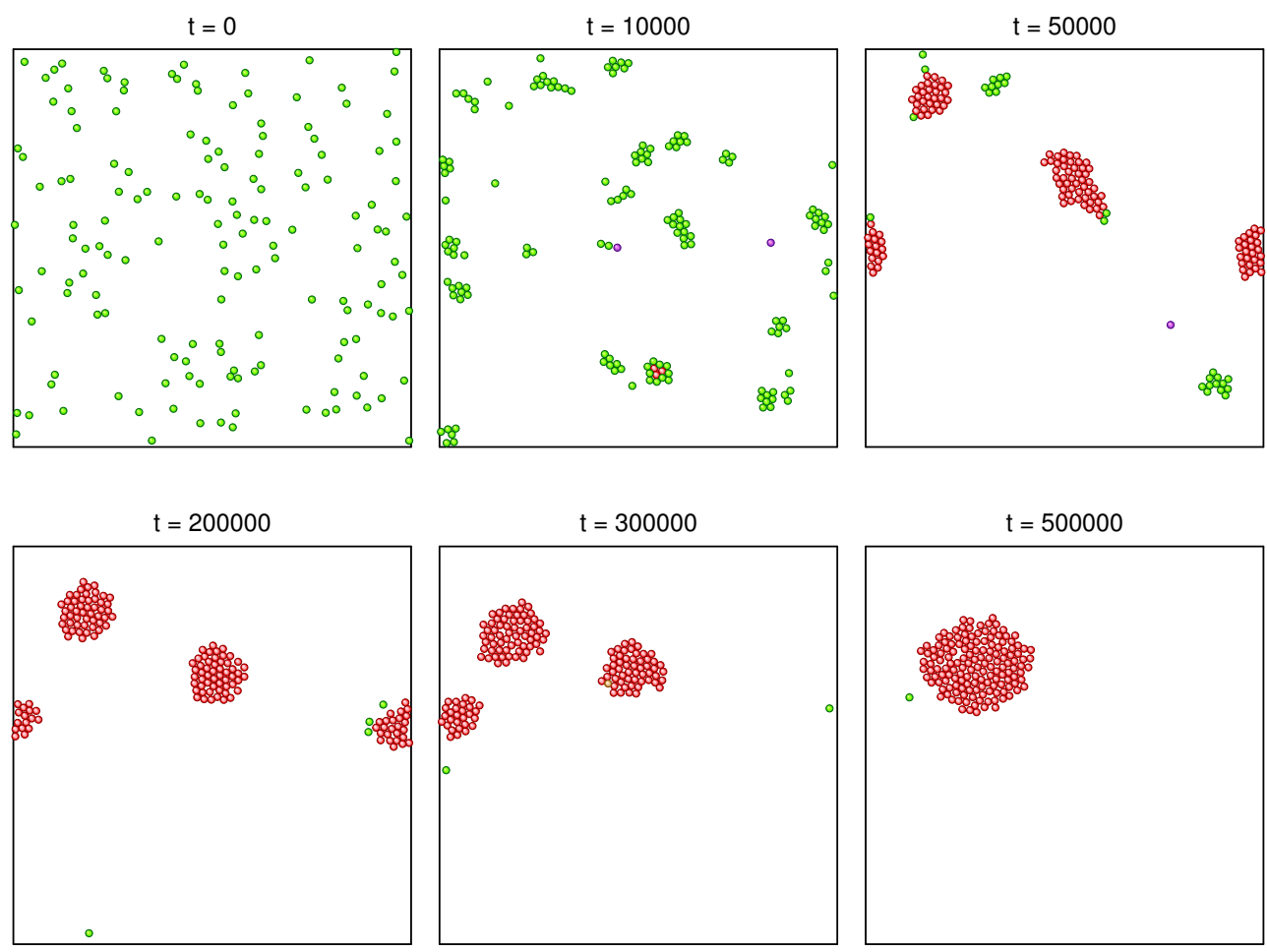

Abbildung 5.9: Entwicklung der Bindungskonfiguration einer Simulation mit $N=150$ Bindungen und Boltzmann-Dynamik. $t$ gibt die Iteration an, bei der die gezeigte Konfiguration vorliegt. In grün sind geschlosssen metastabile Bindungen gezeigt, in blau instabile und in rot stabile Bindungen. Offen stabile Bindungen sind lila gefärbt und offen metastabile Bindungen braun. Im Verlauf der Simulation entwickelt sich die zunächst überwiegend metastabile homogene Konfiguration hin zu einem Bindungscluster aus stabilen Bindungen.

sich die Verteilung der Energie zu niedrigen Werten zusammen und entwickelt sich zu einer schmalen Verteilung bei kleinen Energiewerten wenn ein stabiler Bindungcluster vorliegt.

Es ist möglich stabile Cluster zu erhalten, wenn die Raten auf die übrigen Simulationsparameter abgestimmt werden. Ein Problem bei der Wahl der on-off-Parameter ist, dass Parameter die zu Beginn einer Simulation mit homogener Bindungsverteilung gerade so viel Dynamik zulassen, dass nicht alle Bindungen aufreissen in der später geclusterten Konfiguration kaum noch Auswirkungen haben. Die Assoziations -und Dissoziatinsraten sind also abhängig von der Bindungskonfiguration. Das ist ein grundlegendes Problem, das in dieser Arbeit auftaucht und auch in realen biologischen Systemen eine große Rolle spielen könnte.

Aus diesem Grund wird später mit einer geclusterten Anfangskonfiguration simuliert um Dynamik am Bindungscluster untersuchen zu können. Dies wird in Abhängigkeit des Clusterradius und der Dichte der Bindungen im Cluster untersucht. 


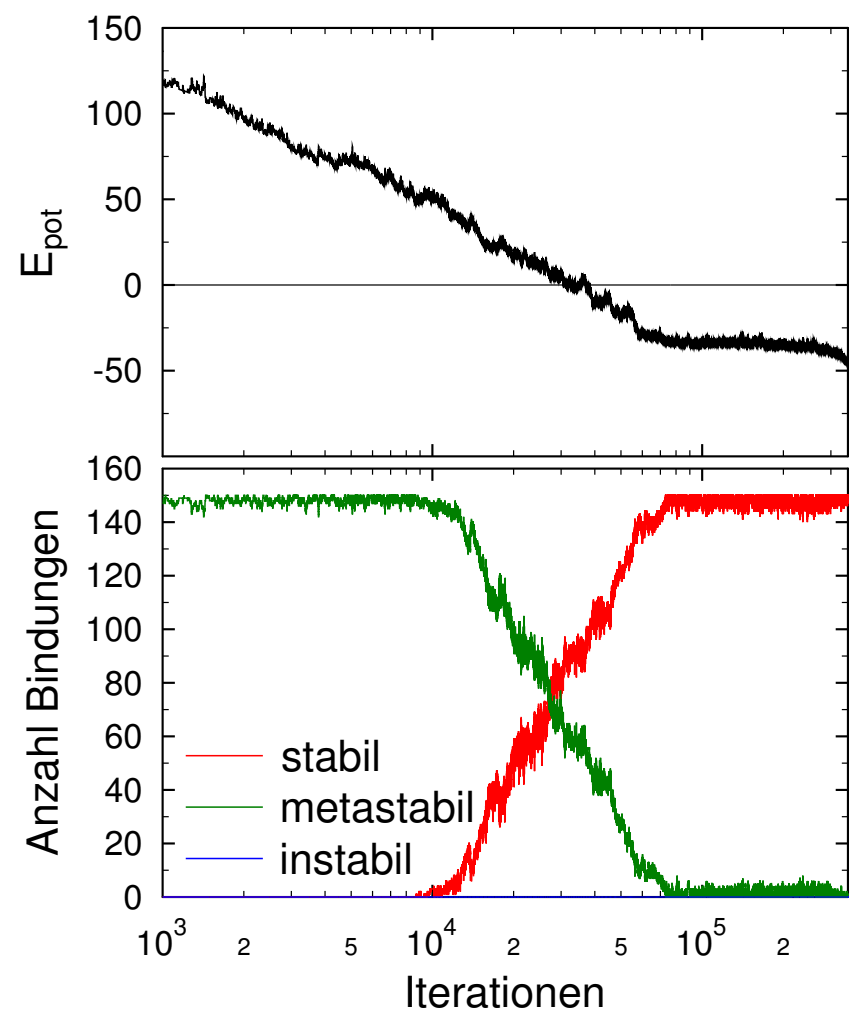

Abbildung 5.10: Potentieller Energieverlauf während der Simulation. Nach einer bestimmten Anzahl an Iterationen wird die Energie negativ und das System damit stabil. Unten ist ausgehend von einer Bindungsanzahl von 150 gezeigt, wie sich diese während der Simulation auf die drei möglichen geschlossenen Zustände (stabil, metastabil, instabil) aufteilen. Zu Beginn sind die meisten Bindungen metastabil, aber mit zunehmender Clusterbildung entstehen auch stabile Bindungen, welche am Ende der Simulation die Mehrheit darstellen. 


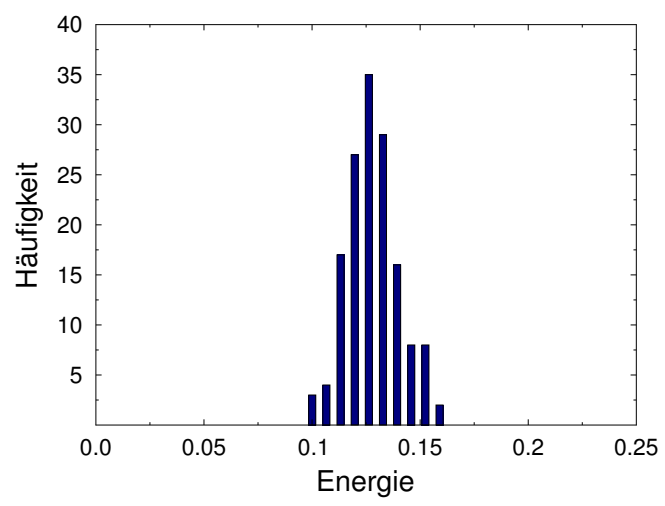

(a) Ausgangskonfiguration

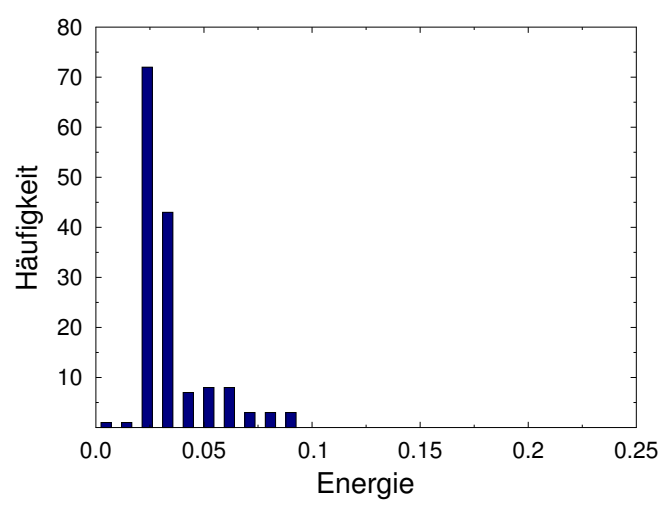

(c) nach 50000 Iterationen

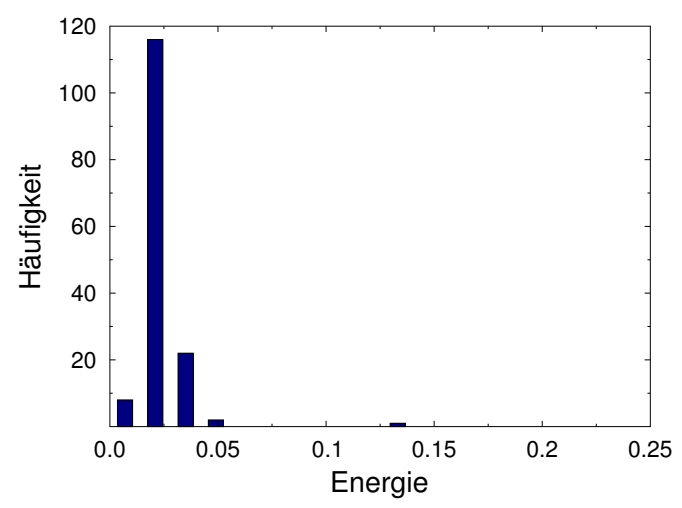

(e) nach 300000 Iterationen

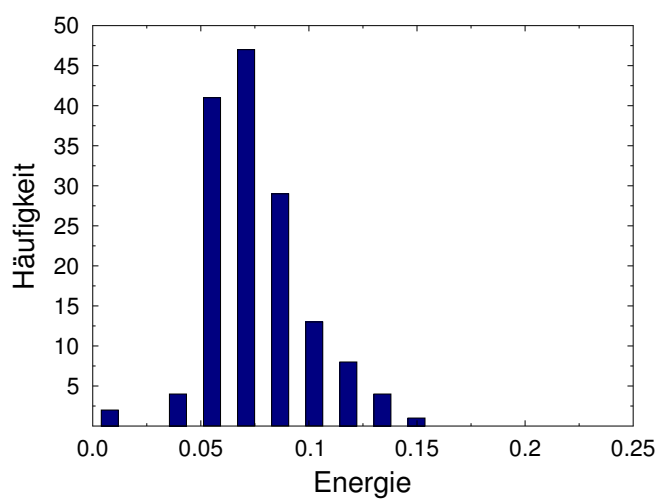

(b) nach 10000 Iterationen

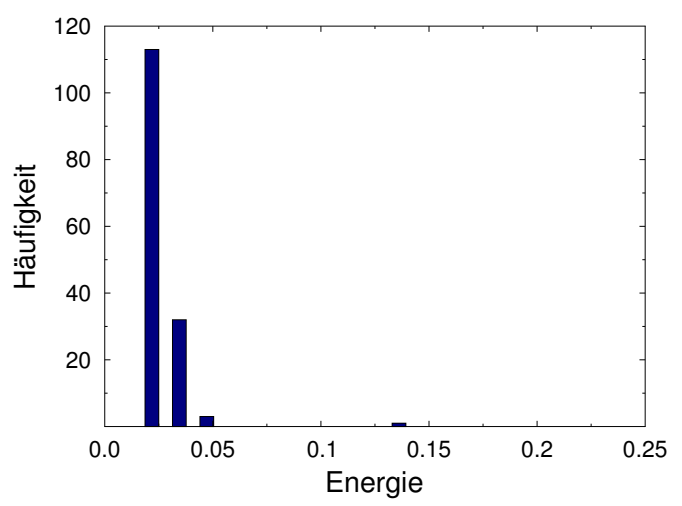

(d) nach 200000 Iterationen

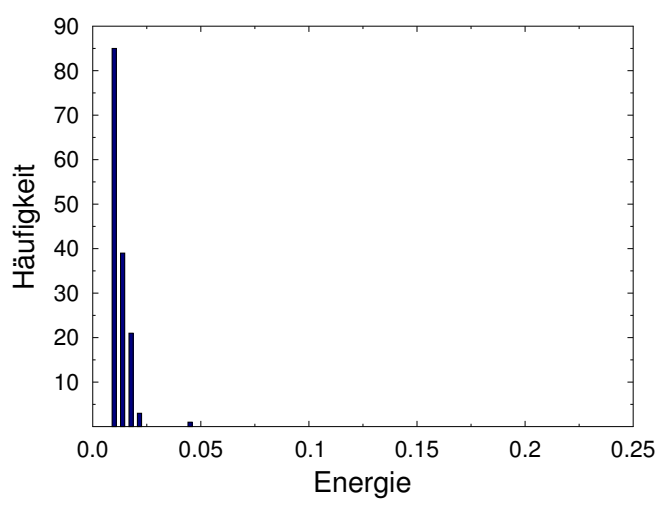

(f) nach 500000 Iterationen

Abbildung 5.11: Häufigkeit der Energiewerte auf die Bindungen für verschiedene Zeitpunkte der Simulation entsprechend der in 5.9 gezeigten Bindungskonfigurationen. 


\subsubsection{Lebenszeit einer Bindungskonfiguration}

Die Lebenszeit von zufällig verteilten homogenen Bindungskonfigurationen wird in Abhängigkeit der Dissoziationsparameter untersucht. Die Lebenszeit als Funktion von $k_{\text {off }}^{0}$ wird für verschiedene $F_{\mathrm{a}}^{\text {off }}$ ermittelt. Sind die Konfigurationen nach 50000 Iterationen noch intakt werden sie als stabil angenommen. Je Wertepaar werden 100 verschiedene Zufallszahlenfolgen verwendet. Es werden Werte von $k_{\text {off }}^{0}$ zwischen $10^{-6}$ und $10^{-3}$ simuliert. Für $F_{a}^{\text {off }}$ werden die Werte 1,$0 ; 3,0 ; 10,0$ und 100,0 eingesetzt. $E_{a}^{\text {on }}=5,0$ und $k_{\mathrm{on}}^{0}=10$ werden an dieser Stelle nicht variiert.

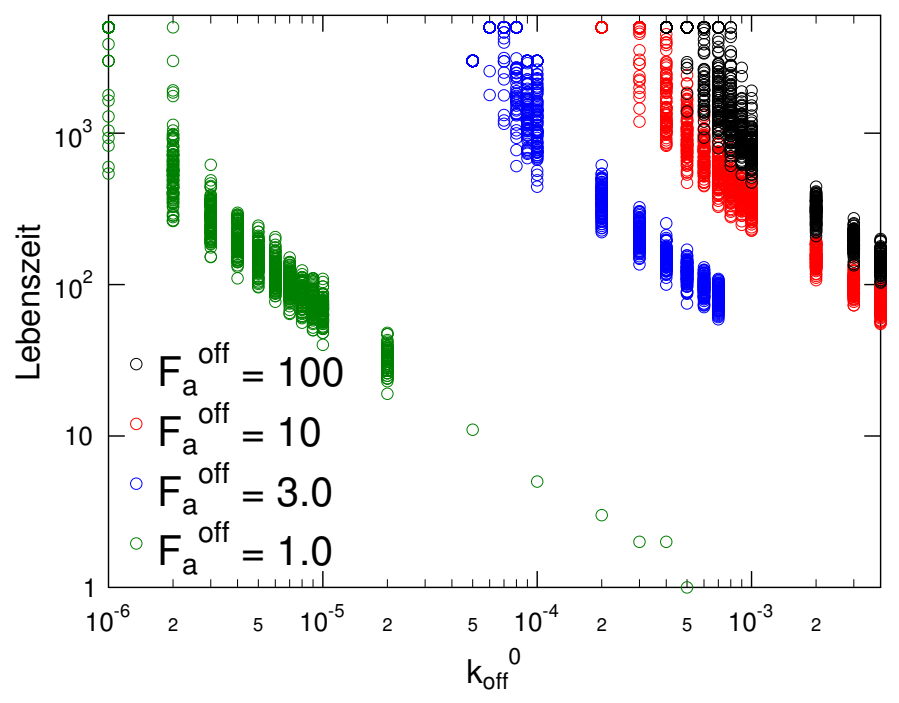

Abbildung 5.12: Lebenszeit von Bindungskonfigurationen in Abhängigkeit der für die Dissoziation verantwortlichen Parameter. Sind die Konfigurationen nach 50000 Iterationen noch intakt werden sie als stabil angenommen.

In der doppellogarithmischen Auftragung der Lebenszeit gegen $k_{\text {off }}^{0}$ in Abbildung 5.12 sieht man einen linearen Zusammenhang. Je größer der Wert für $F_{\mathrm{a}}^{\text {off }}$, desto länger die Lebenszeit der Konfiguration. Ebenso stabilisieren kleinere $k_{\text {off }}^{0}$ entsprechend Gleichung 4.26 die Bindungskonfiguration. 


\subsubsection{Clusterstabilität}

Im Folgenden wird die Stabilität der Cluster genauer untersucht. Dafür wird zunächst eine kreisförmige Anfangskonfiguration generiert und parallel dazu in weiteren Simulationen vier gleich große Cluster in den Zentren der Quadranten der Simulationsbox positioniert und deren Stabilität untersucht.

\subsubsection{Simulation eines Clusters}

In der hier gezeigten Simulation beträgt der Radius des Clusters zu Beginn der Simulation 1000. Durch die bereits bestehende Clusterung zu Beginn, ist es möglich destabilisierendere Parameter für die Bestimmung der Öffnungswahrscheinlichkeit zu verwenden. Dies hat zur Folge, dass während der Simulation mehr offene Bindungen existieren, siehe Abbildung 5.13. Die eingesetzten Parameter für die im Folgenden gezeigte Simulation sind $k_{\text {off }}^{0}=2 \cdot 10^{-3} ; F_{\mathrm{a}}^{\text {off }}=3,0 k_{\mathrm{on}}^{0}=1,0$ und $E_{\mathrm{a}}^{\text {on }}=10,0$.
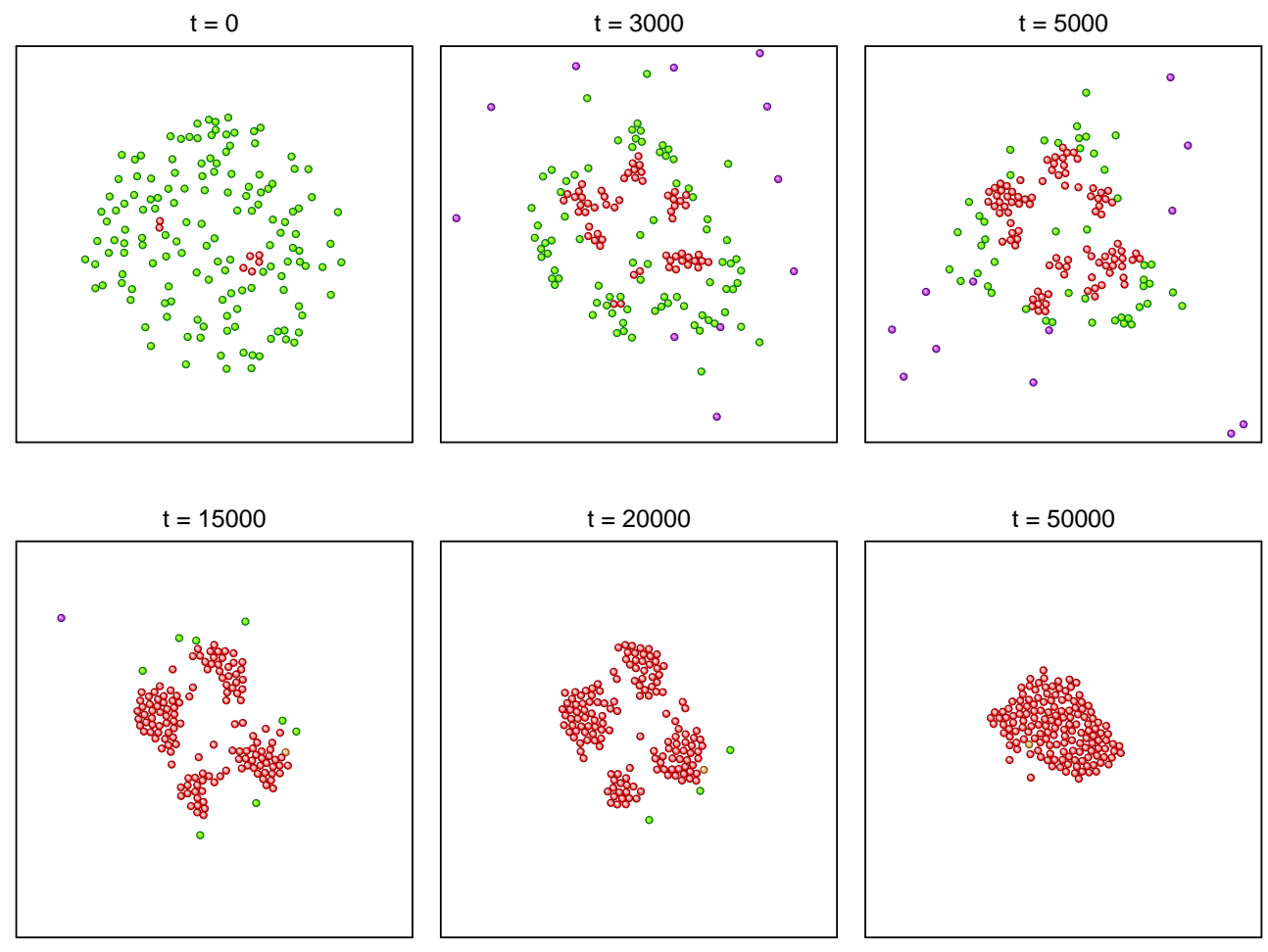

Abbildung 5.13: Entwicklung einer initial geclusterten Bindungskonfiguration mit einem Radius $r=1000$ und $N=150$ Bindungen. $t$ gibt die Iteration an, bei der die gezeigte Konfiguration vorliegt. In grün sind geschlosssen metastabile Bindungen gezeigt, in blau instabile und in rot stabile Bindungen. Offen stabile Bindungen sind lila gefärbt und offen metastabile Bindungen braun. Im Verlauf der Simulation entwickelt sich die zunächst überwiegend metastabile Konfiguration hin zu einem Bindungscluster aus stabilen Bindungen. 
Die Bindungen des metastabilen Clusters mit Radius $r=1000$ bilden zunächst vier Cluster aus stabilen Bindungen. Diese vier Cluster verschmelzen im Simulationsverlauf zu einem großen Cluster aus allen Bindungen. Bei $t=3000$ und $t=5000$ ist die Anzahl geschlossener Bindungen auf Grund der hohen Öffnungswahrscheinlichkeit geringer als in der Anfangskonfiguration.

Die potentielle Energie einer bereits geclusterten Anfangskonfiguration ist niedriger als die einer homogenen Bindungsverteilung, siehe Abbildung 5.14.

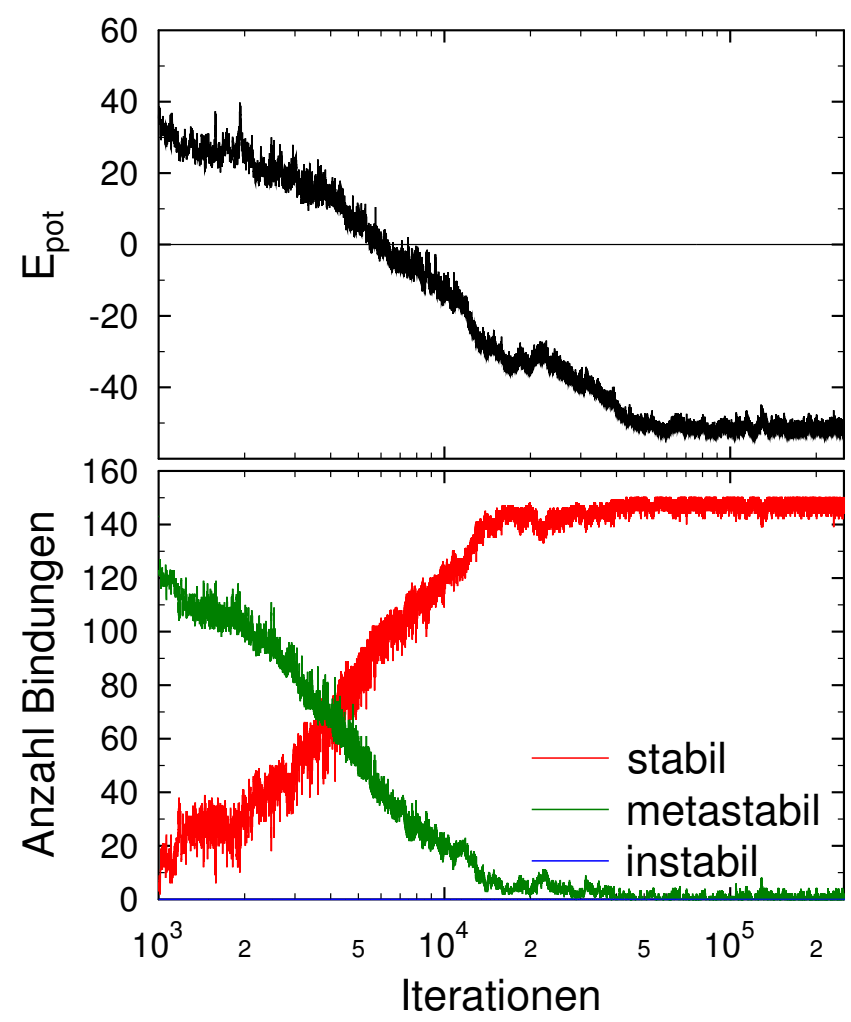

Abbildung 5.14: Potentieller Energieverlauf während der Simulation. Nach einer bestimmten Anzahl an Iterationen wird die Energie negativ und das System damit stabil. Unten ist ausgehend von der Bindungsanzahl von 150 gezeigt, wie sich die Bindungen während der Simulation auf die drei möglichen geschlossenen Zustände (stabil, metastabil, instabil) aufteilen. Zu Beginn sind die meisten Bindungen metastabil, aber mit zunehmender Clusterbildung entstehen auch stabile Bindungen, welche am Ende der Simulation die Mehrheit darstellen.

Wie bereits beschrieben werden während der Simulation metastabile Bindungen in stabile Bindungen konvertiert und die Energie sinkt auf negative Werte.

Auch für die Simulation der geclusterten Anfangskonfiguration dienen Histogramme zur Untersuchung der Energieverteilung über die Bindungen im Simulationsverlauf. Die Energieverteilung wird bei $t=3000$ zunächst breiter und es kommen höhere Energien vor. Das liegt zum einen daran, dass die Gesamtzahl der geschlossenen Bindungen kleiner ist und damit die Last pro Bindung steigt. Zum anderen beginnen die Bindungen kleinere Cluster zu bilden und es bilden sich stabile Bindungen, der Energieunterschied zwischen den verschiedenen Bindungen wird damit größer. Mit der Bildung eines stabilen Clusters wird die Verteilung der Energien schmaler und verschiebt sich zu kleineren Werten. 


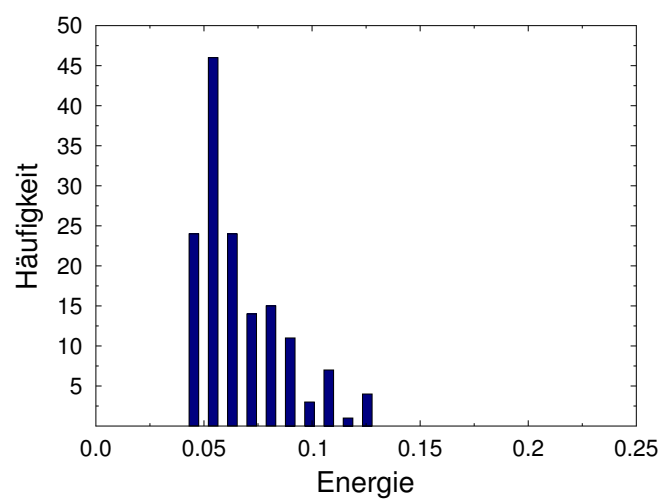

(a) Ausgangskonfiguration

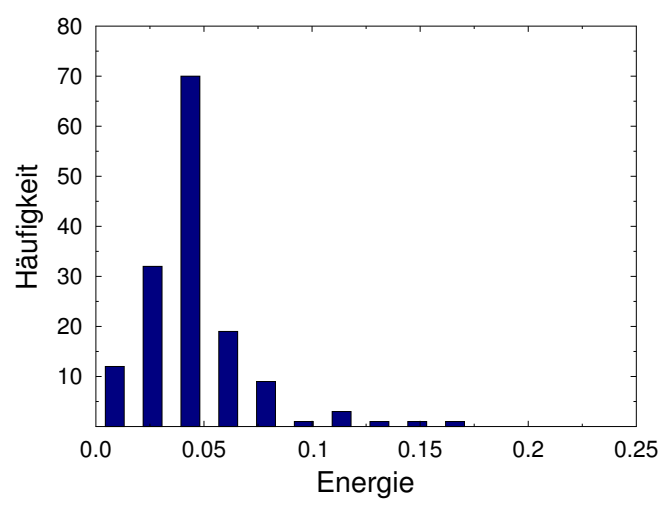

(c) nach 5000 Iterationen

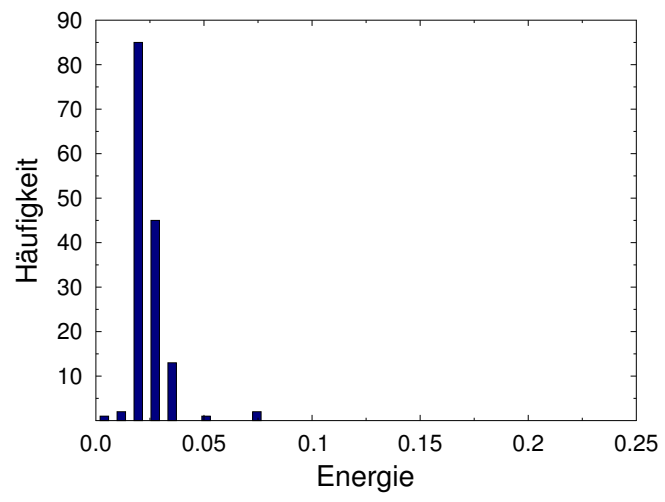

(e) nach 20000 Iterationen

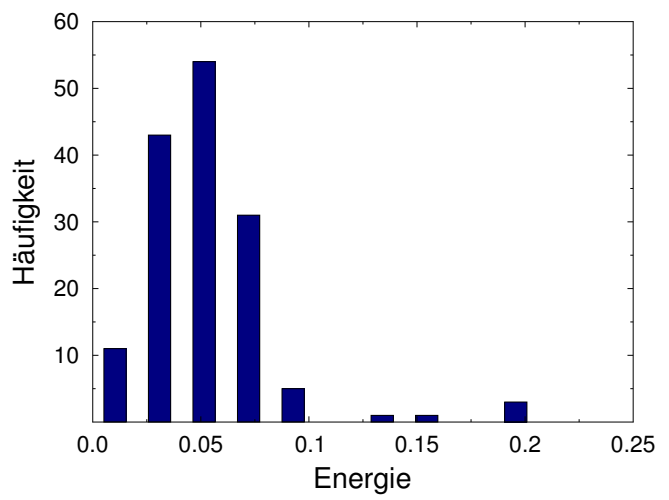

(b) nach 3000 Iterationen

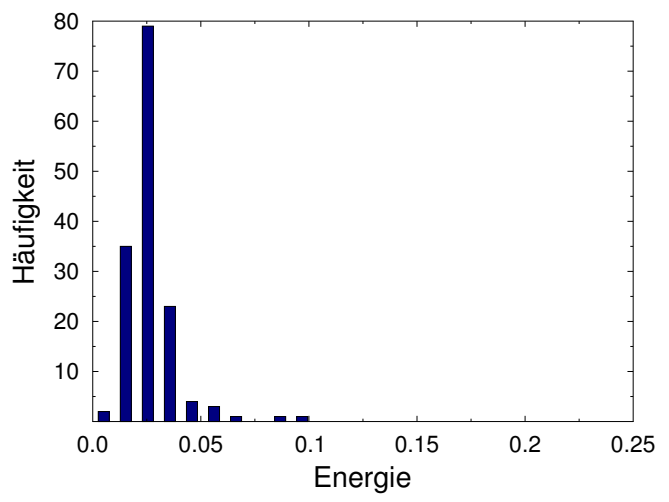

(d) nach 15000 Iterationen

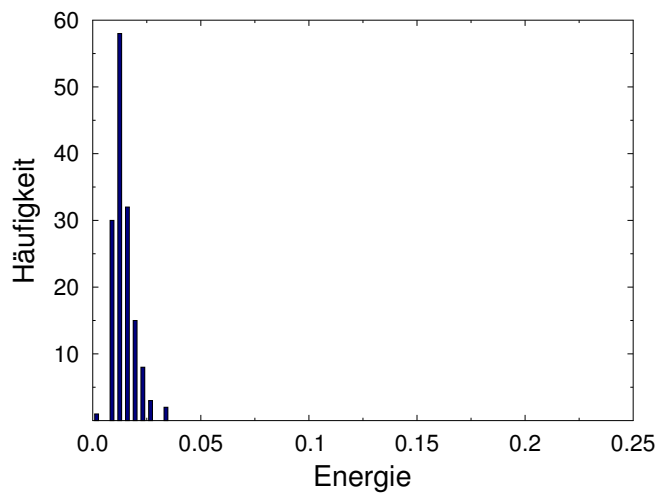

(f) nach 50000 Iterationen

Abbildung 5.15: Energieverteilung über die Bindungen während einer Simulation mit einer geclusterten Anfangskonfiguration mit dem Radius $r=1000$. 
Lebenszeiten der Bindungen Die Entwicklung der Lebenszeit der Bindungen im Verlauf der Clusterbildung gibt Aufschluss über eventuelle Reifeprozesse der Konfiguration durch Übergang einer homogenen Bindungsverteilung zu einem Bindungscluster. $^{2}$ Es können mittlere Lebenszeiten von Bindungen als Funktion ihres Entstehungszeitpunktes ausgewertet werden. Diese sind abhänig von der Konfiguration der Bindungen und den eingestellten Boltzmann-Wahrscheinlichkeiten.

Die mittlere Lebenszeit der Bindungen als Funktion ihrer Entstehungszeit ist in Abbildung 5.16 für die hier gezeigte Simulation dargestellt.

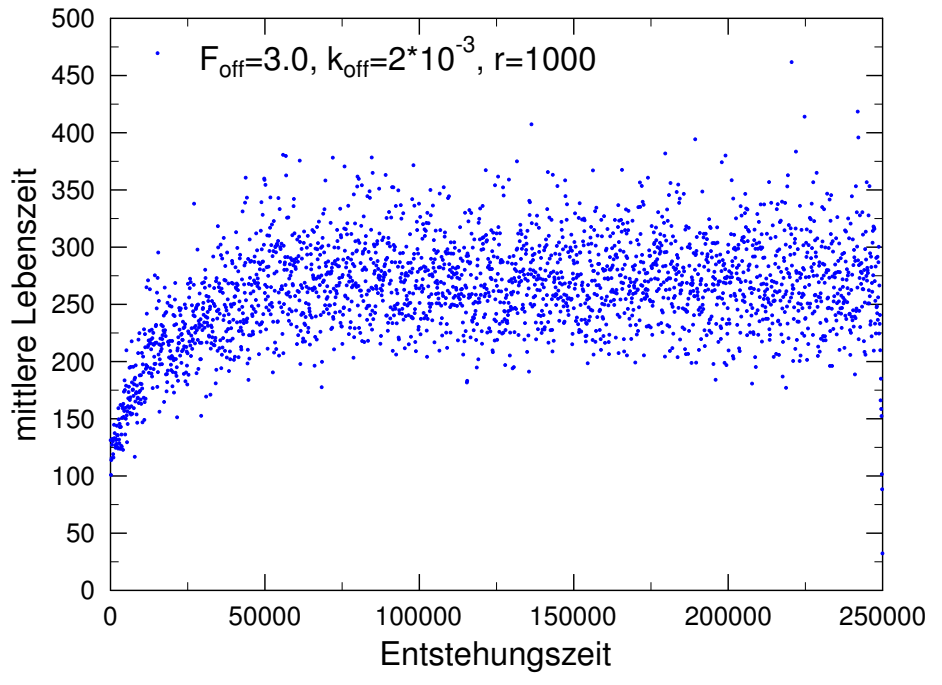

Abbildung 5.16: Mittlere Lebenszeit der Bindungen als Funktion ihres Entstehungszeitpunktes. Für die Anfangskonfiguration mit einem Cluster von $r=1000$ liegen die Lebenszeiten der Bindungen zwischen 100 und 200. Bei $t=50000$ liegt bereits ein dicht gepackter stabiler Cluster vor und die Lebenszeiten der Bindungen haben Werte zwischen 200 und 350.

Anhand dieses Graphen sieht man die Abhängigkeit der mittleren Lebenszeit von der Gesamtkonfiguration der Bindungen. Von $t=0$ bis $t=50000$ Iterationen erfolgt der Übergang eines losen Bindungscluster mit $r=1000$ zu einem dicht gepackten stabilen Cluster. In diesem Zeitraum steigt die mittlere Lebenszeit stetig an. Bei $t=50000$ ist ein Plateau erreicht und die mittleren Lebenszeiten im dicht gepackten stabilen Bindungscluster bewegen sich zwischen 200 und 350. Das Wachstum des Clusters entspricht also einem Reifeprozess, in dessen Verlauf die Adhäsionsbindungen an Stabilität gewinnen und dadurch eine längere Lebenszeit erhalten.

${ }^{2}$ Dieser Prozess entspricht der Ostwald-Reifung. 


\subsubsection{Attraktive Wechselwirkungen zwischen Bindungsclustern}

Simulationen beginnend mit einer homogenen Bindungsverteilung und die eines Clusters variablen Radius führen immer zu einem Cluster aus allen $N$ Bindungen. Simulationen ausgehend von vier gleich großen Clustern in den Zentren der Quadranten der Simulationsbox sollen Informationen über die Stabilität kleiner Cluster gegenüber einem großen Cluster, sowie die attraktiven Wechselwirkungen zwischen Bindungsclustern geben. Die vier Cluster haben in den gezeigten Simulationen jeweils einen Radius $r=300$ und bestehen aus 37 Bindungen. Die erste gezeigte Simulation wird mit einer reduzierten Federkonstante von $\kappa=0,1$ durchgeführt. Die vier Cluster sind zu Beginn überwiegend aus metastabilen Bindungen aufgebaut, siehe Abbildung 5.17.
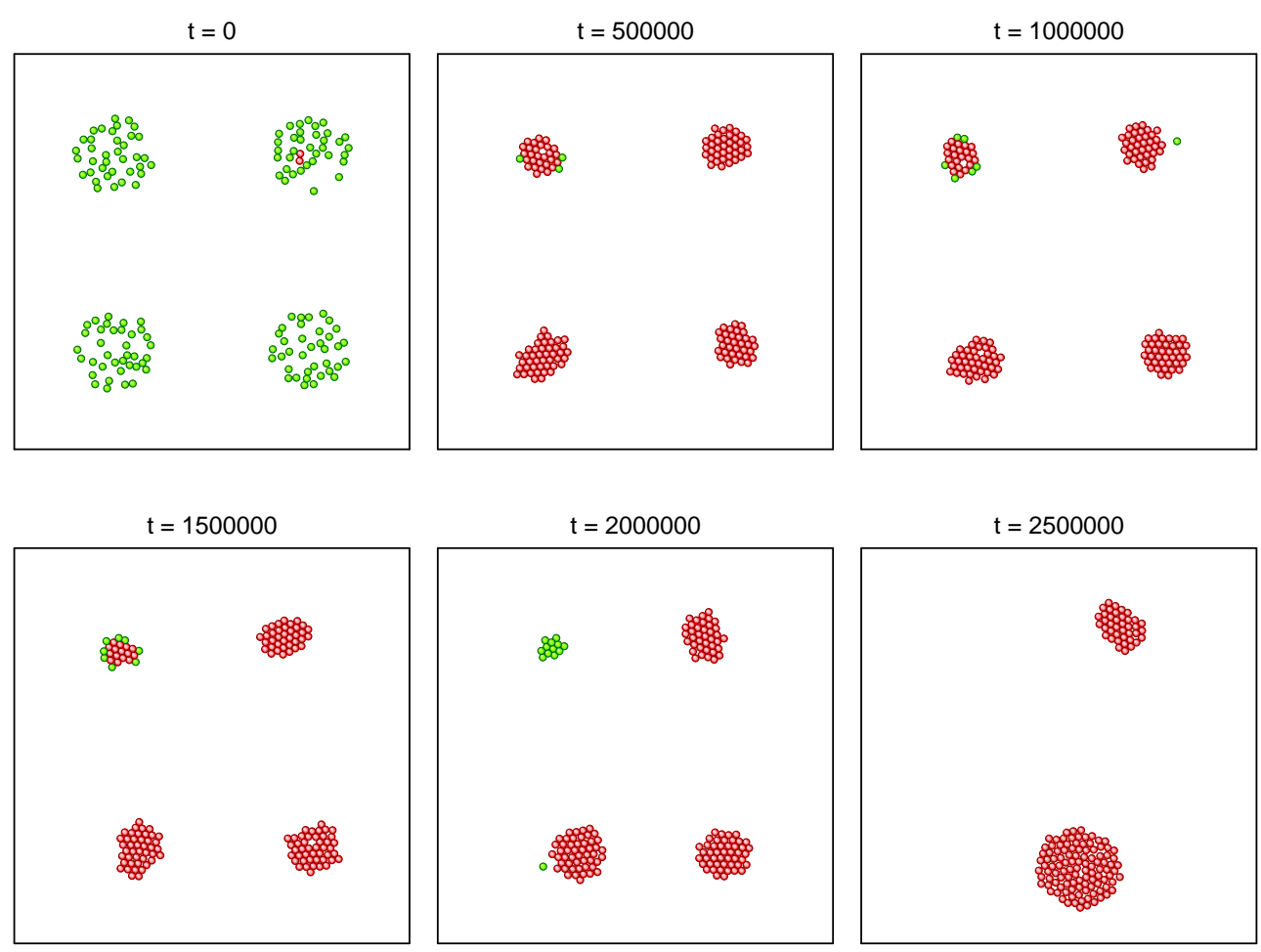

Abbildung 5.17: Zeitverlauf der Bindungskonfiguration ausgehend von vier gleich großen Clustern aus insgesamt $N=148$ Bindungen. $t$ gibt die Iteration an, bei der die gezeigte Konfiguration vorliegt. In grün sind geschlosssen metastabile Bindungen gezeigt und in rot stabile Bindungen.

In der Anfangsphase erhöht sich die Dichte der Bindungen innerhalb der vier Cluster bei gleichbleibender Bindungsanzahl und nach 50000 Iterationen haben sich die metastabilen Bindungen einander angenähert und dadurch stabilisiert. Im weiteren Verlauf sieht man, dass die Bindungsanzahl des Clusters links oben abnimmt und dieser ab einem gewissen Zeitpunkt wieder metastabil wird. Nach 250000 Iterationen sind lediglich noch zwei stabile Cluster vorhanden, welche vorraussichtlich bei längerer Simulationszeit zu einem Cluster verschmelzen würden. Der in Abbildung 5.18 gezeigte Verlauf 
der potentiellen Energie zeigt, dass die Energie der Startkonfiguration geringer ist als die der geclusterten Startkonfiguration mit $r=1000$. Die Anziehung der Bindungen und der damit verbundenn Bildung vier stabiler Cluster führt zu einem Absinken der Energie auf circa -20. Auf diesem Niveau bleibt die Energie fast bis zum Ende der Simulation, bis sie nochmal deutlich abfällt. Dieser Abfall bei circa $2 \cdot 10^{6}$ Iterationen ist auf die Verschmelzung der Bindungscluster zurückzuführen.

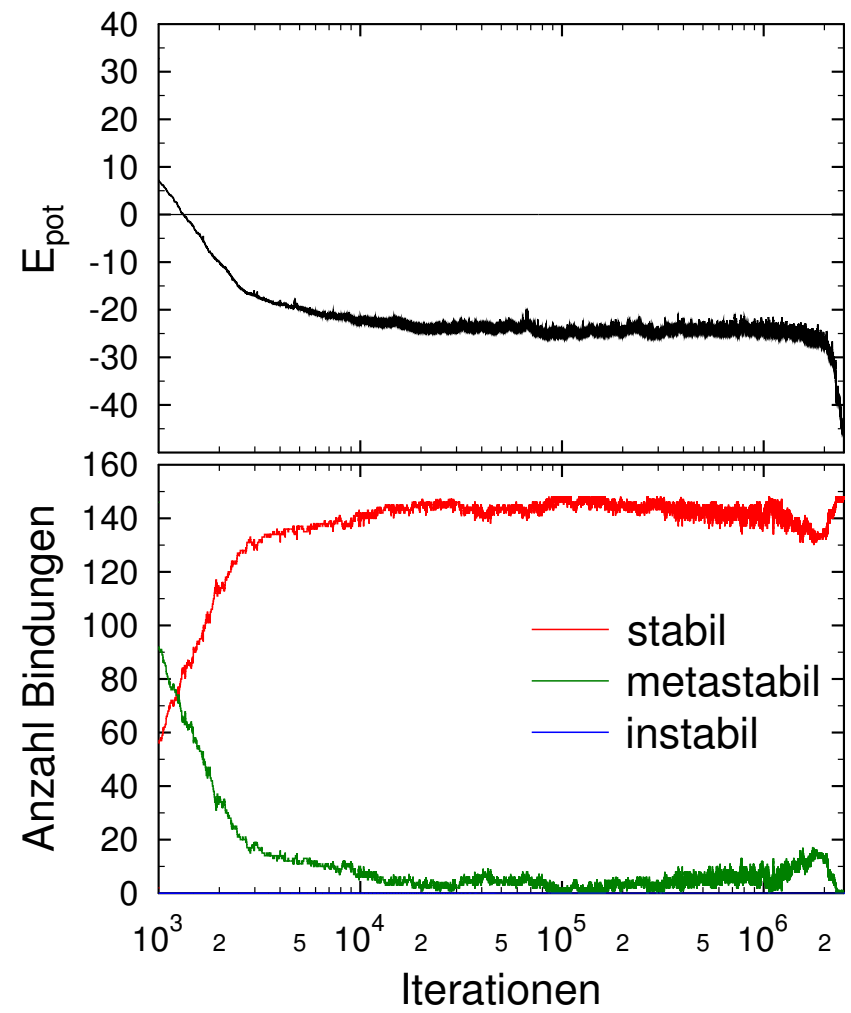

\begin{abstract}
Abbildung 5.18: Verlauf der potentiellen Energie und der Anzahl geschlossener Bindungszustände. Ausgehend von vier Bindungsclustern aus je 37 Bindungen.
\end{abstract}

Auch die Anzahl stabiler Bindungen steigt zu Beginn stetig an und verläuft dann entsprechend der Energie auf einem konstanten Wert.

Um den Einfluss der Membranelastizität auf die attraktiven Wechselwirkungen von Bindungsclustern zu untersuchen wird in einer weiteren Simulation ein Wert $\kappa=0,2$ verwendet. Wiederum haben die vier Bindungscluster je einen Radius $r=300$ und bestehen aus je 37 Bindungen. Abbildung 5.19 zeigt Bindungsanordnungen zu sechs verschiedenen Zeitpunkten der Simulation.

Die Konfigurationen bei $t=2,5 \cdot 10^{5}$ und $t=7,5 \cdot 10^{5}$ zeigen, dass ein Annähern der Bindungen innerhalb der Ursprungscluster bei $\kappa=0,2$ nicht ausreichend ist um alle Bindungen zu stabilisieren. Lediglich die Bindungen im Zentrum der Cluster sind stabil und von metastabil geschlossenen Bindungen umgeben. Anhand der Konfigurationen bei $t=1 \cdot 10^{6}$ und $t=1,5 \cdot 10^{6}$ sieht man, dass sich die Bindungscluster aufeinander zu bewegen und schließlich bei $t=2 \cdot 10^{6}$ einen stabilen Cluster aus allen Bindungen bilden. 

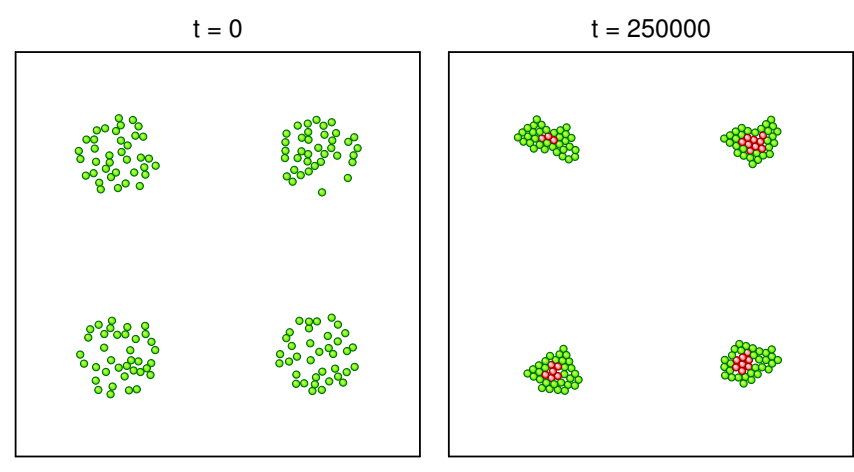

$t=1000000$

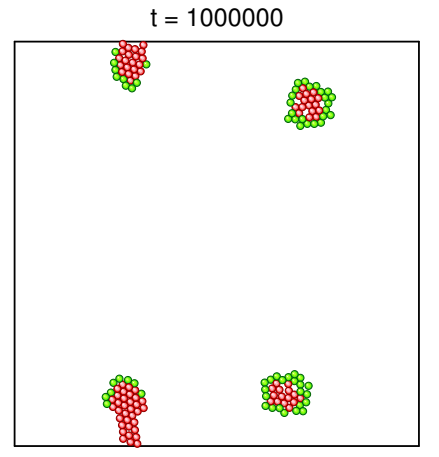

$t=1500000$

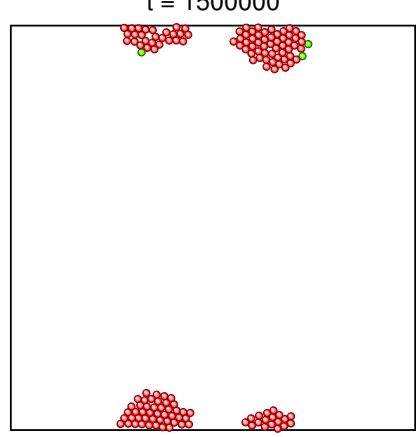

$t=750000$

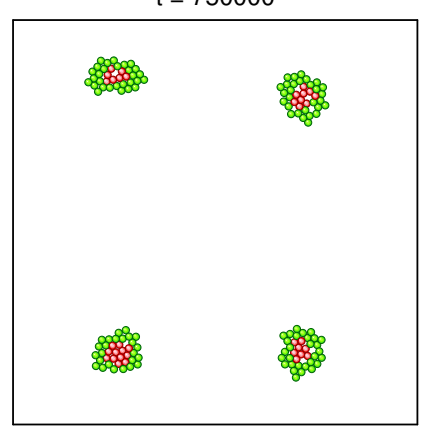

$t=2000000$

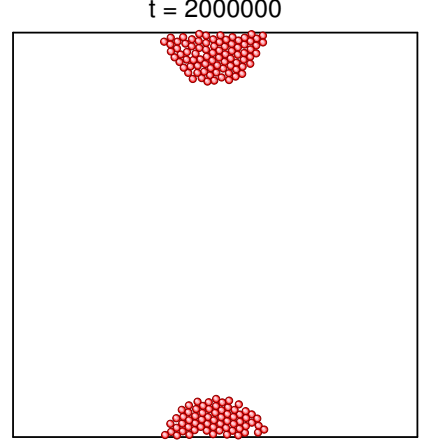

Abbildung 5.19: Entwicklung der Bindungskonfiguration ausgehend von vier Bindungscluster mit je 37 Bindungen und $\kappa=0,2 . t$ gibt die Iteration an, bei der die gezeigte Konfiguration vorliegt. In grün sind geschlosssen metastabile Bindungen und in rot stabile Bindungen gezeigt. Vier metastabile Cluster verschmelzen innerhalb von $2 \cdot 10^{6}$ Iterationen zu einem stabilen Cluster.

Enstprechend des höheren $\kappa$-Wertes ist die Energie zu Beginn der Simulation höher als in der zuvor gezeigten Simulation, siehe Abbildungen 5.18 und 5.20. Die Energie fällt im Anfangsbereich stetig ab, bis sich die Bindungen innerhalb der Cluster bei circa $t=1 \cdot 10^{4}$ angenähert haben und erste stabile Bindungen in den Zentren der Cluster entstehen. Nach diesem ersten Stabilisierunsgprozess bleibt die Energie auf einem Wert von ungefähr 20, bis sie bei $t=1 \cdot 10^{6}$ Simulationsschritten weiter abfällt. Wie in Abbildung 5.19 gezeigt, beginnen die Cluster hier zu verschmelzen und damit werden weitere stabile Bindungen erzeugt. 


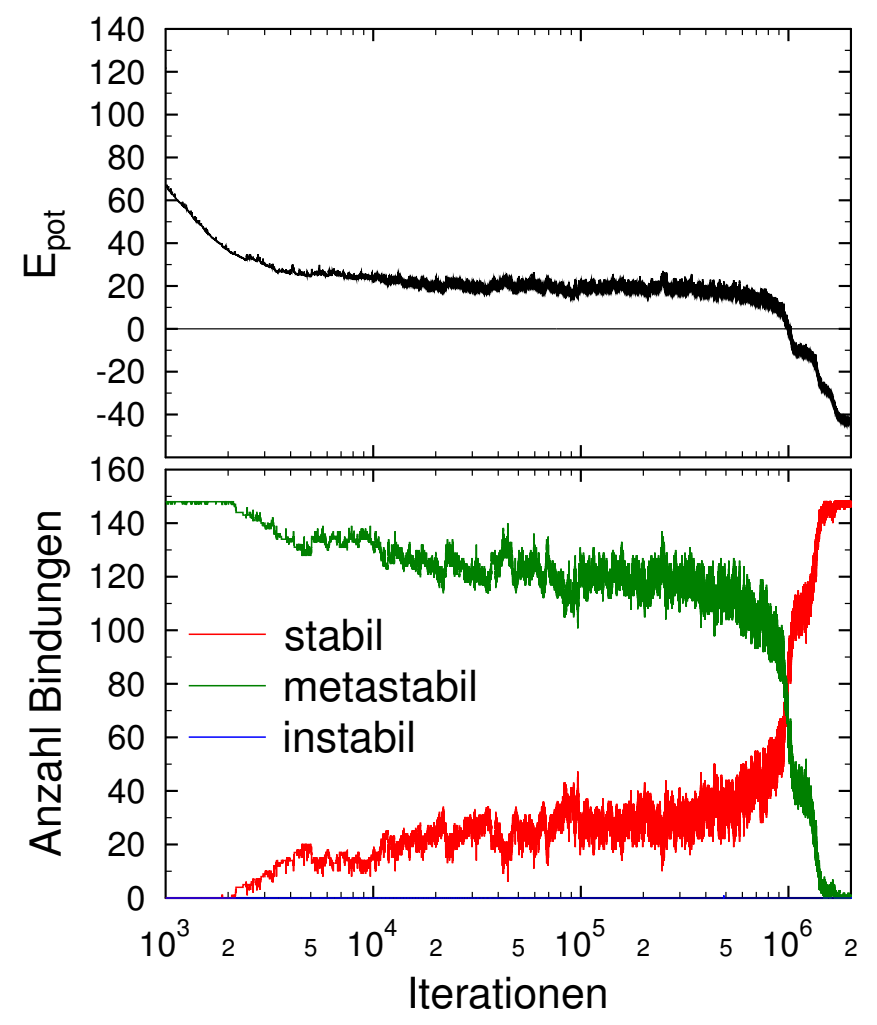

Abbildung 5.20: Potentieller Energieverlauf während der Simulation. Nach einer bestimmten Anzahl an Iterationen wird die Energie negativ und das System damit stabil. Unten ist ausgehend von einer Bindungsanzahl von 148 gezeigt, wie sich diese während der Simulation auf die drei möglichen geschlossenen Zustände (stabil, metastabil, instabil) aufteilen. Zu Beginn sind die meisten Bindungen metastabil, aber mit zunehmender Clusterbildung entstehen auch stabile Bindungen, welche am Ende der Simulation die Mehrheit darstellen. 


\subsubsection{Kraftverteilung innerhalb der Bindungscluster}

Die Kraftverteilung in geclusterten Anfangskonfigurationen wird untersucht, in dem die Kraft auf die Bindungen als Funktion zum Abstand des Massezentrums (center of mass, COM) aufgezeichnet wird. Hier werden immer 100 Konfigurationen mit unterschiedlicher Initiierung des Zufallszahlengenerators erzeugt und deren Kräfte berechnet. Es wird jeweils eine typische Anfangskonfiguration gezeigt.

Variation der Bindungsanzahl Wird die Bindungsanzahl bei gleichem Clusterradius $r=600$ und $\kappa=0,1$ variiert ergeben sich die in Abbildung 5.21 gezeigten Anfangskonfigurationen. Die Bindungsanzahl $N$ nimmt von links nach rechts von $N=150$ bis $N=50$ ab. Geschlossen stabile Bindungen sind rot, geschlossen metastabile Bindungen grün, offen stabile Bindungen lila und offen metastabile Bindungen braun dargestellt. Die Stabilität des Clusters nimmt mit der Bindungsanzahl ab. Bei $N=150$ Bindungen besteht der Cluster überwiegend aus stabilen Bindungen. Schon die Reduzierung auf $N=130$ Bindungen führt dazu, dass der Clusterrand metastabil wird. Besteht die Anfangskonfiguration aus $N=50-100$ Bindungen sind diese überwiegend geschlossen metastabil.

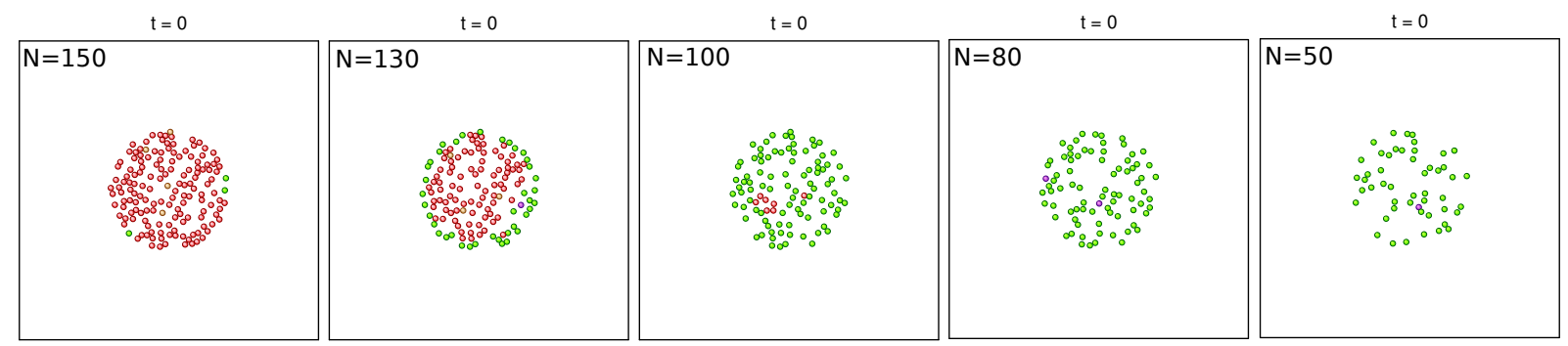

Abbildung 5.21: Anfangskonfiguration für Cluster unterschiedlicher Bindungsanzahl zwischen $N=150$ und $N=50$ mit $\kappa=0,1$. In grün sind geschlosssen metastabile Bindungen gezeigt, in blau instabile und in rot stabile Bindungen. Offen stabile Bindungen sind lila gefärbt und offen metastabile Bindungen braun.

Die Auftragung der Kraft auf die Bindungen als Funktion ihres Abstandes zum Massezentrum (COM) in Abbildung 5.21 gibt Aufschluss über die Kraftverteilung im Bindungscluster. Im Zentrum des Clusters tragen die Bindungen eine geringere Kraft als am Clusterrand. Die schwarze Kurve zeigt die Kraftverteilung in einem Cluster aus 150 Bindungen. Mit zunehmendem Abstand zum COM steigt die Kraft auf die Bindungen in geringem $\mathrm{Maße}$ an. Je weniger Bindungen den Cluster bilden, desto höher die Kraft pro Bindung.

Die Risskraft der Bindungen beträgt $f_{\text {rup }}=1$. Lediglich für den Cluster aus 50 Bindungen, erreichen Bindungen weit entfernt vom COM Kräfte dieser Höhe.

Durch die Erhöhung der Federkonstante der Membran auf einen Wert von $\kappa=0,4$, erreicht man eine Erhöhung der Kraft pro Bindung. Die Bindungskonfigurationen für Cluster verschiedener Bindungsanzahl für $\kappa=0,4$ ist in Abbildung 5.23 gezeigt. Im 


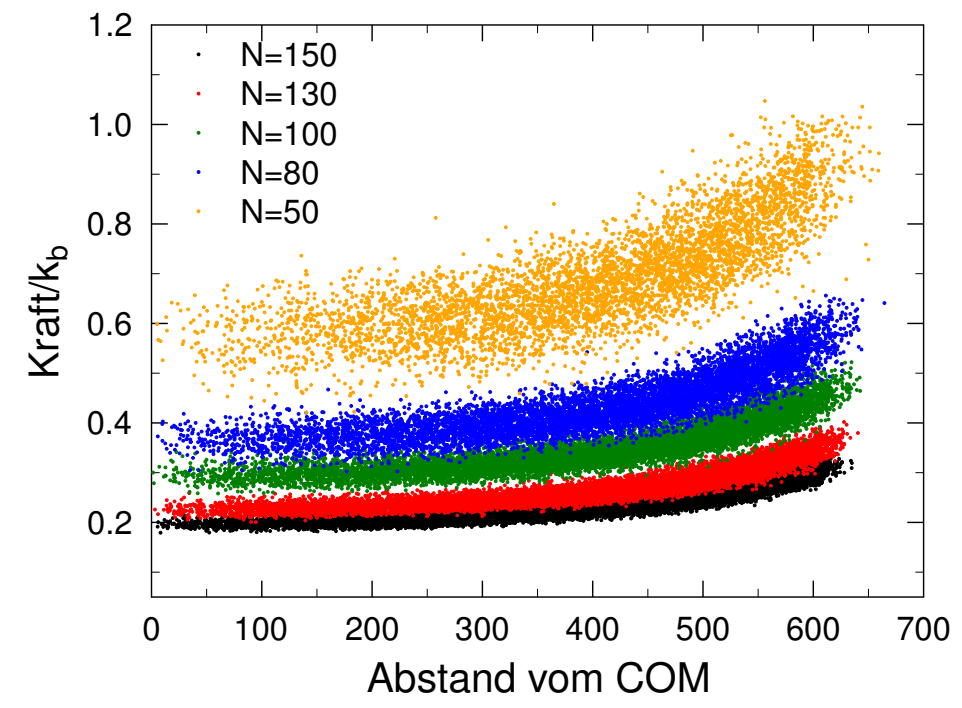

Abbildung 5.22: Kraft auf die Bindungen als Funktion des Abstandes vom Massezentrum des Clusters bei Variation der Bindungsanzahl mit $\kappa=0,1$ und $r=600$. Die Risskraft $f_{\text {rup }}$ einer Bindung beträgt 1 .

Vergleich zur Konfiguration mit $\kappa=0,1$ sind hier bereits im Cluster mit $N=150$ Bindungen überwiegend metastabile Bindungen vorhanden. Erniedrigung der Bindungsanzahl führt bereits in der Erzeugungsphase zu einem Zusammenziehen des Bindungsclusters um diesen zu stabilisieren (Abbildung 5.23).
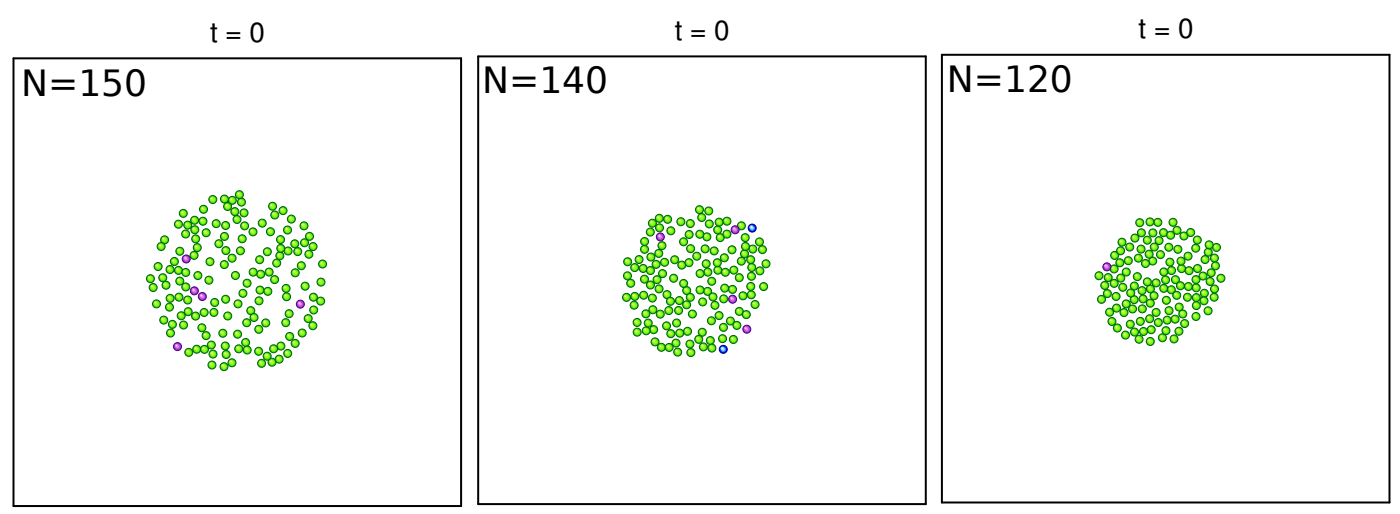

Abbildung 5.23: Anfangskonfiguration für Cluster unterschiedlicher Bindungsanzahl mit $\kappa=0,4$ und $r=600$. In grün sind geschlosssen metastabile Bindungen gezeigt, in blau instabile und in rot stabile Bindungen. Offen stabile Bindungen sind lila gefärbt und offen metastabile Bindungen braun.

Die Kraft pro Bindung als Funktion des Abstandes zum COM für einen Clusterradius $r=600$ und $\kappa=0,4$ ist in Abbildung 5.24 dargestellt. Die Anzahl der Bindungen im Cluster beträgt $N=150, N=140$ und $N=120$.

Abbildung 5.24 zeigt in schwarz die Kräfteverteilung auf die Bindungen für einen Cluster aus $N=150$, in rot für $N=140$ und in grün für $N=120$ Bindungen. Die Kraft auf die Bindungen ist größer, wenn der Cluster aus weniger Bindungen aufgebaut ist. Am Clusterrand sind die Bindungen Kräften ausgesetzt die größer sind als die Risskraft $f_{\text {rup }}=1$ 


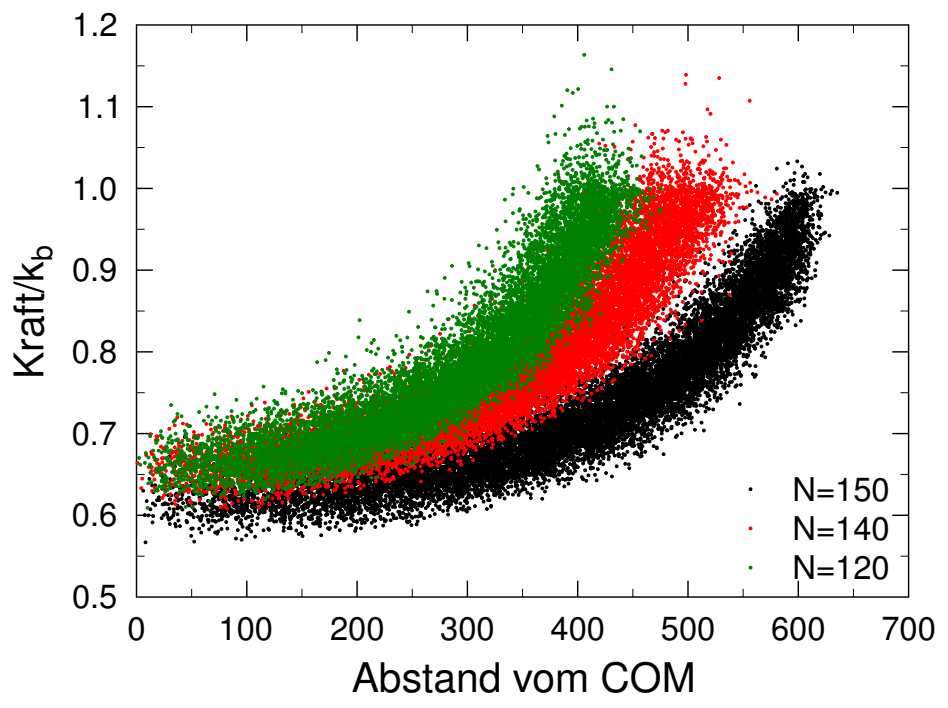

Abbildung 5.24: Kräfteverteilung auf die Bindungen als Funktion des Abstandes vom Zentrum des Clusters für $\kappa=0,4$ und $r=600$.

Variation des Clusterradius In diesem Abschnitt wird der Radius des Bindungsclusters $r$ bei konstanter Bindungsanzahl $(N=150)$ zwischen 450 und 1050 variiert. Abbildung 5.25 zeigt die Anfangskonfigurationen der verschieden stark ausgedehnten Bindungscluster.

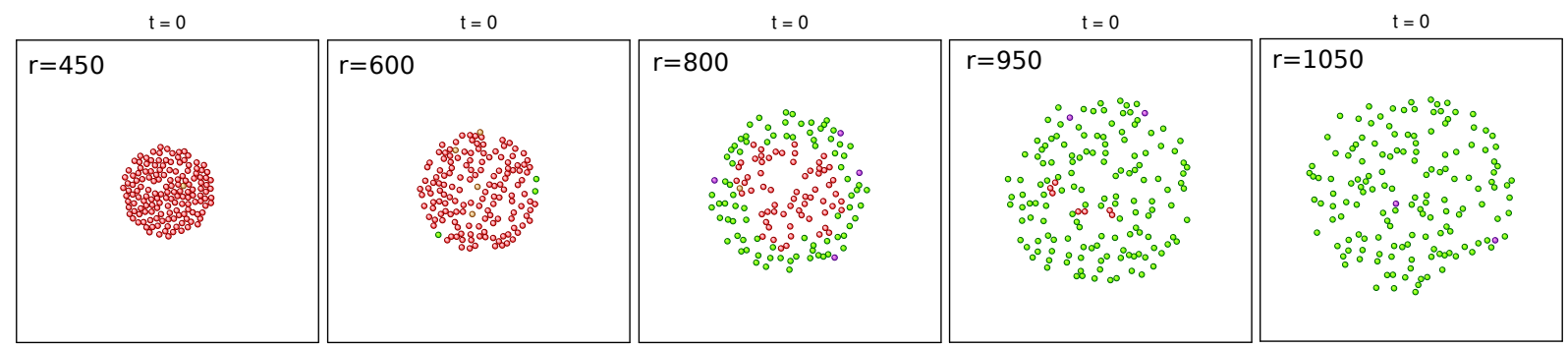

Abbildung 5.25: Anfangskonfigurationen für Cluster verschiedener Radien mit konstanter Anzahl Bindungen $N=150$. In grün sind geschlosssen metastabile Bindungen gezeigt und in rot stabile Bindungen. Offen stabile Bindungen sind lila gefärbt und offen metastabile Bindungen braun.

Die Cluster mit den Radien $r=450$ und $r=600$ bestehen überwiegend aus geschlossen stabilen Bindungen. Bei einem Radius $r=800$ ist ein stabiler Kern von einer metastabilen Region umgeben. Ab einer Ausdehnung von $r=950$ sind die Bindungen innerhalb der Cluster überwiegend metastabil. Ausdehnung des Clusters destabilisiert diesen. ${ }^{3}$ Dieses Verhalten lässt sich auch anhand von Abbildung 5.26 erkennen.

Der Cluster mit dem kleinsten Radius ist in rot dargestellt. Die Bindungen in diesem Cluster sind den geringsten Kräften ausgesetzt. Je größer der Radius, desto höher die Kraft pro Bindung sowohl im Clusterzentrum als auch am Rand des Clusters.

\footnotetext{
${ }^{3} \mathrm{Im}$ Gegensatz zu allen Einfedermodellen, in denen eine Expansion der Cluster zur Energieabnahme führt.
} 


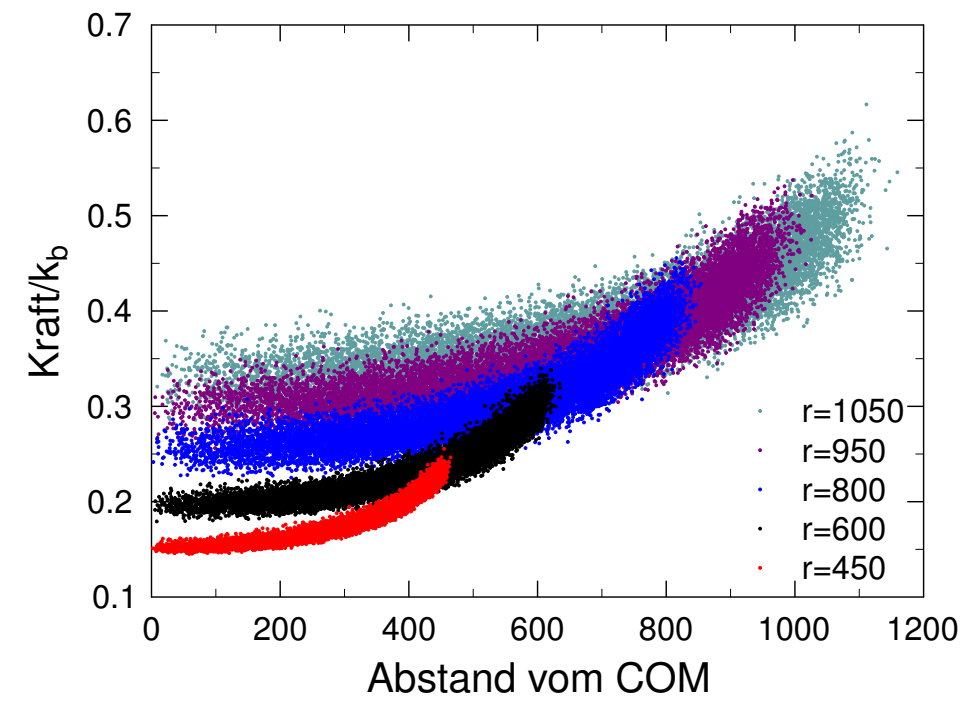

Abbildung 5.26: Kraftverteilung auf Bindungen mit geclusterten Anfangskonfigurationen der Radien $r=450-1050$.

Variation der Elastizität Hier wird die Elastiziät der Membran zwischen 0,05 und 0,4 variiert und die Stabilität und Kräfteverteilung über die Bindungen in einem Cluster des Anfangsradius $r=600$ untersucht. Die Anfangskonfigurationen sind in Abbildung 5.27 dargestellt.

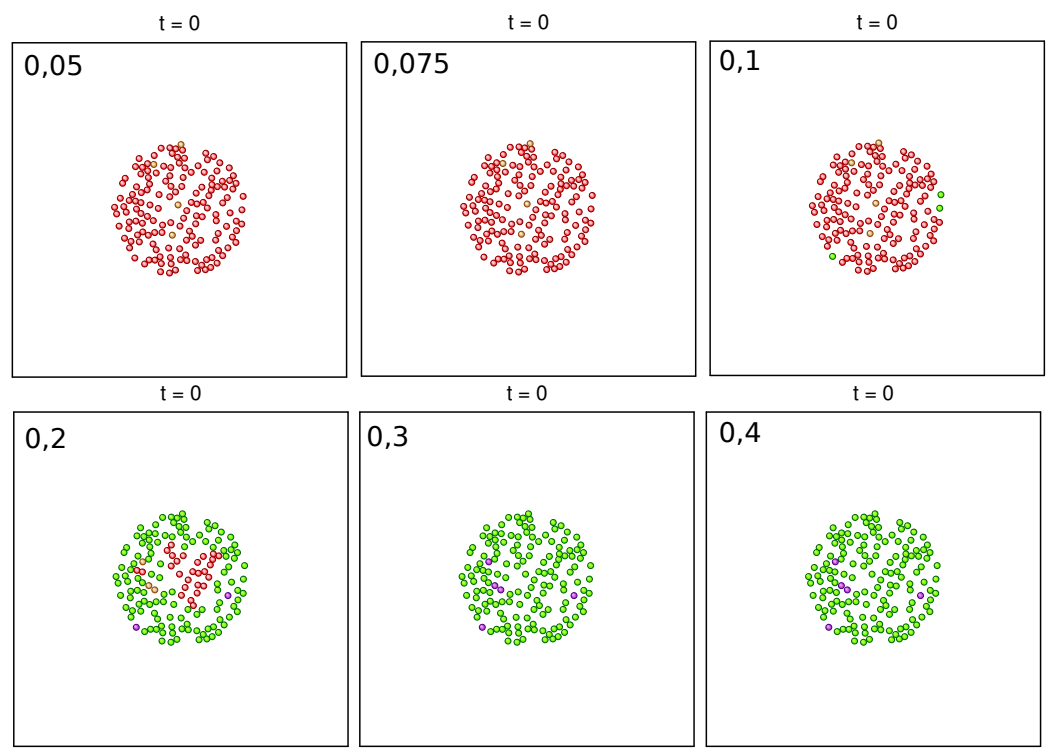

Abbildung 5.27: Anfangskonfigurationen für Cluster bei verschiedenen Werten für $\kappa$ mit konstanter Anzahl Bindungen $N=150$. In grün sind geschlosssen metastabile Bindungen gezeigt und in rot stabile Bindungen. Offen stabile Bindungen sind lila gefärbt und offen metastabile Bindungen braun.

Für den geringsten Wert von $\kappa$ sind die Bindungen geschlossen stabil. Je größer der Wert für $\kappa$ desto größer wird der Anteil geschlossen metastabiler Bindungen. Die Kraft auf die Bindungen als Funktion des Abstandes zum COM für verschiedene Werte von $\kappa$ ist in Abbildung 5.28 gezeigt.

Je größer $\kappa$, desto höher die Kraft auf die Bindungen. Für große $\kappa$ ist die Kraft auf Bindungen am Rand des Clusters sehr viel höher als für Bindungen im Zentrum des Clusters. 


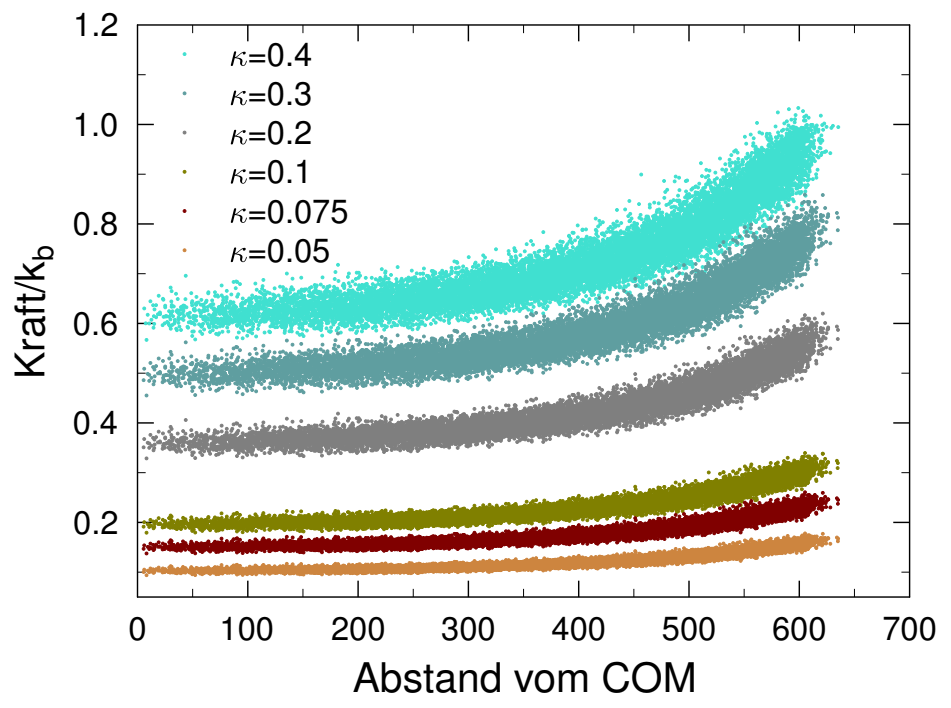

Abbildung 5.28: Kraftverteilung über die 150 Bindungen in einem Cluster mit $r=600$ bei Variation von $\kappa$.

Variation des Radius bei konstanter Bindungsdichte Bisher wird immer bei Erhöhung des Clusterradius die Anzahl der Bindungen konstant belassen und damit die Dichte der Bindungen im Cluster verringert. Im Folgenden wird nun der Radius des Clusters variiert und die Anzahl der Bindungen so angepasst, dass die Fläche die einer Bindung zur Verfügung steht konstant bleibt.

Es werden drei verschiedene Clusterradien bei konstanter Bindungsdichte und $\kappa=0,4$ simuliert, siehe Abbildung 5.29. Die Konfiguration mit 100 Bindungen und einem Clusterradius von 490 ist instabil und durchläuft zur Stabilisierung eine annealing-Phase. Die Konfiguration nach der annealing-Phase ist im letzten Teil von Abbildung 5.29 gezeigt.

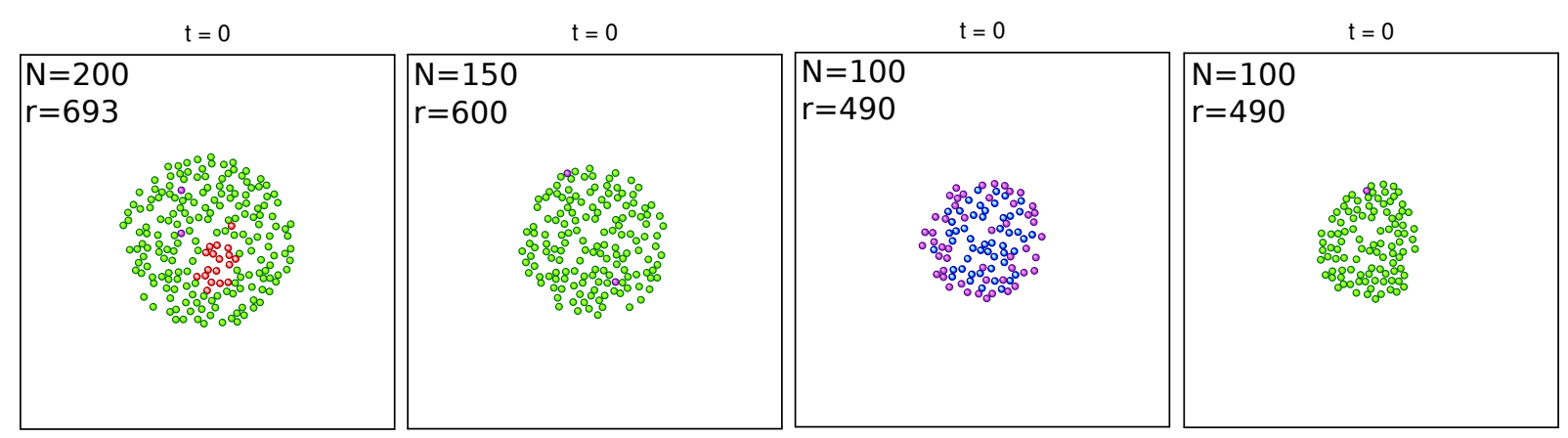

Abbildung 5.29: Anfangskonfiguration für Cluster verschiedenen Radius, aber konstanter Bindungsdichte mit $\kappa=0,4$. In grün sind geschlosssen metastabile Bindungen gezeigt, in blau instabile und in rot stabile Bindungen. Offen stabile Bindungen sind lila gefärbt und offen metastabile Bindungen braun.

Die Kraft auf die Bindungen als Funktion des Abstandes vom COM für Cluster konstanter Bindungsdichte ist in Abbildung 5.30 gezeigt.

In schwarz sind die Werte des größten Clusters aus $N=200$ Bindungen dargestellt, in 


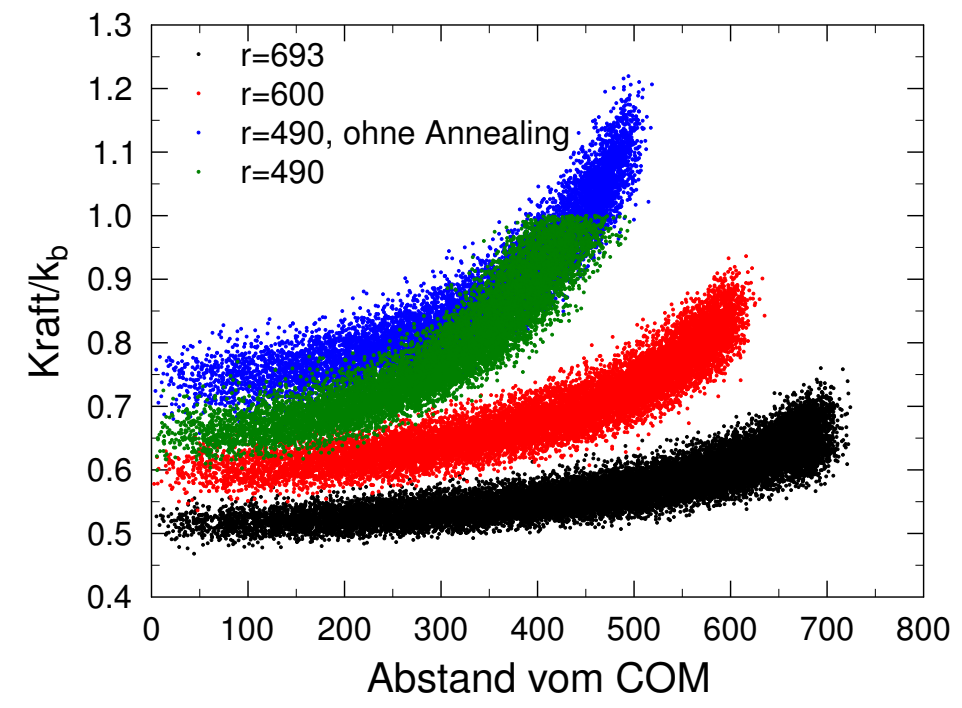

Abbildung 5.30: Darstellung der Kraft auf die Bindungen als Funktion des Abstandes vom Clusterzentrum bei konstanter Bindungsdichte $(\rho=$ konst. $)$ und $\kappa=0,4$

rot die Werte des Cluster aus $N=150$ Bindungen und in grün und blau, die des Clusters mit $N=100$ Bindungen. Die grünen Punkte entsprechen denen, des Clusters nach der durchlaufenen annealing-Phase. Man sieht, dass hier der maximale Abstand vom $C O M$ verringert ist und die maximal vorkommende Kraft bei $f_{\text {rup }}=1$ liegt. Bei gleicher Bindungsdichte steigt die Kraft auf Bindungen am Rand eines Cluster im Vergleich zur Kraft auf zentrale Bindungen mit sinkender Clustergröße an.

Stabilität kleiner Cluster gegenüber großer Cluster Um diese Abhängigkeit der Stabilität im Zusammenhang mit der Clustergröße zu untersuchen wird ein Cluster aus $N=148$ Bindungen in einer Simulationsbox der Länge 3000 mit einem Cluster aus $N=37$ Bindungen in einer Box der Seitenlänge 1500 verglichen. Man hat also einen Cluster aus $\frac{1}{4}$ der Bindungen in einer Simulationsbox mit $\frac{1}{4}$ der Fläche. Die Dichte der Bindungen in den jeweiligen Clustern wird konstant gehalten. Abbildung 5.31 zeigt die jeweiligen Cluster. Der Cluster aus $N=148$ Bindungen besteht überwiegend aus geschlossen stabilen (roten) Bindungen, wohingegen der kleine Cluster aus $N=47$ Bindungen aus geschlossen metastabilen (grünen) Bindungen aufgebaut ist.
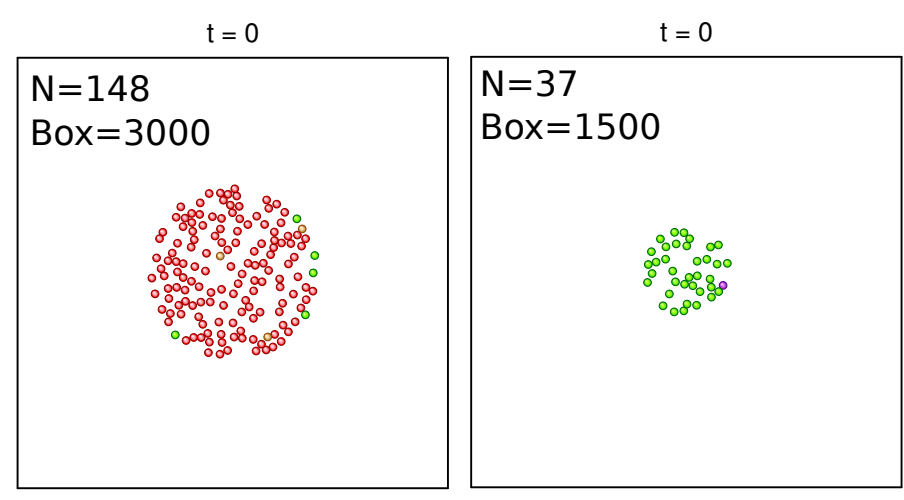

\begin{abstract}
Abbildung 5.31: Konfigurationen der Cluster aus $N=148$ und $N=37$ Bindungen. In grün sind geschlosssen metastabile Bindungen gezeigt, in blau instabile und in rot stabile Bindungen. Offen stabile Bindungen sind lila gefärbt und offen metastabile Bindungen braun.
\end{abstract}


In Abbildung 5.32 ist die Kraft als Funktion des Abstandes zum Massezentrum COM für die in Abbildung 5.31 gezeigten Bindungscluster aufgetragen.

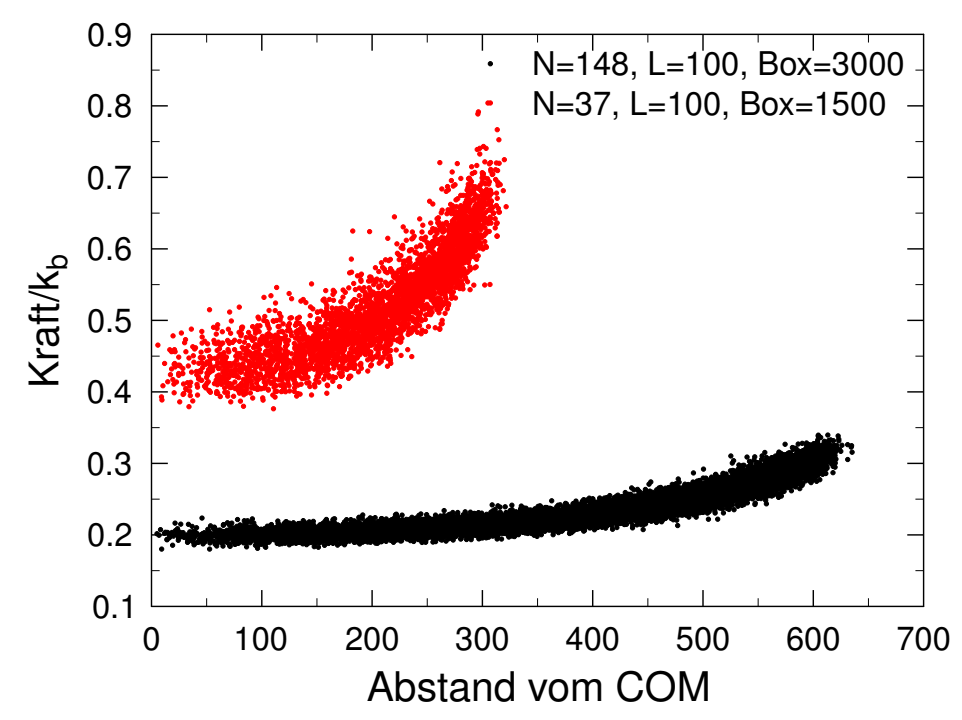

\begin{abstract}
Abbildung 5.32: Kräfteverteilung für Bindungen in Clustern unterschiedlicher Größe bei $\rho=$ konst.
\end{abstract}

In rot ist die Kraft als Funktion des Abstandes vom COM für den Cluster aus $N=37$ Bindungen gezeigt. Man sieht, dass die Kraft auf Bindungen am Clusterrand fast doppelt so hoch ist, wie die im Inneren des Clusters. Die schwarzen Datenpunkte stellen die Werte für den Cluster mit $N=148$ Bindungen dar. Hier tragen die Bindungen am Clusterrand ebenfalls eine höhere Kraft als im Inneren, dieser Effekt ist jedoch weniger stark ausgeprägt als für den kleinen Cluster.

Bindungs-Cluster-Anziehung Dieser Abschnitt beschäftigt sich mit der Frage, wie sich die Kraft auf Bindungen außerhalb des Bindungsclusters verhält. Dafür werden für drei verschiedene $\kappa$ Einzelbindungen in einen bestimmten Abstand zum Zentrum des Clusters positioniert und die Kraft auf die Bindungen als Funktion des Abstandes zum Massezentrum berechnet.

Simulation für $\kappa=0,1$ Die Einzelbindung wird auf eine Position auf der $x$-Achse gesetzt, welche in Abbildung 5.33 angegeben ist. Der Cluster aus $N=150$ Bindungen mit $r=600$ und $\kappa=0,1$ besteht aus geschlossen stabilen Bindungen. Die Einzelbindung, die von dem Cluster entfernt wird, ist bereits auf der Position $x=700$ geschlossen metastabil.

In Abbildung 5.34 ist die Kraft auf die Bindungen als Funktion des Abstandes zum Clusterzentrum dargestellt.

Die Kräfte innerhalb der Cluster liegen erwartungsgemäß für alle drei Cluster im gleichen Größenbereich. Mit Abstand der Einzelbindung zum Zentrum des Clusters steigt die Kraft auf diese Bindung. Für die grünen Datenpunkte, entsprechend einer Entfernung der Bindung von 1400 zum Massezentrum, liegt die Kraft auf die Bindung bei 


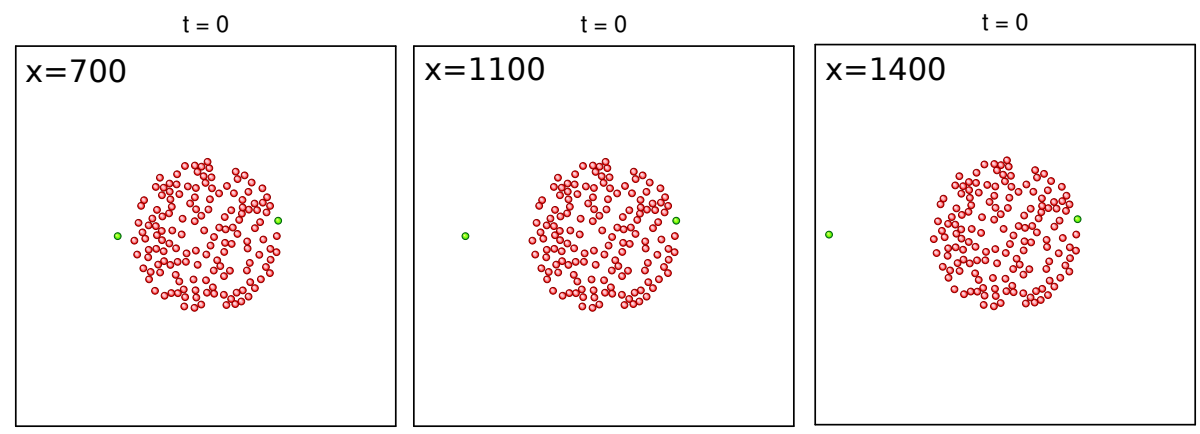

Abbildung 5.33: Anfangskonfigurationen für Bindungscluster mit einer Einzelbindung im Abstand $x$ zum Zentrum des Clusters. In grün sind metastabile Bindungen gezeigt und in rot stabile Bindungen.

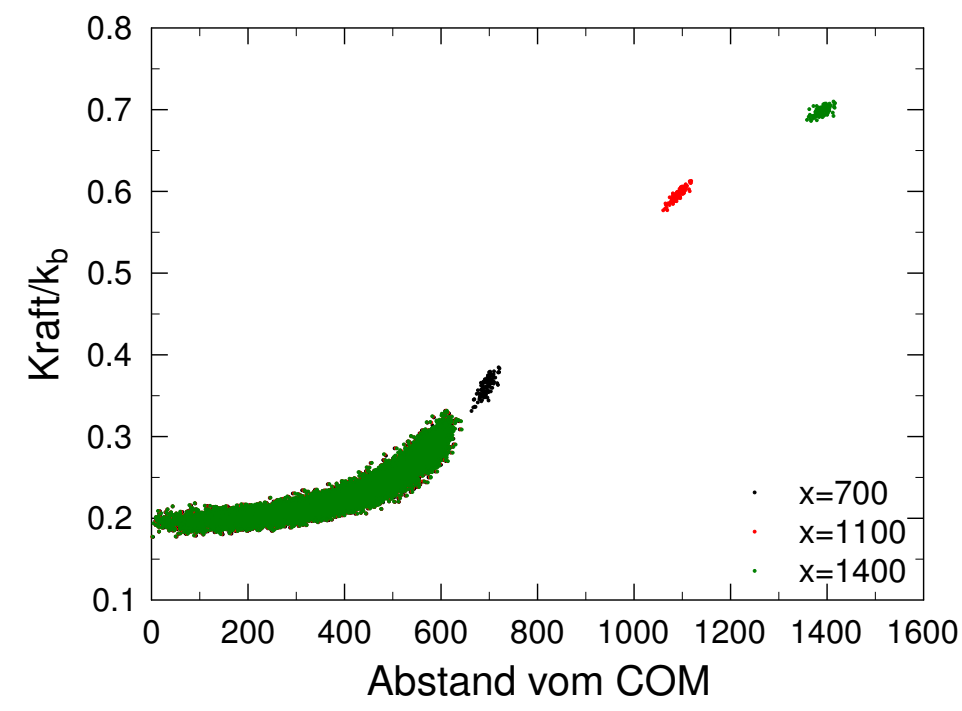

Abbildung 5.34: Verteilung der Kräfte für Bindungen innerhalb eines Clusters und eine Einzelbindung im Abstand $x$ zum Zentrum des Clusters für $\kappa=0,1$ als Funktion des Abstandes zum COM.

circa 0,7, das bedeutet unter der Risskraft der Bindung. Um Bedingungen zu untersuchen bei denen die Einzelbindungen instabil sind wird im Folgenden $\kappa$ erhöht um die Kraft auf die Bindungen zu erhöhen. Bei diesen Simulationen ist der Einfluss der periodischen Randbedingungen zu beachten. Entfernt man die Einzelbindungen weit von dem Cluster in der zentralen Simulationsbox erfährt sie Effekte durch die virtuellen Abbilder des Clusters.

Simulation für $\kappa=0,2$ Bei einem Wert von $\kappa=0,2$ ist lediglich das Zentrum des Clusters geschlossen stabil und der Randbereich geschlossen metastabil. Die Einzelbindung ist ab einer Entfernung von $x=1100$ zum Massezentrum offen stabil, siehe Abbildung 5.35.

Man sieht in Abbildung 5.36, dass ab einer Entfernung der Einzelbindung vom Zentrum des Clusters von $x=1100$ die Risskraft der Bindung überschritten wird und die Bindung damit geschlossen instabil wird. 

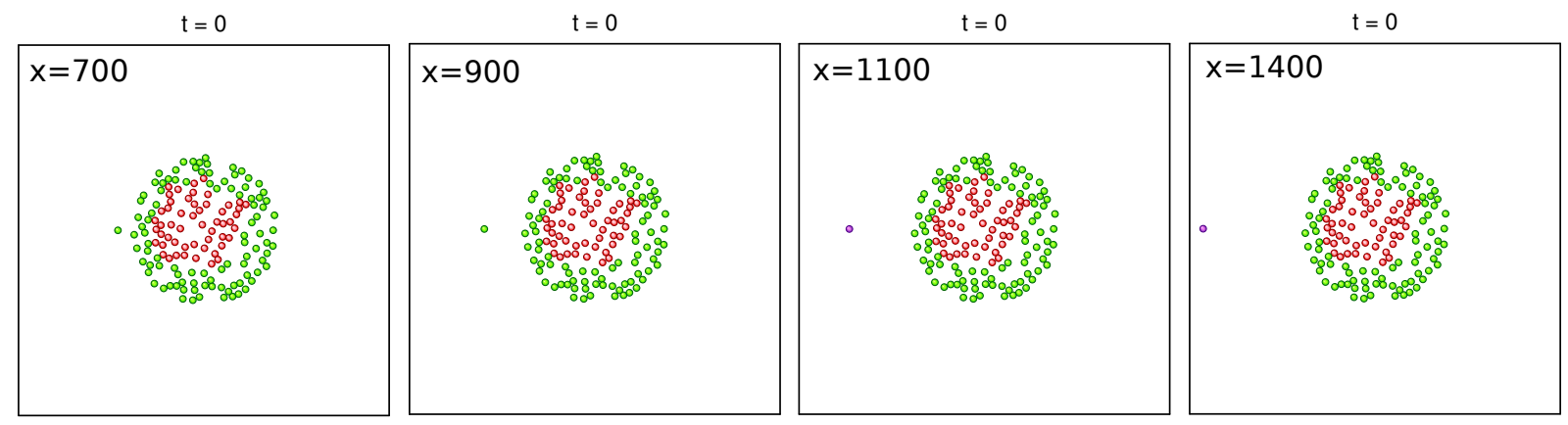

Abbildung 5.35: Anfangskonfigurationen für Bindungscluster mit einer Einzelbindung im Abstand $x$ zum Zentrum des Clusters. In grün sind geschlossen metastabile Bindungen, in rot geschlossen stabile Bindungen und in lila offen stabile Bindungen dargestellt.

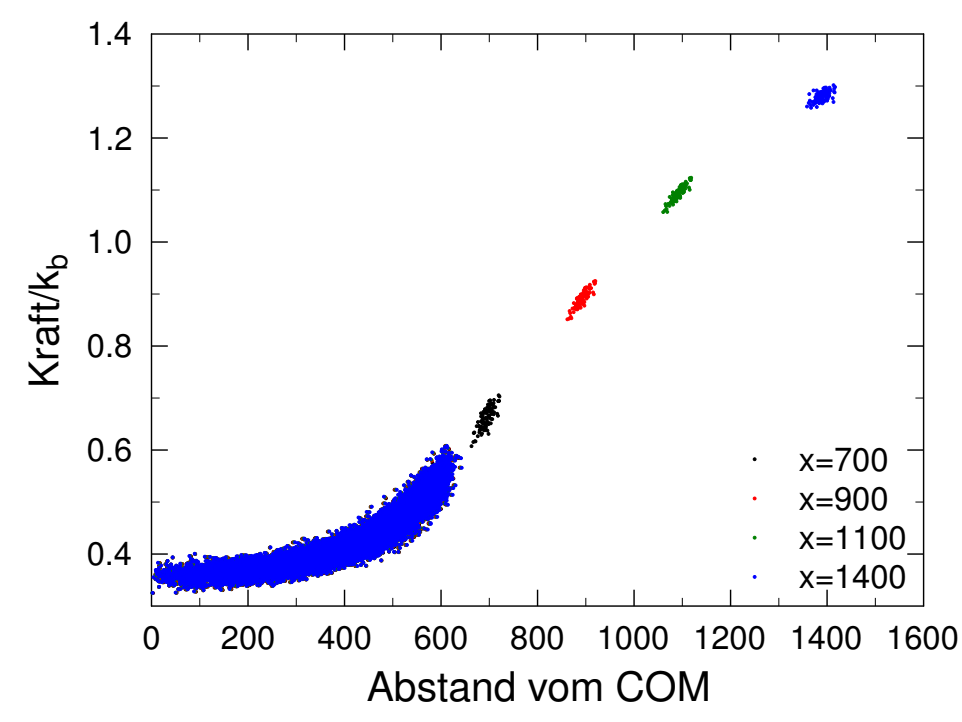

\begin{abstract}
Abbildung 5.36: Verteilung der Kräfte für Bindungen innerhalb eines Clusters und eine Einzelbindung im Abstand $x$ zum Zentrum des Clusters für $\kappa=0,2$ als Funktion des Abstandes zum COM.
\end{abstract}

Die Einzelbindungen an den Positionen $x=700$ und $x=900$ sind geschlossen metastabil, was auch an der auf sie wirkenden Kraft zu erkennen ist. Diese liegt bei einem Wert kleiner der Risskraft $f_{\text {rup }}=1$. Erhöht man den Abstand einer Einzelbindung zum Massezentrum des Clusters führt das zu einer Erhöhung der auf sie wirkenden Kraft bis hin zu Werten größer $f_{\text {rup }}=1$ und damit zur Öffnung der Bindung.

Simulation für $\kappa=0,4$ Eine weitere Erhöhung von $\kappa$ hat zur Folge, dass der Cluster aus geschlossen metastabilen (grünen) Bindungen besteht. Abbildung 5.37 zeigt die Konfigurationen für $\kappa=0,4$. Bereits Einzelbindungen in unmittelbarer Clusternähe bei $x=700$ und einem Clusterradius von $r=600$ befinden sich im offen stabilen Zustand.

Die Kraft auf die Bindungen als Funktion des Abstands zum Massenzentrum des Clusters ist in Abbildung 5.38 gezeigt.

Bereits am Rand des Bindungsclusters wirkt eine Kraft im Bereich der Risskraft auf die Bindungen. Mit zunehmendem Abstand der Einzelbindungen zum Cluster steigt die auf 


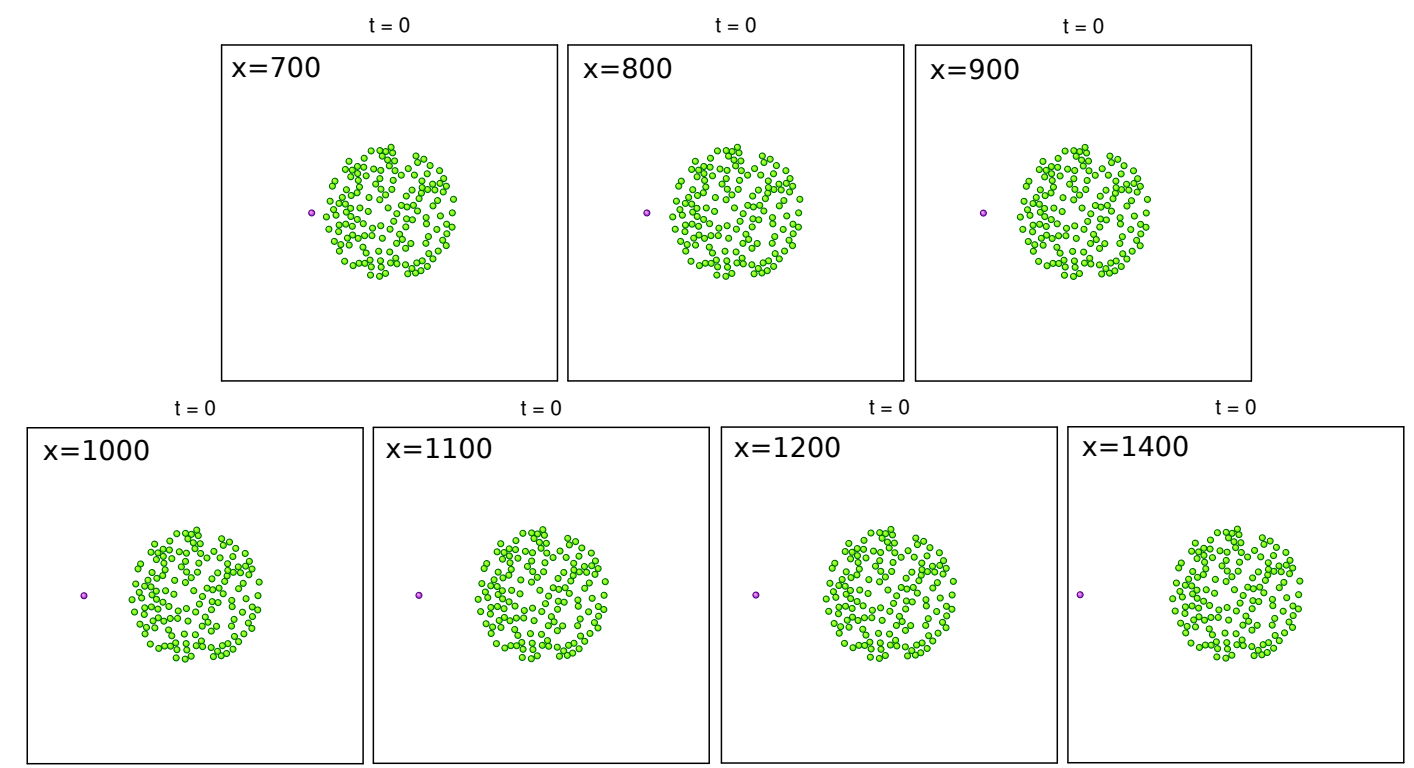

Abbildung 5.37: Anfangskonfigurationen für Bindungscluster mit einer Einzelbindung im Abstand $x$ zum Zentrum des Clusters. In grün sind geschlossen metastabile Bindungen und in lila offen stabile Bindungen dargestellt.

sie wirkende Kraft bis zu Werten von ungefähr 2,2. In einer Simulation würden diese Bindungen geöffnet werden. 


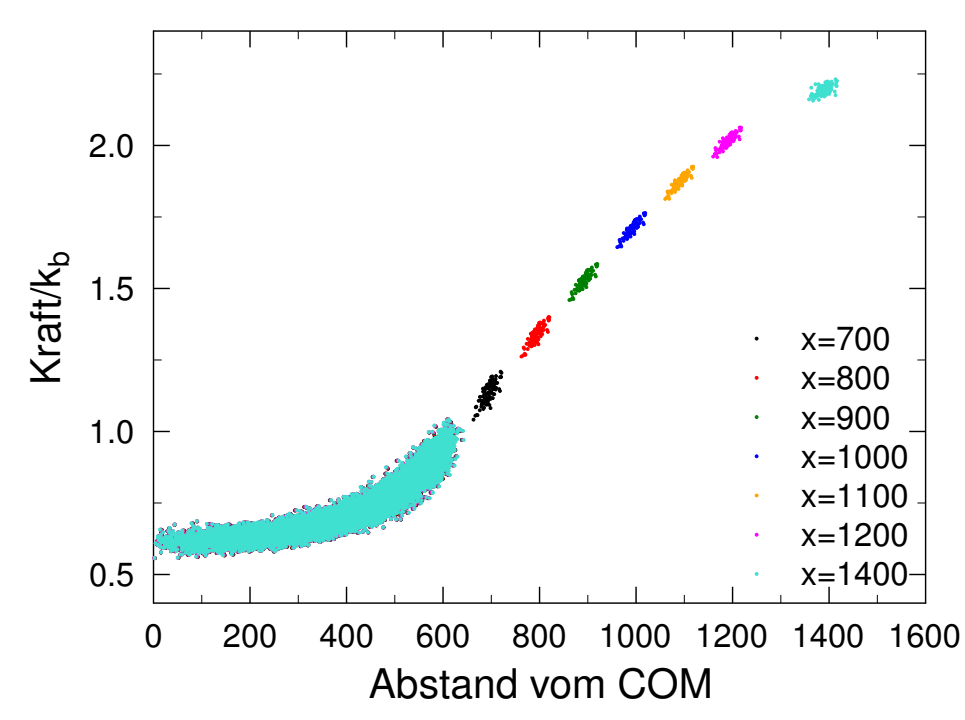

Abbildung 5.38: Kräfteverteilung der Bindungen als Funktion des Abstandes zum Zentrum des Clusters für $\kappa=0,4$. 



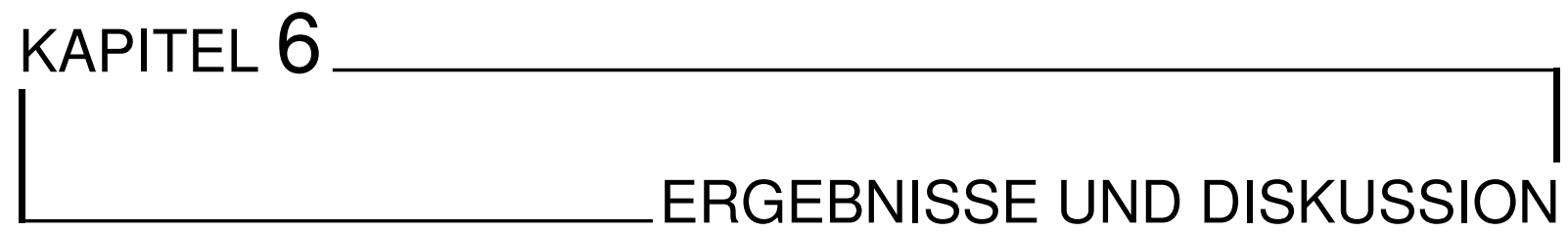

Das Mehrfedernmodell erklärt die treibende Kraft zur Ausbildung von Adhäsionsclustern. Das Modell zeigt die Existenz metastabiler Bindungszustände, attraktiver Wechselwirkungen zwischen den Bindungen, die emergent aus der Kopplung der Bindungen an die Membran entstehen und die Verteilung der Systemenergie zwischen Membranund Bindungsenergiereservoir. Trotz allem wird durch die vorliegende Arbeit auch eine Schwierigkeit aufgedeckt, die inhärent auch in realen biologischen Systemen eine Rolle spielen wird. Kinetische Konstanten die zu einer Stochastik führen in der Cluster gebildet werden, stabil sind und wachsen, sind möglicherweise nicht in der Lage, in den geformten Clustern zu einer Dynamik zu führen, die ausreicht, den Cluster durch Bindungsriss auf einer endlichen Größe zu stabilisieren. Eine Balance zwischen initialem Clusterwachstum und einem Vermeiden des runaway-growth konnte in dieser Arbeit nicht gefunden oder eingestellt werden.

Das harmonische Mehrfedernmodell und die zugehörigen Simulationen führen zu den im Folgenden zusammgefassten Ergebnissen.

\subsection{Stabilitätsgrenzen im harmonischen Mehrfedernmodell}

Die Existenz metastabiler Bindungszustände im harmonischen Mehrfedernmodell ist ein Schlüsselschritt zur Erklärung der Bildung und Stabilität von Adhäsionsclustern. Aus diesem Grund wird hier auf die vorhandenen Stabilitätsgrenzen näher eingegangen. Abbildung 4.14 in Abschnitt 4.2 zeigt die Potentiale von Bindungsfeder und Membran in Abhängigkeit der Membranhöhe. Im Gleichgewicht müssen die auf die Bindung und die Membran wirkenden Kräfte vom Betrag her gleich groß sein $-f_{\mathrm{b}}=f_{\mathrm{m}}$. Im Folgenden sind für kritische Membranhöhen, das heißt Membran-Substrat-Abstände, der Verlauf der potentiellen Energie, sowie die Kraft in Bezug auf die Bindung $\left(E_{\mathrm{b}}, f_{\mathrm{b}}\right)$ und die Membran $\left(E_{\mathrm{m}}, f_{\mathrm{m}}\right)$ in Abhängigkeit des Membran-Substrat-Abstands darge- 
stellt. Man stelle sich vor, die Membran wird an das Substrat angenähert, ihre Gleichgewichtslage (Minimum in der potentiellen Energie) befindet sich zunächst weit vom Substrat entfernt. Hier sind geschlossene Bindungen instabil, ab einem bestimmten Abstand $\left(\gamma^{2}\right)$ wird es möglich geschlossen metastabile Bindungen zu bilden (siehe auch Kapitel 4). Weiteres Annähern führt zu einer Stabilisierung, und geschlossen stabile Bindungen treten im Abstand $\gamma$ auf.

\subsection{1 Übergang zwischen Instabilität und Metastabilität geschlossener Bindungen}

Der erste hier gezeigte Bereich, ist der, in dem die Membran sich im Abstand $\gamma^{2}$ zum Substrat befindet. Bei dem hier verwendeten Parameter $\kappa=0,1$ entspricht $\gamma^{2}=11,0$.
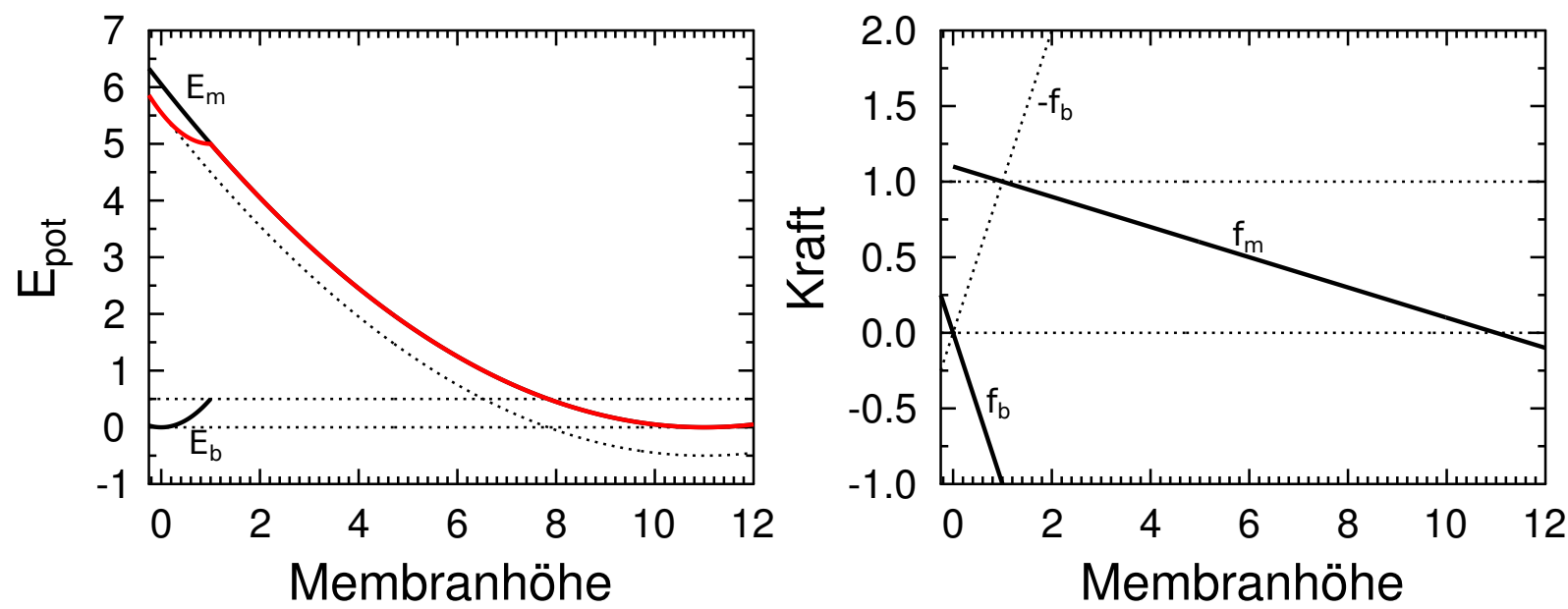

Abbildung 6.1: Potentielle Energie (links) und Kraft (rechts) in Abhängigkeit der Membranhöhe für den Übergang des geschlossen instabilen in den geschlossen metastabilen Zustand. Links: Die potentielle Energie der Membran $E_{\mathrm{m}}$ wird durch eine breitere Parabel beschrieben als die der Bindung $E_{\mathrm{b}}$ (durchegzogene schwarze Linien). Die Differenz von $E_{\mathrm{m}}$ und $E_{\mathrm{b}}$ ergibt die gestrichelte Linie. Wenn die Bindung geschlossen ist führt das zum frei werden der Bindungsbildungsenergie $\Delta E_{\mathrm{b}}$ und zu einem lokalen Minimum der potentiellen Energie (rote Linie). Rechts: Im Gleichgewicht muss gelten $-f_{\mathrm{b}}=f_{\mathrm{m}}$ die Bindung befindet sich somit im Schnittpunkt der beiden Geraden. Dieser Schnittpunkt liegt im gezeigten Beispiel bei 1,0, also der maximal möglichen auf eine Bindung wirkende Kraft $f_{\text {rup }}$.

In Abbildung 6.1 ist die potentielle Energie sowie die Kraft von Bindung und Membran als Funktion der Membranhöhe dargestellt. Die potentielle Energie der Membran $E_{\mathrm{m}}$ wird durch eine breitere Parabel beschrieben, als die der Bindung $E_{\mathrm{b}}$ (durchgezogene schwarze Linien). Die Differenz von $E_{\mathrm{m}}$ und $E_{\mathrm{b}}$ ergibt die gestrichelte Linie. Wenn die Bindung geschlossen ist, führt das zum frei werden der Bindungsbildungsenergie $\Delta E_{\mathrm{b}}$ und gegebenenfalls zu einem lokalen Minimum der potentiellen Energie (rote Linie). Dieses lokale Minimum ist verantwortlich für die Möglichkeit der Bildung geschlossen metastabiler Bindungen. Da es aber nicht den energetisch günstigsten Zustand dar- 
stellt, ist der offene Zustand weiterhin der einzig stabile Zustand. Im rechten Teil der Abbildung sieht man die Kraft als Funktion der Membranhöhe. Im Gleichgewicht muss gelten $-f_{\mathrm{b}}=f_{\mathrm{m}}$; die Bindung befindet sich somit im Schnittpunkt der beiden Geraden. Dieser Schnittpunkt liegt im gezeigten Beispiel bei 1,0. Also der maximal möglichen Kraft $f_{\text {rup }}$ die auf eine Bindung wirken kann bevor diese reißt.

\subsection{2 Übergang zwischen Metastabilität und Stabilität geschlossener Bindungen bzw. Stabilität und Metastabilität offener Bindungen}

Weiteres Annähern der Gleichgewichtshöhe der Membran an das Substrat resultiert in dem in Abbildung 6.2 gezeigten Szenario.
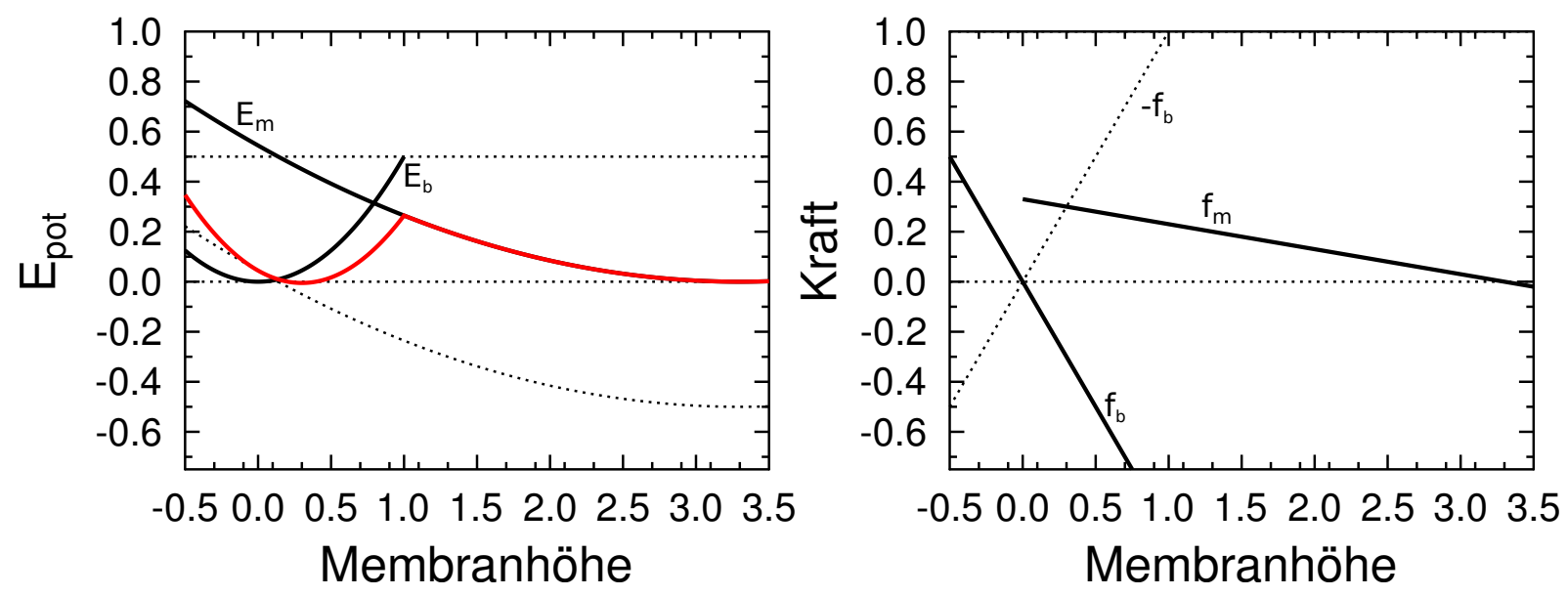

Abbildung 6.2: Potentielle Energie (links) und Kraft (rechts) in Abhängigkeit der Membranhöhe für den Übergang des geschlossen metastabilen in den geschlossen stabilen Zustand, bzw. entsprechend dem offen stabilen in den offen metastabilen Zustand. Bindungsschluss führt zum frei werden der Bindungsbildungsenergie $\Delta E_{\mathrm{b}}$ und zu einem lokalen Minimum der potentiellen Energie (rote Linie), welches hier bei einer Energie von 0 liegt. Rechts: Der Schnittpunkt der Geraden liegt in diesem Fall unterhalb 1,0, und damit unter $f_{\text {rup }}$, die Bindungen sind also über dem Schnittpunkt geschlossen metastabil und unterhalb dieses Punktes geschlossen stabil.

Dargestellt sind potentielle Energie und Kraft auf Bindung und Membran bei einer Gleichgewichtshöhe der Membran von $\gamma$. Diese entspricht für $\kappa=0,1$ einem Wert von $\gamma=3$,3. Die Parabel zur Beschreibung der Membranenergie $E_{\mathrm{m}}$ ist, entsprechend der verwendeten Federkonstanten, breiter als die der Bindung. Die Differenz aus Membranenergie und Bindungsenergie ist anhand einer gestrichelten Linie gezeigt. Das Schließen der Bindung führt zum Energiegewinn $\Delta E_{\mathrm{b}}$ und damit zur Ausbildung des in rot dargestellten lokalen Minimums. Dieses liegt energetisch auf der gleichen Höhe wie die Gleichgewichtshöhen von Membran und Bindung. Wir befinden uns also in einem Grenzbereich, in dem erste geschlossen stabile Bindungen möglich wären und 
der offene Zustand metastabil wird. In der Auftragung auf der rechten Seite sieht man, dass der Schnittpunkt der Geraden $-f_{\mathrm{b}}$ und $f_{\mathrm{m}}$ unterhalb der Risskraft $f_{\text {rup }}$ der Bindung liegt. Die Bindung ist oberhalb des Schnittpunktes geschlossen metastabil und unterhalb des Schnittpunkts geschlossen stabil. Der Übergang in den geschlossen stabilen Zustand geht damit einher, dass der offene Zustand zunächst metastabil wird.

\subsection{3 Übergang zwischen Metabilität und Instabilität offener Bindungen}

Beim Unterschreiten einer bestimmten Gleichgewichtshöhe der Membran wird der offene Zustand instabil und der geschlossene Zustand ist damit der einzig mögliche Zustand in dem eine Bindung sich befinden kann.
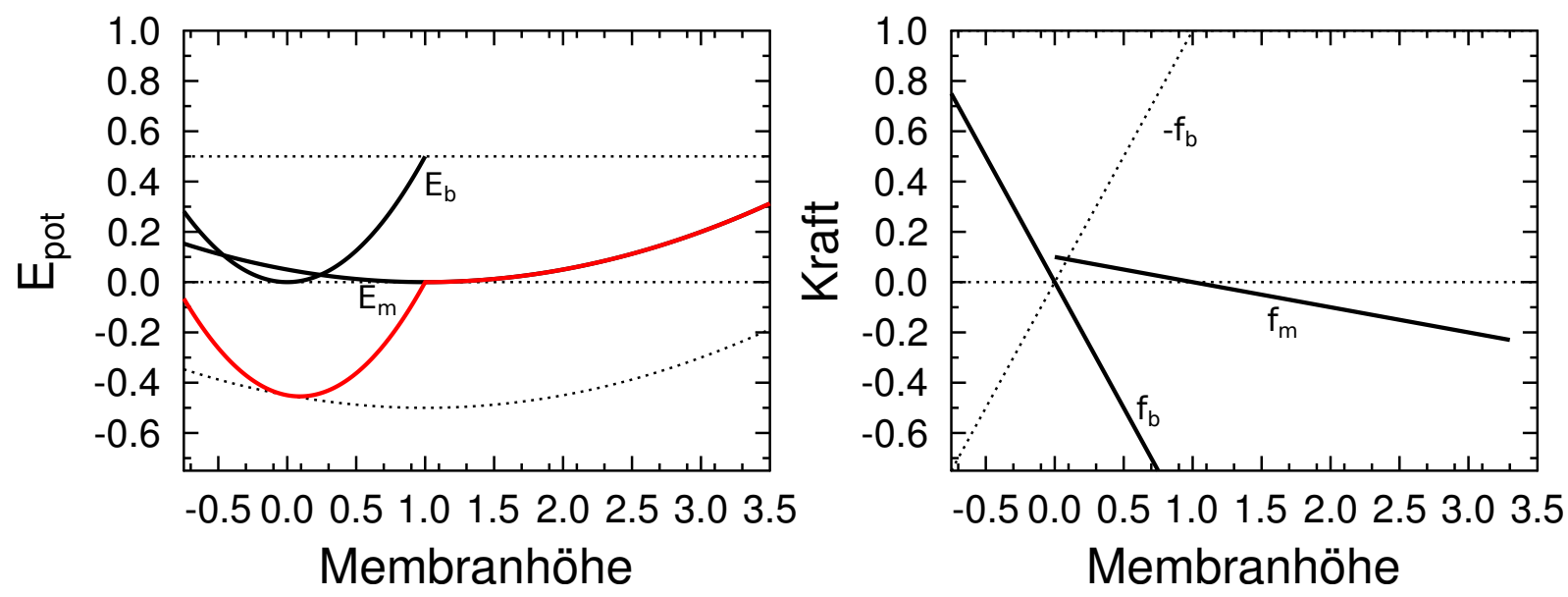

Abbildung 6.3: Potentielle Energie (links) und Kraft (rechts) in Abhängigkeit der Membranhöhe für den Übergang des offen metastabilen in den offen instabilen Zustand. Bindungsschluss führt zum frei werden der Bindungsbildungsenergie $\Delta E_{\mathrm{b}}$ und zu einem lokalen Minimum der potentiellen Energie (rote Linie), welches hier bei einem negativen Energiewert liegt.

In Abbildung 6.3 ist gezeigt wann dieser Übergang des offen metastabilen in den instabilen Zustand geschieht. Die Gleichgewichtshöhe der Membran an diesem Punkt beträgt 1,0, dies entspricht der maximalen Auslenkung der Bindung bevor diese reißt. Das Minimum der potentiellen Energie nach Bindungsschluss und damit frei werden der Energie $\Delta E_{\mathrm{b}}$ hat negative Werte. Der geschlossene Zustand ist somit energetisch der bevorzugte Zustand des Systems. 


\subsection{Attraktive Wechselwirkungen und Clusterbildung}

Im harmonischen Mehrfedernmodell ergibt sich eine intrinsische attraktive Wechselwirkung zwischen Bindungen, welche in Abschnitt 4.2.3 erläutert wird. Die attraktiven Wechselwirkungen zwischen Adhäsionsbindungen führt in einem geeigneten Parameterraum zur Bildung von Adhäsionsclustern aus einer homogenen Bindungsverteilung unter Minimierung der potentiellen Energie des Systems, siehe Abschnitt 5.2.1. Während der Clusterbildung werden geschlossen metastabile und instabile Bindungen in geschlossen stabile Bindungen konvertiert. Um die attraktiven Wechselwirkungen im Modell zu überprüfen, wird eine Bindung in den Ursprung des Koordinatensystems auf Position $(0,0)$ platziert. Eine zweite Bindung wird entlang der $x$-Achse auf diese Bindung zubewegt.

Abbildung 6.4 zeigt die Stabilität des geschlossenen und des offenen Zustandes als Funktion des Abstandes zu einer Nachbarbindung. Annähern von zwei Bindungen führt zu einer Stabilisierung des geschlossenen Zustandes und einer Destabilisierung des offenen Zustandes.

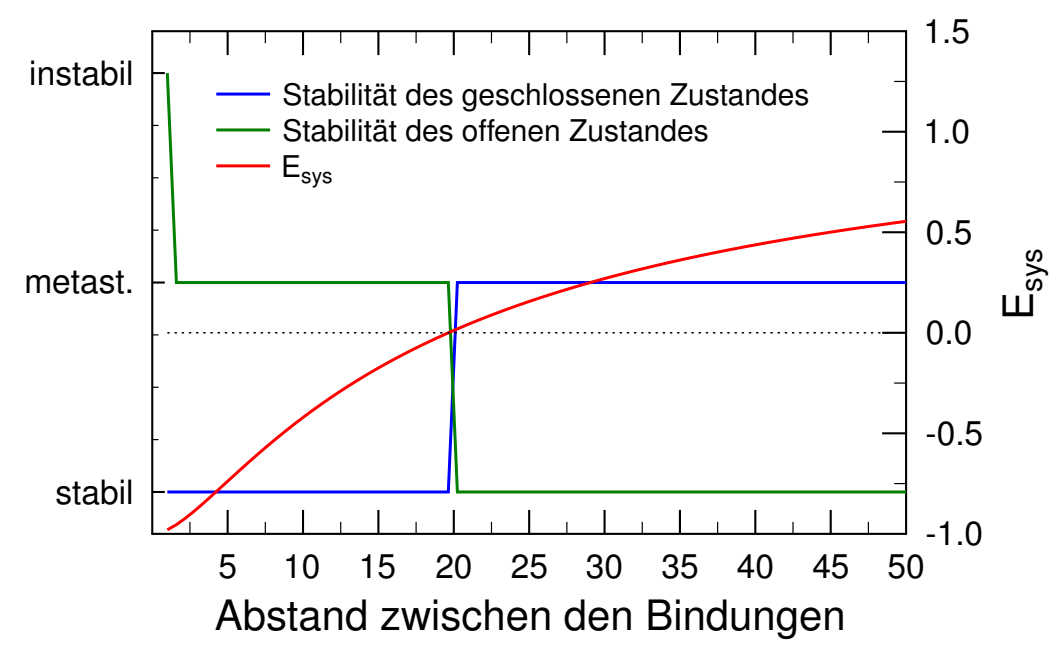

Abbildung 6.4: Stabilität des geschlossenen sowie des offenen Zustandes einer Bindung als Funktion des Abstandes zu einer anderen Bindung.

Aufzeichnung der potentiellen Energie als Funktion des Abstandes zwischen den Bindungen zeigt, eine Stabilisierung der Bindungen mit abnehmendem Abstand, siehe Abbildung 6.5. Erklären lässt sich die Stabilisierung anhand der gezeigten Auslenkung der Membran, welche im Falle von vorhandenen Bindungen in ihrer Umgebung kleiner wird, da die Membran durch die bereits bestehende Bindung bereits deformiert ist und damit der Abstand zwischen Membran und Substrat verringert ist.

In den Abbildungen 6.4 und 6.5 ist der Effekt der zuvor beschriebenen attraktiven Wechselwirkung zwischen Adhäsionsbindungen gezeigt. Im harmonischen Mehrfedernmodell entsteht die attraktive Wechselwirkung durch die Aufteilung der Gesamtenergie in Bindungs- und Membrananteile und ist damit abhängig von den jeweiligen Kraftkonstanten beziehungsweise von $\kappa$. Eine erste geschlossene Bindung investiert 

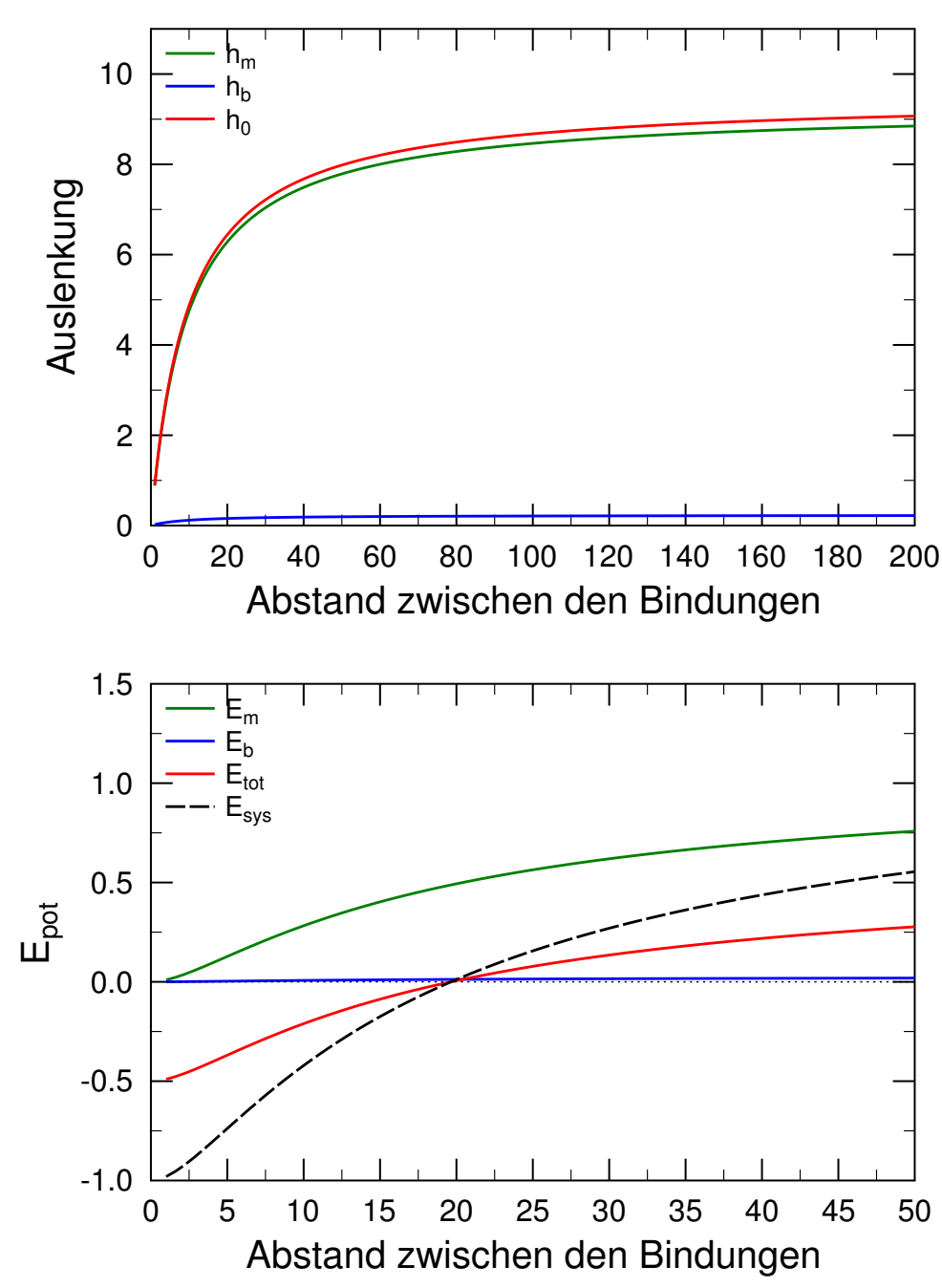

\begin{abstract}
Abbildung 6.5: Auslenkung (oben) und potentielle Energie (unten) von Membran und Bindung, sowie dem Gesamtsystem in Abhängigkeit des Abstandes zwischen zwei Bindungen. $h_{\mathrm{m}}$ bezeichnet die Auslenkung der Membran aus inrer Gleichgewichtslage und $h_{\mathrm{b}}$ die Auslenkung der Bindung. $h_{0}$ steht hier für den Abstand zwischen Membran und Substrat, der durch die Bindung überbrückt wird. $E_{\mathrm{m}}$ zeigt die in der Membran gespeicherte Energie, $E_{\mathrm{b}}$, die der Bindung. Bindungsschluss führt zum frei werden der Bindungsbildungsenergie $\Delta E_{\mathrm{b}}$. Damit ist $E_{\mathrm{tot}}=E_{\mathrm{m}}+E_{\mathrm{b}}-\Delta E_{\mathrm{b}}$ für geschlossene Bindungen und $E_{\text {tot }}=E_{\mathrm{m}}+E_{\mathrm{b}}$ für offene Bindungen. $E_{\text {sys }}$ ist die Gesamtenergie des Systems aus zwei Bindungen.
\end{abstract}

bereits den Anteil Membranenergie um die Membran zu verbiegen und in Kontakt mit dem Substrat zu bringen. Jeder weitere Bindungsschluss in der Nachbarschaft der ersten Bindung muss eine geringere Höhenänderung der Membran überbrücken und damit weniger Energie aufbringen. Das in Abschnitt 3.8 von Hammer und Paszek beschriebene Gitter-Federnmodell beschreibt einen ähnlichen Effekt zur Kooperativität von Adhäsionsbindungen. Zelle und Substrat werden ohne Bindungsstellen als flache isotrope elastische Körper beschrieben. Die Bildung einer Bindung deformiert die Zellmembran in einem Bereich um diese Bindung und elastische Energie muss investiert werden. In dieser deformierten Region um die Bindung bilden sich neue Bindungen auf Grund des geringeren Zell-Substrat-Abstandes einfacher als in flachen Regionen weit weg von Bindungen. Mit dem verringerten Zell-Substrat-Abstand ändern sich die in Abschnitt 3.8 gezeigten abstandsabhängigen Raten und die Bildung von Bindungen ist begünstigt. Auch in den Modellen von Smith et al., welche in Abschnitt 3.6 erläutert werden, wird ein Nachbareffekt beschrieben der zur Anordnung von Bindungen 
in Domänen führt. Dieser von Smith et al. untersuchte Effekt ist jedoch auf ein anderes Phänomen zurückzuführen, das im harmonischen Mehrfedernmodell und in dem Modell von Paszek und Hammer vernachlässigt wird. Für eine fluktuierende Membran über einem Substrat bedingen Adhäsionsbindungen eine Einschränkung der Fluktuation und damit einen Entropieverlust. Zwei Bindungen die von einander entfernt sind schränken die freie Fluktuation dabei stärker ein, als Bindungen in direkter Nachbarschaft, da bei direkt benachbarten Bindungen die Fluktuation der Membran nur an einer Position gestört wird.[81] Smith et al. diskutieren dabei den Effekt des Abstandes zwischen Bindungen in dichten und weniger dichten Bindungsdomänen. Diese Effekte wurden in Abschnitt 3.6 beschrieben. Der Einfluss von Fluktuationen der Membran auf die Kooperativität von Adhäsionsbindungen wird im harmonischen Mehrfedernmodell nicht untersucht. Im Mehrfedernmodell dieser Arbeit wird die Bildung von Adhäsionsclustern ausgehend von einer bestimmten Anzahl homogen verteilter Bindungen untersucht. Der Kontakt zwischen Membran und Substrat besteht damit bereits und es liegt keine frei fluktuierende Membran vor, da die Adhäsionsbindungen als pinning-Punkte wirken und die Fluktuationen reduzieren. Das Verhalten der Membran entspricht dem einer natürlichen Zellmembran, in der Ondulationen auf Grund der vorliegenden Membranspannung unterdrückt sind.[4]
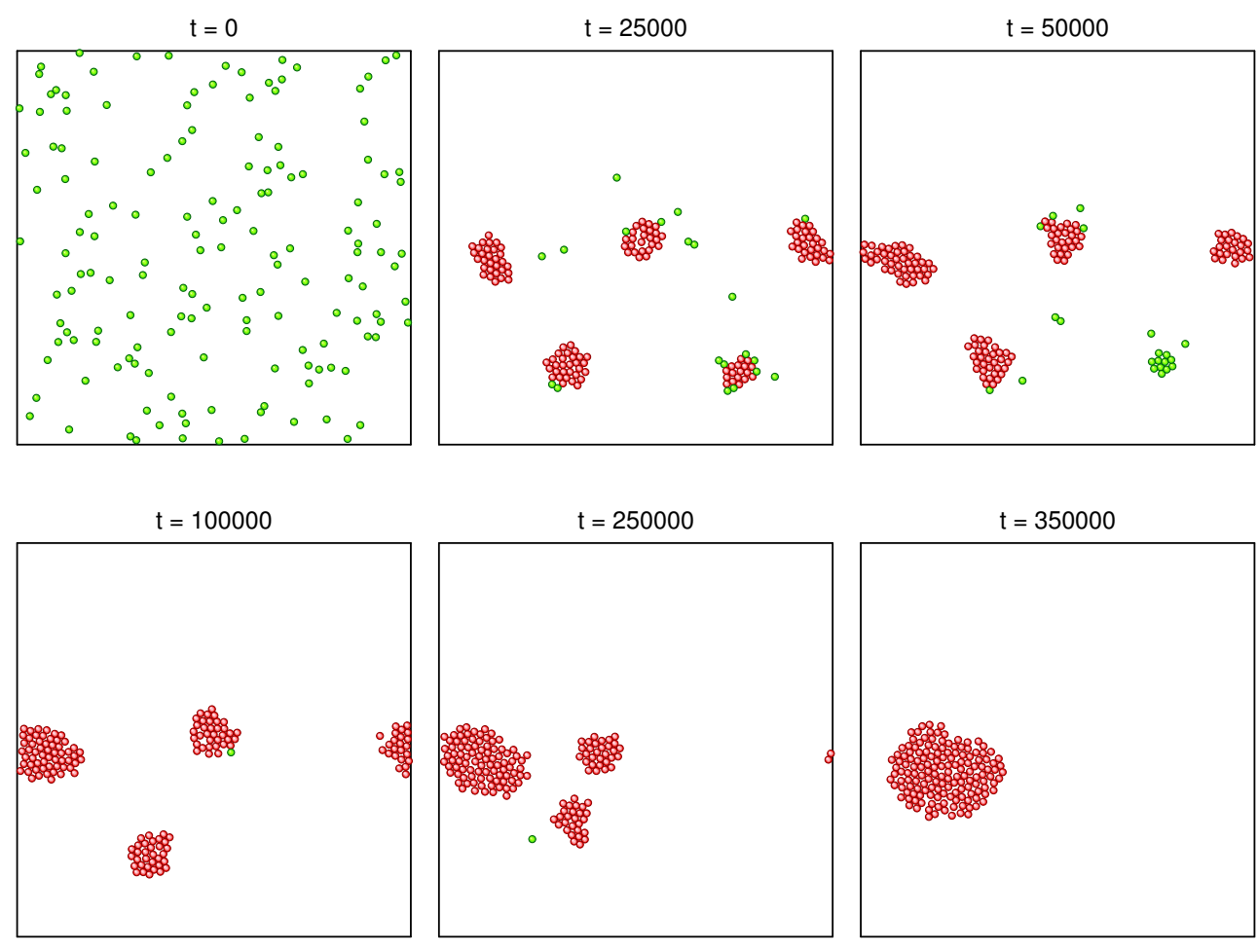

Abbildung 6.6: Zeitverlauf einer Bindungskonfiguration ausgehend von 150 homogen verteilten Bindungen. $t$ gibt die Iteration an, bei der die gezeigte Konfiguration vorliegt. In grün sind geschlosssen metastabile Bindungen gezeigt und in rot geschlossen stabile Bindungen. 
Abbildung 6.6 zeigt nochmals den Effekt der attraktiven Wechselwirkungen zwischen Adhäsionsbindungen im harmonischen Mehrfedernmodell. Bei $t=0$ liegen alle 150 Bindungen in einem geschlossen metastabilen Zustand vor. Im Zeitverlauf der Simulation bilden sich zunächst kleine Bindungscluster aus geschlossen stabilen Bindungen, welche dann bei $t=350000$ zu einem stabilen Cluster verschmelzen. Die Anziehung von Adhäsionsbindungen führt somit zu einer Stabilisierung der zunächst metastabilen Bindungskonfiguration.

\subsubsection{Dynamische Bindungsöffnung}

Dynamische Prozesse wie das Öffnen geschlossen instabiler Bindungen und statistische Öffnungs- und Bindungsschlussereignisse können in das harmonische Mehrfedernmodell implementiert werden. Bei variabler Bindungsanzahl durch dynamische Bindungsöffnung kommt es bei einigen Parametereinstellungen zum Reissen aller Membran-Substrat-Bindungen, einhergehend mit einem Anstieg der potentiellen Energie. Bei anderen Bedingungen entwickelt sich die Konfiguration unter Energieminimierung zu einem stabilen Bindungscluster. Rissereignisse einzelner Bindungen sind wie in Kapitel 5 gezeigt durch Sprünge in der potentiellen Energie detektierbar. Sie verlaufen konzertiert, eine Bindung reisst selten alleine, ein Rissereignis löst das Reissen weiterer Bindungen oder die Konversion geschlossen stabiler Bindungen zu geschlossen metastabilen Bindungen aus. Der Riss einer Bindung führt zu einer Erhöhung der Energie aller noch existierenden Bindungen, aus diesem Grund führen Einzelrissereignisse zum Riss weiterer Bindungen beziehungsweise zur Destabilisierung anderer Bindungen.

In Abbildung 6.7 sind die Boltzmann-Wahrscheinlichkeiten $p_{o n}$ sowie $p_{\text {off }}$ gegen die Membranhöhe aufgetragen.

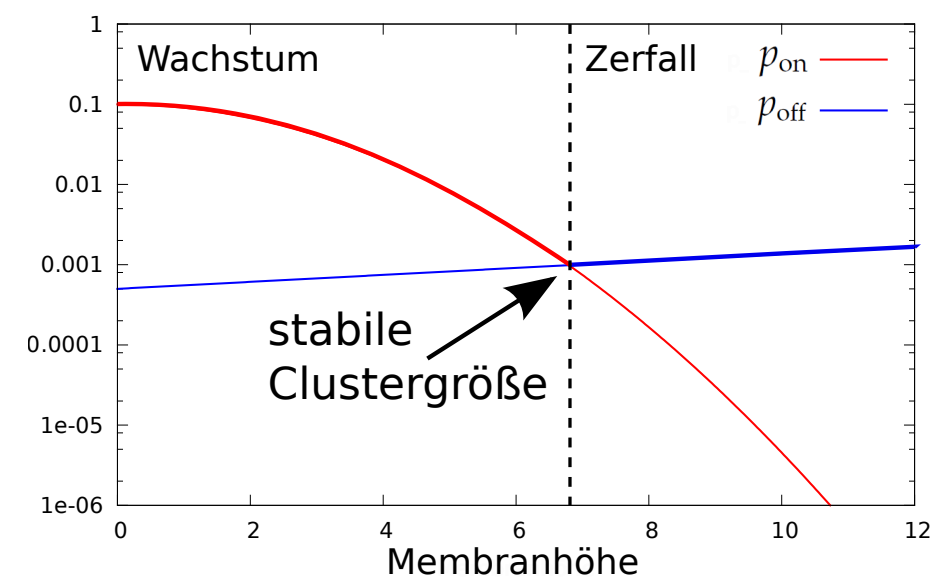

Abbildung 6.7: $\quad$ Auftragung der Bindungsschluss- und Öffnungswahrscheinlichkeit als Funktion der Membranhöhe. Im Schnittpunkt der beiden Kurven sollte eine stabile Clustergröße erreicht werden.

Bei $p_{o f f}>p_{o n}$ zerfällt der Bindungscluster, bei $p_{o n}>p_{o f f}$ wächst dieser. Im Schnittpunkt der beiden Kurven sollten Cluster stabiler Größe vorliegen können. 


\subsubsection{Kraftverteilung in geclusterten Bindungen}

Die Ergebnisse in Abschnitt 5.2.3 zeigen, dass Cluster, die ausschließlich aus stabilen Bindungen aufgebaut sind eine flache (fast konstante) Kraftverteilung besitzen, wohingegen Cluster aus metastabilen Bindungen im Randbereich des Clusters deutlich erhöhte Kräfte erfahren. Dieser Effekt wird in den Abbildungen 5.31 und 5.32 besonders deutlich. Der große Cluster aus nahezu 148 stabilen Bindungen zeigt über einen weiten Bereich eine quasi konstante Kraftverteilung. Bei dem kleinen Cluster aus 37 Bindungen steigt die Kraft am Rand des Clusters stark an. 

KAPITEL 7

ZUSAMMENFASSUNG

Das in dieser Arbeit entwickelte harmonische Mehrfedernmodell erlaubt es, die Bildung von Adhäsionsclustern unter Minimierung der potentiellen Energie zu verstehen. Es handelt sich um eine Erweiterung konventioneller zwei-Zustand-Modelle durch die Einführung metastabiler Zustände, assoziiert mit hysteretischem Verhalten in der Bindungsschluss/-riss-Dynamik. Eine Membran ist über eine variable Anzahl Bindungen an ein Substrat gebunden. Sie verhält sich elastisch, mit einer effektiven Kraftkonstanten $k_{\mathrm{m}}$, welche kleiner ist als die Kraftkonstante der Bindungen $k_{\mathrm{b}}$. Senkrecht zur Substratebene wirkt ein Spannungsfeld an der Membran. Es ergibt sich eine Verteilung von lokalen Membran-Substrat-Abständen, welche an den Positionen der Bindungen Null betragen und mit steigendem Abstand von Bindungen monoton bis zu einem Maximalwert $L$ zunehmen.

Das formulierte Modell ermöglicht es, das Vorhandensein von langreichweitiger attraktiver Wechselwirkung zwischen Bindungen, die durch eine endliche Membranelastizität entsteht, zu erklären. Diese ist die treibende Kraft für die Bildung von Adhäsionsclustern (Abschnitt 4.2.3). In Kombination mit einer thermisch assisitierten Bindungsöffnung kann das Modell die kinetische Stabilität endlicher Bindungscluster erklären.

Das Modell zeigt, dass die spontane Bildung von Adhäsionsclustern eine inhärente Systemeigenschaft ist. Sie ergibt sich aus der Konkurrenz zwischen Membran- und Bindungsenergiereservoir. Die Implementierung endlicher Lebenszeiten der Adhäsionsbindungen kann durch Einführung einer Boltzmann-Dynamik erreicht werden. Geschlossene Bindungen werden mit einer bestimmten Wahrscheinlichkeit abhängig von der frei werden Membranhöhe geöffnet und offene Bindungen mit einer BoltzmannWahrscheinlichkeit abhängig vom zu überbrückenden Membran-Substrat-Abstand geschlossen. Je nach Wahl der Parameter führt der Einbezug der Boltzmann-Dynamik zur Bildung stabiler Bindungskonfigurationen oder der Öffnung aller Bindungen und damit dem Ablösen der Membran vom Substrat.

Die Entwicklung der Bindungskonfiguration und die Stabilität von Bindungsclustern ist in hohem Maße abhängig von der Elastizität der Membran und damit von dem Modell- 
parameter $\kappa$. Des weiteren besteht eine Abhängigkeit der Öffnungs- und Bindungsschlussraten von der aktuellen Konfiguration. Generell beinhaltet das harmonische Mehrfedernmodell nur sehr wenige Modellparameter und ist in der Lage die Bildung von Adhäsionsclustern in einer bereits über homogen verteilte Bindungen fixierten Membran zu erklären.

Im Rahmen dieser Arbeit konnte gezeigt werden, dass die Bildung von Bindungsclustern unabhängig von intrazellulären Aktivierungsprozessen alleine auf Basis des vorgestellten physikalischen Modells möglich ist. Die Clusterbildung unter Minimierung der potentiellen Energie ergibt sich aus der Aufteilung der Energie in einen Membranund einen Bindungsanteil. Neben intrazellulären Signalwegen, ist damit eine weitere Ursache für die Beobachtung gefunden, dass in der Zellbiologie immer Fokalkontakte aus geclusterten Bindungen auftreten. 


\section{Variationsrechnung}

In der Variationsrechnung geht man davon aus, dass die Gesamtkraft $F$ konstant ist. Sie setzt sich aus den Einzelkräften $f_{\mathrm{h}}$ aller homogen verteilten Bindungen $(N)$ zusammen.

$$
F=\text { konst. } \Rightarrow N \cdot f_{\mathrm{h}}=\sum_{i=1}^{N}\left(f_{\mathrm{h}}+\delta f_{\mathrm{i}}\right) \Rightarrow \sum_{i} \delta f_{\mathrm{i}}=0
$$

Die Energie der homogenen Bindungsverteilung ist:

$$
E_{\mathrm{h}}=\frac{1}{2 k} \cdot N \cdot f_{\mathrm{h}}^{2}
$$

Die Energie der inhomogenen Bindungsverteilung $E_{\mathrm{ih}}$ ist gegeben durch:

$$
\begin{aligned}
E_{\mathrm{ih}} & =\frac{1}{2 k} \sum_{i}\left(f_{\mathrm{h}}+\delta f_{\mathrm{i}}\right)^{2} \\
& =\frac{N}{2 k} f_{\mathrm{h}}^{2}+\frac{1}{k} f_{\mathrm{h}} \sum_{i} \delta f_{\mathrm{i}}+\sum_{i} \delta f_{\mathrm{i}}^{2}
\end{aligned}
$$

mit

$$
\begin{gathered}
\frac{N}{2 k} f_{\mathrm{h}}^{2}=E_{\mathrm{h}} \\
\frac{1}{k} f_{\mathrm{h}} \sum_{i} \delta f_{\mathrm{i}}=0 \\
\sum_{i} \delta f_{\mathrm{i}}^{2} \geq 0
\end{gathered}
$$

daraus folgt:

$$
E_{\mathrm{ih}} \leq E_{\mathrm{h}}
$$




\section{Formfunktion}

Zur Beschreibung der Form von Lipidbilayern zwischen zwei parallelen Ringen geben Powers et al. analytische Lösungen an.[75] Sie zeigen, dass die Membran für kleine Ringabstände die Form einer Katenoide annimmt und für große Abstände die zylindrischer Röhren (tether).

Die Membranform für verschiedene Ringabstände ist durch folgende Gleichung analytisch zugängig:

$$
z_{\text {comp }}(r)=h_{0} \frac{\ln r+K_{0}\left(\frac{r}{\sqrt{\epsilon}}\right)}{-\gamma+\ln (2 \sqrt{\epsilon})}
$$

Mit:

- $\epsilon=\frac{\kappa}{\mu R^{2}}=0,005$

- $\mu R^{2} \gg \kappa$

- $\kappa=10-15 k_{\mathrm{B}} T$ : elastisches Biegemodul

- $\mu$ : Spannung

- $h_{0}$ : Abstand der Ringe

- $R=1$ : Radius des äußeren Rings

- $r$ : Radius des inneren, schmaleren Rings, definiert die Punktkraft an der Membran

- $\gamma=0,5772$ : Euler Konstante 


\section{Parameterverzeichnis: Harmonisches Mehrfedernmodell}

A $\gamma=\sqrt{\frac{1+\kappa}{\kappa}}$ $\delta$

$\Delta E_{b}=0.5$

$E_{i}^{(b)}$

$E_{i}^{(m)}$

$E_{\mathrm{m}}$

$E_{\mathrm{b}}$

$E_{k}^{(m)}$

$E_{k}^{(b)}$

$E_{\text {rup }}$

$E_{\text {pot }}$

$E_{\mathrm{a}}^{\mathrm{on}}=2 k_{\mathrm{B}} T$

F

$F_{k}^{(m)}$

$F_{k}^{(b)}$

$F_{\text {rup }}^{(b)}=1$

$F_{\mathrm{B}}$

$F_{\mathrm{a}}^{\text {off }}$

$h_{0}$

$\mathcal{H}$

$\mathcal{H}_{\mathrm{bs}}$

$\mathcal{H}_{\text {mem }}$

$h\left(\vec{r}, S_{N}\right)$

$h_{\mathrm{b}}$

$h_{\text {rup }}=1$
Membranfläche

vereinfachte Darstellung der Federkonstante

Membran-Substrat-Abstand

Energiegewinn durch Bindungsschluss

Energie der Einzelbindung

Membranbeitrag zur Gesamtenergie der Bindung $i$

Energie der Membran

Energie der Bindung

Membrandeformationsenergie auf Grund der $k$-ten Bindung

elastische Energie der $k$-ten Bindung

Energie bei der eine Bindung reißt

potentielle Energie

Aktivierungsenergie für Bindungsschluss

Kraft auf die Bindung

Rückstellkraft der Membran auf die $k$-te Bindung

Kraft auf die $k$-te Bindung

Risskraft der Bindung

intrinsische Kraftskalierung Bell-Modell

intrinsische Kraftskalierung für Boltzmann-Wahrscheinlichkeit

Gleichgewichtshöhe der Membran

Hamiltonian des Gesamtsystems

Hamiltonian des Bindungssystems

Hamiltonian des Membransystems

Membran-Substrat-Abstand

Höhe der ausgelenkten Bindung

maximale Auslenkung der Bindung 


$\begin{array}{ll}k_{b}=1 & \text { Kraftkonstante der Bindung } \\ k_{m} & \text { Kraftkonstante der Membran } \\ \kappa=\frac{k_{m}}{k_{b}} & \text { reduzierte Federkonstante } \\ \kappa_{\mathrm{c}} & \text { Biegemodul der Membran } \\ k_{\mathrm{on}}^{0} & \text { Rate des Bindungsschluss in Abwesenheit einer Kraft } \\ k_{\mathrm{B}} T & \text { Boltzmann-Konstante } \times \text { Temperatur } \\ k_{\text {off }}^{0} & \text { Rissrate in Abwesenheit einer applizierten Kraft } \\ \lambda & \text { Federkonstante pro Fläche des unspezifischen Rückstellpotentials } \\ l_{0} & \text { Gleichgewichtslänge der Bindung } \\ l_{\mathrm{i}} & \text { Auslenkung der } i \text {-ten Bindung aus ihrer Gleichgewichtslänge } \\ l_{\text {bind }} & \text { Reaktionsradius der Bindungsstelle } \\ L & \text { maximale Höhe der Membran über dem Substrat } \\ N & \text { Anzahl der Bindungen } \\ p_{\text {on }} & \text { Wahrscheinlichkeit des Bindungsschluss } \\ p_{\text {off }} & \text { Wahrscheinlichkeit des Bindungsriss } \\ \vec{r} & \text { Positionsvektor der Bindung } \\ \varrho_{e}\left(\vec{r}, S_{N}\right) & \text { Oberflächenenergiedichte der Membran } \\ S_{N} & \text { Bindungskonfiguration } \\ S_{\mathrm{N} \backslash \mathrm{k}} & \text { Bindungskonfiguration } S_{N} \text { nach Öffnen der Bindung } k \\ \vec{\sigma} & \text { Zugspannung an der Membran }\end{array}$


[1] David Lepzelter, Oliver Bates, and Muhammad Zaman. Integrin clustering in two and three dimensions. Langmuir, 28:5379-5386, 2012.

[2] J. Thomas Parsons, Alan Rick Horwitz, and Martin A. Schwartz. Cell adhesion: integrating cytoskeletal dynamics and cellular tension. NATURE REVIEWS MOLECULAR CELL BIOLOGY, 11(9):633-643, SEP 2010.

[3] Benjamin Geiger, Joachim P. Spatz, and Alexander D. Bershadsky. Environmental sensing through focal adhesions. NATURE REVIEWS MOLECULAR CELL BIOLOGY, 10(1):21-33, JAN 2009.

[4] E. Sackmann and R.F. Bruinsma. Cell adhesion as wetting transition? CHEMPHYSCHEM, 3(3):262-269, MAR 122002.

[5] Katharina P. Landsberg, Reza Farhadifar, Jonas Ranft, Daiki Umetsu, Thomas J. Widmann, Thomas Bittig, Amani Said, Frank Juelicher, and Christian Dahmann. Increased Cell Bond Tension Governs Cell Sorting at the Drosophila Anteroposterior Compartment Boundary. CURRENT BIOLOGY, 19(22):1950-1955, DEC 1 2009.

[6] Benoit Ladoux and Alice Nicolas. Physically based principles of cell adhesion mechanosensitivity in tissues. REPORTS ON PROGRESS IN PHYSICS, 75(11), NOV 2012.

[7] Huajian Gao, Jin Qian, and Bin Chen. Probing mechanical principles of focal contacts in cell-matrix adhesion with a coupled stochastic-elastic modelling framework. JOURNAL OF THE ROYAL SOCIETY INTERFACE, 8(62):1217-1232, SEP 72011.

[8] B. Geiger, A. Bershadsky, R. Pankov, and K.M. Yamada. Transmembrane extracellular matrix-cytoskeleton crosstalk. NATURE REVIEWS MOLECULAR CELL BIOLOGY, 2(11):793-805, NOV 2001. 
[9] Matthew Paszek and Valerie Weaver. Enforcing Order on Signaling. SCIENCE, 327(5971):1335-1336, MAR 122010.

[10] Jin Qian, Jizeng Wang, and Huajian Gao. Lifetime and strength of adhesive molecular bond clusters between elastic media. LANGMUIR, 24(4):1262-1270, FEB 192008.

[11] Erich Sackmann. Thermo-elasticity and adhesion as regulators of cell membrane architecture and function. JOURNAL OF PHYSICS-CONDENSED MATTER, 18(45):R785-R825, NOV 152006.

[12] Matthew J. Paszek, David Boettiger, Valerie M. Weaver, and Daniel A. Hammer. Integrin Clustering Is Driven by Mechanical Resistance from the Glycocalyx and the Substrate. PLOS COMPUTATIONAL BIOLOGY, 5(12), DEC 2009.

[13] Christine Selhuber-Unkel, Monica Lopez-Garcia, Horst Kessler, and Joachim P. Spatz. Cooperativity in Adhesion Cluster Formation during Initial Cell Adhesion. BIOPHYSICAL JOURNAL, 95(11):5424-5431, DEC 12008.

[14] C. Selhuber-Unkel, T. Erdmann, M. Lopez-Garcia, H. Kessler, U. S. Schwarz, and J. P. Spatz. Cell Adhesion Strength Is Controlled by Intermolecular Spacing of Adhesion Receptors. BIOPHYSICAL JOURNAL, 98(4):543-551, FEB 172010.

[15] D. Leckband. The Surface Force Apparatus - A tool for probing molecular protein interactions. NATURE, 376(6541):617-618, AUG 171995.

[16] M. Benz, T. Gutsmann, N.H. Chen, R. Tadmor, and J. Israelachvili. Correlation of AFM and SFA measurements concerning the stability of supported lipid bilayers. BIOPHYSICAL JOURNAL, 86(2):870-879, FEB 2004.

[17] Assaf Zemel, Rumi De, and Samuel A. Safran. Mechanical consequences of cellular force generation. CURRENT OPINION IN SOLID STATE \& MATERIALS SCIENCE, 15(5):169-176, OCT 2011.

[18] A.E. Aplin, A.K. Howe, and R.L. Juliano. Cell adhesion molecules, signal transduction and cell growth. CURRENT OPINION IN CELL BIOLOGY, 11(6):737-744, DEC 1999.

[19] Cell Biology. Springer-Verlag, Berlin, Deutschland, 2007.

[20] B.M. Gumbiner. Cell adhesion: The molecular basis of tissue architecture and morphogenesis. CELL, 84(3):345-357, FEB 91996.

[21] Cheng-han Yu, Jaslyn Bee Khuan Law, Mona Suryana, Hong Yee Low, and Michael P. Sheetz. Early integrin binding to Arg-Gly-Asp peptide activates actin polymerization and contractile movement that stimulates outward translocation. PROCEEDINGS OF THE NATIONAL ACADEMY OF SCIENCES OF THE UNITED STATES OF AMERICA, 108(51):20585-20590, DEC 202011. 
[22] Erik S. Welf, Ulhas P. Naik, and Babatunde A. Ogunnaike. A Spatial Model for Integrin Clustering as a Result of Feedback between Integrin Activation and Integrin Binding. BIOPHYSICAL JOURNAL, 103(6):1379-1389, SEP 192012.

[23] Ping $\mathrm{Hu}$ and Bing-Hao Luo. Integrin bi-directional signaling across the plasma membrane. JOURNAL OF CELLULAR PHYSIOLOGY, 228(2):306-312, FEB 2013.

[24] R.O. Hynes. Cell adhesion: old and new questions. TRENDS IN BIOCHEMICAL SCIENCES, 24(12):M33-M37, DEC 1999.

[25] V. Andasari and M. A. J. Chaplain. Intracellular Modelling of Cell-Matrix Adhesion during Cancer Cell Invasion. MATHEMATICAL MODELLING OF NATURAL PHENOMENA, 7(1):29-48, 2012.

[26] Haguy Wolfenson, Irena Lavelin, and Benjamin Geiger. Dynamic Regulation of the Structure and Functions of Integrin Adhesions. DEVELOPMENTAL CELL, 24(5):447-458, MAR 112013.

[27] Coert Margadant, Hanneke N. Monsuur, Jim C. Norman, and Arnoud Sonnenberg. Mechanisms of integrin activation and trafficking. CURRENT OPINION IN CELL BIOLOGY, 23(5):607-614, OCT 2011.

[28] Johanna Ivaska. Unanchoring integrins in focal adhesions. NATURE CELL BIOLOGY, 14(10):981-983, OCT 2012.

[29] O. Ali, H. Guillou, O. Destaing, C. Albiges-Rizo, M. R. Block, and B. Fourcade. Cooperativity between Integrin Activation and Mechanical Stress Leads to Integrin Clustering. BIOPHYSICAL JOURNAL, 100(11):2595-2604, JUN 82011.

[30] David Boettiger. Mechanical control of integrin-mediated adhesion and signaling. CURRENT OPINION IN CELL BIOLOGY, 24(5):592-599, OCT 2012.

[31] S.K. Sastry and K. Burridge. Focal adhesions: A nexus for intracellular signaling and cytoskeletal dynamics. EXPERIMENTAL CELL RESEARCH, 261(1):25-36, NOV 252000.

[32] Ai Kia Yip, Katsuhiko Iwasaki, Chaitanya Ursekar, Hiroaki Machiyama, Mayur Saxena, Huiling Chen, Ichiro Harada, Keng-Hwee Chiam, and Yasuhiro Sawada. Cellular Response to Substrate Rigidity Is Governed by Either Stress or Strain. BIOPHYSICAL JOURNAL, 104(1):19-29, JAN 82013.

[33] Allison L. Berrier and Kenneth M. Yamada. Cell-matrix adhesion. JOURNAL OF CELLULAR PHYSIOLOGY, 213(3):565-573, DEC 2007. 
[34] T. Shemesh, B. Geiger, A.D. Bershadsky, and M.M. Kozlov. Focal adhesions as mechanosensors: A physical mechanism. PROCEEDINGS OF THE NATIONAL ACADEMY OF SCIENCES OF THE UNITED STATES OF AMERICA, 102(35):12383-12388, AUG 302005.

[35] Elizabeth C. Lessey, Christophe Guilluy, and Keith Burridge. From Mechanical Force to RhoA Activation. BIOCHEMISTRY, 51(38):7420-7432, SEP 252012.

[36] Ana-Suncana Smith and Erich Sackmann. Progress in Mimetic Studies of Cell Adhesion and the Mechanosensing. CHEMPHYSCHEM, 10(1):66-78, JAN 12 2009.

[37] Venkat Maruthamuthu, Yvonne Aratyn-Schaus, and Margaret L. Gardel. Conserved $\mathrm{F}$-actin dynamics and force transmission at cell adhesions. CURRENT OPINION IN CELL BIOLOGY, 22(5):583-588, OCT 2010.

[38] Jianyong Huang, Xiaoling Peng, Chunyang Xiong, and Jing Fang. Influence of substrate stiffness on cell-substrate interfacial adhesion and spreading: A mechano-chemical coupling model. JOURNAL OF COLLOID AND INTERFACE SCIENCE, 355(2):503-508, MAR 152011.

[39] Jin Qian and Huajian Gao. Soft Matrices Suppress Cooperative Behaviors among Receptor-Ligand Bonds in Cell Adhesion. PLOS ONE, 5(8), AUG 232010.

[40] G.I. Bell. Models for Specific Adhesion of Cells to Cells. SCIENCE, 200(4342):618-627, 1978.

[41] G.I. Bell, M. Dembo, and P. Bongrand. Cell-adhesion - Competition between nonspecific repulsion and specific bonding. BIOPHYSICAL JOURNAL, 45(6):10511064, 1984.

[42] H.A. Kramers. Brownian Motion in a Field of Force and the Diffusion Model of Chemical Reactions. PHYSICA, VII(4):284-304, 1940.

[43] Thorsten Erdmann. Stochastic dynamics of adhesion clusters under force. PhD thesis, Universität Potsdam, 2005.

[44] Olga K. Dudko. Single-molecule mechanics: New insights from the escape-over-abarrier problem. PROCEEDINGS OF THE NATIONAL ACADEMY OF SCIENCES OF THE UNITED STATES OF AMERICA, 106(22):8795-8796, JUN 22009.

[45] L. B. Freund. Characterizing the resistance generated by a molecular bond as it is forcibly separated. PROCEEDINGS OF THE NATIONAL ACADEMY OF SCIENCES OF THE UNITED STATES OF AMERICA, 106(22):8818-8823, JUN 22009. 
[46] Ana-Suncana Smith and Udo Seifert. Vesicles as a model for controlled (de-) adhesion of cells: a thermodynamic approach. SOFT MATTER, 3(3):275-289, 2007.

[47] U. Seifert. Rupture of multiple parallel molecular bonds under dynamic loading. PHYSICAL REVIEW LETTERS, 84(12):2750-2753, MAR 202000.

[48] T. Erdmann and U. S. Schwarz. Impact of receptor-ligand distance on adhesion cluster stability. EUROPEAN PHYSICAL JOURNAL E, 22(2):123-137, FEB 2007.

[49] T. Erdmann and U.S. Schwarz. Stochastic dynamics of adhesion clusters under shared constant force and with rebinding. JOURNAL OF CHEMICAL PHYSICS, 121(18):8997-9017, NOV 82004.

[50] T. Erdmann and U.S. Schwarz. Stability of adhesion clusters under constant force. PHYSICAL REVIEW LETTERS, 92(10), MAR 122004.

[51] U.S. Schwarz, T. Erdmann, and I.B. Bischofs. Focal adhesions as mechanosensors: The two-spring model. BIOSYSTEMS, 83(2-3):225-232, FEB-MAR 2006. 5th International Conference on Systems Biology (ICSB 2004), Heidelberg, GERMANY, OCT 09-13, 2004.

[52] Yuan Lin and L. B. Freund. Optimum size of a molecular bond cluster in adhesion. PHYSICAL REVIEW E, 78(2, Part 1), AUG 2008.

[53] Florian Rehfeldt, Adam J. Engler, Adam Eckhardt, Fariyal Ahmed, and Dennis E. Discher. Cell responses to the mechanochemical microenvironment - Implications for regenerative medicine and drug delivery. ADVANCED DRUG DELIVERY REVIEWS, 59(13):1329-1339, NOV 102007.

[54] Sam Walcott, Dong-Hwee Kim, Denis Wirz, and Sean X. Sun. Nucleation and Decay Initiation Are the Stiffness-Sensitive Phases of Focal Adhesion Maturation. BIOPHYSICAL JOURNAL, 101(12):2919-2928, DEC 212011.

[55] Jin Qian, Jizeng Wang, Yuan Lin, and Huajian Gao. Lifetime and Strength of Periodic Bond Clusters between Elastic Media under Inclined Loading. BIOPHYSICAL JOURNAL, 97(9):2438-2445, NOV 42009.

[56] Bastien Loubet, Udo Seifert, and Michael Andersen Lomholt. Effective tension and fluctuations in active membranes. PHYSICAL REVIEW E, 85(3, Part 1), MAR 232012.

[57] K.R. Mecke, T. Charitat, and F. Graner. Fluctuating lipid bilayer in an arbitrary potential: Theory and experimental determination of bending rigidity. LANGMUIR, 19(6):2080-2087, MAR 182003.

[58] W. Helfrich. Elastic properties of lipid bilayers: Theory and possible experiments. Z. Naturforsch. Teil A, 33(305):693-703, 1978. 
[59] Heinrich Krobath, Bartosz Rozycki, Reinhard Lipowsky, and Thomas R. Weikl. Line Tension and Stability of Domains in Cell-Adhesion Zones Mediated by Long and Short Receptor-Ligand Complexes. PLOS ONE, 6(8), AUG 172011.

[60] Thomas Speck, Ellen Reister, and Udo Seifert. Specific adhesion of membranes: Mapping to an effective bond lattice gas. PHYSICAL REVIEW E, 82(021923), 2010.

[61] Daniel Schmidt, Timo Bihr, Udo Seifert, and Ana-Suncana Smith. Coexistence of dilute and densely packed domains of ligand-receptor bonds in membrane adhesion. EPL, 99(3), AUG 2012.

[62] Ellen Reister-Gottfried, Kheya Sengupta, Barbara Lorz, Erich Sackmann, Udo Seifert, and Ana-Suncana Smith. Dynamics of Specific Vesicle-Substrate Adhesion: From Local Events to Global Dynamics. PHYSICAL REVIEW LETTERS, 101(20), NOV 142008.

[63] Ellen Reister, Timo Bihr, Udo Seifert, and Ana-Suncana Smith. Two intertwined facets of adherent membranes: membrane roughness and correlations between ligand-receptors bonds. NEW JOURNAL OF PHYSICS, 13, FEB 32011.

[64] B. Rozycki, R. Lipowsky, and T. R. Weikl. Segregation of receptor-ligand complexes in cell adhesion zones: phase diagrams and the role of thermal membrane roughness. NEW JOURNAL OF PHYSICS, 12, SEP 82010.

[65] Thomas R. Weikl, Mesfin Asfaw, Heinrich Krobath, Bartosz Rozycki, and Reinhard Lipowsky. Adhesion of membranes via receptor-ligand complexes: Domain formation, binding cooperativity, and active processes. SOFT MATTER, 5(17):32133224, 2009.

[66] Thomas Speck and Richard L. C. Vink. Random pinning limits the size of membrane adhesion domains. PHYSICAL REVIEW E, 86(3, Part 1), SEP 272012.

[67] Timo Bihr, Udo Seifert, and Ana-Suncana Smith. Nucleation of Ligand-Receptor Domains in Membrane Adhesion. PHYSICAL REVIEW LETTERS, 109(25), DEC 192012.

[68] T.R. Weikl, D. Andelman, S. Komura, and R. Lipowsky. Adhesion of membranes with competing specific and generic interactions. EUROPEAN PHYSICAL JOURNAL E, 8(1):59-66, MAY 2002.

[69] R. Bruinsma, A. Behrisch, and E. Sackmann. Adhesive switching of membranes: Experiment and theory. PHYSICAL REVIEW E, 61(4, Part b):4253-4267, APR 2000.

[70] J.O. Rädler, T.J. Feder, H.H. Strey, and E. Sackmann. Fluctuation analysis of tension-controlled undulation forces between giant vesicles and solid substrates. PHYSICAL REVIEW E, 51(5, Part b):4526-4536, MAY 1995. 
[71] R. Lipowsky. Structure and Dynamics of Membranes, volume 1B. Elsevier, Amsterdam, Niederlande, 1995.

[72] Thorsten Erdmann and Ulrich S. Schwarz. Bistability of cell-matrix adhesions resulting from nonlinear receptor-ligand dynamics. BIOPHYSICAL JOURNAL, 91(6):L60-L62, SEP 2006.

[73] Ellen Reister-Gottfried, Kheya Sengupta, Barbara Lorz, Erich Sackmann, Udo Seifert, and Ana-Suncana Smith. Dynamics of Specific Vesicle-Substrate Adhesion: From Local Events to Global Dynamics. PHYSICAL REVIEW LETTERS, 101(20), NOV 142008.

[74] Eva Sunnick, Andreas Janshoff, and Burkhard Geil. Energetics of adhesion cluster formation in the context of biological membranes. PHYSICAL REVIEW E, 86(5, Part 1), NOV 262012.

[75] T.R. Powers, G. Huber, and R.E. Goldstein. Fluid-membrane tethers: Minimal surfaces and elastic boundary layers. PHYSICAL REVIEW E, 65(4, Part 1), APR 2002.

[76] N. Metropolis. Monte-Carlo - In the Beginning and Some Great Expectations. LECTURE NOTES IN PHYSICS, 240:62-70, 1985.

[77] Introduction to Computational Chemistry. John Wiley \& Sons Ltd, 2007.

[78] N. Metropolis, A.W. Rosenbluth, M.N. Rosenbluth, A.H. Teller, and E. Teller. Equation of State Calculations by Fast Computing Machines. JOURNAL OF CHEMICAL PHYSICS, 21(6):1087-1092, 1953.

[79] J.A. Barker and D. Henderson. What is Liquid - Understanding States of Matter. REVIEWS OF MODERN PHYSICS, 48(4):587-671, 1976.

[80] K.W. Kratky. New Boundary-Conditions for Computer Experiments of Thermodynamic Systems. JOURNAL OF COMPUTATIONAL PHYSICS, 37(2):205-217, 1980.

[81] Ales Iglic. Advances in planar lipid bilayers and liposomes, volume 14. Elsevier, Oxford, UK, 2011. 